\title{
Cochrane
}

Library

Cochrane Database of Systematic Reviews

\section{Treadmill training and body weight support for walking after stroke} (Review)

Mehrholz J, Thomas S, Elsner B

Mehrholz J, Thomas S, Elsner B.

Treadmill training and body weight support for walking after stroke.

Cochrane Database of Systematic Reviews 2017, Issue 8. Art. No.: CD002840.

DOI: 10.1002/14651858.CD002840.pub4.

www.cochranelibrary.com 
TABLE OF CONTENTS

HEADER

ABSTRACT

PLAIN LANGUAGE SUMMARY

SUMMARY OF FINDINGS

BACKGROUND

OBJECTIVES

METHODS

RESULTS

Figure 1.

Figure 2.

Figure 3.

Figure 4.

DISCUSSION

AUTHORS' CONCLUSIONS

ACKNOWLEDGEMENTS

REFERENCES

CHARACTERISTICS OF STUDIES

DATA AND ANALYSES

Analysis 1.1. Comparison 1 Treadmill (with or without body weight support) versus other intervention, Outcome 1 Walking speed $(\mathrm{m} / \mathrm{s})$ at end of treatment.

Analysis 1.2. Comparison 1 Treadmill (with or without body weight support) versus other intervention, Outcome 2 Walking endurance $(\mathrm{m})$ at end of treatment.

Analysis 2.1. Comparison 2 Treadmill and body weight support versus other interventions, Outcome 1 Dependence on personal assistance to walk at end of treatment.

Analysis 2.2. Comparison 2 Treadmill and body weight support versus other interventions, Outcome 2 Walking speed ( $\mathrm{m} / \mathrm{s}$ ) at end of treatment.

Analysis 2.3. Comparison 2 Treadmill and body weight support versus other interventions, Outcome 3 Walking endurance $(\mathrm{m})$ at end of treatment.

Analysis 2.4. Comparison 2 Treadmill and body weight support versus other interventions, Outcome 4 Dependence on personal assistance to walk at end of scheduled follow-up.

Analysis 2.5. Comparison 2 Treadmill and body weight support versus other interventions, Outcome 5 Walking speed ( $\mathrm{m} / \mathrm{s})$ at end of scheduled follow-up.

Analysis 2.6. Comparison 2 Treadmill and body weight support versus other interventions, Outcome 6 Walking endurance (m) at end of scheduled follow-up.

Analysis 3.1. Comparison 3 Treadmill training without body weight support versus other interventions, Outcome 1 Walking speed $(\mathrm{m} / \mathrm{s})$ at end of treatment.

Analysis 3.2. Comparison 3 Treadmill training without body weight support versus other interventions, Outcome 2 Walking endurance $(\mathrm{m})$ at end of treatment.

Analysis 4.1. Comparison 4 Treadmill and body weight support versus treadmill only, Outcome 1 Dependence on personal assistance to walk at end of treatment.

Analysis 4.2. Comparison 4 Treadmill and body weight support versus treadmill only, Outcome 2 Walking speed $(\mathrm{m} / \mathrm{s})$ at end of treatment.

Analysis 4.3. Comparison 4 Treadmill and body weight support versus treadmill only, Outcome 3 Walking endurance $(\mathrm{m})$ at end of treatment.

Analysis 4.4. Comparison 4 Treadmill and body weight support versus treadmill only, Outcome 4 Dependence on personal assistance to walk at end of scheduled follow-up.

Analysis 4.5. Comparison 4 Treadmill and body weight support versus treadmill only, Outcome 5 Walking speed $(\mathrm{m} / \mathrm{s})$ at end of scheduled follow-up.

Analysis 4.6. Comparison 4 Treadmill and body weight support versus treadmill only, Outcome 6 Walking endurance $(\mathrm{m})$ at end of scheduled follow-up.

Analysis 5.1. Comparison 5 Adverse events for all included trials, Outcome 1 Adverse events during the treatment.

Analysis 6.1. Comparison 6 Dropouts for all included trials, Outcome 1 Dropouts.

Analysis 7.1. Comparison 7 Sensitivity analysis: by trial methodology (all trials involving treadmill training), Outcome 1 Walking speed. 
Analysis 8.1. Comparison 8 Subgroup analysis: treadmill (with or without body weight support) versus other, by duration of illness (independent in walking only), Outcome 1 Walking speed $(\mathrm{m} / \mathrm{s})$ at end of treatment.

Analysis 8.2. Comparison 8 Subgroup analysis: treadmill (with or without body weight support) versus other, by duration of illness (independent in walking only), Outcome 2 Walking endurance $(\mathrm{m})$ at end of treatment.

Analysis 9.1. Comparison 9 Subgroup analysis: treadmill (with or without body weight support) versus other, by intensity (frequency) of training (independent in walking only), Outcome 1 Walking speed $(\mathrm{m} / \mathrm{s}$ ) at end of treatment.

Analysis 9.2. Comparison 9 Subgroup analysis: treadmill (with or without body weight support) versus other, by intensity (frequency) of training (independent in walking only), Outcome 2 Walking endurance $(\mathrm{m})$ at end of treatment.

Analysis 10.1. Comparison 10 Subgroup analysis: treadmill (with or without body weight support) versus other, by duration of training period (independent in walking only), Outcome 1 Walking speed $(\mathrm{m} / \mathrm{s})$ at end of treatment.

Analysis 10.2. Comparison 10 Subgroup analysis: treadmill (with or without body weight support) versus other, by duration of training period (independent in walking only), Outcome 2 Walking endurance $(\mathrm{m})$ at end of treatment. ADDITIONAL TABLES

APPENDICES

WHAT'S NEW

HISTORY

CONTRIBUTIONS OF AUTHORS

DECLARATIONS OF INTEREST

SOURCES OF SUPPORT

DIFFERENCES BETWEEN PROTOCOL AND REVIEW 
[Intervention Review]

\title{
Treadmill training and body weight support for walking after stroke
}

\author{
Jan Mehrholzํㅗ Simone Thomas², Bernhard Elsner ${ }^{3}$
}

1Department of Public Health, Dresden Medical School, Technical University Dresden, Dresden, Germany. ${ }^{2}$ Wissenschaftliches Institut, Klinik Bavaria Kreischa, Kreischa, Germany. ${ }^{3}$ Department of Public Health, Dresden Medical School, Technical University Dresden, Dresden, Germany

Contact address: Jan Mehrholz, Department of Public Health, Dresden Medical School, Technical University Dresden, Fetscherstr. 74, Dresden, 01307, Germany.jan.mehrholz@tu-dresden.de,jan.mehrholz@srh.de.

Editorial group: Cochrane Stroke Group.

Publication status and date: New search for studies and content updated (conclusions changed), published in Issue 8, 2017.

Citation: Mehrholz J, Thomas S, Elsner B. Treadmill training and body weight support for walking after stroke. Cochrane Database of Systematic Reviews 2017, Issue 8. Art. No.: CD002840. DOI: 10.1002/14651858.CD002840.pub4.

Copyright @ 2017 The Cochrane Collaboration. Published by John Wiley \& Sons, Ltd.

\section{A B S T R A C T}

\section{Background}

Treadmill training, with or without body weight support using a harness, is used in rehabilitation and might help to improve walking after stroke. This is an update of the Cochrane review first published in 2003 and updated in 2005 and 2014.

\section{Objectives}

To determine if treadmill training and body weight support, individually or in combination, improve walking ability, quality of life, activities of daily living, dependency or death, and institutionalisation or death, compared with other physiotherapy gait-training interventions after stroke. The secondary objective was to determine the safety and acceptability of this method of gait training.

\section{Search methods}

We searched the Cochrane Stroke Group Trials Register (last searched 14 February 2017), the Cochrane Central Register of Controlled Trials (CENTRAL) and the Database of Reviews of Effects (DARE) (the Cochrane Library 2017, Issue 2), MEDLINE (1966 to 14 February 2017), Embase (1980 to 14 February 2017), CINAHL (1982 to 14 February 2017), AMED (1985 to 14 February 2017) and SPORTDiscus (1949 to 14 February 2017). We also handsearched relevant conference proceedings and ongoing trials and research registers, screened reference lists, and contacted trialists to identify further trials.

\section{Selection criteria}

Randomised or quasi-randomised controlled and cross-over trials of treadmill training and body weight support, individually or in combination, for the treatment of walking after stroke.

\section{Data collection and analysis}

Two review authors independently selected trials, extracted data, and assessed risk of bias and methodological quality. The primary outcomes investigated were walking speed, endurance, and dependency.

\section{Main results}

We included 56 trials with 3105 participants in this updated review. The average age of the participants was 60 years, and the studies were carried out in both inpatient and outpatient settings. All participants had at least some walking difficulties and many could not walk without assistance. Overall, the use of treadmill training did not increase the chances of walking independently compared with other physiotherapy interventions (risk difference (RD) $-0.00,95 \%$ confidence interval $(\mathrm{Cl})-0.02$ to $0.02 ; 18$ trials, 1210 participants; $\mathrm{P}=0.94 ; I^{2}=0 \% ;$ low-quality evidence). Overall, the use of treadmill training in walking rehabilitation for people after stroke increased the walking velocity and walking endurance significantly. The pooled mean difference (MD) (random-effects model) for walking velocity was $0.06 \mathrm{~m} / \mathrm{s}(95 \% \mathrm{Cl} 0.03$ to 0.09 ; 
47 trials, 2323 participants; $P<0.0001 ; I^{2}=44 \%$; moderate-quality evidence) and the pooled MD for walking endurance was 14.19 metres $\left(95 \% \mathrm{Cl} 2.92\right.$ to $25.46 ; 28$ trials, 1680 participants; $\mathrm{P}=0.01 ; \mathrm{I}^{2}=27 \%$; moderate-quality evidence). Overall, the use of treadmill training with body weight support in walking rehabilitation for people after stroke did not increase the walking velocity and walking endurance at the end of scheduled follow-up. The pooled MD (random-effects model) for walking velocity was $0.03 \mathrm{~m} / \mathrm{s}(95 \% \mathrm{Cl}-0.05$ to $0.10 ; 12$ trials, 954 participants; $P=0.50 ; I^{2}=55 \%$; low-quality evidence) and the pooled MD for walking endurance was 21.64 metres $(95 \% \mathrm{Cl}-4.70$ to 47.98 ; 10 trials, 882 participants; $P=0.11 ; I^{2}=47 \%$; low-quality evidence). In 38 studies with a total of 1571 participants who were independent in walking at study onset, the use of treadmill training increased the walking velocity significantly. The pooled MD (random-effects model) for walking velocity was $0.08 \mathrm{~m} / \mathrm{s}\left(95 \% \mathrm{Cl} 0.05\right.$ to $\left.0.12 ; \mathrm{P}<0.00001 ; \mathrm{I}^{2}=49 \%\right)$. There were insufficient data to comment on any effects on quality of life or activities of daily living. Adverse events and dropouts did not occur more frequently in people receiving treadmill training and these were not judged to be clinically serious events.

\section{Authors' conclusions}

Overall, people after stroke who receive treadmill training, with or without body weight support, are not more likely to improve their ability to walk independently compared with people after stroke not receiving treadmill training, but walking speed and walking endurance may improve slightly in the short term. Specifically, people with stroke who are able to walk (but not people who are dependent in walking at start of treatment) appear to benefit most from this type of intervention with regard to walking speed and walking endurance. This review did not find, however, that improvements in walking speed and endurance may have persisting beneficial effects. Further research should specifically investigate the effects of different frequencies, durations, or intensities (in terms of speed increments and inclination) of treadmill training, as well as the use of handrails, in ambulatory participants, but not in dependent walkers.

\section{PLAIN LANGUAGE SUMMARY}

\section{Treadmill training and body weight support for walking after stroke}

Review question: We wanted to assess whether walking practice on a treadmill with the body being supported by a harness as the only form of training versus in combination with other kinds of training, could improve walking when compared with other training methods for walking or no treatment. This is an update of the Cochrane review first published in 2003 and updated in 2005 and 2014.

Background: About $60 \%$ of people who have had a stroke have difficulties with walking, and improving walking is one of the main goals of rehabilitation. Treadmill training, with or without body weight support, uses specialist equipment to assist walking practice.

Study characteristics: We identified 56 relevant trials, involving 3105 participants, up to March 2017. Twenty-six studies (1410 participants) compared treadmill training with body weight support to another physiotherapy treatment; 20 studies (889 participants) compared treadmill training without body weight support to other physiotherapy treatment, no treatment, or sham treatment; two studies (100 participants) compared treadmill training with body weight support to treadmill training without body weight support; and four studies (147 participants) did not state whether they used body weight support or not. The average age of the participants was 60 years, and the studies were carried out in both inpatient and outpatient settings.

Key results: The results of this review were partly inconclusive. People after stroke who receive treadmill training with or without body weight support are not more likely to improve their ability to walk independently. The quality of this evidence was low. However, treadmill training with or without body weight support may improve walking speed and walking capacity compared with people not receiving treadmill training. The quality of this evidence was moderate. More specifically, people after stroke who are able to walk at the start of therapy appear to benefit most from this type of intervention, but people who are not able to walk independently at therapy onset do not benefit. This review found that improvements in walking speed and endurance in people who can walk have no lasting positive effect. Unwanted events such as falls and dropouts were not more common in people receiving treadmill training.

Further analysis showed that treadmill training in the first three months after stroke produces only modest improvements in walking speed and endurance. For people treated at a later stage (more than six months after their stroke) the effects were smaller. More frequent treadmill training (for example, five times per week) appears to produce greater effects on walking speed and endurance; however, this was not conclusive. Brief periods of treadmill training (duration of four weeks) provided a modest improvement in walking speed but not enough to be clinically important.

Effects of the age of participants or the type of stroke were not investigated in this review.

In practice, it appears that people who can walk after stroke, but not those who cannot, may profit from treadmill training (with and without body weight support) to improve their walking abilities. Further research should specifically investigate the effects of different frequencies, durations or intensities (in terms of speed increments and inclination) of treadmill training, as well as the use of handrails. Future trials should include people who can already walk, but not dependent walkers who are unable to walk unaided. Future research should analyse age groups, gender, and type of stroke to see who might benefit most from this treatment.

\section{Quality of the evidence}

The quality of evidence for treadmill training for walking after stroke was low to moderate. It was moderate for walking speed and walking endurance at the end of treatment and low for improving the ability to walk independently. 


\begin{tabular}{|c|c|c|c|c|c|c|c|}
\hline \multirow{13}{*}{ 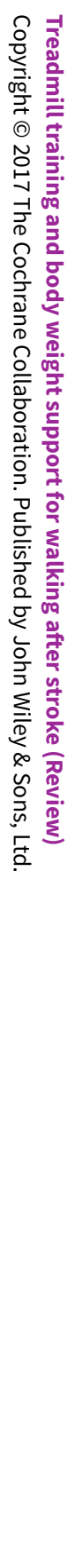 } & \multicolumn{2}{|c|}{$\begin{array}{l}\text { S U M M A R Y O F F I N D I N G S } \\
\text { Summary of findings for the main comparison. }\end{array}$} & eadmill (with or without body we & ight support) ve & sus other inte & ention for walk & g after stroke \\
\hline & \multicolumn{7}{|c|}{ Treadmill (with or without body weight support) versus other intervention for walking after stroke } \\
\hline & \multicolumn{7}{|c|}{$\begin{array}{l}\text { Patient or population: adults who had suffered a stroke and exhibited an abnormal gait pattern } \\
\text { Settings: inpatient and outpatient setting } \\
\text { Intervention: treadmill (with or without body weight support) versus other intervention }\end{array}$} \\
\hline & \multirow[t]{3}{*}{ Outcomes } & \multicolumn{2}{|c|}{ Illustrative comparative risks* $(95 \% \mathrm{CI})$} & \multirow{3}{*}{$\begin{array}{l}\text { Relative effect } \\
(95 \% \mathrm{CI})\end{array}$} & \multirow{3}{*}{$\begin{array}{l}\text { No of partici- } \\
\text { pants } \\
\text { (studies) }\end{array}$} & \multirow{3}{*}{$\begin{array}{l}\text { Quality of the } \\
\text { evidence } \\
\text { (GRADE) }\end{array}$} & \multirow[t]{3}{*}{ Comments } \\
\hline & & Assumed risk & Corresponding risk & & & & \\
\hline & & Control & $\begin{array}{l}\text { Treadmill (with or without body } \\
\text { weight support) versus other in- } \\
\text { tervention }\end{array}$ & & & & \\
\hline & \multirow{4}{*}{$\begin{array}{l}\text { Dropouts - by end of } \\
\text { treatment } \\
\text { Numbers of dropouts } \\
\text { and adverse events }\end{array}$} & Study population & & \multirow[t]{4}{*}{ See comment } & \multirow{4}{*}{$\begin{array}{l}3105 \\
\text { (56 studies) }\end{array}$} & \multirow{4}{*}{$\begin{array}{l}\oplus \oplus \ominus \ominus \\
\text { low } 1\end{array}$} & \multirow{4}{*}{$\begin{array}{l}\text { Risks were cal- } \\
\text { culated from } \\
\text { pooled risk dif- } \\
\text { ferences }\end{array}$} \\
\hline & & 91 per 1000 & $\begin{array}{l}93 \text { per } 1000 \\
\text { (81 to } 101)\end{array}$ & & & & \\
\hline & & \multicolumn{2}{|l|}{ Moderate } & & & & \\
\hline & & 31 per 1000 & $\begin{array}{l}32 \text { per } 1000 \\
(28 \text { to } 34)\end{array}$ & & & & \\
\hline & $\begin{array}{l}\text { Walking speed }(\mathbf{m} / \mathbf{s}) \text { at } \\
\text { end of treatment } \\
\text { timed measures of gait }\end{array}$ & $\begin{array}{l}\text { The mean walking speed } \\
\text { (m/s) at end of treatment } \\
\text { in the control groups was } \\
\mathbf{0 . 4 8} \mathbf{~ m} / \mathbf{s}\end{array}$ & $\begin{array}{l}\text { The mean walking speed }(\mathrm{m} / \mathrm{s}) \text { at } \\
\text { end of treatment in the intervention } \\
\text { groups was } \\
\mathbf{0 . 0 6} \text { higher } \\
\text { (0.03 to } 0.09 \text { higher) }\end{array}$ & & $\begin{array}{l}2323 \\
\text { (47 studies) }\end{array}$ & $\begin{array}{l}\oplus \oplus \oplus \ominus \\
\text { moderate } 1,2,3\end{array}$ & \\
\hline & $\begin{array}{l}\text { Walking speed }(\mathrm{m} / \mathrm{s}) \text { at } \\
\text { end of treatment - de- } \\
\text { pendent in walking at } \\
\text { start of treatment } \\
\text { timed measures of gait }\end{array}$ & $\begin{array}{l}\text { The mean walking speed } \\
\text { (m/s) at end of treatment } \\
\text { - dependent in walking at } \\
\text { start of treatment in the } \\
\text { control groups was } \\
\mathbf{0 . 3 2} \mathbf{~ m / s}\end{array}$ & $\begin{array}{l}\text { The mean walking speed }(\mathrm{m} / \mathrm{s}) \text { at } \\
\text { end of treatment - dependent in } \\
\text { walking at start of treatment in the } \\
\text { intervention groups was } \\
\mathbf{0 . 0 1} \text { lower } \\
\text { ( } 0.06 \text { lower to } 0.03 \text { higher) }\end{array}$ & & $\begin{array}{l}752 \\
\text { (9 studies) }\end{array}$ & $\begin{array}{l}\oplus \oplus \Theta \odot \\
\text { low } 1,2\end{array}$ & \\
\hline & $\begin{array}{l}\text { Walking speed }(\mathrm{m} / \mathrm{s}) \text { at } \\
\text { end of treatment - in- }\end{array}$ & $\begin{array}{l}\text { The mean walking speed } \\
(\mathrm{m} / \mathrm{s}) \text { at end of treatment } \\
\text { - independent in walking }\end{array}$ & $\begin{array}{l}\text { The mean walking speed }(\mathrm{m} / \mathrm{s}) \text { at } \\
\text { end of treatment - independent in }\end{array}$ & & $\begin{array}{l}1571 \\
\text { (38 studies) }\end{array}$ & $\begin{array}{l}\oplus \oplus \odot \odot \\
\text { low } 1,2\end{array}$ & \\
\hline
\end{tabular}


dependent in walking

at start of treatment

timed measures of gait

Walking endurance ( $m$ )

at end of treatment

timed measures of gait

The mean walking en-

durance $(m)$ at end of

treatment in the control

groups was

$177 \mathrm{~m}$

Walking endurance $(m)$

at end of treatment -

dependent in walking

at start of treatment

timed measures of gait

The mean walking en-

durance $(m)$ at end of

treatment - dependent

in walking at start of

treatment in the control

groups was

$115 \mathrm{~m}$

\section{Walking endurance ( $m$ )}

at end of treatment -

independent in walk-

ing at start of treat-

ment

timed measures of gait

The mean walking en-

durance $(m)$ at end of

treatment - indepen-

dent in walking at start of

treatment in the control

groups was

$240 \mathrm{~m}$ walking at start of treatment in the

intervention groups was

$\mathbf{0 . 0 9}$ higher

( 0.05 to 0.12 higher)

The mean walking endurance $(m)$ at

end of treatment in the intervention

groups was

14.19 higher

(2.92 to 25.46 higher)

The mean walking endurance $(\mathrm{m})$

at end of treatment - dependent in

walking at start of treatment in the

(5 studies)

intervention groups was

$\mathbf{5 . 0 9}$ lower

(23.41 lower to 13.22 higher)

The mean walking endurance $(\mathrm{m})$ at

end of treatment - independent in

1041

walking at start of treatment in the

(23 studies) $\quad$ low 1,2

intervention groups was

19.72 higher

(6.61 to 32.83 higher)

*The basis for the assumed risk (e.g. the median control group risk across studies) is provided in footnotes. The corresponding risk (and its $95 \%$ confidence interval) is based on the assumed risk in the comparison group and the relative effect of the intervention (and its $95 \% \mathrm{Cl}$ ).

Cl: Confidence interval; RR: Risk ratio;

GRADE Working Group grades of evidence

High quality: Further research is very unlikely to change our confidence in the estimate of effect.

Moderate quality: Further research is likely to have an important impact on our confidence in the estimate of effect and may change the estimate.

Low quality: Further research is very likely to have an important impact on our confidence in the estimate of effect and is likely to change the estimate.

Very low quality: We are very uncertain about the estimate.

1 Downgraded because $95 \% \mathrm{Cl}$ contains effect size of no difference and the minimal important difference.

2 Downgraded due to several ratings with 'high' or 'unclear' risk of bias

3 Upgraded due to evidence of a dose-response gradient 


\section{B A C K G R O U N D}

\section{Description of the condition}

Stroke ranks as the sixth highest cause of burden of disease worldwide in terms of disability adjusted life years and is the single most important cause of severe disability in people living in their own homes (Murray 2012). An inability or an impaired ability to walk is a significant contributor to long-term disability and burden of care after stroke. Approximately one-third of people surviving acute stroke are unable to walk three months after admission to a general hospital (Langhorne 2009).

High-quality evidence from systematic reviews indicates that organised (stroke unit) care decreases physical dependence after stroke compared with general medical care (SUTC 2013). This organised care is characterised by early mobilisation and multidisciplinary rehabilitation (including physiotherapy) coordinated by regular team meetings (Langhorne 2002). The effectiveness of specific physiotherapy gait-training strategies, however, is still not very clear. A review of studies comparing different physiotherapy treatments for participants with stroke concluded that "There is insufficient evidence to conclude that any one physiotherapy approach is more effective in promoting recovery of lower limb function or postural control following stroke than any other approach." (Pollock 2014).

\section{Description of the intervention}

Walking on a treadmill, with or without body weight supported via a harness connected to an overhead support system, is a method of treating walking impairments post-stroke that is becoming increasingly popular. Use of a treadmill permits a greater number of steps to be performed within a training session; that is, it increases the amount of task-specific practice completed. For example, Hesse 2003 reported that people after stroke can perform up to 1000 steps in a 20-minute treadmill training session, compared with only 50 to 100 steps during a 20-minute session of conventional physiotherapy (neurophysiological approach). The speed of the treadmill, the amount of body weight support, and the amount of assistance provided by the physiotherapist can all be adjusted in order to provide a sufficient training intensity. This intervention emerged from research involving spinalised cats (Barbeau 1987) and was first used in clinical settings in the 1980s (Finch 1985). Since then, treadmill training with partial body weight support has been increasingly promoted as a treatment to drive recovery after stroke (Charalambous 2013; Langhorne 2009).

Treadmill training with body weight support is costly in terms of equipment and human resources. In addition, the equipment is not portable, so stroke participants must attend a suitably equipped healthcare facility in order to access this treatment. Several published randomised controlled trials (RCTs) have evaluated treadmill training with or without body weight support (Charalambous 2013; Polese 2013).

\section{How the intervention might work}

Improving walking after stroke is one of the main goals of rehabilitation. There is increasing evidence that high-intensity, repetitive, task-specific training might result in better gait rehabilitation (French 2016; Langhorne 2009). One example of potentially intensive, repetitive, task-specific gait-training is treadmill training. Treadmill training can be used to give patients intensive practice (in terms of high repetitions) of complex gait cycles and is being used as a method for increasing walking speed and walking distance in people who had a stroke. The advantage of treadmill training, compared with walking training overground, may be that higher walking speeds and a higher number of gait cycles can be achieved. Treadmill training, therefore, might be effective at improving walking parameters such as gait speed and walking distance after stroke (Polese 2013).

\section{Why it is important to do this review}

Several non-Cochrane systematic reviews evaluating treadmill training, with and without body weight support, have been published since this Cochrane review first appeared in the Cochrane Library 2003, Issue 3 (e.g. Manning 2003; Teasell 2003; Van Peppen 2004) and more recently updates during 2013 (Charalambous 2013; Polese 2013). However, all of these reviews are now out of date or had some methodological weaknesses (e.g. they did not used a comprehensive search strategy for all relevant databases or were prone to language bias because non-English studies were not included).

Updating this Cochrane review is required in order to justify the large equipment and human resource cost required to implement treadmill training, as well as to confirm the safety and acceptance of this method of training. The first update of this review was published in 2005 and included 15 trials with 622 participants; the second update was published in 2014 and included already 44 trials with 2658 participants. This is the third update of this Cochrane review. The search for trials was extended from June 2013 to March 2017. The aim of this review is to provide an update of the best available evidence about the above-mentioned approach.

\section{O B JECT IVES}

To determine if treadmill training and body weight support, individually or in combination, improve walking ability, quality of life, activities of daily living, dependency or death, and institutionalisation or death, compared with other physiotherapy gait-training interventions after stroke. The secondary objective was to determine the safety and acceptability of this method of gaittraining.

\section{METHODS}

\section{Criteria for considering studies for this review}

\section{Types of studies}

We included truly randomised and quasi-randomised controlled trials (including cross-over trials) in the review. We considered procedures such as coin tossing and dice rolling as random. Quasirandom allocation procedures included allocation by hospital record number or birth date, or alternation. We only included the first arm of the data from cross-over trials. We assessed concealment, blinding, and the number of withdrawals for all trials, but we did not use these data as inclusion or exclusion criteria.

Treadmill training and body weight support, individually or in combination, must have been implemented in one of the experimental conditions. We were looking for trials that made one of the following comparisons: 
- treadmill training with body weight support versus other physiotherapy, placebo, or no intervention;

- treadmill training without body weight support versus other physiotherapy, placebo, or no intervention;

- treadmill training with body weight support versus treadmill training without body weight support; and

- body weight support (without treadmill training) versus other physiotherapy, placebo, or no intervention.

Treadmill training and body weight support, individually or in combination, may have been implemented with physiotherapy co-intervention(s). Where co-intervention(s) were comparable for experimental and control groups, we grouped the trials according to the first four comparisons. In some cases, however, the co-intervention(s) used were not the same for the treatment and control groups. For example, treadmill training with body weight support may be implemented as one component of a task-oriented physiotherapy program and compared with non task-oriented physiotherapy (Richards 1993). Task-oriented physiotherapy programs involve task and context-specific training of motor skills based on a movement science or motor relearning framework (Carr 1998). Non-task-oriented physiotherapy includes neurophysiological approaches to treatment, such as Bobath (Bobath 1990), Brunnstrom (Brunnstrom 1970), Rood (Goff 1969) and proprioceptive neuromuscular facilitation (Knott 1968). While these trials cannot differentiate the effects of treadmill training and body weight support from other co-interventions, they do evaluate the intervention as part of a treatment package. We identified such trials and described them separately.

We included trials that evaluated any intensity and duration of treadmill training and body weight support that exceeded a single treatment session. Where necessary, we obtained details of the treatment and control interventions via correspondence with the trialists.

\section{Types of participants}

We included trials of adults who had suffered a stroke and exhibited an abnormal gait pattern. We used the World Health Organization's (WHO) definition of stroke: "rapidly developing clinical signs of focal (at times global) disturbance of cerebral function, lasting more than 24 hours or leading to death, with no apparent cause other than that of vascular origin." (Hatano 1976). We defined an abnormal gait pattern as walking with a slow speed, exhibiting kinematic deviations during gait (Moore 1993; Moseley 1993), or an inability to walk.

We envisaged that some trials may have included participants with other types of upper motor neurone lesions (e.g. traumatic brain injury, multiple sclerosis). However, we did not identify any mixed trials. If we identify trials using mixed types of participants in future updates of this review, we will attempt to obtain data for the stroke subgroup only via correspondence with the trialists.

\section{Types of interventions}

The primary question was whether treadmill training and body weight support, individually or in combination, could improve walking compared with other gait-training methods, placebo or no treatment. We therefore included any trial that attempted to evaluate such a comparison. Treadmill training involves walking on a standard treadmill; assistance, feedback or guidance may be provided by a health professional (usually a physiotherapist). Some of the participant's body weight may be supported during this training using a harness attached to an overhead support system. Alternatively, this type of body weight support can be used without a treadmill.

\section{Types of outcome measures}

\section{Primary outcomes}

The primary analyses focused on the ability to walk, both at the end of the treatment period (that is, immediate or short-term effects) and at the end of the scheduled follow-up (that is, longterm effects). We examined the ability to walk using dichotomous and continuous variables.

The dichotomous variable was 'dependence on personal assistance', where we defined 'dependence' as the inability to walk indoors (with or without a gait aid) without personal assistance or supervision. If reported, we used data from functional scales (or parts of functional scales relating to walking) to define the level of dependence. Suitable scales (with criterion for 'dependence') are:

- Motor Assessment Scale (Carr 1985), a score of two or less;

- Functional Independence Measure (Hamilton 1994), a score of five or less for the walking item;

- Barthel Index (Collin 1988), a score of three (independent, but may use any aid) or less for the ambulation item;

- Rivermead Mobility Index (Collen 1991), an answer of 'no' to the 'walking inside, with an aid if necessary' item; and

- Functional Ambulation Category (Holden 1984), a score of two or less.

We used walking dependence at the start of treatment to group trials in each comparison in the analyses.

The continuous variables were:

- independent walking speed measured over a short distance (e.g. six to 10 metres); and

- independent walking endurance measured over a long distance (e.g. Six-Minute Walk Test) expressed as a total distance walked.

These tests could be performed with or without a gait aid, but must have been completed without personal assistance. Wade 1992 reported that independent walking speed over a short distance is a simple, reliable, valid, and sensitive measure of walking performance. Walking over a long distance is a valid (Wade 1992) and reliable (Guyatt 1984) measure of walking endurance with established reference equations (Enright 1998). Where participants could not walk unless assisted, we allocated a speed and distance score of zero.

\section{Secondary outcomes}

Secondary outcome measures included participant quality of life, ability to perform activities of daily living, and the combined outcomes of death or dependency, and death or institutional care. Quality of life scales included the Frenchay Activities Index, Medical Outcomes Study Short Form Health Survey Questionnaire, Nottingham Health Profile, Quality of Life Index and Sickness Impact Profile (De Haan 1993). 
Activities of daily living scales included the Barthel Index, Modified Rankin Scale and Nottingham Extended Activities of Daily Living Scale (Wade 1992); and the Index of Activities of Daily Living, Instrumental Activities of Daily Living Scale, Functional Activities Questionnaire, and Blessed Functional Activities Scale (Pohjasvaara 1997).

We used the Stroke Unit Trialists' Collaboration definitions for death or dependency and death or institutional care (SUTC 2013). The criterion for dependency is scoring less than 18 on the Barthel Index or greater than two on the Modified Rankin Scale, while institutional care refers to care in a residential home, nursing home, or hospital at the end of the scheduled follow-up.

We determined the safety and acceptance of treadmill training. We used the prevalence of adverse events during the treatment period as a measure of safety. We categorised adverse events into injurious falls, other injury, major cardiovascular events, and any other adverse outcomes. We examined the reason for participants withdrawing from the studies as a marker for acceptance. We analysed these withdrawal data qualitatively.

\section{Search methods for identification of studies}

See the 'Specialized register' section in the Cochrane Stroke Group module. For this update, we extended the search for trials from March 2005 (when the first update of this review was published) to 14 February 2017. We searched for trials in all languages and arranged translation of relevant trial reports published in languages other then English.

\section{Electronic searches}

We searched the Cochrane Stroke Group Trials Register (last searched 14 February 2017) and the following electronic bibliographic databases:

- Cochrane Central Register of Controlled Trials (CENTRAL; 2017, Issue 4) in the Cochrane Library (searched 10 April 2017) (Appendix 1);

- MEDLINE Ovid (1966 to 14 February 2017) (Appendix 2);

- Embase Ovid (1980 to 14 February 2017) (Appendix 3);

- CINAHL EBSCO (Cumulative Index to Nursing and Allied Health Literature; 1982 to 14 February 2017) (Appendix 4);

- AMED Ovid ( Allied and Complementary Medicine; 1985 to 14 February 2017) (Appendix 5); and

- SPORTDiscus EBSCO (1949 to 14 February 2017) (Appendix 6).

We developed the search strategies with the help of the Cochrane Information Specialist and adapted the MEDLINE search strategy for the other databases.

We identified and searched the following ongoing trials and research registers:

- International Standard Randomised Controlled Trial Number Register (www.isrctn.com; searched 9 March 2017);

- US National Institutes of Health Ongoing Trials Register ClinicalTrials.gov (www.clinicaltrials.gov; searched 9 March 2017) (Appendix 7);

- Stroke Trials Register (www.strokecenter.org; searched 9 March 2017); and
- World Health Organization (WHO) International Clinical Trials Registry Platform (ICTRP) (searched 9 March 2017) (Appendix 8).

\section{Searching other resources}

We also:

- handsearched the following relevant conference proceedings:

* World Congress of NeuroRehabilitation (2006 to 2016);

* World Congress of Physical Medicine and Rehabilitation (2005 to 2015);

* World Congress of Physical Therapy (2007 to 2015);

* Deutsche Gesellschaft für Neurotraumatologie und Klinische Neurorehabilitation (2005 to 2016);

* Deutsche Gesellschaft für Neurologie (2005 to 2016);

* Deutsche Gesellschaft für Neurorehabilitation (2005 to 2016); and

* Asian Oceania Conference of Physical and Rehabilitation (2008 to 2016);

- screened reference lists of all relevant articles; and

- contacted trialists, experts, and researchers in our field of study.

\section{Data collection and analysis}

\section{Selection of studies}

For this update, two review authors (BE and $J M$ ) read the titles and abstracts of the records identified from the electronic searches and eliminated obviously irrelevant studies. We retrieved the full texts of the remaining studies and two review authors (BE and JM) ranked the studies as relevant, possibly relevant or irrelevant according to our inclusion criteria (types of studies, participants, aims of interventions). Two review authors (JM, ST) then examined whether the relevant and possibly relevant publications fitted the population, intervention, comparison, outcome (PICO) strategy of our study question. We resolved disagreements by discussion with all authors. If we needed further information, we contacted trial authors.

We excluded studies that did not match our inclusion criteria regarding the type of study, participants or type of interventions and those that were not RCTs.

\section{Data extraction and management}

For this update, two review authors (BE, JM) independently extracted trial and outcome data from the selected trials. If one of the review authors was involved in an included trial, another review author extracted the trial and outcome data from that trial. In accordance with the 'Risk of bias' tool described in the Cochrane Handbook for Systematic Reviews of Interventions (Higgins 2011), we used checklists to independently assess:

- methods of random sequence generation;

- methods of allocation concealment;

- blinding of assessors;

- blinding of participants;

- adverse effects and dropouts;

- important imbalances in prognostic factors at baseline;

- participants (country, number of participants, age, gender, type of stroke, time from stroke onset to study entry, inclusion 
and exclusion criteria, cognition, pre-existing neurological impairment(s), neurological history);

- comparison (details of interventions in treatment and control groups, duration of treatment, details of co-interventions in the groups);

- outcomes and their time point of measurement.

All review authors checked the extracted data for agreement. If these authors could not reach consensus, a researcher not involved in data extraction arbitrated. If necessary, we contacted the researchers to request more information.

\section{Assessment of risk of bias in included studies}

For this update of the review, two authors (BE and JM) independently assessed the risk of bias in the included trials in accordance with the Cochrane Handbook for Systematic Reviews of Interventions (Higgins 2011). We described the agreement between authors during the assessment of risk of bias and we resolved disagreement by reaching consensus through discussion. We contacted trialists for clarification and to request missing information.

\section{Measures of treatment effect}

For all outcomes representing continuous data, we entered means and standard deviations. We calculated a pooled estimate of the mean difference (MD) with $95 \%$ confidence interval $(\mathrm{Cl})$. If studies did not use the same outcome measure, we calculated standardised mean differences (SMD) instead of MDs. For all binary outcomes, we calculated risk differences (RD) with 95\% Cl. For all analyses, we used Cochrane's Review Manager software, RevMan 5.2 (RevMan 2012) and used a random-effects model.

\section{Unit of analysis issues}

In the event that individuals underwent more than one intervention, as in a cross-over trial, we only used data from the first phase of the study before cross-over.

If outcomes were repeatedly observed in participants (e.g. followup at four and six weeks), we reported the measures at the longest time point post intervention from each study.

\section{Dealing with missing data}

We contacted the relevant principal investigators to retrieve missing data. Where possible, we extracted data to allow an intention-to-treat (ITT) analysis in which all randomised participants were analysed

in the groups to which they were originally assigned. We did not make assumptions about loss to follow-up for continuous data. We analysed results for those who completed the trial.

\section{Assessment of heterogeneity}

We used the $I^{2}$ statistic to assess hterogeneity. We used a randomeffects model, regardless of the level of heterogeneity. Thus, in the case of heterogeneity, we did not violate the preconditions of a fixed-effect model approach.

\section{Assessment of reporting biases}

We inspected funnel plots for assessing the risk of publication bias.

\section{Data synthesis \\ GRADE and 'Summary of findings' table}

We created a 'Summary of findings for the main comparison' using the following outcomes.

- Walking speed $(\mathrm{m} / \mathrm{s})$ at the end of treatment. Scale from: 0 to infinity.

- Walking speed $(\mathrm{m} / \mathrm{s})$ at the end of treatment - dependent in walking at the start of treatment. Scale from: 0 to infinity.

- Walking speed $(\mathrm{m} / \mathrm{s})$ at the end of treatment - independent in walking at the start of treatment. Scale from: 0 to infinity.

- Walking endurance $(m)$ at the end of the intervention phase. Scale from: 0 to infinity.

- Walking endurance $(\mathrm{m})$ at the end of treatment - dependent in walking at the start of treatment. Scale from: 0 to infinity.

- Walking endurance $(\mathrm{m})$ at the end of treatment - independent in walking at the start of treatment. Scale from: 0 to infinity.

- Dropouts - by the end of treatment. Numbers of dropouts and adverse events.

We used the eight GRADE considerations (study limitations, consistency of effect, imprecision, indirectness, publication bias, large effect, plausible confounding would change the effect, and dose response gradient) to assess the quality of the body of evidence as it related to the studies which contributed data to the meta-analyses for the prespecified outcomes (Atkins 2004). We used methods and recommendations described in Section 8.5 and Chapter 12 of the Cochrane Handbook for Systematic Reviews of Interventions (Higgins 2011) using GRADEpro GDT software (GRADEpro GDT). We justified all decisions to down- or up-grade the quality of studies using footnotes, and we made comments to aid the reader's understanding of the review, where necessary.

\section{Subgroup analysis and investigation of heterogeneity}

We did three subgroup analyses:

- for time between the stroke and the start of training (first subgroup defined as in the first 3 months after stroke, second subgroup defined by duration of illness of more than 3 months)

- the intensity of training (subgroups defined by a weekly frequency of 5 times per week, 3 to 4 times a week and 3 times per week or less), and

- the duration of training (subgroups defined by categories of more than 4 weeks, 4 weeks or less than 4 weeks).

The scientific rationale for defining these categories in subgroups is that these above categories were described in the research (e.g. in study protocols for trials assessing the effects of treadmill training) and they are used in clinical rehabilitation after stroke.

However, for the types of co-interventions implemented in conjunction with treadmill training, we were not able to conduct a subgroup analysis.

We conducted subgroup analyses according to whether participants in the trials were dependent or independent walkers.

\section{Sensitivity analysis}

We performed a sensitivity analysis based on the mehodological quality of trials (involving treadmill training) including true versus 
quasi-randomisation, concealed versus unconcealed allocation, and blinded versus non-blinded outcome assessment.

\section{RES U L T S}

\section{Description of studies}

See: Characteristics of included studies; Characteristics of excluded studies; Characteristics of studies awaiting classification; Characteristics of ongoing studies

\section{Results of the search}

\section{4 version}

For the 2014 version of this review, we identified 12725 potentially relevant trials through electronic searching; we considered 246 full papers and included 44 trials with 2658 participants (Ada 2003; Ada 2010; Ada 2013; Da Cunha Filho 2002; Deniz 2011; Du 2006; Duncan 2011; Eich 2004; Franceschini 2009; Gan 2012; Globas 2011; Hoyer 2012; Jaffe 2004; Kang 2012; Kim 2011; Kosak 2000;
Kuys 2011; Langhammer 2010; Laufer 2001; Liston 2000; Luft 2008; MacKay-Lyons 2013; Macko 2005; Mehrberg 2001; Moore 2010; Nilsson 2001a; Nilsson 2001b; Olawale 2009; Pohl 2002; Richards 1993; Richards 2004; Scheidtmann 1999; Smith 2008; Sullivan 2007; Suputtitada 2004; Takami 2010; Toledano-Zarhi 2011; Visintin 1998a; Visintin 1998b; Weng 2004; Weng 2006; Werner 2002a; Yang 2010; Yen 2008; Zhang 2008; Zhu 2004)

\section{7 version}

In this update, the searches of the electronic databases and trials registers generated 10700 unique references for screening. After excluding nonrelevant citations, we obtained the full texts of 27 papers; of these, we included 12 trials in the qualitative and quantitative analysis of the review (Bonnyaud 2013; Bonnyaud 2013a; Combs-Miller 2014; DePaul 2015; Gama 2017; Kim 2016; Mao 2015; Middleton 2014; Park 2013; Park 2015; Ribeiro 2013; Srivastava 2016).

Figure 1 shows the flow diagram for the selection of studies. 
Figure 1. Flow diagram. Please note that the number of full-texts is not necessarily equal to the number of studies that means that there often are several full-texts of a single trial (e.g. as is the case for Ada 2003 or DEGAS 2007).

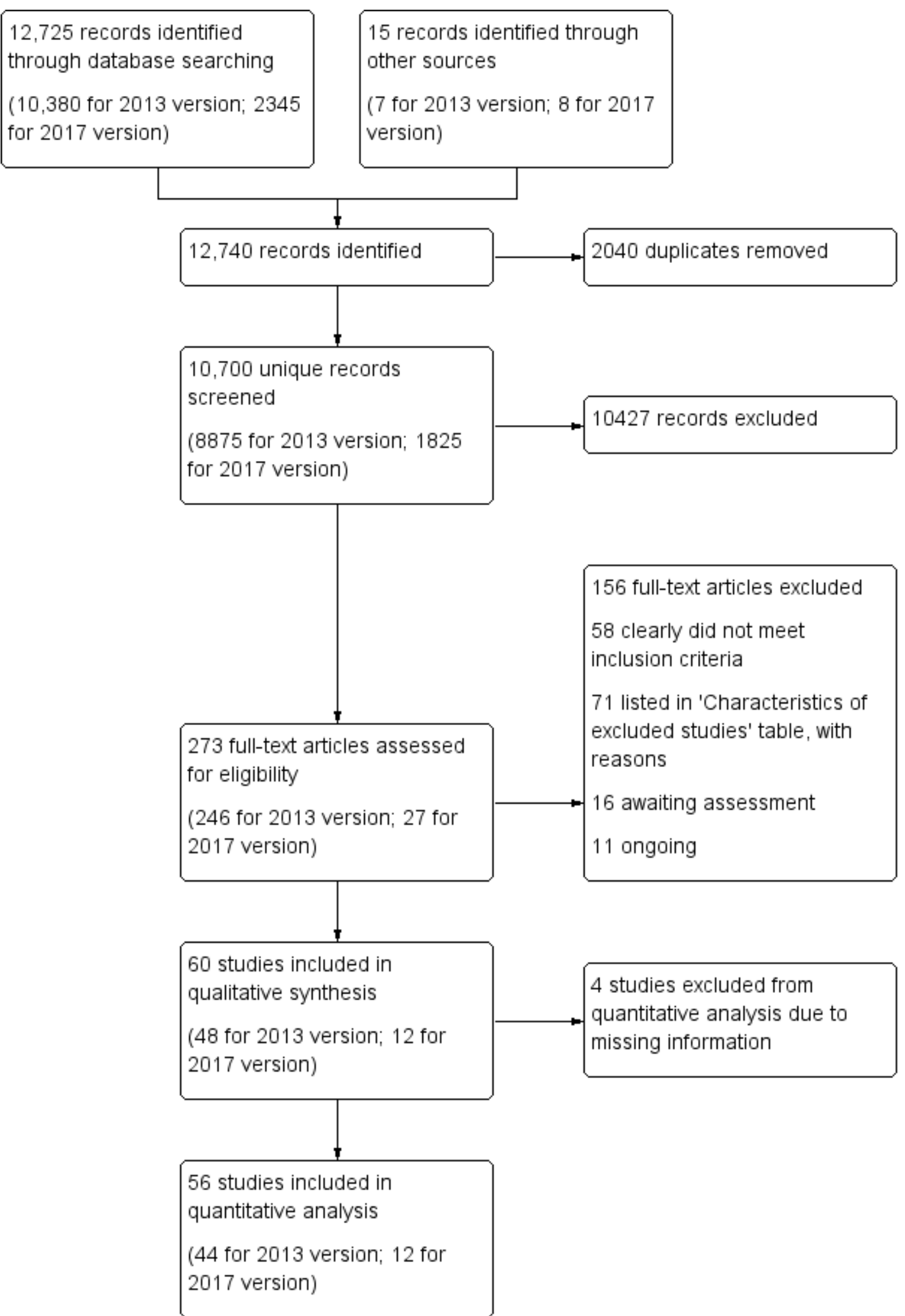




\section{Included studies}

We included 56 studies, involving a total of 3105 participants, in the quantitative analysis of this review (see the Characteristics of included studies). Two included studies have been split up into two sub-studies each (Nilsson 2001; Visintin 1998).

Twenty-six studies (1410 participants) compared treadmill training with body weight support to another physiotherapy intervention (Analysis 2.2); 20 studies (889 participants) compared treadmill training without body weight support to another physiotherapy intervention, no intervention or sham intervention (Analysis 3.1); two studies (100 participants) compared treadmill training with body weight support to treadmill training without body weight support; and four studies (147 participants) did not state whether they used body weight support or not.

No studies compared body weight support without treadmill training to another physiotherapy intervention.

The data from two studies were subdivided for the analyses and the corresponding participants were not double-counted. The Nilsson 2001 and Visintin 1998 studies recruited both dependent and independent walkers, so the data were subdivided into two comparisons for each trial. For the Nilsson 2001 trial, we separately analysed data from the 54 participants ( 26 experimental and 28 control) who were dependent walkers at the start of treatment (Nilsson 2001a) and data from the 19 participants (10 experimental and nine control) who were independent walkers at the start of treatment (Nilsson 2001b). For the Visintin 1998 trial, we performed separate analyses for data from the 59 participants (33 experimental and 26 control) (Visintin 1998a) and 20 participants (10 experimental and 10 control) (Visintin 1998b) who were dependent and independent walkers at the start of treatment, respectively. We obtained these walking dependency data through correspondence with the authors.

The characteristics of participants in the included studies are listed in Table 1. The characteristics of the experimental interventions are listed in Table 2. The outcomes used in the included studies are described in detail in the Characteristics of included studies. The reporting of adverse events and dropouts was incomplete for all trials and described in detail in Table 3 and Table 4. If these data were not explicitly reported, we attempted to obtain the missing information through correspondence with the trialists.

\section{Excluded studies}

We excluded 72 studies for various reasons (see Characteristics of excluded studies). Fivteen studies are still awaiting classification, mainly due to being conference abstracts with sparse outcome data reported and we were unable to contact the authors (see the Characteristics of studies awaiting classification). Eleven studies are ongoing (see the Characteristics of ongoing studies).

We excluded all these studies from the main analysis.

\section{Risk of bias in included studies}

Two authors (JM and ST) independently assessed the methodological quality of the included trials using the 'Risk of bias' tool (using the categories random sequence generation, allocation concealment and blinding of outcome assessors; Figure 2). 
Figure 2. 'Risk of bias' summary: review authors' judgements about each risk of bias item for each included study.

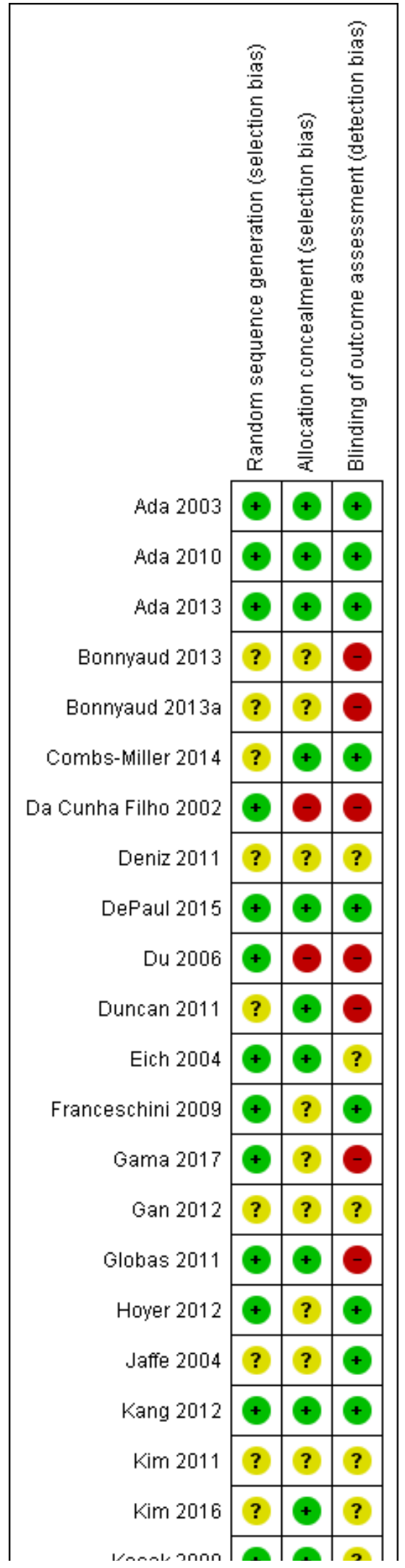


Figure 2. (Continued)

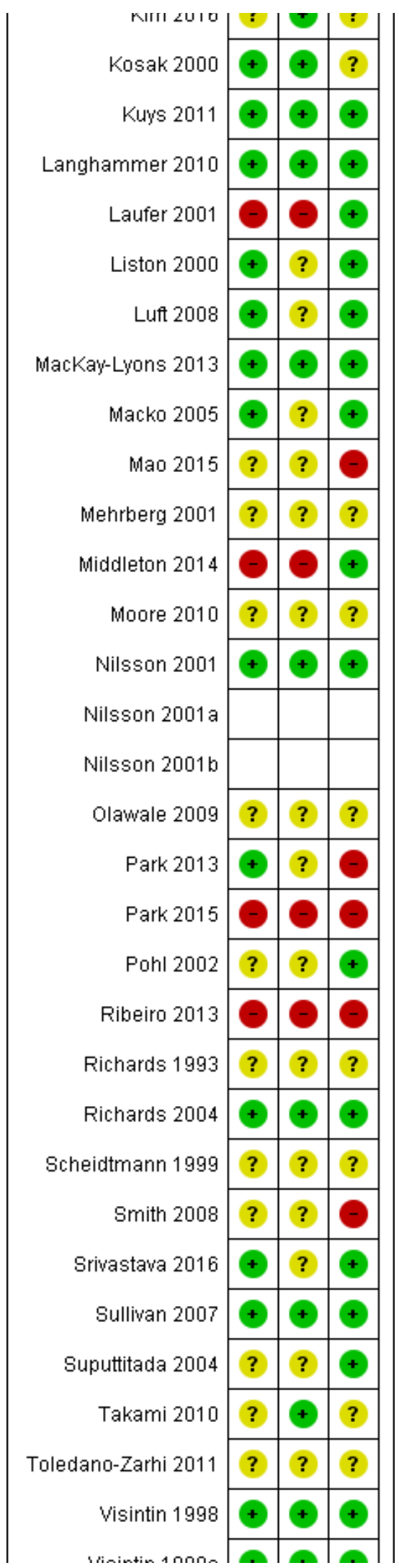


Figure 2. (Continued)

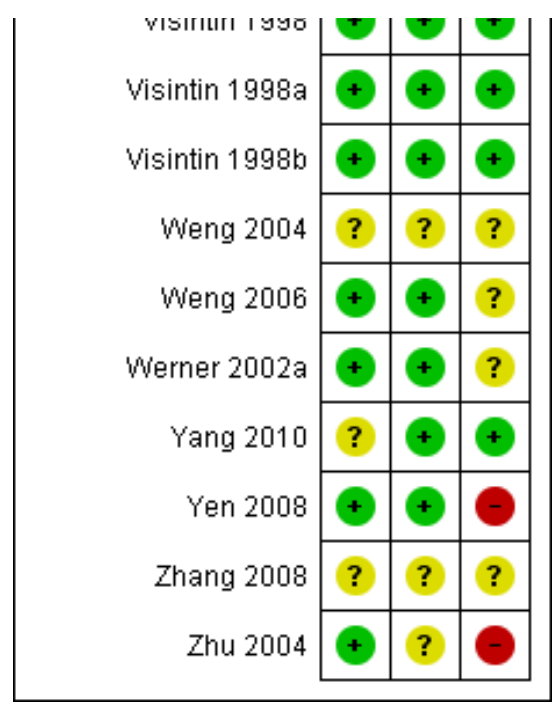

We wrote to all trialists requesting clarification of some design features or the provision of missing information in order to complete the quality ratings (correspondence was via email or letter, with a reminder being send after three weeks and then every three months if we did not get a response). If no data were provided or no contact achieved, we used published data only for all analysis.

Three trials used a cross-over design with random allocation to the order of treatments (Liston 2000; Scheidtmann 1999; Werner 2002a). All other studies used a parallel-group design with true randomisation or quasi-randomisation (Laufer 2001) to groups.
We explored publication bias visually by inspecting funnel plots for all comparisons (plots only shown for analyses 1.1 and 1.2 (Figure 3; Figure 4)). Our inspection did not indicate clear evidence for publication bias or our inspection was not suggestive of systematic heterogeneity. The only systematic heterogeneity in the funnel plots was found between categories of people after stroke who were dependent or independent walkers at study onset (as we described in detail above). 
Figure 3. Funnel plot of comparison: 1 Treadmill (with or without body weight support) versus other intervention, outcome: 1.1 Walking speed $(\mathrm{m} / \mathrm{s})$ at end of treatment.

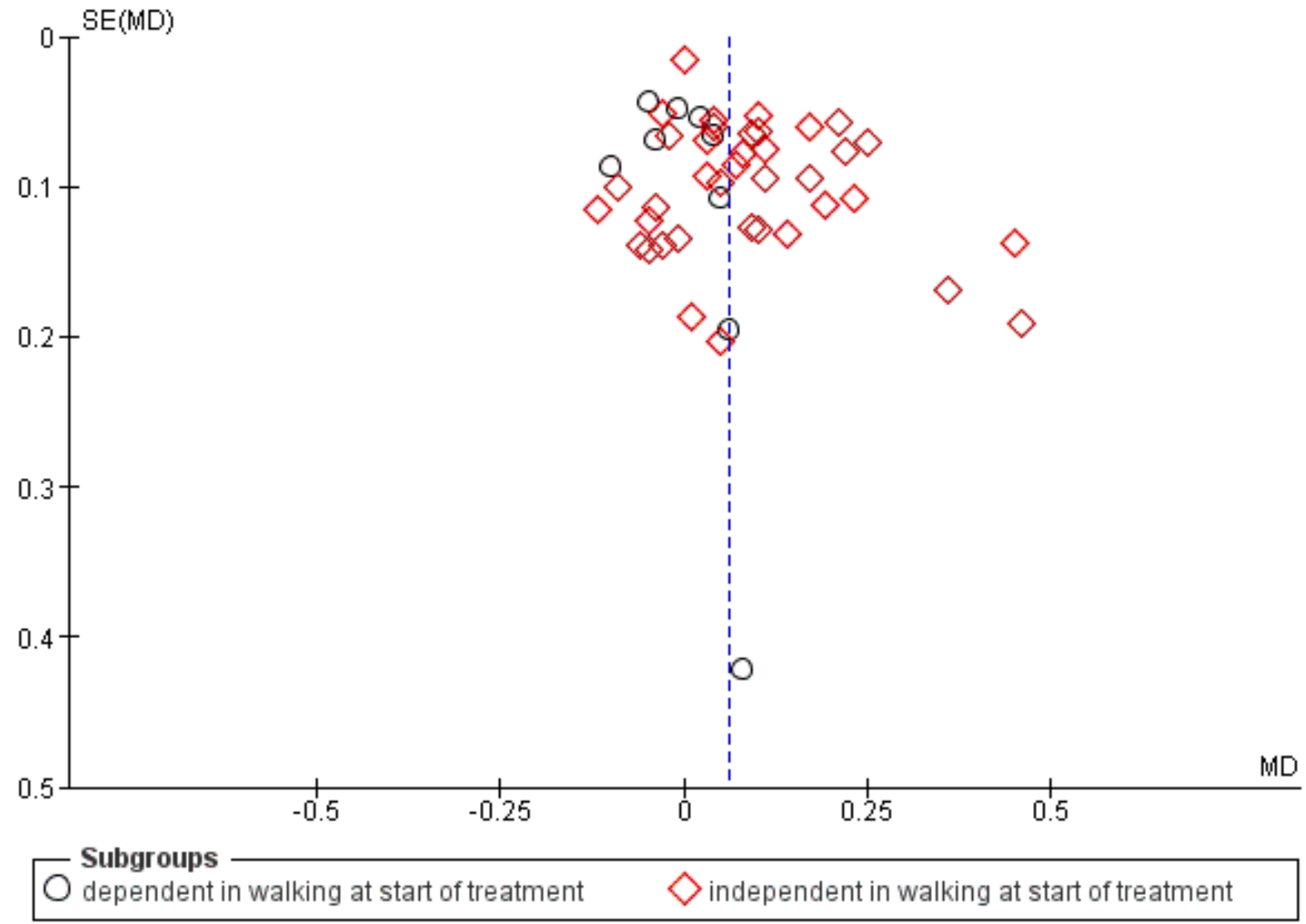


Figure 4. Funnel plot of comparison: 1 Treadmill (with or without body weight support) versus other intervention, outcome: 1.2 Walking endurance $(m)$ at end of treatment.

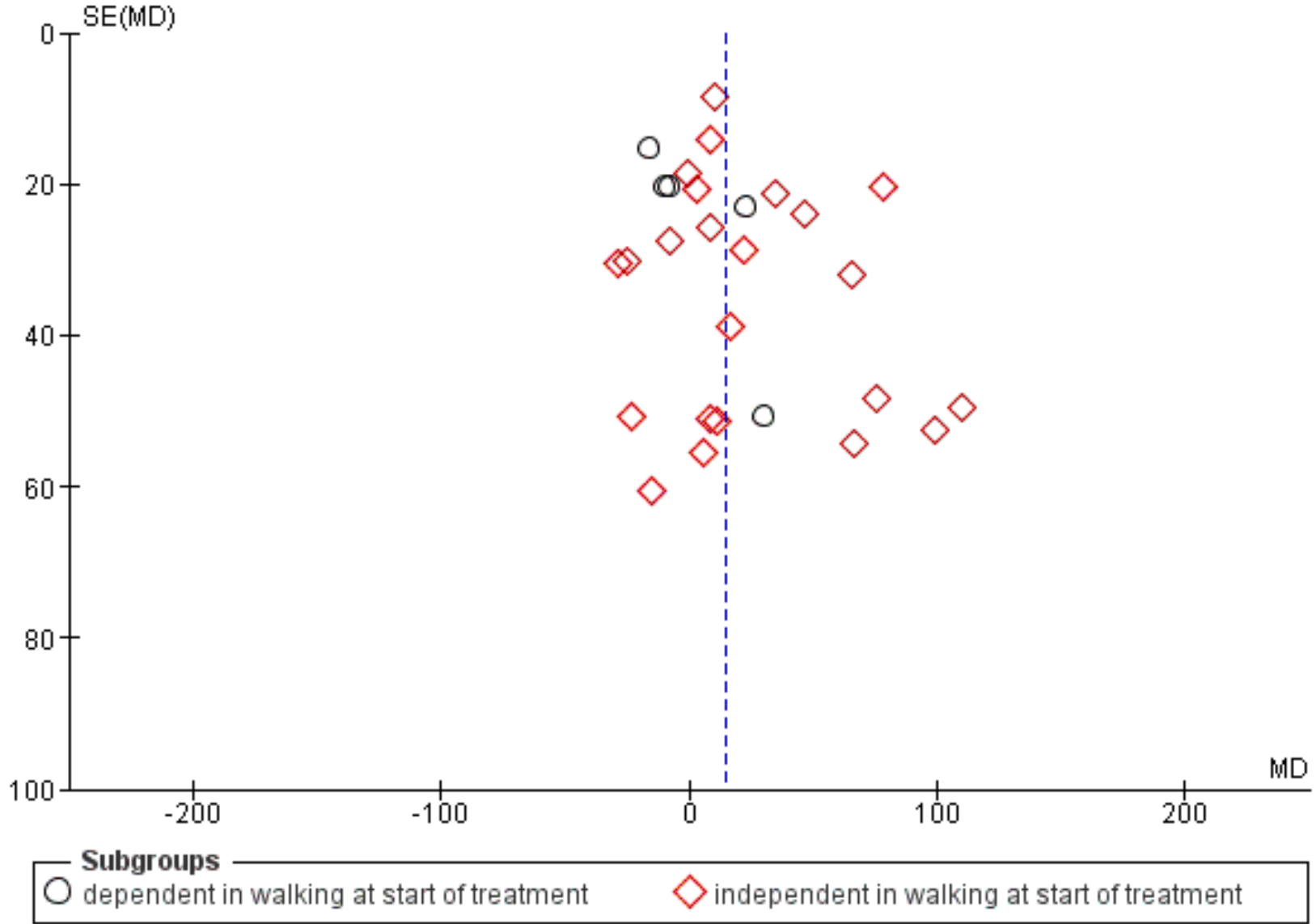

\section{Allocation}

Twenty-nine of the 56 included studies described appropriately the method of random sequence generation (see Figure 2).

Twenty-three of the 56 included studies described appropriately the method of concealing allocation of participants to groups (see Figure 2).

\section{Blinding}

Twenty-five of the 56 included studies described the outcome assessors as being blinded to group allocation (see Figure 2).

\section{Incomplete outcome data}

Twenty-three of the 56 included studies described incomplete outcome data; however, the dropouts appeared not to be substantial. The dropouts were balanced between the groups and therefore do not appear to indicate potential bias.

\section{Selective reporting}

For the majority of studies, particularly the older trials, we could not find study protocols. In these cases we assessed whether all the outcomes listed in the methods section of the publication were then reported in the results section.
In most cases, where these study protocols were available, there was no evidence of selective reporting of outcomes relevant to this review.

\section{Other potential sources of bias}

We were not aware of other potential sources of bias.

\section{Effects of interventions}

See: Summary of findings for the main comparison Treadmill (with or without body weight support) versus other intervention for walking after stroke

\section{Comparison 1: Treadmill (with or without body weight support) versus other intervention}

\section{Outcome 1.1: Walking speed $(\mathrm{m} / \mathrm{s})$ at the end of the treatment}

Forty-seven studies, with a total of 2323 participants, provided data for walking velocity (metres per second, $\mathrm{m} / \mathrm{s}$ ) at study end (Analysis 1.1).

Overall, the use of treadmill training in walking rehabilitation for people after stroke increased walking velocity significantly. The pooled mean difference (MD, random-effects model) for walking velocity was $0.06 \mathrm{~m} / \mathrm{s}(95 \% \mathrm{Cl} 0.03$ to $0.09 ; \mathrm{P}<0.0001$; level of heterogeneity $1^{2}=44 \%$; moderate-quality evidence) (Analysis 1.1 ). 
In nine studies, with a total of 752 participants who were dependent in walking at study onset, the use of treadmill training in walking rehabilitation for people after stroke did not increase walking velocity significantly. The pooled mean difference (MD, randomeffects model) for walking velocity was $-0.01 \mathrm{~m} / \mathrm{s}(95 \% \mathrm{Cl}-0.06$ to $0.03 ; \mathrm{P}=0.52$; level of heterogeneity $\mathrm{I}^{2}=0 \%$; low-quality evidence) (Analysis 1.1).

In 38 studies, with a total of 1571 participants who were independent in walking at study onset, the use of treadmill training in walking rehabilitation for people after stroke increased walking velocity significantly. The pooled MD (random-effects model) for walking velocity was $0.08 \mathrm{~m} / \mathrm{s}(95 \% \mathrm{Cl} 0.05$ to $0.12 ; \mathrm{P}<0.00001$; level of heterogeneity $\mathrm{I}^{2}=49 \%$; low-quality evidence) (Analysis 1.1).

We found statistically significant subgroup differences in walking velocity between dependent and independent walkers $\left(\mathrm{Chi}^{2}=\right.$ $11.94, \mathrm{df}=1, \mathrm{P}=0.0005)$.

\section{Outcome 1.2: Walking endurance $(m)$ at the end of treatment}

Twenty-eight trials, with a total of 1680 participants, provided data for walking endurance (walking capacity; metres $(\mathrm{m})$ walked in six minutes) at study end (Analysis 1.2).

Overall, the use of treadmill training in walking rehabilitation for people after stroke did not increase walking endurance significantly. The pooled MD (random-effects model) for walking endurance was $14.19 \mathrm{~m}(95 \% \mathrm{Cl} 2.92$ to $25.46 ; \mathrm{P}=0.09$; level of heterogeneity $\mathrm{I}^{2}=27 \%$; moderate-quality evidence) (Analysis 1.2).

In five studies, with a total of 639 participants who were dependent in walking at study onset, the use of treadmill training in walking rehabilitation for people after stroke did not increase walking endurance significantly. The pooled MD (random-effects model) for walking endurance was $-5.09 \mathrm{~m}(95 \% \mathrm{Cl}-23.41$ to $13.22 ; \mathrm{P}=0.59$; level of heterogeneity $\mathrm{I}^{2}=0 \%$; low-quality evidence) (Analysis 1.2).

In 23 studies, with a total of 1041 participants who were independent in walking at study onset, the use of treadmill training in walking rehabilitation for people after stroke increased walking endurance significantly. The pooled MD (random-effects model) for walking endurance was $19.72 \mathrm{~m}(95 \% \mathrm{Cl} 6.61$ to 32.83; $\mathrm{P}=0.003$; level of heterogeneity $\mathrm{I}^{2}=27 \%$; low-quality evidence) (Analysis 1.2).

We found statistically significant subgroup differences in walking endurance between dependent and independent walkers $\left(\mathrm{Chi}^{2}=\right.$ 4.66, $\mathrm{df}=1, \mathrm{P}=0.03)$.

\section{Comparison 2: Treadmill and body weight support versus other interventions}

\section{Outcome 2.1: Dependence on personal assistance to walk at end} of the treatment

Nineteen studies, with a total of 1210 participants, measured dependence on personal assistance to walk at the end of the treatment (Analysis 2.1).

Overall, the use of treadmill training with body weight support in walking rehabilitation for people after stroke did not increase the chance of walking independently compared with other physiotherapy interventions ( $\mathrm{RD} 0.00,95 \% \mathrm{Cl}-0.02$ to $0.02 ; \mathrm{P}=0.92$; level of heterogeneity $\mathrm{I}^{2}=0 \%$ ) (Analysis 2.1).
In eight studies, with a total of 814 participants who were dependent in walking at study onset, the use of treadmill training with body weight support in walking rehabilitation for people after stroke did not increase the chance of walking independently compared with other physiotherapy interventions (RD - $0.00,95 \% \mathrm{Cl}$ -0.03 to $0.03 ; \mathrm{P}=0.92$; level of heterogeneity $\mathrm{I}^{2}=0 \%$ ) (Analysis 2.1).

In 11 studies, with a total of 396 participants who were independent in walking at study onset, the use of treadmill training with body weight support in walking rehabilitation for people after stroke did not increase the chance of walking independently compared with other physiotherapy interventions (RD $-0.00,95 \% \mathrm{Cl}-0.03$ to 0.03 ; $\mathrm{P}$ $=1.00$; level of heterogeneity $\mathrm{I}^{2}=0 \%$ ) (Analysis 2.1).

We did not find statistically significant differences between dependent and independent walkers $\left(C^{2}{ }^{2}=0.01, d f=1, P=0.94\right)$.

\section{Outcome 2.2: Walking speed $(\mathrm{m} / \mathrm{s})$ at end of the treatment}

Twenty-six studies, with a total of 1410 participants, provided data for walking velocity (metres per second, $\mathrm{m} / \mathrm{s}$ ) at study end (Analysis 2.2).

Overall, the use of treadmill training with body weight support in walking rehabilitation for people after stroke increased walking velocity significantly. The pooled MD (random-effects model) for walking velocity was $0.07 \mathrm{~m} / \mathrm{s}(95 \% \mathrm{Cl} 0.02$ to $0.11 ; \mathrm{P}=0.005$; level of heterogeneity $\mathrm{I}^{2}=52 \%$ ) (Analysis 2.2).

In eight studies, with a total of 738 participants who were dependent in walking at study onset, the use of treadmill training with body weight support in walking rehabilitation for people after stroke did not increase walking velocity significantly. The pooled MD (random-effects model) for walking velocity was $-0.01 \mathrm{~m} / \mathrm{s}(95 \%$ $\mathrm{Cl}-0.06$ to $0.03 ; \mathrm{P}=0.51$; level of heterogeneity $\mathrm{I}^{2}=0 \%$ ) (Analysis 2.2).

In 18 studies, with a total of 672 participants who were independent in walking at study onset, the use of treadmill training with body weight support in walking rehabilitation for people after stroke did increase walking velocity significantly. The pooled MD (randomeffects model) for walking velocity was $0.11 \mathrm{~m} / \mathrm{s}(95 \% \mathrm{Cl} 0.06$ to 0.17 ; $\mathrm{P}<0.0001$; level of heterogeneity $\mathrm{I}^{2}=42 \%$ ) (Analysis 2.2).

We found statistically significant subgroup differences in walking velocity between dependent and independent walkers $\left(\mathrm{Chi}^{2}=\right.$ 14.88, $\mathrm{df}=1, \mathrm{P}=0.0001$ )

\section{Outcome 2.3: Walking endurance $(m)$ at end of the treatment}

Fifteen trials, with a total of 1062 participants, provided data for walking endurance (walking capacity; metres $(\mathrm{m})$ walked in six minutes) at study end (Analysis 2.3).

Overall, the use of treadmill training with body weight support in walking rehabilitation for people after stroke did not increase walking endurance significantly. The pooled MD (random-effects model) for walking endurance was $20.79 \mathrm{~m}(95 \% \mathrm{Cl} 0.43$ to 41.14; P $=0.05$; level of heterogeneity $\mathrm{I}^{2}=51 \%$ ) (Analysis 2.3).

In five studies, with a total of 639 participants who were dependent in walking at study onset, the use of treadmill training with body weight support in walking rehabilitation for people after stroke did not increase walking endurance significantly. The pooled MD 
(random-effects model) for walking endurance was -5.09 m $(95 \% \mathrm{Cl}$ -23.41 to $13.22 ; \mathrm{P}=0.59$; level of heterogeneity $\mathrm{I}^{2}=0 \%$ ) (Analysis 2.3).

In 10 studies, with a total of 423 participants who were independent in walking at study onset, the use of treadmill training with body weight support in walking rehabilitation for people after stroke increased walking endurance significantly. The pooled MD (random-effects model) for walking endurance was $36.91 \mathrm{~m}(95 \% \mathrm{Cl}$ 11.14 to $62.68 ; \mathrm{P}=0.005$; level of heterogeneity $\mathrm{I}^{2}=39 \%$ ) (Analysis 2.3).

We found statistically significant subgroup differences in walking endurance between dependent and independent walkers $\left(\mathrm{Chi}^{2}=\right.$ $6.78, \mathrm{df}=1, \mathrm{P}=0.009$ ).

\section{Outcome 2.4: Dependence on personal assistance to walk at end of scheduled follow-up}

Five studies, with a total of 285 participants, measured dependence on personal assistance to walk at the end of scheduled follow-up (Analysis 2.4).

In two studies, with a total of 170 participants who were dependent in walking at study onset, the use of treadmill training with body weight support in walking rehabilitation for people after stroke did not increase the chance of walking independently compared with other physiotherapy interventions (RD $-0.02,95 \% \mathrm{Cl}-0.18$ to 0.15 ; $\mathrm{P}$ $=0.83$; level of heterogeneity $1^{2}=40 \%$ ) (Analysis 2.4).

In three studies, with a total of 115 participants who were independent in walking at study onset, the use of treadmill training with body weight support in walking rehabilitation for people after stroke did not increase the chance of walking independently compared with other physiotherapy interventions (RD $0.00,95 \% \mathrm{Cl}$ -0.05 to $0.05 ; \mathrm{P}=1.00$; level of heterogeneity $\mathrm{I}^{2}=0 \%$ ) (Analysis 2.4 ).

\section{Outcome 2.5: Walking speed $(\mathrm{m} / \mathrm{s})$ at end of scheduled follow-up}

Twelve trials, with a total of 944 participants, provided data for walking velocity (metres per second, $\mathrm{m} / \mathrm{s}$ ) at the end of scheduled follow-up (Analysis 2.5).

Overall, the use of treadmill training with body weight support in walking rehabilitation for people after stroke did not increase walking velocity at the end of scheduled follow-up significantly. The pooled MD (random-effects model) for walking velocity was $0.03 \mathrm{~m} /$ $\mathrm{S}(95 \% \mathrm{Cl}-0.05$ to $0.10 ; \mathrm{P}=0.50$; level of heterogeneity $\mathrm{l} 2=55 \%)$ (Analysis 2.5).

In three studies, with a total of 556 participants who were dependent in walking at the end of scheduled follow-up, the use of treadmill training with body weight support in walking rehabilitation for people after stroke did not increase walking velocity significantly. The pooled MD (random-effects model) for walking velocity was $-0.05 \mathrm{~m} / \mathrm{s}(95 \% \mathrm{Cl}-0.13$ to $0.03 ; \mathrm{P}=0.20$; level of heterogeneity $\mathrm{I}^{2}=0 \%$ ) (Analysis 2.5).

In nine studies, with a total of 388 participants who were independent in walking at the end of scheduled follow-up, the use of treadmill training with body weight support in walking rehabilitation for people after stroke did not increase walking velocity significantly. The pooled MD (random-effects model) for walking velocity was $0.06 \mathrm{~m} / \mathrm{s}(95 \% \mathrm{Cl}-0.03$ to $0.15 ; \mathrm{P}=0.19$; level of heterogeneity $\mathrm{I}^{2}=55 \%$ ) (Analysis 2.5 ).

\section{Outcome 2.6: Walking endurance (m) at end of scheduled follow-} up

Ten trials, with a total of 882 participants, provided data for walking endurance (walking capacity; metres $(\mathrm{m})$ walked in six minutes) at the end of scheduled follow-up (Analysis 2.6).

Overall, the use of treadmill training with body weight support in walking rehabilitation for people after stroke did not increase walking endurance at the end of scheduled follow-up significantly. The pooled MD (random-effects model) for walking endurance was $21.64 \mathrm{~m}\left(95 \% \mathrm{Cl}--4.70\right.$ to $47.98 ; \mathrm{P}=0.11$; level of heterogeneity $\mathrm{I}^{2}=$ 47\%) (Analysis 2.6).

In two studies, with a total of 510 participants who were dependent in walking at study onset, the use of treadmill training with body weight support in walking rehabilitation for people after stroke did not increase walking endurance significantly. The pooled MD (random-effects model) for walking endurance was -6.78 $\mathrm{m}(95 \% \mathrm{Cl}$ -34.57 to $21.02 ; \mathrm{P}=0.63$; level of heterogeneity $\mathrm{I}^{2}=0 \%$ ) (Analysis 2.6).

In eight studies, with a total of 372 participants who were independent in walking at study onset, the use of treadmill training with body weight support in walking rehabilitation for people after stroke did not increase walking endurance significantly. The pooled MD (random-effects model) for walking endurance was $31.55 \mathrm{~m}$ $\left(95 \% \mathrm{Cl} 0.57\right.$ to 62.53 ; $\mathrm{P}=0.05$; level of heterogeneity $\mathrm{I}^{2}=41 \%$ ) (Analysis 2.6).

\section{Comparison 3: Treadmill training without body weight support versus other interventions}

\section{Outcome 3.1: Walking speed $(\mathrm{m} / \mathrm{s})$ at the end of the treatment}

Twenty trials, with a total of 889 participants who were ambulatory at study onset, provided data for walking velocity (metres per second, $\mathrm{m} / \mathrm{s}$ ) at the end of the treatment (Analysis 3.1).

Overall, the use of treadmill training without body weight support in gait rehabilitation for ambulatory people after stroke increased walking velocity significantly. The pooled MD (random-effects model) for walking velocity was $0.05 \mathrm{~m} / \mathrm{s}(95 \% \mathrm{Cl} 0.01$ to $0.09 ; \mathrm{P}=$ 0.01 ; level of heterogeneity $12=26 \%$ ) (Analysis 3.1 ).

\section{Outcome 3.2: Walking endurance $(m)$ at end of treatment}

Thirteen trials, with a total of 608 participants, provided data for walking endurance (walking capacity; metres $(\mathrm{m})$ walked in six minutes) at the end of the treatment (Analysis 3.2).

Overall, the use of treadmill training without body weight support in gait rehabilitation for people after stroke did not increase walking endurance significantly. The pooled MD (random-effects model) for walking velocity was $9.25 \mathrm{~m}(95 \% \mathrm{Cl}-1.99$ to $20.50 ; \mathrm{P}=0.11$; level of heterogeneity $\mathrm{I}^{2}=0 \%$ ) (Analysis 3.2).

\section{Comparison 4: Treadmill and body weight support versus treadmill only}

In this update of the review, we found only one additional study for this outcome (Srivastava 2016). Only two trials with 99 participants 
were included in this comparison (Srivastava 2016; Visintin 1998) (more details may be found in Analysis 4.1, Analysis 4.1; Analysis 4.2; Analysis 4.3; Analysis 4.4; Analysis 4.5; Analysis 4.6).

Because there are only sparse data for this comparison, we decided not to pool these studies and to describe the study results without presenting 'totals' and without applying inference tests (Analysis 4.1, Analysis 4.1; Analysis 4.2; Analysis 4.3; Analysis 4.4; Analysis 4.5; Analysis 4.6).

\section{Comparison 5: Adverse events for all included trials}

\section{Outcome 5.1: Adverse events during the treatment}

Twenty-four trials, with a total of 1504 participants, provided data for adverse events during the treatment (Analysis 5.1).

Overall, the use of treadmill training with or without body weight support in gait rehabilitation for people after stroke did not increase the risk of adverse events during the treatment ( $R D$ (random-effects model) $0.02,95 \% \mathrm{Cl}-0.01$ to $0.05 ; \mathrm{P}=0.14$; level of heterogeneity $\mathrm{I}^{2}$ $=51 \%)$. The adverse events during the treatment are described in detail for each trial in Table 3.

\section{Comparison 6: Dropouts for all included trials}

\section{Outcome 6.1: Dropouts}

\subsection{1: Dropouts by the end of the treatment}

Fifty-six trials, with a total of 3105 participants, provided data for dropouts at study end (Analysis 6.1).

Overall, the use of treadmill training with or without body weight support in gait rehabilitation for people after stroke did not increase the risk of participants dropping out by the end of the treatment (RD (random-effects model) $0.00,95 \% \mathrm{Cl}-0.01$ to $0.01 ; \mathrm{P}=0.74$; level of heterogeneity $I^{2}=0 \%$ ). The reasons for dropouts and all adverse events during the treatment are described in detail for each trial in Table 3 and Table 4.

\subsection{2: Dropouts by the end of scheduled follow-up (cumulative)}

Fourteen trials, with a total of 780 participants, provided data for dropouts by the end of scheduled follow-up (cumulative) (Analysis 6.1).

Overall, the use of treadmill training with or without body weight support in gait rehabilitation for people after stroke did not increase the risk of participants dropping out by the end of scheduled followup (cumulative) (RD (random-effects model) - $0.02,95 \% \mathrm{Cl}-0.06$ to $0.03 ; P=0.47$; level of heterogeneity $\mathrm{I}^{2}=0 \%$ ). The reasons for dropouts are described in detail for each trial in Table 3 and Table 4.

\section{Comparison 7: Sensitivity analysis: by trial methodology}

\section{Outcome 7.1: Walking speed $(\mathrm{m} / \mathrm{s})$ at the end of the treatment (all trials involving treadmill training)}

To examine the robustness of the results, we specified variables (adequate sequence generation process, adequate concealed allocation and blinded assessors for primary outcome) in a sensitivity analysis that we believed could influence the size of the effect observed for walking speed $(\mathrm{m} / \mathrm{s})$ at the end of the treatment (Analysis 7.1). We included both participants who were dependent and independent in walking at study onset.

\subsection{1: trials with adequate sequence generation process}

We included 27 trials, with a total of 1242 participants, that had an adequate sequence generation process (Analysis 7.1). The use of treadmill training in walking rehabilitation for people after stroke increased walking velocity significantly. The pooled MD (randomeffects model) for walking velocity was $0.03 \mathrm{~m} / \mathrm{s}(95 \% \mathrm{Cl} 0.00$ to 0.06 ; $P=0.02$; level of heterogeneity $\mathrm{I}^{2}=5 \%$ ).

\subsection{2: trials with adequate concealed allocation}

We included 21 trials, with a total of 1266 participants, that had adequate concealed allocation (Analysis 7.1). The use of treadmill training in walking rehabilitation for people after stroke increased walking velocity significantly. The pooled MD (random-effects model) for walking velocity was $0.06 \mathrm{~m} / \mathrm{s}(95 \% \mathrm{Cl} 0.01$ to $0.10 ; \mathrm{P}=$ 0.008 ; level of heterogeneity $\mathrm{I}^{2}=26 \%$ ).

\subsection{3: trials with blinded assessors for the primary outcome}

We included 24 trials, with a total of 1554 participants, that had blinded assessors for the primary outcome (Analysis 7.1). The use of treadmill training in walking rehabilitation for people after stroke increased walking velocity significantly. The pooled MD (randomeffects model) for walking velocity was $0.06 \mathrm{~m} / \mathrm{s}(95 \% \mathrm{Cl} 0.02$ to 0.11 ; $\mathrm{P}=0.008$; level of heterogeneity $\mathrm{I}^{2}=38 \%$ ).

Comparison 8: Subgroup analysis: treadmill (with or without body weight support) versus other, by duration of illness (independent in walking only)

\section{Outcome 8.1: Walking speed $(\mathrm{m} / \mathrm{s})$ at the end of the treatment}

In our planned subgroup analysis comparing walking speed at the end of the intervention phase in people in the acute and chronic phases of stroke, we arranged all included studies in one of two subgroups (acute and chronic phase).

\subsubsection{Acute phase: less than or equal to three months after stroke, independent in walking}

Eleven trials, with a total of 347 participants, investigated people in the acute or subacute phase, defined as less than or equal to three months after stroke (Analysis 8.1). The use of treadmill training in walking rehabilitation for people after stroke increased walking velocity significantly. The pooled MD (random-effects model) for walking velocity was $0.15 \mathrm{~m} / \mathrm{s}(95 \% \mathrm{Cl} 0.07$ to $0.23 ; \mathrm{P}=0.0002$; level of heterogeneity $1^{2}=44 \%$ ).

\subsubsection{Chronic phase: more than three months after stroke, independent in walking}

Twenty-six trials, with a total of 1209 participants, investigated people in the chronic phase, defined as more than three months after stroke (Analysis 8.1). The use of treadmill training in walking rehabilitation for people after stroke increased walking velocity significantly. The pooled MD (random-effects model) for walking velocity was $0.06 \mathrm{~m} / \mathrm{s}(95 \% \mathrm{Cl} 0.02$ to $0.10 ; \mathrm{P}=0.001$; level of heterogeneity $\mathrm{l}^{2}=39 \%$ ).

We did not find statistically significant differences in walking velocity between participants treated in the acute/subacute phase compared with participants treated in the chronic phase after stroke $\left(\mathrm{Chi}^{2}=3.95, \mathrm{df}=1, \mathrm{P}=0.05\right)$. 


\section{Outcome 8.2: Walking endurance $(\mathrm{m})$ at the end of the treatment}

8.2.1 Acute phase: less than or equal to three months after stroke, independent in walking

Five trials, with a total of 178 participants, investigated people in the acute or subacute phase, defined as less than or equal to three months after stroke (Analysis 8.2). The use of treadmill training in walking rehabilitation for people after stroke increased walking endurance significantly. The pooled MD (random-effects model) for walking endurance was $48.6 \mathrm{~m}(95 \% \mathrm{Cl} 23.97$ to $73.32 ; \mathrm{P}=0.0001$; level of heterogeneity $\left.\right|^{2}=6 \%$ ).

\subsubsection{Chronic phase: more than three months after stroke,} independent in walking

Eighteen trials, with a total of 863 participants, investigated people in the chronic phase, defined as more than three months after stroke (Analysis 8.2). The use of treadmill training in walking rehabilitation for people after stroke did not increase walking endurance significantly. The pooled MD (random-effects model) for walking endurance was $10.69 \mathrm{~m}(95 \% \mathrm{Cl}-0.28$ to $21.66 ; \mathrm{P}=0.06$; level of heterogeneity $I^{2}=2 \%$ ).

We found statistically significant differences in walking endurance between participants treated in the acute/subacute phase compared with participants treated in the chronic phase after stroke $\left(\mathrm{Chi}^{2}=7.59, \mathrm{df}=1, \mathrm{P}=0.006\right)$.

Comparison 9: Subgroup analysis: treadmill (with or without body weight support) versus other interventions, by intensity (frequency) of training (independent in walking only)

In our planned subgroup analysis comparing walking speed at the end of the intervention phase at different intensities (frequencies) of training, we arranged all included studies in one of three subgroups (treadmill training five times per week or more, three to four times per week, less than three times per week or unclear frequency).

\section{Outcome 9.1: Walking speed $(\mathrm{m} / \mathrm{s})$ at the end of the treatment}

\subsubsection{Treadmill training five times per week or more}

Nineteen trials, with a total of 671 participants, investigated people with an intensity (frequency) of training of five times per week or more (Analysis 9.1). The use of treadmill training in walking rehabilitation for people after stroke increased walking velocity significantly. The pooled MD (random-effects model) for walking velocity was $0.04 \mathrm{~m} / \mathrm{s}(95 \% \mathrm{Cl} 0.02$ to $0.07 ; \mathrm{P}=0.0004$; level of heterogeneity $\left.\right|^{2}=64 \%$ ).

\subsubsection{Treadmill training three to four times per week}

Sixteen trials, with a total of 784 participants, investigated people with an intensity (frequency) of training three to four times per week (Analysis 9.1). The use of treadmill training in walking rehabilitation for people after stroke increased walking velocity significantly. The pooled MD (random-effects model) for walking velocity was $0.08 \mathrm{~m} / \mathrm{s}(95 \% \mathrm{Cl} 0.03$ to $0.12 ; \mathrm{P}=0.0008$; level of heterogeneity $\mathrm{I}^{2}=22 \%$ ).

\subsubsection{Treadmill training less than three times per week or unclear frequency}

Three trials, with a total of 116 participants, investigated people with an intensity (frequency) of training less than three times a week (Analysis 9.1). The use of treadmill training in walking rehabilitation for people after stroke did not increase walking velocity significantly. The pooled MD (random-effects model) for walking velocity was $0.02 \mathrm{~m} / \mathrm{s}(95 \% \mathrm{Cl}-0.06$ to $0.10 ; \mathrm{P}=0.61$; level of heterogeneity $\left.\right|^{2}=0 \%$ ).

We did not find statistically significant differences in walking velocity between participants treated at different intensities of training $\left(\mathrm{Chi}^{2}=2.09, \mathrm{df}=2, \mathrm{P}=0.35\right)$.

\section{Outcome 9.2: walking endurance $(\mathrm{m})$ at the end of the treatment}

\subsubsection{Treadmill training five times per week}

Nine trials, with a total of 392 participants, investigated people with an intensity (frequency) of training of five times a week or more (Analysis 9.2). The use of treadmill training in walking rehabilitation for people after stroke increased walking endurance significantly. The pooled MD (random-effects model) for walking endurance was $27.25 \mathrm{~m} \mathrm{(95 \%} \mathrm{Cl} 5.37$ to $49.13 ; \mathrm{P}=0.01$; level of heterogeneity $\mathrm{I}^{2}=$ $45 \%)$.

\subsubsection{Treadmill training three to four times per week}

Thirteen trials, with a total of 621 participants, investigated people with an intensity (frequency) of training of three to four times per week (Analysis 9.2). The use of treadmill training in walking rehabilitation for people after stroke did not increase walking endurance significantly. The pooled MD (random-effects model) for walking endurance was $12.41 \mathrm{~m}(95 \% \mathrm{Cl}-3.15$ to $27.97 ; \mathrm{P}=0.12$; level of heterogeneity $\left.\right|^{2}=10 \%$ ).

\subsubsection{Treadmill training less than three times per week or unclear}

One trial, with a total of 28 participants, investigated people with an intensity (frequency) of training of less than three times a week (Analysis 9.2). The use of treadmill training in walking rehabilitation for people after stroke did not increase walking endurance significantly. The pooled MD (random-effects model) for walking endurance was $-15.00 \mathrm{~m}(95 \% \mathrm{Cl}-133.26$ to $103.26 ; \mathrm{P}=0.80$; level of heterogeneity not applicable).

We did not find statistically significant differences in walking endurance between participants treated at different intensities of training $\left(\mathrm{Chi}^{2}=1.46, \mathrm{df}=2, \mathrm{P}=0.48\right)$.

\section{Comparison 10: Subgroup analysis: treadmill (with or without body weight support) versus other interventions, by duration of training period (independent in walking only)}

In our planned subgroup analysis comparing walking speed at the end of the intervention phase after different durations of treatment, we arranged all included studies into one of three subgroups (treadmill training duration of more than four weeks, equal to four weeks or less than four weeks).

\section{Outcome 10.1 Walking speed $(\mathrm{m} / \mathrm{s})$ at the end of the treatment}

\subsubsection{Treadmill training duration of more than four weeks}

Fourteen trials, with a total of 802 participants, investigated people with a duration of training of more than four weeks (Analysis 10.1). The use of treadmill training in walking rehabilitation for people after stroke increased walking velocity significantly. The pooled MD (random-effects model) for walking velocity was $0.05 \mathrm{~m} / \mathrm{s}(95 \% \mathrm{Cl}$ 0.01 to $0.09 ; P=0.02$; level of heterogeneity $\mathrm{I}^{2}=0 \%$ ). 


\subsubsection{Treadmill training duration of four weeks}

Thirteen trials, with a total of 404 participants, investigated people with a duration of training of four weeks (Analysis 10.1). The use of treadmill training in walking rehabilitation for people after stroke increased walking velocity significantly. The pooled MD (randomeffects model) for walking velocity was $0.13 \mathrm{~m} / \mathrm{s}(95 \% \mathrm{Cl} 0.07$ to 0.19 ; $\mathrm{P}<0.0001$; level of heterogeneity $\mathrm{I}^{2}=30 \%$ ).

\subsubsection{Treadmill training duration of less than four weeks}

Eleven trials, with a total of 365 participants, investigated people with a duration of training of less than four weeks (Analysis 10.1). The use of treadmill training in walking rehabilitation for people after stroke increased walking velocity significantly. The pooled MD (random-effects model) for walking velocity was $0.08 \mathrm{~m} / \mathrm{s}(95 \% \mathrm{Cl}$ 0.01 to $0.14 ; P=0.03$; level of heterogeneity $1^{2}=63 \%$ ).

We found statistically significant differences in walking velocity between participants treated with training for different durations $\left(\mathrm{Chi}^{2}=8.68, \mathrm{df}=2, \mathrm{P}=0.01\right)$.

\section{Outcome 10.2: Walking endurance $(m)$ at the end of the treatment}

In our planned subgroup analysis comparing walking endurance at the end of the intervention phase after different durations of treatment, we arranged all included studies into one of three subgroups (treadmill training duration of more than four weeks, equal to four weeks, or less than four weeks).

\subsubsection{Treadmill training duration of more than four weeks}

Twelve trials, with a total of 706 participants, investigated people with a duration of training of more than four weeks (Analysis 10.2). The use of treadmill training in walking rehabilitation for people after stroke increased walking endurance significantly. The pooled MD (random-effects model) for walking endurance was $19.09 \mathrm{~m}$ $(95 \% \mathrm{Cl} 2.29$ to $35.88 ; \mathrm{P}=0.03$; level of heterogeneity $\mathrm{I} 2=0 \%$ ).

\subsubsection{Treadmill training duration of four weeks}

Five trials, with a total of 146 participants, investigated people with a duration of training of four weeks (Analysis 10.2). The use of treadmill training in walking rehabilitation for people after stroke did not increase walking endurance significantly. The pooled MD (random-effects model) for walking endurance was $29.40 \mathrm{~m}(95 \% \mathrm{Cl}$ -4.75 to $63.54 ; P=0.09$; level of heterogeneity $\mathrm{I}^{2}=65 \%$ ).

\subsubsection{Treadmill training duration of less than four weeks}

Four trials, with a total of 129 participants, investigated people with a duration of training of less than four weeks (Analysis 10.2). The use of treadmill training in walking rehabilitation for people after stroke did not increase walking endurance significantly. The pooled MD (random-effects model) for walking endurance was $9.82 \mathrm{~m}$ (95\% $\mathrm{Cl}-15.48$ to 35.13 ; $\mathrm{P}=0.45$; level of heterogeneity $\mathrm{I}^{2}=13 \%$ ).

We did not find statistically significant differences in walking endurance between participants treated with training for different durations $\left(\mathrm{Chi}^{2}=0.85, \mathrm{df}=2, \mathrm{P}=0.66\right)$.

\section{Other outcomes}

We did not analyse the secondary outcomes of participant quality of life, ability to perform activities of daily living, and the combined outcomes of death or dependency, and death or institutional care either because these variables were not reported or due to insufficient data in many of the included studies.

We did not perform the planned subgroup analyses for the types of co-interventions implemented in conjunction with treadmill training due to insufficient data.

\section{DISCUSSION}

\section{Summary of main results}

The aim of this review was to evaluate the effect of treadmill training and body weight support, individually or in combination, for walking after stroke. We included 56 trials with 3105 participants in this update. Overall, the use of treadmill training with body weight support did not increase the chance of walking independently compared with people after stroke receiving other physiotherapy interventions, but not treadmill training. The use of treadmill training with body weight support in walking rehabilitation for people after stroke did increase the walking velocity and walking endurance significantly compared with other physiotherapy interventions.

Overall, treadmill training with or without body weight support produced statistically significant higher walking speed and endurance, $0.06 \mathrm{~m} / \mathrm{s}$ and $14 \mathrm{~m}$ respectively, compared with people not receiving treadmill training. For people who could walk independently at the start of treatment, treadmill training with or without body weight support produced statistically significant higher walking speed and endurance, $0.09 \mathrm{~m} / \mathrm{s}$ and $20 \mathrm{~m}$ respectively, compared with people not receiving treadmill training. These results raise the question: how clinically relevant are these statistically significant effects?

For people after stroke, Flansbjer 2005 described the smallest possible change (the standard error of measurement (SEM) and the smallest real clinical differences (95\% SRD). The SEMs and the 95\% SRDs for walking speed were $0.07 \mathrm{~m} / \mathrm{s}$ and 0.15 to $0.25 \mathrm{~m} / \mathrm{s}$ and the SEMs and the 95\% SRDs for walking endurance were $18.6 \mathrm{~m}$ and 37 to $66 \mathrm{~m}$. Our results might, according to Flansbjer 2005, be interpreted as follows: the overall effects of treadmill training, with or without body weight support, can not be measured in practice and should not be interpreted as a clinically relevant improvement.

We did not find any benefit for people after stroke who could not walk independently at the start of treatment. We did not find enough studies of the effects of treadmill training, with or body weight support, on activities and quality of life to draw any appropriate conclusions, nor did we find enough studies of the effects of body weight support without treadmill training to draw any appropriate conclusions.

Adverse events and dropouts did not occur more frequently in people receiving treadmill training and these were not judged to be clinically serious events.

Our subgroup analysis showed that, for people after stroke who walked independently, treadmill training in the first three months after stroke produced walking speeds that were statistically but not clinically relevant (Flansbjer 2005). For people treated in the chronic phase, the effects on walking speed were lower (and not clinically relevant). However, the subgroup differences did not differ significantly. 
Our subgroup analysis showed that, for people after stroke who walked independently, treadmill training in the first three months after stroke produced a walking endurance that was statistically and clinically relevant (Flansbjer 2005). For people treated in the chronic phase, the effects on walking endurance were lower (not clinically relevant). The subgroup differences did differ significantly, indicating that people treated in the first three months after stroke had higher gains in walking endurance compared with training in the chronic phase after stroke.

Our subgroup analysis showed that, for people after stroke who walked independently, treadmill training with higher intensities (frequency of training: five times versus three to four times versus less than three times per week) may produce greater effects on walking speed and endurance. However, this trend toward subgroup differences was not significant.

Possible conclusions based on our findings are that treadmill training can be used when people after stroke can walk independently and when improvement of walking speed and endurance is the aim of therapy. The greatest effect of treadmill training is to be expected in the first three months after stroke. It was, however, not absolutely clear from this review if therapists should apply particular periods or particular frequencies of treatments, for example, training for five times a week or for four weeks.

\section{Overall completeness and applicability of evidence}

The results of this review seem to be quite generalisable to inpatient settings in industrialised countries. However, there are factors producing uncertainty for generalisations.

- The investigated study population was quite heterogeneous (e.g. age, time post-stroke, severity of stroke and especially walking ability).

- The investigated experimental and control conditions were heterogeneous (e.g. type of training, frequency, and duration of training; some studies had no active control group or were compared with no intervention).

Hence, the results may be of limited applicability for all people after stroke.

\section{Quality of the evidence}

We found heterogeneity regarding trial design (parallel-group or cross-over design, two or more intervention groups), but it is not clear if this could have limited the quality of the evidence. Furthermore, in our sensitivity analysis examining the effects of methodological quality on the effectiveness of the intervention, we found that the benefits (improving walking speed) were relatively robust when we removed trials with an inadequate sequence generation process, inadequate concealed allocation, and no blinded assessors for the primary outcome (Analysis 7.1).

Although the methodological quality of the included trials generally seemed moderate (Figure 2), trials investigating treadmill training with or without body weight support are subject to potential methodological limitations. These limitations included inability to blind the therapist and participants, so-called contamination (provision of the intervention to the control group), and co-intervention (when the same therapist unintentionally provided additional care to either treatment or comparison group). All these potential methodological limitations introduced the possibility of performance bias. However, as discussed previously, this was not supported in our sensitivity analyses by methodological quality.

\section{Potential biases in the review process}

The methodological rigour of Cochrane reviews minimises bias in the process of conducting systematic reviews. We are confident that our detailed search strategy, combined with detailed handsearching efforts, identified all relevant trials. It is possible that we did not identify studies published in the grey literature, but it would be unlikely that this would have a significant impact on our results. Because the grey literature tends to include trials with relatively small numbers of participants and inconclusive results, inclusion of this literature may have actually decreased the size of the effect detected in our review (McAuley 2000).

Another potential source for the introduction of bias could have been that one of the review authors (JM) was involved in conducting and analysing one of the included trials (Pohl 2002). However, the third review author (BE) extracted the outcome data from raw data and described the risk of bias of this trial. Excluding Pohl 2002 from the pooled analyses did not change the results significantly, so we believe that this one trial has not biased our overall evidence.

\section{Agreements and disagreements with other studies or reviews}

There are several recent reviews about treadmill training, with or without body weight support; for example, two reviews were published in 2013 (Charalambous 2013; Polese 2013).

The review of Polese 2013 included nine studies of treadmill training with 977 participants and concluded that treadmill training resulted in faster walking than no intervention or a non-walking intervention immediately after the intervention period (MD $0.14 \mathrm{~m} /$ $\mathrm{s}, 95 \% \mathrm{Cl} 0.09$ to 0.19 ). The review of Charalambous 2013 included 15 studies of treadmill training and concluded that treadmillbased interventions post-stroke may increase and retain walking speed, but a pooled analysis with forest plots was not provided. In comparison, we found more studies (44 studies included in this update) than in the reviews of Charalambous 2013 and Polese 2013 and we found smaller effects on walking speed, MD $0.07 \mathrm{~m} /$ $\mathrm{s}, 95 \% \mathrm{Cl} 0.03$ to 0.11 (based on 35 included studies of treadmill training with 1891 participants). These differences could be due to the comprehensive search in our review update and to our inclusion of studies not published in English. This update is the most comprehensive review about the topic to date.

In this update of the review, we have found significant effects for walking velocity and endurance but not for dependence, and we also found that people who have had a stroke and who can walk independently profit more from treadmill training than those who cannot walk. Initially, this might be difficult to interpret. However, we believe that the overall results of this review were somewhat 'confounded' by the results of people who could not walk. We found evidence that this participant group may not profit from treadmill training. Treadmill training appears, therefore, to be an appropriate adjunct intervention that might improve certain important walking parameters, such as speed and endurance for people who are already able walk alone. This might appear a 
little ironic to researchers because treadmill training with body weight support was designed to get non-ambulatory walkers walking. Another Cochrane review found evidence that the chance of regaining independent walking ability after stroke increases when electromechanical and robotic-assisted gait-training devices are used in combination with physiotherapy (Mehrholz 2017). Interestingly, whereas independent walking improved, neither walking velocity nor walking capacity improved. Perhaps one conclusion could be that different interventions are suitable for different participants. For example, for severely affected people who cannot walk independently, electromechanical and roboticassisted gait-training devices in combination with physiotherapy are recommended (Mehrholz 2017). However, when people who have had a stroke recover and start walking, then treadmill training may improve important walking parameters such as speed and endurance, as our update showed. Therefore, the combination of approaches should be considered.

Finally, it should be mentioned that treadmill training in and of itself is perhaps not the 'main issue'. We believe that treadmill training just offers a very easy approach for high-intensity, repetitive, task-specific walking training, which is recommended for gait rehabilitation (Langhorne 2009).

\section{A U THORS' CONCLUSIONS}

\section{Implications for practice}

The results of this review were conclusive in part. Overall, after stroke, people who receive treadmill training, with or without body weight support, are not more likely to improve their ability to walk independently, but their speed of walking and their walking capacity may improve. More specifically, those who are able to walk independently (but not those who are unable to walk independently) seem to benefit from this type of intervention. This review found that improvements in walking speed and endurance in people who are able to walk independently have no persisting beneficial effects. However, our review suggests that, after stroke, people who are not able to walk independently at the start of treatment may not benefit from treadmill training with or without body weight support.

In practice, therapists should be aware that treadmill training may be used as an option but not as stand-alone treatment to improve the walking speed and endurance of people who are able to walk independently. It appears that people who are able to walk independently, but not those who are unable to walk independently, may profit from treadmill training, with and without body weight support, to improve their walking abilities.

\section{Implications for research}

Further research should specifically investigate the effects of different frequencies, durations, or intensities (in terms of speed increments and inclination) of treadmill training, as well as the use of handrails. To answer these research questions, future trials should include people who are already ambulatory and exclude those who are non-ambulatory.

\section{ACKNOWLEDGEMENTS}

We thank Odie Geiger for consumer peer reviewing the final version of this review and the valuable comments. We thank the Cochrane Stroke Group and the original review author team of the 2005 published Cochrane review. We acknowledge the former review team for all requested data and their support for the present update. We therefore especially thank Anne Moseley, Angela Stark, Ian Cameron, and Alex Pollock. We thank Joshua Cheyne and Brenda Thomas for help with developing the search strategy, Hazel Fraser for providing us with relevant information about trials and systematic reviews from the Cochrane Stroke Group Trials Register, and Gabi Voigt for conducting searches and for providing us with many helpful studies. We thank Louise Ada, Inacio da Cunha Filho, Catherine Dean, Stefan Hesse, David Jaffe, Marc Kosak, Yocheved Laufer, Richard Macko, Jane Mickelborough, Lena Nilsson, Klaus Scheidmann, Martha Visintin, and Cordula Werner for providing additional or unpublished data from their trials; Jutta Jablonski, Pauline van Es, and Rob de Bie for screening, quality rating and data extraction of German language trials; Yoetsu Ogata for screening the Japanese language trials; Ellen Wang and Chris Lin for screening the Chinese language trials; Dr Bing Gu for helping us translate Chinese trials; David McKenzie and Jarmila McKenzie for screening a Slovak language trial; Aurelien Descatoire for screening a French language trial; Stephanie Nelson for assisting with handsearching the conference proceedings and screening a French language trial; Paul Hansen for sharing his bibliography of treadmill training publications; and Michelle Starkey (Executive Officer, Stroke Recovery Association) for reviewing the plain language summary. 


\section{REFERE N CES}

\section{References to studies included in this review}

Ada 2003 \{published and unpublished data\}

Ada L, Dean C, Crompton S, Hall J, Bampton J. The efficacy of treadmill training in improving walking in individuals after stroke in the community: a placebo-controlled, randomised trial. VIIth International Physiotherapy Congress. Sydney: Australian Physiotherapy Association, 2002:61.

Ada L, Dean C, Hall J, Bampton J, Crompton S. A treadmill and overground walking program improves walking in individuals residing in the community after stroke: a placebo-controlled, randomised trial. 14th International Congress of The World Confederation for Physical Therapy. Spain, Barcelona. 2003:RRPL-1170.

Ada L, Dean CM, Hall JM, Bampton J, Crompton S. A treadmill and overground walking program improves walking in individuals residing in the community after stroke: a placebocontrolled randomised trial. Internal Medicine Journal 2004;34(1-2):A7.

* Ada L, Dean CM, Hall JM, Bampton J, Crompton S. A treadmill and overground walking program improves walking in persons residing in the community after stroke: a placebocontrolled, randomized trial. Archives of Physical Medicine and Rehabilitation 2003; Vol. 84, issue 10:1486-91.

NCT00167531. The efficacy of treadmill training in establishing walking after stroke. clinicaltrials.gov (first received 12 September 2005).

\section{Ada 2010 \{published data only\}}

Ada L, Dean C, Morris M. Establishing walking using treadmill training in non-ambulatory patients during inpatient stroke rehabilitation: the MOBILISE trial. Australian Journal of Physiotherapy 2009;4 Suppl:2.

Ada L, Dean C, Morris M, Simpson J, Katrak P. Establishing walking using treadmill walking with body weight support in subacute non-ambulatory stroke: the MOBILISE Trial I. International Journal of Stroke 2010;5:24-5.

Ada L, Dean CM, Morris ME. Supported treadmill training to establish walking in non-ambulatory patients early after stroke. BMC Neurology 2007;7:29.

* Ada L, Dean CM, Morris ME, Simpson JM, Katrak P. Randomized trial of treadmill walking with body weight support to establish walking in subacute stroke: the MOBILISE trial. Stroke 2010;41(6):1237-42.

Dean C, Ada L, Bampton J, Morris M, Katrak P, Potts S. Improving walking speed and capacity using treadmill walking with body weight support in subacute non-ambulatory stroke: the Mobilise trial II. International Journal of Stroke 2010;5:12-3.

Dean C, Ada L, Morris M. Improving walking using treadmill training in non-ambulatory patients during inpatient stroke rehabilitation: the MOBILISE trial. Australian Journal of Physiotherapy 2009;4 Suppl:8.
Dean CM, Ada L, Bampton J, Morris ME, Katrak PH, Potts S. Treadmill walking with body weight support in subacute non-ambulatory stroke improves walking capacity more than overground walking: a randomised trial. Journal of Physiotherapy 2010;56(2):97-103.

\section{Ada 2013 \{published data only\}}

ACTRN12607000227493. AMBULATE: 2 months versus 4 months of walking training to improve community ambulation after stroke. www.anzctr.org.au (first received 24 April 2007).

* Ada L, Dean C, Lindley R. Randomized trial of treadmill training to improve walking in community-dwelling people after stroke: the AMBULATE trial. International Journal of Stroke 2013;8(6):436-44

Ada L, Dean CM, Lindley R, Lloyd G. Improving community ambulation after stroke: the AMBULATE trial. BMC Neurology 2009;9:8.

Ada L, Dean CM, Lindley R, Vargas J. Improving walking after stroke: the Ambulate trial. Neurorehabilitation and Neural Repair 2012;26(6):674-5.

Lindley RI, Dean C, Ada L. Can treadmill training improve walking in the chronic phase of stroke? The AMBULATE randomised controlled trial. Cerebrovascular Diseases 2012; Vol. 33, issue Suppl 2:61.

\section{Bonnyaud 2013 \{published data only\}}

Bonnyaud C, Pradon D, Zory R, Bensmail D, Vuillerme N, Roche N. Does a single gait training session performed either overground or on a treadmill induce specific short-term effects on gait parameters in patients with hemiparesis? A randomized controlled study. Topics in Stroke Rehabilitation 2013;20:509-18.

\section{Bonnyaud 2013a \{published data only\}}

* Bonnyaud C, Pradon D, Zory R, Bussel B, Bensmail D, Vuillerme $\mathrm{N}$, et al. Effects of a gait training session combined with a mass on the non-paretic lower limb on locomotion of hemiparetic patients: a randomized controlled clinical trial. Gait \& Posture 2013;37:627-30

Bonnyaud C, Zory R, Robertson J, Bensmail D, Vuillerme N, Roche N. Effect of an overground training session versus a treadmill training session on timed up and go in hemiparetic patients. Topics in Stroke Rehabilitation 2014;21:477-83.

\section{Combs-Miller 2014 \{published data only\}}

Combs SA, Tucker L, Harmeyer A, Ertel T, Colburn D, Parameswaran AK. Body weight-supported treadmill training vs. over-ground walking training for persons with chronic stroke: a randomized controlled trial. Archives of Physical Medicine \& Rehabilitation 2012;93(10):e36.

* Combs-Miller SA, Kalpathi PA, Colburn D, Ertel T, Harmeyer A, Tucker L, et al. Body weight-supported treadmill training vs. overground walking training for persons with chronic stroke: a pilot randomized controlled trial. Clinical Rehabilitation 2014;28:873-84. 
NCT01180738. Body weight supported treadmill training vs. overground walking training in persons with chronic stroke. clinicaltrials.gov/show/NCT01180738 (first received 9 August 2010).

\section{Da Cunha Filho 2002 \{published and unpublished data\}}

Da Cunha Filho IT. Acute Stroke Rehabilitation Outcomes with Supported Treadmill Ambulation Training [PhD thesis]. Texas Woman's University, 2001.

* Da Cunha Filho IT, Lim PA, Qureshy H, Henson H, Monga T, Protas EJ. Gait outcomes after acute stroke rehabilitation with supported treadmill ambulation training: a randomized controlled pilot study. Archives of Physical Medicine and Rehabilitation 2002;83(9):1258-65.

Da Cunha Filho IT, Lim PAC, Qureshy H, Henson H, Monga T, Protas EJ. A comparison of regular rehabilitation and regular rehabilitation with supported treadmill ambulation training for acute stroke patients. Journal of Rehabilitation Research and Development 2001;38(2):245-55.

Lim PAC, Henson H, Cunha I, Qureshy H, Monga TN, Protas EJ. Body weight-supported gait training in stroke patients. American Journal of Physical Medicine 2000;79(2):203.

NCT00037895. Stroke rehabilitation outcomes with supported treadmill ambulation training. clinicaltrials.gov (first received 24 May 2002).

\section{Deniz 2011 \{published data only\}}

Deniz L, Armagan O, Ozgen M, Oner S. Effectiveness of gait training with partial body-weight support in subacute stroke patients. Turk Serebrovaskuler Hastaliklar Dergisi 2011;17(1):13-9.

\section{DePaul 2015 \{published data only\}}

DePaul VG, Wishart LR, Richardson J, Thabane L, Ma J, Lee TD. Varied overground walking training versus body-weightsupported treadmill training in adults within 1 year of stroke: a randomized controlled trial. Neurorehabilitation and Neural Repair 2015;29:329-40.

\section{Du 2006 \{published data only\}}

Du JB, Song WQ, Wang MB. The application of partial body weight support treadmill training in hemiplegia rehabilitation after stroke. Chinese Journal of Cerebrovascular Diseases 2006;3(8):361-4.

\section{Duncan 2011 \{published data only\}}

Duncan P, Sullivan K, Behrman A, Azen S, Wu S, Dobkin B, et al. Locomotor Experience Applied Post-Stroke (LEAPS): a randomized controlled trial. International Journal of Stroke 2008;3(Suppl 1):132.

Duncan PW. Locomotor Experience Applied Post-Stroke (LEAPS). Stroke 2007;38(10):e120.

* Duncan PW, Sullivan KJ, Behrman AL, Azen SP, Wu SS, Nadeau SE, et al. Body-weight-supported treadmill rehabilitation after stroke. New England Journal of Medicine 2011;364(21):2026-36.
Duncan PW, Sullivan KJ, Behrman AL, Azen SP, Wu SS, Nadeau SE, et al. Locomotor Experience Applied Post-Stroke (LEAPS): a randomized controlled trial (abstract - CT P20). International Stroke Conference; 2008 February 20-22. New Orleans (USA): American Stroke Association, 2008.

Duncan PW, Sullivan KJ, Behrman AL, Azen SP, Wu SS, Nadeau SE, et al. Protocol for the Locomotor Experience Applied Post-stroke (LEAPS) trial: a randomized controlled trial. BMC Neurology 2007;7:39.

NCT00243919. Locomotor Experience Applied Post Stroke trial (LEAPS). clinicaltrials.gov (first received 24 October 2005).

Nadeau SE, Wu SS, Dobkin BH, Azen SP, Rose DK, Tilson JK, et al. Effects of task-specific and impairment-based training compared with usual care on functional walking ability after inpatient stroke rehabilitation: Leaps trial. Neurorehabilitation and Neural Repair 2013;27(4):370-80.

Rose DK, Behrman AL, Cen Y, Sullivan KJ, Martin D, Schofield RS, et al. Response to exercise tolerance testing in subacute stroke across severity levels. Stroke 2008;39(2):618-9.

Tilson JK, Sullivan KJ, Cen SY, Rose DK, Koradia CH, Azen SP, et al. Meaningful gait speed improvement during the first 60 days poststroke: minimal clinically important difference. Physical Therapy 2010;90(2):196-208.

\section{Eich 2004 \{published data only\}}

Eich HJ, Hesse S, Mach H. Aerobic endurance training of hemiparetic patients who are able to walk, results of a prospective randomised study [Aerobes ausdauertraining gehfähiger hemiparetischer patienten, ergebnisse einer prospektiven randomisierten studie]. Deutsche Zeitschrift fur Sportmedizin 2003;54(7-8):S98.

${ }^{*}$ Eich HJ, Mach H, Werner C, Hesse S. Aerobic treadmill plus Bobath walking training improves walking in subacute stroke: a randomised controlled trial. Clinical Rehabilitation 2004;18:640-51.

Eich HJ, Parchmann H, Hesse S, Mach H, Werner C. Aerobic treadmill training plus physiotherapy improves walking ability in subacute stroke patients. A randomized controlled study. Neurologie und Rehabilitation 2004;10(4):187-216.

Hesse S, Eich HJ, Mach H, Parchmann H, Werner C. Aerobic treadmill training plus physiotherapy improves walking speed and capacity in subacute, moderately affected patients after stroke [Aerobes laufbandtraining plus physiotherapie verbessert das gehen von mäßig schwer betroffenen patienten nach schlaganfall]. Neurologie und Rehabilitation 2005;11(1):7-12.

Hesse S, Eich HJ, Mach H, Werner C. Aerobic treadmill training of ambulatory hemiparetic patients: a randomised study. 3 rd World Congress in Neurological Rehabilitation; 2002; Venice (Italy). World Federation for NeuroRehabilitation, 2002.

Hesse S, Eich HJ, Mach H, Werner C. Aerobic treadmill training of ambulatory hemiparetic patients: a randomized study. Neurorehabilitation \& Neural Repair 2001;15(4):311. 
Mach $\mathrm{H}$, Werner C, Eich HJ, Hesse S. Aerobic treadmill training in hemiparetic patients: a randomized study. Neurologie und Rehabilitation 2003;9(6):S6.

\section{Franceschini 2009 \{published data only\}}

* Franceschini M, Carda S, Agosti M, Antenucci R, Malgrati D, Cisari C. Walking after stroke: what does treadmill training with body weight support add to overground gait training in patients early after stroke? A single-blind, randomized, controlled trial. Stroke 2009;40(9):3079-85.

Saccavini M, Zaccaria B, Franceschini M, Maestrini E, Agosti M, Mammi P, et al. Treadmill walking with bodyweight support in stroke patients during acute phase: a randomized controlled trial. Cerebrovascular Diseases 2009;27(Suppl 6):216-7.

\section{Gama 2017 \{published data only\}}

Gama GL, Celestino ML, Barela JA, Forrester L, Whittal J, Barela AM. Effects of gait training with body weight support on a treadmill versus overground in individuals with stroke. Archives of Physical Medicine and Rehabilitation 2017;98(4):738-45.

\section{Gan 2012 \{published data only\}}

Gan SW, Azarcon AC, Cadiao JJ, Gabua AM, Javier RS, Orayle EM, et al. A randomized controlled trial on the efficacy of body weight support overground ambulation versus body weight support treadmill training among post-stroke patients of a tertiary hospital. Physical Medicine and Rehabilitation 2012;1:S182.

\section{Globas 2011 \{published data only\}}

* Globas C, Becker C, Cerny J, Lam JM, Lindemann U, Forrester LW, et al. Chronic stroke survivors benefit from highintensity aerobic treadmill exercise: a randomized controlled trial. Neurorehabilitation and Neural Repair 2011;26(1):85-95.

Globas C, Becker C, Cerny J, Lam JM, Lindemann U, Forrester LW, et al. Elderly chronic stroke survivors benefit from aerobic treadmill exercise: a randomized, controlled trial. Stroke 2011;42(3):e323.

Lam JM, Globas C, Cerny J, Hertler B, Uludag K, Forrester LW, et al. Predictors of response to treadmill exercise in stroke survivors. Neurorehabilitation and Neural Repair 2010;24(6):567-74.

NCT00614224. Structural neuroplasticity associated with aerobic treadmill training in geriatric chronic stroke survivors. clinicaltrials.gov. (first received 31 January 2008).

\section{Hoyer 2012 \{published data only\}}

Hoyer E, Jahnsen R, Stanghelle JK, Strand LI. Body weight supported treadmill training versus traditional training in patients dependent on walking assistance after stroke: a randomized controlled trial. Disability Rehabilitation 2012;34(3):210-9.

\section{Jaffe 2004 \{published and unpublished data\}}

Brown DA, Jaffe DL, Buckley EL. Use of virtual objects to improve gait velocity in individuals with post-stroke hemiplegia. Neurology Report 2002;26:105.
Jaffe DL. Results using stepping-over response training to improve walking in individuals with poststroke hemiplegia. 3rd National Rehabilitation Research and Development Conference. Arlington (USA), 2002.

Jaffe DL. Using virtual reality to improve walking following stroke. Center on Disabilities Technology and Persons with Disabilities Conference. Northridge, California (USA), 2002.

Jaffe DL, Brown DA. Improving stepping-over responses in the elderly using simulated obstacles. www.stanford.edu/ dljaffe/ SOR/jaffe.pdf (accessed prior to 14 July 2017).

* Jaffe DL, Brown DA, Pierson-Carey CD, Buckley EL, Lew HL. Stepping over obstacles to improve walking in individuals with poststroke hemiplegia. Journal of Rehabilitation Research and Development 2004;41(3A):283-92.

Kang 2012 \{published data only\}

Kang H-K, Kim Y, Chung Y, Hwang S. Effects of treadmill training with optic flow on balance and gait in individuals following stroke: randomized controlled trials. Clinical Rehabilitation 2012;26(3):246-55

Kim 2011 \{published data only\}

Kim C, Gong W, Kim S. The effects of lower extremity muscle strengthening exercise and treadmill walking exercise on the gait and balance of stroke patients. Journal of Physical Therapy Science 2011;23(3):405-8.

\section{Kim 2016 \{published data only\}}

Kim N, Lee BH, Kim Y, Min W. Effects of virtual reality treadmill training on community balance confidence and gait in people post-stroke: a randomized controlled trial. Journal of Experimental Stroke and Translational Medicine 2016;9:1-7.

\section{Kosak 2000 \{published and unpublished data\}}

Kosak M, Reding M. Early aggressive mobilization is as effective as treadmill training for ambulation recovery in patients with stroke. Journal of Stroke and Cerebrovascular Diseases 1998;7(5):372.

Kosak MC, Brennan JA, Slomovicz LG, Tachkov A, Reding MJ. Body weight supported treadmill training versus traditional physical therapy. Stroke 1997;28(1):268

* Kosak MC, Reding MJ. Comparison of partial body weightsupported treadmill gait training versus aggressive bracing assisted walking post stroke. Neurorehabilitation and Neural Repair 2000;14(1):13-9.

\section{Kuys 2011 \{published data only\}}

ACTRN12607000412437. Treadmill walking to improve walking and fitness following stroke: a single blinded pilot randomised controlled trial. www.anzctr.org.au (first received 16 May 2007)

Kuys S, Brauer S, Ada L. Treadmill training to improve walking following stroke: a randomised controlled trial. International Journal of Stroke 2008;3(Suppl):347.

Kuys SS, Brauer SG, Ada L. High-intensity treadmill walking during inpatient rehabilitation: feasibility of a randomised trial. Australian Journal of Physiotherapy 2009, issue 4 Suppl:12-3. 
* Kuys SS, Brauer SG, Ada L. Higher-intensity treadmill walking during rehabilitation after stroke in feasible and not detrimental to walking pattern or quality: a pilot randomized trial. Clinical Rehabilitation 2011;25(4):316-26.

\section{Langhammer 2010 \{published data only\}}

Langhammer B, Johan, Stanghelle K. Outdoors or indoors walking, what is more beneficial? A comparison of exercise methods in a randomized trial. Brain Injury 2010;24(3):172.

Langhammer B, Stanghelle JK. Exercise on a treadmill or walking outdoors? A randomized controlled trial comparing effectiveness of two walking exercise programmes late after stroke. Clinical Rehabilitation 2010;24(1):46-54.

Langhammer B, Stanghelle JK. Improving gait after stroketreadmill or walking; quantity or quality. Journal of Cyber Therapy and Rehabilitation 2009;2(3):191-8.

\section{Laufer 2001 \{published data only\}}

Laufer Y, Dickstein R, Chefez Y, Marcovitz E. The effect of treadmill training on the ambulation of stroke survivors in the early stages of rehabilitation: a randomized study. Journal of Rehabilitation Research and Development 2001;38(1):69-78.

\section{Liston 2000 \{published and unpublished data\}}

* Liston R, Mickelborough J, Harris B, Hann AW, Tallis RC. Conventional physiotherapy and treadmill re-training for higher-level gait disorders in cerebrovascular disease. Age \& Ageing 2000;29(4):311-8.

Mickelborough J, Liston R, Harris B, Wynn Hann A, Tallis RC. An evaluation of conventional physiotherapy and treadmill retraining of higher-level gait disorders in patients with cerebral multi-infarct states. Age \& Ageing 1999;28 Suppl 2:54.

\section{Luft 2008 \{published data only\}}

Lam JM, Globas C, Cerny J, Hertler B, Uludag K, Forrester LW, et al. Predictors of response to treadmill exercise in stroke survivors. Neurorehabilitation and Neural Repair 2010;24(6):567-74.

* Luft AR, Macko RF, Forrester LW, Villagra F, Ivey F, Sorkin JD, et al. Treadmill exercise activates subcortical neural networks and improves walking after stroke: a randomized controlled trial. Stroke 2008;39(12):3341-50.

\section{MacKay-Lyons 2013 \{published data only\}}

MacKay-Lyons M, McDonald A, Matheson J, Howlett J. Physiological changes following a 12-week program of bodyweight supported treadmill training early post-stroke: a randomized clinical trial. International Journal of Stroke 2008;3(Suppl):348.

* Mackay-Lyons M, McDonald A, Matheson J, Eskes G, Klus MA. Dual effects of body-weight supported treadmill training on cardiovascular fitness and walking ability early after stroke: a randomized controlled trial. Neurorehabilitation and Neural Repair 2013;27(7):644-53.

\section{Macko 2005 \{published and unpublished data\}}

Clark B, Harris-Love M, Forrester L, Macko R, Smith GV. Effects of treadmill training on dynamic balance measures in chronic hemiparesis. 3rd World Congress in Neurological Rehabilitation; Venice (Italy). World Federation for NeuroRehabilitation, 2002.

Clark B, Harris-Love M, Forrester L, Macko R, Smith GW. Effects of treadmill training on dynamic balance measures in chronic hemiparesis. Neurorehabilitation and Neural Repair 2001;15(4):315.

Ivey FM, Ryan AS, Hafer-Macko CE, Goldberg AP, Macko RF. Treadmill aerobic training improves glucose tolerance and indices of insulin sensitivity in disabled stroke survivors: a preliminary report. Stroke 2007;38(10):2752-8.

Limpar P, Macko RF, Sorkin JD, Katzel LI, Hanley DF. Safety of treadmill aerobic exercise in chronic hemiparetic stroke patients. Stroke 2004;35(1):286.

* Macko RF, Ivey FM, Forrester LW, Hanley D, Sorkin JD, Katzel LI, et al. Treadmill exercise rehabilitation improves ambulatory function and cardiovascular fitness in patients with chronic stroke: a randomized, controlled trial. Stroke 2005;36(10):2206-11.

NCT00018421. Effects of exercise on patients with hemiparetic stroke. clinicaltrials.gov/show/NCT00018421 (first received 3 July 2001).

\section{Mao 2015 \{published data only\}}

Mao YR, Lo WL, Lin Q, Li L, Xiao X, Raghavan P, et al. The effect of body weight support treadmill training on gait recovery, proximal lower limb motor pattern, and balance in patients with subacute stroke. BioMed Research International 2015;2015:175719.

\section{Mehrberg 2001 \{published data only\}}

Mehrberg RD, Flick C, Dervay J, Carmody J, Carrington C, Jermer M. Clinical evaluation of a new over ground partial body weight support assistive device in hemiparetic stroke patients. Archives of Physical Medicine \& Rehabilitation 2001;82:1293.

\section{Middleton 2014 \{published data only\}}

Middleton A, Merlo-Rains A, Peters DM, Greene JV, Blanck EL, Moran R, et al. Body weight-supported treadmill training is no better than overground training for individuals with chronic stroke: a randomized controlled trial. Topics in Stroke Rehabilitation 2014;21:462-76.

\section{Moore 2010 \{published data only\}}

* Moore JL, Roth EJ, Killian C, Hornby TG. Locomotor training improves daily stepping activity and gait efficiency in individuals poststroke who have reached a "plateau" in recovery. Stroke 2010;41(1):129-35.

\section{Nilsson 2001 \{published and unpublished data\}}

Hansen PD, Grimby G, Carlsson J, Nilsson L. Body-weightsupport gait training. Clinical Rehabilitation 2002;16(3):343-5.

Nilsson L, Carlsson J, Danielsson A, Fugl-Meyer A, Hellstrom K, Kristensen $L$, et al. Walking training of patients with hemiparesis 
at an early stage after stroke. 14th International Congress of The World Confederation for Physical Therapy; Barcelona (Spain). 2003:RR-PL-1729.

* Nilsson L, Carlsson J, Danielsson A, Fugl-Myer A, Hellstrom K, Kristensen $L$, et al. Walking training of patients with hemiparesis at an early stage after stroke: a comparison of walking training on a treadmill with body weight support and walking training on the ground. Clinical Rehabilitation 2001;15(5):515-27.

\section{Nilsson 2001a $\{$ published and unpublished data\}}

Nilsson L, Carlsson J, Danielsson A, Fugl-Myer A, Hellstrom K, Kristensen $L$, et al. Walking training of patients with hemiparesis at an early stage after stroke: a comparison of walking training on a treadmill with body weight support and walking training on the ground. Clinical Rehabilitation 2001;15(5):515-27.

\section{Nilsson 2001b \{published and unpublished data\}}

Nilsson L, Carlsson J, Danielsson A, Fugl-Myer A, Hellstrom K, Kristensen $L$, et al. Walking training of patients with hemiparesis at an early stage after stroke: a comparison of walking training on a treadmill with body weight support and walking training on the ground. Clinical Rehabilitation 2001;15(5):515-27.

\section{Olawale 2009 \{published data only\}}

Olawale O, Appiah-Kubi K, Jones-Okai D. Exercise training improves walking function in an African group of stroke survivors: a randomized controlled trial. Physiotherapy 2007;93(Suppl 1):s562-3.

* Olawale OA, Jaja SI, Anigbogu CN, Appiah-Kubi KO, JonesOkai D. Effects of two exercise training techniques on walking function in adult patients with stroke. Nigerian Quarterly Journal of Hospital Medicine 2009;19(2):88-94.

Olawale OA, Jaja SI, Anigbogu CN, Appiah-Kubi KO, JonesOkai D. Exercise training improves walking function in an African group of stroke survivors: a randomized controlled trial. Clinical Rehabilitation 2011;5:442-50.

\section{Park 2013 \{published data only\}}

Park IM, Lee YS, Moon BM, Sim SM. A comparison of the effects of overground gait training and treadmill gait training according to stroke patients' gait velocity. Journal of Physical Therapy Science 2013;25:379-82.

\section{Park 2015 \{published data only\}}

Park J, Park S-Y, Kim Y-W, Woo Y. Comparison between treadmill training with rhythmic auditory stimulation and ground walking with rhythmic auditory stimulation on gait ability in chronic stroke patients: a pilot study. NeuroRehabilitation 2015;37:193-202.

\section{Pohl 2002 \{published data only\}}

Mehrholz J, Ritschel C, Ruckriem S, Pohl M. Speed-dependent treadmill training in hemiparetic stroke patients. A randomized controlled trial. 14th International Congress of The World Confederation for Physical Therapy; Barcelona (Spain). 2003:RRPL-0168. a randomized controlled trial. Neurorehabilitation and Neural Repair 2001;15:311.

* Pohl M, Mehrholz J, Ritschel C, Ruckriem S. Speed-dependent treadmill training in ambulatory hemiparetic stroke patients: a randomized controlled trial. Stroke 2002;33:553-8.

Pohl M, Mehrholz J, Ritschel C, Ruckriem S. Speed-dependent treadmill training in ambulatory stroke patients: a randomized controlled trial. 3rd World Congress in Neurological Rehabilitation. Venice, Italy, 2002:T3.

Ribeiro 2013 \{published data only\}

Ribeiro T, Britto H, Oliveira D, Silva E, Galvao E, Lindquist A. Effects of treadmill training with partial body weight support and the proprioceptive neuromuscular facilitation method on hemiparetic gait: a randomized controlled study. European Journal of Physical and Rehabilitation Medicine 2013;49:451-61.

\section{Richards 1993 \{published data only\}}

Malouin F, Richards CL, Wood-Dauphinee S, Williams JI. Effects of an intense task-oriented gait-training program in acute stroke patients: a pilot study. In: Woollacott M, Horak F editor(s). Posture and Gait: Control Mechanisms. Portland (ORE): University of Oregon Books, 1992:407-10.

Malouin F, Richards CL, Wood-Dauphinee S, Williams JY. Effects of early and intensive gait training in stroke patients: a pilot study. Physical Therapy 1991;71(6):S58.

Malouin F, Richards Cl, Wood-Dauphinee S, Williams JI. A randomized controlled trial comparing early and intensive task-specific therapy to conventional therapy in acute-stroke patients. Canadian Journal of Rehabilitation 1993;7(1):27-8.

Malouin F, Richards Cl, Wood-Dauphinee S, Williams Jl. Early standing and intensive locomotor training after stroke. International Congress on Stroke Rehabilitation. Berlin: German Society for Neurological Rehabilitation, 1993:41.

Richards CL, Malouin F. Evaluation and therapy of disturbed motor control in spastic paresis: therapeutic considerations for locomotor disorders. Neurology Report 1997;21:85-90.

* Richards CL, Malouin F, Wood-Dauphinee S, Williams JI, Bouchard JP, Brunet D. Task-specific physical therapy for optimization of gait recovery in acute stroke patients. Archives of Physical Medicine \& Rehabilitation 1993;74(6):612-20.

\section{Richards 2004 \{published data only\}}

Richards CL, Malouin F, Bravo G, Dumas F, Wood-Dauphinee S. The role of technology in task-oriented locomotor training in acute stroke: a randomized controlled trial. 14th International Congress of The World Confederation for Physical Therapy; Barcelona (Spain). 2003:RR-PL-1592.

* Richards CL, Malouin F, Bravo G, Dumas F, Wood-Dauphinee S. The role of technology in task-oriented training in persons with subacute stroke: a randomized controlled trial. Neurorehabilitation \& Neural Repair 2004;18(4):199-211.

Pohl M, Mehrholz J, Ritschel C, Ruckriem S. Speed-dependent treadmill training in ambulatory hemiparetic stroke patients: 
Scheidtmann 1999 \{published and unpublished data\}

Scheidtmann K, Brunner H, Muller F, Weinandy-Trapp M, Wulf D, Koenig E. Treadmill training in early poststroke patients - do timing and walking ability matter? [Sequenzeffekte in der laufbandtherapie]. Neurological Rehabilitation 1999;5(4):198-202.

\section{Smith 2008 \{published data only\}}

Smith PS. The Effect of Treadmill Training on Functional Limitation and Disability Measures in Persons in the Chronic Stage of Recovery from Stroke [PhD Thesis]. Texas Woman's University, 2006.

* Smith PS, Thompson M. Treadmill training post stroke: are there any secondary benefits? A pilot study. Clinical Rehabilitation 2008;22(10-11):997-1002.

\section{Srivastava 2016 \{published data only\}}

Srivastava A, Taly AB, Gupta A, Kumar S, Murali T. Bodyweightsupported treadmill training for retraining gait among chronic stroke survivors: a randomized controlled study. Annals of Physical and Rehabilitation Medicine 2016;59:235-41.

\section{Sullivan 2007 \{published data only\}}

Carey JR. Locomotor and strength training in adults who were ambulatory after stroke: invited commentary. Physical Therapy 2007;87(12):1603-5.

Klassen T, Mulroy SJ, Sullivan KJ. Gait parameters associated with responsiveness to a task-specific and/or strength training program post-stroke. Journal of Neurologic Physical Therapy 2005;29(4):198.

Mulroy SJ, Klassen T, Gronley JK, Eberly VJ, Brown DA, Sullivan KJ. Gait parameters associated with responsiveness to treadmill training with body-weight support after stroke: an exploratory study. Physical Therapy 2010;90(2):209-23.

* Sullivan KJ, Brown DA, Klassen T, Mulroy S, Ge T, Azen SP, et al. Effects of task-specific locomotor and strength training in adults who were ambulatory after stroke: results of the STEPS randomized clinical trial. Physical Therapy 2007;87(12):1580-602

Sullivan KJ, Brown DA, Mulroy S, Winstein CJ. Author response: Locomotor and strength training in adults who were ambulatory after stroke. Physical Therapy 2007;87(12):1605-7.

\section{Suputtitada 2004 \{published data only\}}

Suputtitada A, Yooktanan P, Rarerng-Ying T. Effect of partial body weight support treadmill training in chronic stroke patients. Chotmaihet Thangphaet 2004;87 Suppl 2:S107-11.

\section{Takami 2010 \{published data only\}}

Takami A, Wakayama S. Effects of partial body weight support while training acute stroke patients to walk backwards on a treadmill - a controlled clinical trial using randomized allocation. Journal of Physical Therapy Science 2010;22(2):177-87.

\section{Toledano-Zarhi 2011 \{published data only\}}

Toledano A, Katz-Leurer M, Carmeli E, Kamerman T, Merzeliak O, Adler $\mathrm{Y}$, et al. A pilot randomized clinical trial of an early supervised aerobic exercise training program after minor ischemic strokes. Stroke 2009;40(4):e252.

* Toledano-Zarhi A, Tanne D, Carmeli E, Katz-Leurer M. Feasibility, safety and efficacy of an early aerobic rehabilitation program for patients after minor ischemic stroke: a pilot randomized controlled trial. NeuroRehabilitation 2011;28(2):85-90.

Visintin 1998 \{published and unpublished data\}

Barbeau H, Visintin M. Optimal outcomes obtained with body-weight support combined with treadmill training in stroke subjects. Archives of Physical Medicine \& Rehabilitation 2003;84(10):1458-65.

Selzer ME, Zorowitz RD. Frontiers in neurorehabilitation: translating basic research into clinical advances. Journal of Neurologic Rehabilitation 1998;12:149-51.

* Visintin M, Barbeau H, Korner-Bitensky N, Mayo NE. A new approach to retrain gait in stroke patients through body weight support and treadmill stimulation. Stroke 1998;29(6):1122-8.

Visintin M, Korner-Bitensky N, Barbeau H, Mayo N. A new approach to retraining gait following stroke through body weight support and treadmill simulation. 12th International Congress of the World Confederation of Physical Therapy. Washington DC: American Physical Therapy Association, 1995:812.

\section{Visintin 1998a \{published and unpublished data\}}

Visintin M, Barbeau H, Korner-Bitensky N, Mayo NE. A new approach to retrain gait in stroke patients through body weight support and treadmill stimulation. Stroke 1998;29(6):1122-8.

\section{Visintin 1998b \{published and unpublished data\}}

Visintin M, Barbeau H, Korner-Bitensky N, Mayo NE. A new approach to retrain gait in stroke patients through body weight support and treadmill stimulation. Stroke 1998;29(6):1122-8.

\section{Weng 2004 \{published data only\}}

Weng CS, Bi S, Tian Z, Yu ZZ, Xu J, Bi SQ, et al. Application of structured speed-dependent treadmill training in hemiplegic patients after stroke. Zhongguo Linchuang Kangfu 2004;8(34):7617-9.

\section{Weng 2006 \{published data only\}}

Weng CS, Wang J, Pan XY, Yu ZZ, Wang G, Gao LP, et al. Effectiveness of backward walking treadmill training in lower extremity function after stroke. Zhonghua Yi Xue Za Zhi 2006;86(37):2635-8.

\section{Werner 2002a \{published and unpublished data\}}

Hesse S, Werner C, Bardeleben A, Von Frankenberg S. Treadmill therapy with partial body weight support and an automated gait trainer for restoration of gait after stroke: a randomized study. 3rd World Congress in Neurological Rehabilitation. Venice (Italy), 2002:T1. 
Hesse S, Werner C, Bardeleben A, Von Frankenberg S. Treadmill therapy with partial body weight support and an automated gait trainer for restoration of gait after stroke: a randomized study. Neurorehabilitation \& Neural Repair 2001;15:310-1.

Hesse S, Werner C, Von Frankenberg S, Bardeleben A. Electromechanical gait trainer for restoration of gait after stroke. 1st World Congress of the International Society of Physical Rehabilitation Medicine (ISPRM); 2001 July 7-13. 2001:489-94.

* Werner C, Von Frankenberg S, Treig T, Konrad M, Hesse S. Treadmill training with partial body weight support and an electromechanical gait trainer for restoration of gait in subacute stroke patients: a randomized crossover study. Stroke 2002;33:2895-901.

Yang 2010 \{published data only\}

Yang YR, Chen IH, Liao KK, Huang CC, Wang RY. Cortical reorganization induced by body weight-supported treadmill training in patients with hemiparesis of different stroke durations. Archives of Physical Medicine and Rehabilitation 2010;91(4):513-8.

\section{Yen 2008 \{published data only\}}

Yen CL, Wang RY, Liao KK, Huang CC, Yang YR. Gait training induced change in corticomotor excitability in patients with chronic stroke. Neurorehabilitation \& Neural Repair 2008;22(1):22-30.

\section{Zhang 2008 \{published data only\}}

* Zhang J-P, Wang J-H, Cao P-W, Chen M. The effect of body weight supported treadmill training on drop foot of hemiplegia. Sichuan Medical Journal 2008;10:1331-4.

Zhang J-P, Wang J-H, Chen W, Liu D-Y. The effect of bodyweight supported treadmill training on drop foot of hemiplegia. Journal of Rehabilitation Medicine 2008;46(Suppl):104.

\section{Zhu 2004 \{published data only\}}

Zhu HX, Dou ZL, Li K, Lan Y, Hu XQ. A preliminary investigation on the correlation of partial body weight support training with hemiplegic gait and ambulation function after brain injury. Zhongguo Linchuang Kangfu 2004;8(25):5205-7.

\section{References to studies excluded from this review}

Aschbacher 2006 \{published data only\}

Aschbacher B. Comparing gait training in patients after stroke with task oriented physiotherapy or robot-assisted treadmill training, a feasibility study (as supplied prior to 14 July 2017). Data on file 2006.

\section{Bayat 2005 \{published data only\}}

Bayat R, Barbeau H, Lamontagne A. Speed and temporaldistance adaptations during treadmill and overground walking following stroke. Neurorehabilitation \& Neural Repair 2005;2:115-24.

\section{Bleckert 2006 \{published data only\}}

Bleckert MG, Felder H, Grunebert C. Treadmill therapy in the acute rehabilitation stage in hemiparetic patients [Laufbandtherapie in der akuten rehabilitationsphase bei patienten mit hemiparese. Pilotstudie zum vergleich lansamer und schneller ganggeschwindigkeiten]. Physioscience 2006;2(2):67-72.

\section{Blennerhassett 2004 \{published data only\}}

Blennerhassett J, Dite W. A randomised controlled trial evaluating additional task-related practice during stroke rehabilitation. Australian Journal of Physiotherapy 2003;49(4 Suppl):s6-7.

* Blennerhassett J, Dite W. Additional task-related practice improves mobility and upper limb function early after stroke: a randomised controlled trial. Australian Journal of Physiotherapy 2004;50(4):219-24.

\section{Borsje 2003 \{unpublished data only\}}

Borsje S, Hochstenbach JBH, Postema K, Mulder TH. Clinical value of motor imagery and bodyweight supported treadmill training for recovery of gait performance of stroke patients in the early phase. European Stroke Conference; 2003 May 21-24. Valencia (Spain), 2003.

\section{Brissot 2006 \{published data only\}}

NCT00284115. Efficacy of a mechanical gait repetitive training technique in hemiparetic stroke patients. clinicaltrials.gov (first received 30 January 2006).

\section{Caldwell 2000 \{unpublished data only\}}

Caldwell C, Medley A. Effects of bicycling, treadmill, and variable surfaces on gait in people following a CVA. Neurology Report 2000;24(5):203.

\section{Daly 2004 \{published data only\}}

Daly JJ, Roenigk K, Holcomb J, Rogers JM, Butler K, Gansen J, et al. A randomized controlled trial of functional neuromuscular stimulation in chronic stroke subjects. Stroke 2006;37(1):172-8.

* Daly JJ, Roenigk KL, Butler KM, Gansen JL, Fredrickson E, Marsolais EB, et al. Response of sagittal plane gait kinematics to weight-supported treadmill training and functional neuromuscular stimulation following stroke. Journal of Rehabilitation Research \& Development 2004;41(6):807-20.

Daly JJ, Rogers J, Strasshofer B, Debogorski AA, Roenigk K, Ruff RL. Treadmill training, weight support, and FNS for stroke gait training. Platform and poster presentations for CSM 2003. Neurology Report 2002;26(4):202-3.

Daly JJ, Ruff RL. Feasibility of combining multi-channel functional neuromuscular stimulation with weight-supported treadmill training. Journal of the Neurological Sciences 2004;225(1-2):105-15

Daly JJ, Sng K, Roenigk K, Fredrickson E, Dohring M. Intralimb coordination deficit in stroke survivors and response to treatment. Gait \& Posture 2007;25(3):412-8. 
Hansen K, Lucarelli J, Torres AM, Roenigk KL, Daly JJ. Muscle activation latency gains for gait, in response to combined treadmill training, weight support, and FNS following stroke. National Science Conference, American Physical Therapy Association; 2003 February; Tampa, Florida, USA. 2003.

NCT0001196. FNS and weight support treadmill training for gait component restoration. clinicaltrials.gov (first received 22 February 2001).

Pundik S, Holcomb J, Daly JJ. Improvements in life-role participation after intensive gait training of chronic stroke survivors. Stroke 2009;40(4):e123.

\section{Daly 2011 \{published data only\}}

Daly J, Zimbelman J, Roenigk K, McCabe J, Rogers J, Butler K, et al. Recovery of coordinated gait: randomized controlled stroke trial of functional electrical stimulation (FES) versus no FES, with weight-supported treadmill and over-ground training. Neurorehabilitation \& Neural Repair 2011;25(7):588-96.

\section{Dean 2000 \{published and unpublished data\}}

* Dean CM, Richards CL, Malouin F. Task-related circuit training improves performance of locomotor tasks in chronic stroke: a randomized, controlled pilot study. Archives of Physical Medicine \& Rehabilitation 2000;81(4):409-17.

Richards CL. Task-oriented gait training for patients with cerebral palsy and stroke. 2nd World Congress in Neurological Rehabilitation. Toronto, 1999:218-27.

Richards CL, Malouin F, Dean C. Maximizing locomotor recovery after stroke. Archives of Physiology \& Biochemistry 2000;108(1-2):1.

\section{DEGAS 2007 \{published data only\}}

* Mehrholz J, Werner C, Hesse S, Pohl M. Immediate and long-term functional impact of repetitive locomotor training as an adjunct to conventional physiotherapy for nonambulatory patients after stroke. Disability and Rehabilitation 2008;30(11):830-6.

Pohl M, Mehrholz J, Rutte K, Dressler C, Gold S, Werner C, et al. Results of aerobic exercise training in patients after stroke. Gait trainer vs conventional therapy. A randomized controlled longitudinal study. First results. Neurologie und Rehabilitation 2003;9(6):S6-7.

Pohl M, Mehrholz J, Werner C, Hesse S. Comparison of aerobic exercise training in patients after stroke - gait trainer versus conventional physiotherapy. A randomized controlled longitudinal study [Vergleich der aeroben ubungsintensitat bei patienten nach schlaganfall - gangtrainer versis konventionelle physiotherapie. Eine randomisierte and kontrollierte longitudinalstudie]. Neurologie und Rehabilitation 2004;10(4):187-216.

Pohl M, Werner C, Holzgraefe M, Kroczek G, Mehrholz J, Wingendorf $\mathrm{I}$, et al. Repetitive locomotor training and physiotherapy improve walking and basic activities of daily living after stroke: a single-blind, randomized multicentre trial (DEutsche GAngtrainerStudie, DEGAS). Clinical Rehabilitation 2007;21(1):17-27.
Werner C, Pohl M, Holzgraefe M, Kroczek G, Mehrholz J, Wingendorf I, et al. 'DEGAS' - German gait training study to evaluate the gait trainer (GT1) combined with physiotherapy compared with physiotherapy alone in acute stroke patients. Neurologie und Rehabilitation 2004;10(4):187-216.

Werner C, Pohl M, Holzgraefe M, Kroczek G, Mehrholz J, Wingendorf I, et al. Design of a multicentre study. Neurologie und Rehabilitation 2003;9(6):S6.

Werner C, Pohl M, Holzgraefe M, Kroczek G, Mehrholz J, Wingendorf $\mathrm{I}$, et al. Locomotor training in subacute stroke patients: results of a multicenter study (DEGAS). Neurologie und Rehabilitation 2006;12(5):262-9.

Dias 2007 \{published data only\}

* Dias D, Lains J, Pereira A, Nunes R, Caldas J, Amaral C, et al. Can we improve gait skills in chronic hemiplegics? A randomised control trial with gait trainer. Europa Medicophysica 2007;43(4):499-504.

Dias D, Lains J, Pereira A, Nunes R, Caldas J, Amaral C, et al. Partial body weight support in chronic hemiplegics: a randomized control trial. 6th Mediterranean Congress of Physical and Rehabilitation Medicine; 2006 October 18-21; Vilamoura, Portugal. 2006.

\section{Druzbicki 2016 \{published data only\}}

Druzbicki M, Przysada G, Guzik A, Kwolek A, BrzozowskaMagon A, Sobolewski M. Evaluation of the impact of exercise of gait on a treadmill on balance of people who suffered from cerebral stroke. Acta of Bioengineering and Biomechanics 2016;18:41-8.

\section{English 2007 \{published data only\}}

English CK, Hillier SL, Stiller KR, Warden-Flood A. Circuit class therapy versus individual physiotherapy sessions during inpatient stroke rehabilitation: a controlled trial. Archives of Physical Medicine and Rehabilitation 2007;88(8):955-63. [0003-9993: (Print)]

\section{Fisher 2008 \{published data only\}}

Fisher S. Use of Autoambulator for mobility improvement in patients with central nervous system (CNS) injury or disease. Neurorehabilitation \& Neural Repair 2008;22(5):556.

Forrester 2004 \{published data only\}

Forrester LW, Villagra F, Macko RF, Hanley DF. Treadmill vs. stretching: short-term CNS adaptations to single bouts of submaximal exercise in chronic stroke patients. Stroke 2004;35(6):e312.

\section{Freivogel 2009 \{published data only\}}

Freivogel S, Schmalohr D, Mehrholz J. Improved walking ability and reduced therapeutic stress with an electromechanical gait device. Journal of Rehabilitation Medicine 2009;41(9):734-9.

\section{Globokar 2005 \{published data only\}}

Globokar D. Gait trainer in neurorehabilitation of patients after stroke. 3rd World Congress of the International Society of Physical and Rehabilitation Medicine - ISPRM; 2005 April 10-14; Sao Paulo, Brazil. 2005. 
Hidler 2009 \{published data only\}

Hidler J, Hornby G. Gait restoration in hemiparetic stroke patients using goal-directed robotic-assisted treadmill training. www.ric.org/research/clinical-trials/detail/?id=169 (first accessed prior to 14 July 2017).

* Hidler J, Nichols D, Pelliccio M, Brady K, Campbell DD, Kahn JH, et al. Multicenter randomized clinical trial evaluating the effectiveness of the Lokomat in subacute stroke. Neurorehabilitation \& Neural Repair 2009;23(1):5-13.

NCT00075283. Walking therapy in hemiparetic stroke patients using robotic-assisted treadmill training. clinicaltrials.gov (first received 8 January 2004).

\section{Hornby 2008 \{published data only\}}

Anonymous. Enhanced gait-related improvements after therapist-versus robotic-assisted locomotor training in subjects with chronic stroke: a randomized controlled study. Stroke 2008; Vol. 39, issue 8:e143.

* Hornby TG, Campbell DD, Kahn JH, Demott T, Moore JL, Roth HR. Enhanced gait-related improvements after therapist - versus robotic-assisted locomotor training in subjects with chronic stroke: a randomized controlled study. Stroke 2008;39(6):1786-92.

Kahn J, Campbell D, Demott T, Moore J, Roth H, Hornby G. Alterations in locomotor performance in individuals with hemiplegia post-stroke following robotic- or therapist-assisted locomotor training. Journal of Neurologic Physical Therapy 2006;30(4):212.

Lewek M, Hayes T, Moore J, Roth H, Hornby TG. Alterations in joint kinesmatics following locomotor training in individuals with chronic stroke. Platforms, thematic posters, and posters for CSM 2007. Journal of Neurologic Physical Therapy 2006;30(4):196.

Lewek MD, Cruz TH, Moore JL, Roth HR, Dhaher YY, Hornby TG. Allowing intralimb kinematic variability during locomotor training poststroke improves kinematic consistency: a subgroup analysis from a randomized clinical trial. Physical Therapy 2009;89(8):829-39.

\section{Husemann 2007 \{published data only\}}

* Husemann B, Muller F, Krewer C, Heller S, Koenig E. Effects of locomotion training with assistance of a robot-driven gait orthosis in hemiparetic patients after stroke: a randomized controlled pilot study. Stroke 2007;38(2):349-54.

Husemann B, Muller F, Krewer C, Lab A, Gille C, Heller S, et al. Effects of locomotion training with assistance of a driven gait orthosis in hemiparetic patients after stroke. Neurologie und Rehabilitation 2004;10(4):187-217.

\section{Jang 2005 \{published data only\}}

Jang SJ, Park SW, Kim ES, Wee HM, Kim YH. Electromechanical gait trainer for restoring gait in hemiparetic stroke patients. 3rd World Congress of the International Society of Physical and Rehabilitation Medicine - ISPRM; 2005 April 10-14; Sao Paulo, Brazil. 2005.

\section{Jeong 2008 \{published data only\}}

Jeong $\mathrm{K}$, $\mathrm{Ha} \mathrm{H}$, Shin $\mathrm{H}$, Ohn S, Sung D, Lee P, et al. Effects of robot-assisted gait therapy on locomotor recovery in stroke patients. Journal of Rehabilitation Medicine 2008;40(Suppl 46):148.

\section{Khanna 2003 \{unpublished data only\}}

Khanna PB. A randomised control study of the immediate and long term benefits of conventional stroke rehabilitation with task related group therapy in chronic stroke patients. www.controlled-trials.com/ (first received ):CRSREF 2704239.

\section{Kim 2001 \{unpublished data only\}}

Kim BO, Lee JJ, Cho KH, Kim SH. Gait training robot (gaitTrainer) in rehabilitation. 1st International Congress of International Society of Physical and Rehabilitation Medicine (ISPRM); 2001 July 7-13; Amsterdam, Netherlands. International Society of Physical and Rehabilitation Medicine (ISPRM), 2001.

\section{Kim 2008 \{published data only\}}

Kim M, Kim Y, Lee P, Kim G, You J, Huh J. Effect of robot-assisted gait therapy on cardio-pulmonary fitness in subacute stroke patients. Neurorehabilitation \& Neural Repair 2008;22(5):594.

\section{Kovrazhkina 2009 \{published data only\}}

Kovrazhkina E, Rumianzeva N, Starizin A, Ivanova G. Rehabilitation of walking in patients with an acute stroke with assistance of a robotic device gait trainer. Cerebrovascular Diseases 2009;27(Suppl 6):210.

Skvortsova V, Ivanova G, Kovrazhkina E, Rumyantseva N, Staritsin A, Sogomonyan E. The efficacy of gait rehabilitation after stroke training with assistance of a robotic device gait trainer: a pilot study. International Journal of Stroke 2008;3(Suppl):355.

Skvortsova VI, Ivanova GE, Kovrazhkina EA, Rumiantseva NA, Staritsyn AN, Suvorov A, et al. The use of a robot-assisted Gait Trainer GT1 in patients in the acute period of cerebral stroke: a pilot study. Zh Nevrol Psikhiatr Im S S Korsakova 2008;Suppl 23:28-34.

* Skvortsova VI, Ivanova GE, Rumiantseva NA, Staritsyn AN, Kovrazhkina EA, Suvorov A. Modern approach to gait restoration in patients in the acute period of cerebral stroke. Zh Nevrol Psikhiatr Im S S Korsakova 2010;110(4):25-30.

\section{Kwakkel 1999 \{published data only\}}

Kwakkel G, Kollen BJ, Wagenaar RC. Long term effects of intensity of upper and lower limb training after stroke: a randomised trial. Journal of Neurology, Neurosurgery, and Psychiatry 2002;72(4):473-9.

Kwakkel G, Wagenaar RC. Effect of duration of upper- and lower-extremity rehabilitation sessions and walking speed on recovery of interlimb co-ordination in hemiplegic gait. Physical Therapy 2002;82:432-48.

* Kwakkel G, Wagenaar RC, Twisk JWR, Lankhorst GJ, Koetsier JC. Intensity of leg and arm training after primary middle-cerebral-artery stroke: a randomised trial. Lancet 1999;354:191-6. 


\section{Langhammer 2000 \{published data only\}}

Langhammer B, Stanghelle JK. Bobath or motor relearning programme? A comparison of two different approaches of physiotherapy in stroke rehabilitation: a randomized controlled study. Clinical Rehabilitation 2000;14:361-9.

\section{Langhammer 2007 \{published data only\}}

Langhammer B, Lindmark B, Stanghelle JK. Living with stroke: exercising for life. Journal of Aging \& Physical Activity 2008;16:S80

Langhammer B, Lindmark B, Stanghelle JK. Stroke patients and long-term training: is it worthwhile? A randomized comparison of two different training strategies after rehabilitation. Clinical Rehabilitation 2007;21(6):495-510.

Langhammer B, Lindmark B, Tanghelle JKS. Motor function, activity and participation one year post stroke: a I follow-up of a randomised controlled trial in persons with stroke. Brain Injury 2010;24(3):171-2.

Langhammer B, Stanghelle JK, Lindmark B. An evaluation of two different exercise regimes during the first year following stroke: a randomised controlled trial. Physiotherapy Theory and Practice 2009;25(2):55-68.

* Langhammer B, Stanghelle JK, Lindmark B. Exercise and health-related quality of life during the first year following acute stroke. A randomized controlled trial. Brain Injury 2008;22(2):135-45

Lau 2010 \{published data only\}

* Lau KW, Mak MK. Speed-dependent treadmill training is effective to improve gait and balance performance in patients with sub-acute stroke. Journal of Rehabilitation Medicine 2011;43(8):709-13.

Lau WK, Mak MKY. The effects of speed-dependent treadmill training on gait and balance performance in patients with subacute stroke. Hong Kong Physiotherapy Journal 2010;28(1):27.

\section{Lee 2013 \{published data only\}}

Lee HJ, Cho KH, Lee WH. The effects of body weight support treadmill training with power-assisted functional electrical stimulation on functional movement and gait in stroke patients. American Journal of Physical Medicine and Rehabilitation 2013;92:1051-9.

\section{Lindquist 2011 \{published data only\}}

Lindquist A, Ribeiro T, Silva E, Galvao E. Influence of treadmill training with body weight support and proprioceptive neuromuscular facilitation on hemiparetic gait. Archives of Physical Medicine and Rehabilitation 2011;92(10):1718.

\section{Macko 2006 \{published data only\}}

Macko RF. Exercise training for hemiparetic stroke. crisp.cit.nih.gov/ (accessed prior to 14 July 2017).

* NCT00430456. Treadmill exercise prescriptions to improve fitness versus ambulatory function after stroke. clinicaltrials.gov/show/NCT00430456 (first received 31 January 2007).

\section{Mayr 2007 \{published data only\}}

Mayr A, Kofler M, Quirbach E, Matzak H, Frohlich K, Saltuari L. Prospective, blinded, randomized crossover study of gait rehabilitation in stroke patients using the Lokomat gait orthosis. Neurorehabilitation \& Neural Repair 2007;21(4):307-14.

\section{Mayr 2008 \{published data only\}}

Mayr A, Saltuari L, Quirbach E. Impact of Lokomat training on gait rehabilitation: a prospective randomized controlled trial in stroke patients. Neurorehabilitation \& Neural Repair 2008;22(5):596.

\section{McCain 2008 \{published data only\}}

McCain KJ, Pollo FE, Baum BS, Coleman SC, Baker S, Smith PS. Locomotor treadmill training with partial body-weight support before overground gait in adults with acute stroke: a pilot study. Archives of Physical Medicine and Rehabilitation 2008;89(4):684-91.

Michael 2011 \{published data only\}

* Michael KM. Combined adaptive physical activity and treadmill training in stroke. Stroke 2011;42(3):e355.

NCT01042990. Testing adaptive physical activity in stroke. clinicaltrials.gov/show/NCT01042990 (accessed 2 September 2013).

NCT00018421 \{published data only\}

NCT00018421. Effects of exercise on patients with hemiparetic stroke. www.clinicaltrials.gov (first received 3 July 2001).

\section{NCT00108030 \{published data only\}}

NCT00108030. PBWST (Partial body-weight supported treadmill training) and muscle power training after sub-acute stroke. clinicaltrials.gov/ct2/show/NCT00108030 (first received 12 April 2005).

\section{NCT00284115 \{published data only\}}

NCT00284115. Efficacy of a mechanical gait repetitive training technique in hemiparetic stroke patients (AVC). www.clinicaltrials.gov (first received 30 January 2006).

\section{NCT00612300 \{published data only\}}

NCT00612300. Gait training for persons with stroke (GTS). clinicaltrials.gov. (first received 28 January 2008).

\section{NCT00891514 \{published data only\}}

NCT00891514. Inflammation and exercise in stroke. www.clinicaltrials.gov (first received 30 April 2009).

NCT01146587 \{published data only\}

NCT01146587. Comparative study of GangTrainer GT1, Lokomat and conventional physiotherapy. www.clinicaltrials.gov (first received 14 June 2010).

\section{NCT01337960 \{published data only\}}

NCT01337960. Ankle robotics training after stroke. clinicaltrials.gov/show/NCT01337960 (first received 15 April 2011). 


\section{NCT01674790 \{published data only\}}

NCT01674790. Combined effects of aerobic exercise and cognitive training on cognition after stroke. www.clinicaltrials.gov (first received 24 August 2012).

\section{NCT02043574 \{published data only\}}

NCT02043574. Nutrition and aerobic exercise in chronic stroke. www.clinicaltrials.gov (first received 6 January 2014).

\section{NCT02680496 \{published data only\}}

NCT02680496. Energy consumption and cardiorespiratory load during walking with and without robot-assistance. www.clinicaltrials.gov (first received 27 January 2016).

\section{NCT02735148 \{published data only\}}

NCT02735148. The effects of body weight supported treadmill training on balance in stroke patients. www.clinicaltrials.gov (first received 30 March 2016).

\section{NCT02798237 \{published data only\}}

NCT02798237. Effects of aerobic training post-stroke. www.clinicaltrials.gov (first received 6 June 2016).

\section{NCT02956096 \{published data only\}}

NCT02956096. Evaluation of autonomic modulation in stroke after transcranial direct current stimulation and treadmill training. www.clinicaltrials.gov (first received 30 September 2016)

\section{NCT03006731 \{published data only\}}

NCT03006731. High intensity interval training for people with stroke deficits. www.clinicaltrials.gov (first received 19 December 2016).

\section{NCT03056287 \{published data only\}}

NCT03056287. Exercise and brain stimulation for post-stroke depression. www.clinicaltrials.gov (first received 8 February 2017).

\section{Pang 2010 \{published data only\}}

Pang MYC, Lau RWK. The effects of treadmill exercise training on hip bone density and tibial bone geometry in stroke survivors: a pilot study. Neurorehabilitation \& Neural Repair 2010;24(4):368-76

\section{Park 2012 \{published data only\}}

Park SE, Kim SH, Lee SB, An HJ, Choi WS, Moon OG, et al. Comparison of underwater and overground treadmill walking to improve gait pattern and muscle strength after stroke. Journal of Physical Therapy Science 2012;24(11):1087-90.

\section{Peurala 2005 \{published data only\}}

Peurala SH, Pitkanen K, Sivenius J, Tarkka I. Body-weight supported gait exercise compared with floor walking in chronic stroke patients. Archives of Physical Medicine \& Rehabilitation 2004;85(9):E7.

* Peurala SH, Tarkka IM, Pitkanen K, Sivenius J. The effectiveness of body weight-supported gait training and floor walking in patients with chronic stroke. Archives of Physical Medicine \& Rehabilitation 2005;86(8):1557-64.
Pitkanen K, Tarkka I, Sivenius J. Walking training with partial body weight support versus conventional walking training of chronic stroke patients: preliminary findings. Neurorehabilitation \& Neural Repair 2001;15(4):312.

Pitkanen K, Tarkka IM, Sivenius J. Walking training with partial body weight support versus conventional walking training of chronic stroke patients: preliminary findings. 3rd World Congress in Neurological Rehabilitation; Venice, Italy. 2002:T7.

Peurala 2009 \{published data only\}

NCT00307762. Gait trainer vs traditional physiotherapy in acute stroke. clinicaltrials.gov (first received 27 March 2006).

Peurala S, Airaksinen O, Jakala P, Tarkka I, Sivenius J. Intensive walking and exercise therapy during early acute stage of stroke. 18th International Conference of the International Society for Posture and Gait Research; Vermont, USA. 2007:103-4.

* Peurala SH, Airaksinen O, Huuskonen P, Jakala P, Juhakoski M, Sandell K, et al. Effects of intensive therapy using gait trainer or floor walking exercises early after stroke. Journal of Rehabilitation Medicine 2009;41(3):166-73.

Peurala SH, Airaksinen O, Jakala P, Tarkka IM, Sivenius J. Effects of intensive gait-oriented physiotherapy during early acute phase of stroke. Journal of Rehabilitation Research and Development 2007;44(5):637-48.

Peurala SH, Pitkanen K, Sivenius J, Tarkka IM. Body-weight supported gait trainer exercises with or without functional electrical stimulation improves gait in patients with chronic stroke. Neurorehabilitation \& Neural Repair 2006;20(1):98.

Ploughman 2008 \{published data only\}

Ploughman M, McCarthy J, Bosse M, Sullivan HJ, Corbett D. Does treadmill exercise improve performance of cognitive or upper-extremity tasks in people with chronic stroke? A randomized cross-over trial. Archives of Physical Medicine and Rehabilitation 2008;89(11):2041-7.

\section{Rimmer 2000 \{published data only\}}

Rimmer JH, Riley B, Creviston T, Nicola T. Exercise training in a predominantly African-American group of stroke survivors. Medicine \& Science in Sports \& Exercise 2000;32:1990-6.

\section{Salbach 2004 \{published data only\}}

Salbach NM, Mayo NE, Robichaud-Ekstrand S, Hanley JA, Richards CL, Wood-Dauphinee S. The effect of a task-oriented walking intervention on improving balance self-efficacy poststroke: a randomized, controlled trial. Journal of the American Geriatrics Society 2005;53(4):576-82. [MEDLINE: $15817001]$

* Salbach NM, Mayo NE, Wood-Dauphinee S, Hanley JA, Richards CL, Cote R. A task-orientated intervention enhances walking distance and speed in the first year post stroke: a randomized controlled trial. Clinical Rehabilitation 2004;18(5):509-19.

\section{Saltuari 2004 \{published data only\}}

Saltuari L. Efficiency of Lokomat training in stroke patients. Neurologie und Rehabilitation 2004;10(4):169-78. 
Schwartz 2009 \{published data only\}

Schwartz I, Katz-Leurer M, Fisher I, Sajin A, Shochina M, Meiner Z. The effectiveness of early locomotor therapy in patients with first CVA. Collaborative Evaluation of Rehabilitation in Stroke Across Europe (CERISE) Congress; 2006 February 10-11. 2006.

* Schwartz I, Sajin A, Fisher I, Neeb M, Shochina M, KatzLeurer $\mathrm{M}$, et al. The effectiveness of locomotor therapy using robotic-assisted gait training in subacute stroke patients: a randomized controlled trial. Physical Medicine and Rehabilitation 2009;1(6):516-23.

\section{Shafshak 2012 \{published data only\}}

* Shafshak TS. Central neuroplasticity and upper limbs functional outcome following repetitive lower limb locomotor training in stroke patients. Physical Medicine and Rehabilitation 2012;10:S298.

Shahine EM, Shafshak TS. Central neuroplasticity and upper limbs functional outcome following repetitive lower limb locomotor training in chronic stroke patients. European Journal of Neurology 2012;19:570.

\section{Sullivan 2002 \{published data only\}}

* Sullivan KJ, Knowlton BJ, Dobkin BH. Step training with body weight support: effect of treadmill speed on practice paradigms on poststroke locomotor recovery. Archives of Physical Medicine \& Rehabilitation 2002;83:683-91.

Sullivan KJ, Knowlton BJ, Dobkin BH. The effect of varying treadmill speed to enhance overground walking in patients with chronic stroke. Stroke 2000;31(1):292.

Sullivan KJ, Knowlton BJ, Dobkin H. Stroke severity and treadmill training as predictors of locomotor recovery in chronic stroke. Neurology Report 2000;24(5):173-4.

\section{Tong 2006 \{published data only\}}

Li LSW. Motor training after stroke. Journal of Neurology, Neurosurgery, and Psychiatry 2005;76(4):605-6.

Li LSW, Tong RKY, Ng MFW, So EFM. Gait training by mechanical gait trainer and functional electrical stimulation for subacute stroke patients: a randomised controlled study. 3rd World Congress of the International Society of Physical and Rehabilitation Medicine - ISPRM; 2005 10-14 April; Sao Paulo, Brazil. 2005.

Li LSW, Tong RYU, Ng MFW, So EFM. Effectiveness of gait trainer in stroke rehabilitation. Journal of the Neurological Sciences 2005;238 Suppl 1:S81.

Ng MF, Tong RK, Li LS. A pilot study of randomized clinical controlled trial of gait training in subacute stroke patients with partial body-weight support electromechanical gait trainer and functional electrical stimulation: six-month follow-up. Stroke 2008;39(1):154-60.

Ng MFW, Tong KY, So EFM, Li LSW. The therapeutic effect of electromechanical gait trainer and functional electrical stimulation for patients with acute stroke. Neurorehabilitation \& Neural Repair 2006;20(1):97.
Tong R, Ng M, Li L. The effect of electromechanical gait trainer combined with functional electrical stimulation for subacute stroke rehabilitation. International Journal of Stroke 2008;3(Suppl):357.

* Tong RK, Ng MF, Li LS. Effectiveness of gait training using an electromechanical gait trainer, with and without functional electric stimulation, in subacute stroke: a randomized controlled trial. Archives of Physical Medicine and Rehabilitation 2006;87(10):1298-304.

\section{Trueblood 2001 \{published data only\}}

Trueblood PR. Partial body weight treadmill training in persons with chronic stroke. Neurorehabilitation 2001;16:141-53.

\section{Tsai 2004 \{published data only\}}

Tsai YC, Yang S, Chern JS. Effect of backward-walk training in proving the balance and weight shifting skill of stroke patients. Stroke 2004;35(6):e319.

\section{Tsang 2012 \{published data only\}}

Tsang MYC, Eng JJ, Tang A, Jue J, Gin KG, Nair P, et al. Impact of aerobic exercise training on cardiac function in stroke patients: a prospective randomized controlled study. Journal of the American Society of Echocardiography 2012;25(6):B11.

\section{Werner 2002b \{published and unpublished data\}}

Bardeleben A, Schaffrin A, Werner C, Hesse S. Treadmill therapy with and without physiotherapy after stroke: a randomized trial [Laufbandtherapie mit und ohne physiotherapie nach schlaganfall: eine randomisierte studie]. Deutsche Gesellschaft fur Neurologische Rehabilitation Annual Conference; 2000 November 23-25. 2000.

Hesse S, Lucke D, Bardeleben A. Chronic nonambulatory hemiparetic subjects: effects of a treadmill training alone and in combination with regular physiotherapy. 2nd World Congress in Neurological Rehabilitation. Toronto, Canada, 1999.

Hesse S, Lucke D, Bardeleben A. Chronic nonambulatory hemiplegic subjects: effects of a treadmill training alone and in combination with regular physiotherapy. Neurorehabilitation \& Neural Repair 1999;13(1):54.

* Werner C, Bardeleben A, Mauritz KH, Kirker S, Hesse S. Treadmill training with partial body weight support and physiotherapy in stroke patients: a preliminary comparison. European Journal of Neurology 2002;9:639-44.

\section{Westlake 2009 \{published data only\}}

Patten C. Internally versus externally guided body weight supported treadmill training [BWSTT] for locomotor recovery post-stroke. www.strokecenter.org/trials/ (accessed prior to 14 July 2017).

* Westlake KP, Patten C. Pilot study of Lokomat versus manualassisted treadmill training for locomotor recovery post-stroke. Journal of NeuroEngineering and Rehabilitation 2009;6:18.

\section{Yagura 2006 \{published data only\}}

Yagura $\mathrm{H}$, Hatakenaka M, Miyai I. Does therapeutic facilitation add to locomotor outcome of body weight-supported treadmill 
training in nonambulatory patients with stroke? A randomized controlled trial. Archives of Physical Medicine and Rehabilitation 2006;87(4):529-35.

\section{Yang 2008 \{published data only\}}

* Yang S, Hwang W-H, Tsai Y-C, Liu F-K, Hsieh L-F, Chern J-S. Improving balance skills in patients who had stroke through virtual reality treadmill training. American Journal of Physical Medicine \& Rehabilitation 2011;90(12):969-78.

Yang YR, Tsai MP, Chuang TY, Sung WH, Wang RY. Virtual realitybased training improves community ambulation in individuals with stroke: a randomized controlled trial. Gait \& Posture 2008;28(2):201-6.

\section{References to studies awaiting assessment}

\section{Baer 2009 \{published data only\}}

Baer G. Treadmill training and sub-acute stroke: a phase II feasibility study. 3rd UK Stroke Forum Conference; Harrogate, UK. 2008:21.

* Baer G, Dennis M, Pitman J, Salisbury L, Smith M. Does treadmill training improve walking after stroke - the long term follow-up from a phase II randomised controlled trial. International Journal of Stroke 2009;4(Suppl 2):8.

Salisbury L, Baer G, Dennis M, Pitman J, Smith M. Does treadmill training affect activities of daily living or quality of life after stroke? Results of a phase II randomised controlled trial. International Journal of Stroke 2009;4 Suppl 2:38.

Smith M, Baer G, Dennis M, Pitman J, Salisbury L. How feasible is the delivery of treadmill training early after stroke within the NHS: findings of a phase II randomised controlled trial. International Journal of Stroke 2009;4 Suppl 2:38.

Statt TC. Treadmill training in sub-acute stroke: report of an ongoing phase II feasibility study of a complex intervention. UK Stroke Forum Conference 2007; Harrogate, UK. 2007.

\section{Bartloff 2009 \{published data only\}}

Bartloff J, Bitting J, Lueke A, Sbertoli C, Sofen L, Walsh J, et al. After-effects of slow isokinetic walk speed training on selfselected gait velocity in persons with chronic post-stroke hemiparesis. Journal of Neurologic Physical Therapy 2009; Vol. 33 , issue 4:231.

\section{Mokrusch 2004 \{published data only\}}

Mokrusch T, Busch K. Treadmill training with functional electric stimulation in stroke patients. Benefits compared with Bobath physiotherapy. Neurologie und Rehabilitation. Hippocampus, 2004; Vol. 10, issue 4:187-216.

\section{Muller 2004 \{published data only\}}

Muller F, Heller S, Krewer C, Husemann B, Koenig E. Effective gait training on the treadmill and the Lokomat: comparison of achievable training time and speed. Neurologie und Rehabilitation. Hippocampus, 2004; Vol. 10, issue 4:187-216.

\section{NCT01789853 \{published data only\}}

NCT01789853. Very intensive early walking in stroke. clinicaltrials.gov/show/NCT01789853 (first received 14 May 2012).

\section{NCT02619110 \{published data only\}}

NCT02619110. The effect of backward walking treadmill training on balance in patient with chronic stroke. www.clinicaltrials.gov (first received 17 November 2015).

\section{Opara 2016 \{published data only\}}

Opara J, Szczygiel J. Effects of treadmill training with partial body-weight support on clinical parameters of GAIT early after stroke - preliminary results. Cerebrovascular Diseases 2016:41:113.

* Szczygiel J, Opara J. Effects of treadmill training with partial body-weight support on biomechanical parameters of gait after stroke. Physiotherapy 2015:eS1151.

Shintani 2005 \{published data only\}

Shintani M, Nagai S, Shimoda S, Wada Y, Sonoda S. High-speed treadmill exercise for stroke hemiplegics. 3rd World Congress of the International Society of Physical and Rehabilitation Medicine - ISPRM; Sao Paulo, Brazil. 2005.

\section{Stephenson 2004 \{published data only\}}

Stephenson J, Maitland M, Beckstead J. Body weight support treadmill training compared with PNF training in persons with chronic stroke. Journal of Neurologic Physical Therapy 2004;28(4):186.

\section{Thompson 2006 \{published data only\}}

Thompson M, Medley A. Post stroke locomotor training: does type of practice make a difference?. Journal of Neurologic Physical Therapy 2006;30(4):209-10.

\section{Venkadesan 2009 \{published data only\}}

Venkadesan R, Kumar MKN. A comparative study of conventional gait training versus conventional and treadmill gait training in subacute stroke patients. Indian Journal of Physiotherapy \& Occupational Therapy 2009;3(4):58-62.

\section{Xiao 2014 \{published data only\}}

Xiao X, Mao YR, Zhao JL, Li L, Xu GQ, Huang DF. Virtual realityenhanced body weight-supported treadmill training improved lower limb motor function in patients with cerebral infarction. Chinese Journal of Tissue Engineering Research 2014:1143-8.

\section{Xu 2008 \{published data only\}}

Xu W, Zhang L-Y, Fan J-T. The comparison of gait rehabilitation in patients with hemiplegia by walking in water and the pneuweight walking therapies. Journal of Rehabilitation Medicine 2008;46 Suppl:73.

\section{Yang 2007 \{published data only\}}

Yang A, Su C, Lin K. Effects of long-term exercise intervention on aerobic capacity and functional ability in stroke patients with prior coronary artery disease. Physiotherapy 2007;93 Suppl 1:s260. 
Zielke 2003 \{published data only\}

Zielke DR. The effect of partial body weight supported treadmill training on gait rehabilitation in early acute stroke patients: preliminary data. Journal of Neurologic Physical Therapy 2003;27(4):177.

\section{References to ongoing studies}

ACTRN12609000645257 \{published data only\}

ACTRN12609000645257. Aerobic exercise to improve cardiovascular and neurological health outcomes in the chronic stroke population. www.anzctr.org.au (first received 22 July 2009).

\section{ISRCTN50586966 \{published data only\}}

ISRCTN50586966. Improving community walking after a stroke, a new approach. www.controlled-trials.com/ISRCTN50586966 (first received 2 February 2013).

\section{Lennihan 2003 \{unpublished data only\}}

Lennihan L, Wootten ME, Wainwright M, Tenteromano L, McMahon D, Cotier J. Treadmill with partial body-weight support versus conventional gait training after stroke. Archives of Physical Medicine \& Rehabilitation 2003;84(9):A5.

\section{Malagoni 2014 \{published data only\}}

Malagoni AM, Lamberti N, Zambon C, Felisatti M, Nardini E, Straudi S, et al. Challenging or low exercise intensity to improve mobility and balance for chronic stroke survivors? Preliminary results of a randomized pilot study comparing two supervised 8-week community based. Acta Clinica Croatica 2014;53:90.

\section{NCT01322607 \{published data only\}}

NCT01322607. Task-oriented training for stroke: impact on function mobility. clinicaltrials.gov/show/NCT01322607 (first received 22 March 2011).

\section{NCT01392391 \{published data only\}}

NCT01392391. Exercise for sub-acute stroke patients in Jamaica. clinicaltrials.gov/show/NCT01392391 (first received 11 July 2011).

\section{NCT01600391 \{published data only\}}

NCT01600391. Visual cues for gait training post-stroke. clinicaltrials.gov/show/NCT01600391 (first received 10 May 2012).

\section{NCT01678547 \{published data only\}}

NCT01678547. Robot walking rehabilitation in stroke patients. clinicaltrials.gov/show/NCT01678547 (first received 31 August 2012).

\section{NCT01777113 \{published data only\}}

NCT01777113. High intensity interval training in chronic stroke patients. clinicaltrials.gov/show/NCT01777113 (first received 3 January 2013).

\section{NCT02108912 \{published data only\}}

NCT02108912. Metabolic costs of walking post stroke. www.clinicaltrials.gov (first received 28 March 2014).
NCT02550015 \{published data only\}

NCT02550015. High intensity interval training after stroke. www.clinicaltrials.gov (first received 8 September 2015).

\section{Additional references}

\section{Atkins 2004}

Atkins D, Best D, Briss PA, Eccles M, Falck-Ytter Y, Flottorp S, et al. GRADE Working Group. Grading quality of evidence and strength of recommendations. British Medical Journal 2004;328:1490.

\section{Barbeau 1987}

Barbeau H, Rossignol S. Recovery of locomotion after chronic spinalization in the adult cat. Brain Research 1987;412:84-95.

\section{Bobath 1990}

Bobath B. Adult Hemiplegia: Evaluation and Treatment. 2nd Edition. London: Butterworth-Heinemann, 1990.

\section{Brunnstrom 1970}

Brunnstrom S. Movement Therapy in Hemiplegia. New York: Harper and Row, 1970.

\section{Carr 1985}

Carr JH, Shepherd RB, Nordholm L, Lynne D. Investigation of a new motor assessment scale for stroke patients. Physical Therapy 1985;65:175-80.

\section{Carr 1998}

Carr JH, Shepherd RB. Neurological Rehabilitation: Optimizing Motor Performance. Oxford: Butterworth-Heinemann, 1998.

\section{Charalambous 2013}

Charalambous CC, Bonilha HS, Kautz SA, Gregory CM, Bowden MG. Rehabilitating walking speed poststroke with treadmill-based interventions: a systematic review of randomized controlled trials. Neurorehabilitation and Neural Repair 2013;27(8):709-21.

\section{Collen 1991}

Collen FM, Wade DT, Robb GF, Bradshaw CM. The Rivermead Mobility Index: a further development of the Rivermead Motor Assessment. International Disability Studies 1991;13:50-4.

\section{Collin 1988}

Collin C, Wade DR, Davies S, Horne V. The Barthel ADL Index: a reliability study. International Disability Studies 1988;10:61-3.

\section{De Haan 1993}

De Haan R, Aaronson N, Limburg M, Hewer RL, Van Crevel H. Measuring quality of life in stroke. Stroke 1993;24:320-7.

\section{Enright 1998}

Enright PL, Sherrill DL. Reference equations for the six-minute walk in healthy adults. American Journal of Respiratory and Critical Care Medicine 1998;158:1384-7. 


\section{Finch 1985}

Finch L, Barbeau H. Hemiplegic gait: new treatment strategies. Physiotherapy Canada 1985;38:36-41.

\section{Flansbjer 2005}

Flansbjer UB, Holmbäck AM, Downham D, Patten C, Lexell J. Reliability of gait performance tests in men and women with hemiparesis after stroke. Journal of Rehabilitation Medicine 2005;37(2):75-82.

\section{French 2016}

French B, Thomas LH, Coupe J, McMahon NE, Connell L, Harrison J, et al. Repetitive task training for improving functional ability after stroke. Cochrane Database of Systematic Reviews 2016, Issue 11. [DOI: 10.1002/14651858.CD006073.pub3]

\section{Goff 1969}

Goff B. Appropriate afferent stimulation. Physiotherapy 1969;55:9-17.

\section{GRADEpro GDT [Computer program]}

GRADE Working Group, McMaster University. GRADEpro GDT. Version accessed prior to 21 July 2017. Hamilton (ON): GRADE Working Group, McMaster University, 2014.

\section{Guyatt 1984}

Guyatt GH, Pugsley SO, Sullivan MJ, Thompson PJ, Berman L, Jones NL, et al. Effect of encouragement on walking test performance. Thorax 1984;39:818-22.

\section{Hamilton 1994}

Hamilton BB, Laughlin JA, Fiedler RC, Granger CV. Interrater reliability of the 7-level functional independence measure (FIM). Scandinavian Journal of Rehabilitation Medicine 1994;26:115-9.

\section{Hatano 1976}

Hatano S. Experience from a multi-centre stroke register: a preliminary report. Bulletin of the World Health Organization 1976;54:541-53.

\section{Hesse 2003}

Hesse S, Werner C. Poststroke motor dysfunction and spasticity: novel pharmacological and physical treatment strategies. CNS Drugs 2003;17(15):1093-107.

\section{Higgins 2011}

Higgins JPT, Green S, editor(s). Cochrane Handbook for Systematic Reviews of Interventions Version 5.1.0 (updated March 2011). The Cochrane Collaboration, 2011. Available from handbook.cochrane.org.

\section{Holden 1984}

Holden MK, Gill KM, Magliozzi MR, Nathan J, PeihlBaker L. Clinical gait assessment in the neurologically impaired: reliability and meaningfulness. Physical Therapy 1984;64(1):35-40.

\section{Knott 1968}

Knott M, Voss DE. Proprioceptive Neuromuscular Facilitation. New York: Harper and Row, 1968.

\section{Langhorne 2002}

Langhorne P, Pollock A. What are the components of effective stroke unit care?. Age \& Ageing 2002;31:365-71.

\section{Langhorne 2009}

Langhorne P, Coupar F, Pollock A. Motor recovery after stroke: a systematic review. Lancet Neurology 2009;8(8):741-54.

\section{Manning 2003}

Manning CD, Pomeroy VM. Effectiveness of treadmill retraining on gait of hemiparetic stroke patients. Physiotherapy 2003;89:337-49.

\section{McAuley 2000}

McAuley L, Pham B, Tugwell P, Moher D. Does the inclusion of grey literature influence estimates of intervention effectiveness reported in meta-analyses?. Lancet 2000;356:1228-31.

\section{Mehrholz 2017}

Mehrholz J, Thomas S, Pohl M, Werner C, Kugler J, Elsner B. Electromechanical-assisted training for walking after stroke. Cochrane Database of Systematic Reviews 2017, Issue 5. [DOI: 10.1002/14651858.CD006185.pub4]

\section{Moore 1993}

Moore S, Schurr K, Moseley A, Wales A, Herbert RD. Observation and analysis of hemiplegic gait. II: swing phase. Australian Journal of Physiotherapy 1993;39:271-7.

\section{Moseley 1993}

Moseley A, Wales A, Herbert RD, Schurr K, Moore S. Observation and analysis of hemiplegic gait. I: stance phase. Australian Journal of Physiotherapy 1993;39:251-6.

\section{Murray 2012}

Murray CJ, Vos T, Lozano R, Naghavi M, Flaxman AD, Michaud C, et al. Disability-adjusted life years (DALYs) for 291 diseases and injuries in 21 regions, 1990-2010: a systematic analysis for the Global Burden of Disease Study 2010. Lancet 2012;380(9859):2197-223.

\section{Pohjasvaara 1997}

Pohjasvaara T, Erkinjuntti T, Vataja R, Kaste M. Comparison of stroke features and disability in daily life in patients with ischemic stroke aged 55 to 70 and 71 to 85 years. Stroke 1997;28(4):729-35.

\section{Polese 2013}

Polese JC, Ada L, Dean CM, Nascimento LR, Teixeira-Salmela LF. Treadmill training is effective for ambulatory adults with stroke: a systematic review. Journal of Physiotherapy 2013;59(2):73-80.

\section{Pollock 2014}

Pollock A, Baer G, Campbell P, Choo PL, Forster A, Morris J, et al. Physical rehabilitation approaches for the recovery of function and mobility following stroke. Cochrane Database of Systematic Reviews 2014, Issue 4. [DOI: 10.1002/14651858.CD001920.pub3] 


\section{RevMan 2012 [Computer program]}

Nordic Cochrane Centre, The Cochrane Collaboration. Review Manager 5 (RevMan 5). Version 5.3. Copenhagen: Nordic Cochrane Centre, The Cochrane Collaboration, 2014.

\section{SUTC 2013}

Stroke Unit Trialists' Collaboration. Organised inpatient (stroke unit) care for stroke. Cochrane Database of Systematic Reviews 2013, Issue 9. [DOI: 10.1002/14651858.CD000197.pub3]

\section{Teasell 2003}

Teasell RW, Bhogal SK, Foley NC, Speechley MR. Gait retraining post stroke. Topics in Stroke Rehabilitation 2003;10:34-65.

\section{Van Peppen 2004}

Van Peppen RP, Kwakkel G, Wood-Dauphinee S, Hendriks HJ, Van der Wees PJ, Dekker J. The impact of physical therapy on functional outcomes after stroke: what's the evidence?. Clinical Rehabilitation 2004;18(8):833-62.

\section{Wade 1992}

Wade DT. Measurement in Neurological Rehabilitation. Oxford: Oxford University Press, 1992.

\section{References to other published versions of this review}

\section{Mehrholz 2014}

Mehrholz J, Pohl M, Elsner B. Treadmill training and body weight support for walking after stroke. Cochrane Database of Systematic Reviews 2014, Issue 1. [DOI: 10.1002/14651858.CD002840.pub3]

\section{CHARACTERISTICS OF STUDIES}

Characteristics of included studies [ordered by study ID]

\section{Moseley 2002}

Moseley A, Stark A, Cameron I, Pollock A. Treadmill training and body weight support for walking after stroke: a systematic review. 7th International Physiotherapy Congress 25-28 May. Sydney (Australia): Australian Physiotherapy Association, 2002.

\section{Moseley 2003a}

Moseley AM, Stark A, Cameron ID, Pollock A. Treadmill training and body weight support for walking after stroke. Stroke 2003;34(12):3006.

\section{Moseley 2003b}

Moseley AM, Stark A, Cameron ID, Pollock A. Treadmill training and body weight support for walking after stroke. Physiotherapy 2003;89(9):515.

\section{Moseley $2003 c$}

Moseley AM, Stark A, Cameron ID, Pollock A. Treadmill training and body weight support for walking after stroke: a Cochrane systematic review. Stroke Society of Australasia 2003 Annual Scientific Meeting; 2003 17-19 September. Sydney (Australia): Stroke Society of Australasia, 2003.

\section{Moseley 2003d}

Moseley AM, Stark A, Cameron ID, Pollock A. Treadmill training and body weight support for walking after stroke: a Cochrane systematic review. Combined Australian Capital Territory Branch and New South Wales Branch of the Australian Physiotherapy Association Mini-Conference; 20033 May. Sydney (Australia): Australian Physiotherapy Association, 2003.

* Indicates the major publication for the study

Ada 2003

Parallel-group design
Concealed randomisation of participants by ranking the participants according to independent walk-
ing speed at baseline (from fastest to slowest) and then allocating each descending pair of participants
by coin toss
$14 \%$ dropouts at the end of treatment and $10 \%$ dropouts at the end of the follow-up phase
Outcome assessors were blinded to group allocation

Participants 14 participants in the EXP group and 15 participants in the CTL group Inclusion criteria: less than 5 years post-stroke; first stroke; clinically diagnosed hemiparesis; aged 50 to 85 years; can walk 10 metres independently with a speed less than $1 \mathrm{~m} / \mathrm{s}$; discharged from rehabilitation Exclusion criteria: cardiovascular disease that would preclude participation in training (assessed by the participant's medical practitioner); severe cognitive deficits that would preclude participation in training

Interventions

Treated as outpatients for $3 \times 30$-minute sessions per week for 4 weeks

Treadmill training (EXP): participants walk on a treadmill (no body weight support was provided using a harness) and complete some overground walking training (the proportion of overground training is gradually increased) 
Ada 2003 (Continued)

Sham training (CTL): home-based exercises based on written instructions with weekly telephone contact to review and update the exercises

\begin{tabular}{|c|c|c|}
\hline Outcomes & \multicolumn{2}{|c|}{$\begin{array}{l}\text { Assessed at baseline, after treatment phase and 3-month follow-up: } \\
\text { - independent preferred walking speed over } 10 \mathrm{~m} \text { (barefoot and without gait aids) } \\
\text { - step length and width } \\
\text { - cadence } \\
\text { - walking endurance - maximum distance covered in } 6 \text { minutes using preferred gait aid } \\
\text { - } 30 \text {-item Stroke Adjusted Sickness Impact Profile }\end{array}$} \\
\hline Notes & \multicolumn{2}{|c|}{ Obtained unpublished data by interview and correspondence with the trialists. } \\
\hline \multicolumn{3}{|l|}{ Risk of bias } \\
\hline Bias & Authors' judgement & Support for judgement \\
\hline $\begin{array}{l}\text { Random sequence genera- } \\
\text { tion (selection bias) }\end{array}$ & Low risk & Randomly allocated by coin toss to 1 of 2 groups \\
\hline $\begin{array}{l}\text { Allocation concealment } \\
\text { (selection bias) }\end{array}$ & Low risk & By an investigator independent of recruitment and measurement \\
\hline $\begin{array}{l}\text { Blinding of outcome as- } \\
\text { sessment (detection bias) } \\
\text { All outcomes }\end{array}$ & Low risk & Assessor blinded \\
\hline
\end{tabular}

\section{Ada 2010}

$\begin{array}{ll}\text { Methods } & \text { Parallel-group design } \\ & \text { Concealed randomisation } \\ & \text { Outcome assessor was blinded to group allocation }\end{array}$

Participants Country: Australia

64 participants in the EXP group and 62 participants in the CTL group Inclusion criteria: within 28 days of their first stroke, between 50 and 85 years of age, hemiparesis or hemiplegia clinically diagnosed, and nonambulatory (defined as scoring 0 or 1 on item 5 (walking) of the Motor Assessment Scale for Stroke)

Exclusion criteria: clinically evident brain stem signs, severe cognitive and/or language deficits that precluded them from following instructions, unstable cardiac status or any premorbid conditions that precluded them from rehabilitation

126 stroke participants who were unable to walk were recruited and randomly allocated to an experimental or a control group within 4 weeks of stroke

Interventions

Both the EXP and the CTL groups underwent a maximum of 30 minutes per day of walking practice with assistance from 1 therapist for 5 days per week

EXP group: involved walking on a treadmill supported in a harness: initial body weight support was set so that the knee was within 15 degrees of extension in mid-stance; initial speed of the treadmill was set so that the therapist had time to assist the leg to swing through while maintaining a reasonable step length

CTL group: involved assisted overground walking 
Ada 2010 (Continued)

Outcomes
The primary outcome was the proportion of participants achieving independent walking within 6 months

Independent walking was defined as being able to walk 15 metres overground barefoot without any aids; participants were tested once per week until they achieved independent walking or were discharged from the rehabilitation unit and were tested again at 6 months

Notes MOBILISE trial

\section{Risk of bias}

\begin{tabular}{lll}
\hline Bias & Authors' judgement & Support for judgement \\
\hline $\begin{array}{l}\text { Random sequence genera- } \\
\text { tion (selection bias) }\end{array}$ & Low risk & Random permuted (computer-generated) blocks \\
\hline $\begin{array}{l}\text { Allocation concealment } \\
\text { (selection bias) }\end{array}$ & Low risk & A central office was used \\
\hline $\begin{array}{l}\text { Blinding of outcome as- } \\
\text { sessment (detection bias) } \\
\text { All outcomes }\end{array}$ & Low risk & Assessor was blinded for primary outcome \\
\hline
\end{tabular}

\section{Ada 2013}

\begin{tabular}{ll}
\hline Methods & RCT \\
Method of randomisation: computer-generated \\
Blinding of outcome assessors: stated as 'yes' by the investigator \\
Adverse events: not stated \\
Deaths: none \\
Dropouts: 4 ( 0 in EXP group A, 1 in EXP group B, 3 in CTL group) \\
ITT: yes
\end{tabular}

Country: Australia
Participants
Ambulatory at study onset
Mean age: 63 years; 64 to 70 years (control and EXP groups, respectively)
Inclusion criteria: within 5 years of their first stroke, adults capable of providing consent (defined
as having a MMSE score of $>23$ ), had been discharged from formal rehabilitation, were community
dwelling and walked slowly (defined as being able to walk 10 metres across flat ground in bare feet
without any aids taking more than 9 seconds)
Exclusion criteria: unstable cardiac status precluding them from participation in a treadmill training
program (i.e. permission not granted by their medical practitioner), or had severe cognitive and/or lan-
guage deficits (aphasia) precluding them from participation in the training sessions (i.e. unable to fol-
low 2-step commands)

Interventions 3 arms:

EXP group A undertook 30 minutes of treadmill and overground walking 3 times per week for 4 months

EXP group B undertook treadmill training for 2 months

CTL group had no intervention

\section{Outcomes}

Outcomes were recorded at baseline and after 2, 4, 6 and 12 months

- distance in the 6-Minute Walk Test 
Ada 2013 (Continued)

- walking speed

- step length and cadence

- health status

- community participation

- self efficacy

- falls

Notes
We combined the results of both treadmill groups (EXP group A and EXP group B) as 1 group and com-
pared with the results of the CTL group

\section{Risk of bias}

\begin{tabular}{lll}
\hline Bias & Authors' judgement & Support for judgement \\
\hline $\begin{array}{l}\text { Random sequence genera- } \\
\text { tion (selection bias) }\end{array}$ & Low risk & $\begin{array}{l}\text { Computer-generated, independent and concealed randomisation was used to } \\
\text { assign each participant in this study }\end{array}$ \\
\hline $\begin{array}{l}\text { Allocation concealment } \\
\text { (selection bias) }\end{array}$ & Low risk & Independent and concealed allocation was used \\
\hline $\begin{array}{l}\text { Blinding of outcome as- } \\
\text { sessment (detection bias) } \\
\text { All outcomes }\end{array}$ & Low risk & $\begin{array}{l}\text { Outcome measures were collected by therapists trained in the measurement } \\
\text { procedures who were blind to group allocation }\end{array}$ \\
\hline
\end{tabular}

Bonnyaud 2013

RCT
Methods of randomisation: not mentioned
Blinding of outcome assessors: not stated by the investigator
Adverse events: not stated
Deaths: not stated
Dropouts: not stated
ITT: not stated

Country: France
60 participants (4 groups, division not stated by the author)
Walking ability at study onset not mentioned
Mean age: 50 years (group GO, GOM; GT, GTM)
Inclusion criteria: chronic stroke
Exclusion criteria: not stated by the author

Interventions 4 arms:

GO: overground without a mass once for $20 \mathrm{~min}$ at comfortable speed

GOM: overground with a mass once for $20 \mathrm{~min}$ at comfortable speed 
Bonnyaud 2013 (Continued)

GT: treadmill without a mass once for $20 \mathrm{~min}$ at comfortable speed

GTM: treadmill with a mass once for 20 min at comfortable speed

Outcomes Outcomes were recorded at baseline, immediately after the single training session and after a 20 min
seated rest

- Spatiotemporal parameters: walking speed, cadence and step length

- Kinematic parameters: peak hip and knee flexion and peak ankle dorsiflexion

- Kinetic parameters: braking and propulsion force peaks and the vertical ground

\section{Notes}

\section{Risk of bias}

\begin{tabular}{lll}
\hline Bias & Authors' judgement & Support for judgement \\
\hline $\begin{array}{l}\text { Random sequence genera- } \\
\text { tion (selection bias) }\end{array}$ & Unclear risk & Method not described \\
\hline $\begin{array}{l}\text { Allocation concealment } \\
\text { (selection bias) }\end{array}$ & Unclear risk & Allocation concealment not described \\
\hline $\begin{array}{l}\text { Blinding of outcome as- } \\
\text { sessment (detection bias) } \\
\text { All outcomes }\end{array}$ & High risk & No blinding of assessor was done \\
\hline
\end{tabular}

\section{Bonnyaud 2013a}

Methods
Method of randomisation: not mentioned
Blinding of outcome assessors: not stated by the investigator
Adverse events: not stated
Deaths: not stated
Dropouts: not stated
ITT: not stated

\section{Participants}

\section{Country: France}

26 participants (2 groups, division not stated by the author), ambulatory at study onset

Mean age: 50 years (group GO and GT)

Inclusion criteria: age greater than 18 years, hemiparesis caused by a single hemispheric stroke, ability to walk 20 minutes without a break and without an assistive device

Exclusion criteria: any comorbid disability other than stroke, such as any visual impairment or musculoskeletal, cardiovascular, or other disorder that would interfere with the study

Interventions 2 arms:

GO: single overground gait-training for $20 \mathrm{~min}$ in a corridor at comfortable speed 
Bonnyaud 2013a (Continued)

GT: single treadmill gait-training for $20 \mathrm{~min}$ at comfortable speed

Outcomes Outcomes were recorded at baseline, immediately after the end of the session and 20 minutes after the end of the session

- spatio temporal parameters: walking speed, cadence, step length, and the percentage of the gait cycle spent in single support phase

- kinematic joint parameters: peak hip and knee flexion and extension and peak ankle dorsiflexion and plantar flexion

\section{Notes}

\section{Risk of bias}

\begin{tabular}{lll}
\hline Bias & Authors' judgement & Support for judgement \\
\hline $\begin{array}{l}\text { Random sequence genera- } \\
\text { tion (selection bias) }\end{array}$ & Unclear risk & method not described \\
\hline $\begin{array}{l}\text { Allocation concealment } \\
\text { (selection bias) }\end{array}$ & Unclear risk & allocation concealment not described \\
\hline $\begin{array}{l}\text { Blinding of outcome as- } \\
\text { sessment (detection bias) } \\
\text { All outcomes }\end{array}$ & High risk & no blinding of assessor was done \\
\hline
\end{tabular}

Combs-Miller 2014

$\begin{array}{ll}\text { Methods } & \text { RCT } \\ \text { Method of randomisation: drawing sealed envelopes } \\ \text { Blinding of outcome assessors: stated as 'yes' by the investigator } \\ \text { Adverse events: not stated } \\ \text { Deaths: not stated } \\ \text { Dropouts: } 2 \text { (0 in group BWSTT, } 2 \text { in group OWT at 3-month follow-up) } \\ \text { ITT: yes }\end{array}$

Country: USA
20 participants (10 in group BWSTT, 10 in group OWT)
Ambulatory at study onset
Mean age: 61 years (56 years BWSTT, 66 years OWT)
Inclusion criteria: minimum of six months post ischaemic or haemorrhagic stroke; age between 21 and
80 years; community dwelling; able to walk with or without an assistive device or orthosis at a self-se-
lected gait speed of < $1.0 \mathrm{~m} / \mathrm{s}$ over 10 m; medically stable with physician release; able to follow two-
step verbal instructions
Exclusion criteria: currently in physical therapy; health conditions prohibiting exercise or influencing
walking ability

\begin{tabular}{ll}
\hline Interventions & arms: \\
& BWSTT group undertook 30 minutes of treadmill training with systematically less body weight support \\
& (start at 30\%), 5 times per week for 2 weeks \\
& OWT group B undertook overground walking training at fast speed, 5 times per week for 2 weeks
\end{tabular}

Outcomes were recorded at baseline and immediately after, and three months following the interven-
tion
- distance in the 6-Minute Walk Test
- $10 \mathrm{~m}$ walking speed


Combs-Miller 2014 (Continued)

- spatio temporal symmetry

- ICF Measure of Participation and ACTivity

Notes

Risk of bias

\begin{tabular}{lll}
\hline Bias & Authors' judgement & Support for judgement \\
\hline $\begin{array}{l}\text { Random sequence genera- } \\
\text { tion (selection bias) }\end{array}$ & Unclear risk & Method for randomisation not clearly described \\
\hline $\begin{array}{l}\text { Allocation concealment } \\
\text { (selection bias) }\end{array}$ & Low risk & $\begin{array}{l}\text { Sealed envelopes as method for allocation concealment after baseline assess- } \\
\text { ment }\end{array}$ \\
\hline $\begin{array}{l}\text { Blinding of outcome as- } \\
\text { sessment (detection bias) } \\
\text { All outcomes }\end{array}$ & Low risk & Blinding of assessor was provided \\
\hline
\end{tabular}

Da Cunha Filho 2002

$\begin{array}{ll}\text { Methods } & \text { Parallel-group design } \\ \text { Participants randomised to groups using a random number table } \\ \text { Allocation to groups was not concealed } \\ 13 \% \text { dropouts at the end of the treatment phase } \\ \text { Outcome assessors were not blinded to group allocation }\end{array}$

7 participants in the EXP group and 8 participants in the CTL group
Inclusion criteria: less than 6 weeks post-stroke; hemiparetic stroke based on clinical examination or
MRI, or both; significant gait deficit - speed of no more than $36 \mathrm{~m} / \mathrm{min}$ or FAC 0 to 2 (that is, needs assis-
tance); sufficient cognition to participate in training (at least 21 on the MMSE); ability to stand and take
at least 1 step with or without assistance; informed consent
Exclusion criteria: any comorbidity or disability other than hemiparesis that would preclude gait-train-
ing; recent myocardial infarction; any uncontrolled health condition for which exercise is contraindicat-
ed (e.g. diabetes); severe lower extremity joint disease or rheumatoid arthritis that would interfere with
gait-training; obesity (mass more than $110 \mathrm{~kg}$ )

Interventions Treated as inpatients for $5 \times 20$-minute sessions per week for 2 to 3 weeks BWSTT (EXP): participants walked on a treadmill with up to $30 \%$ of their body weight supported using a harness Regular gait-training (CTL): strengthening, functional and mobility activities

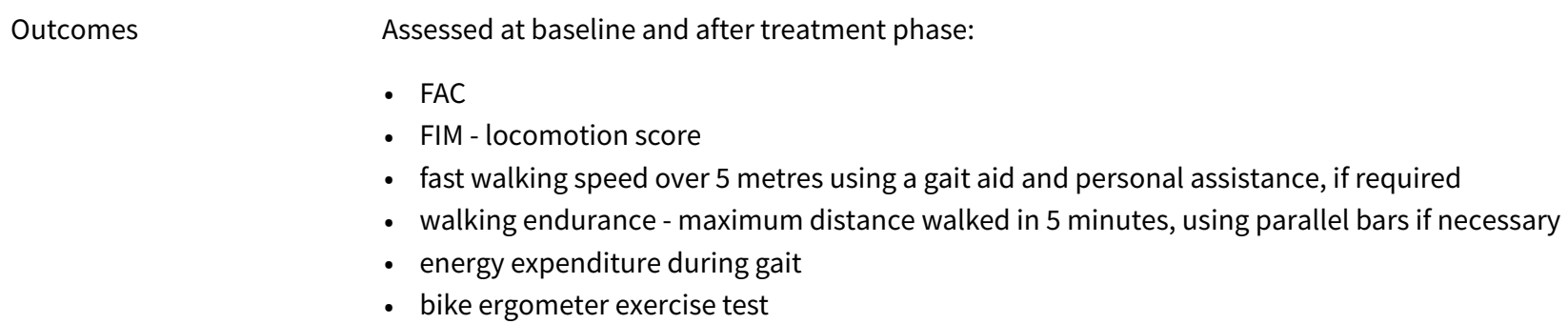

- bike ergometer exercise test

\section{Risk of bias}


Da Cunha Filho 2002 (Continued)

\section{Bias \\ Authors' judgement Support for judgement}

Random sequence genera- Low risk Random number table

tion (selection bias)

$\begin{aligned} & \text { Allocation concealment } \\ & \text { (selection bias) }\end{aligned}$
High risk Inadequate (based on correspondence from the investigator)

(selection bias)

Blinding of outcome as-

High risk

Not blinded (based on correspondence from the investigator)

sessment (detection bias)

All outcomes

Deniz 2011

\begin{tabular}{ll}
\hline Methods & RCT \\
& Method of randomisation: not described \\
& Blinding of outcome assessors: yes \\
& Adverse events: not stated \\
& Deaths: none \\
Dropouts: none \\
ITT:yes
\end{tabular}

Country: Turkey
Participants
Amburticipants (10 in EXP group, 10 in CTL group)
Mean age: 62 years (CTL and EXP groups respectively)
Inclusion criteria: ischaemic or haemorrhagic stroke prior 6 weeks to study enrolment, confirmed by
MRI, MMSE score $\geq 21$, supported or independent 1-minute free-standing, significant loss of ambulation
(FAC $<3$ )
Exclusion criteria: recurrent stroke interfering with the study, severe contractures of the lower ex-
tremity joints, severe cardiac conditions, uncontrolled diabetes mellitus, Parkinson's Disease, current
thrombosis in the legs, aphasia, depression and body weight $>110 \mathrm{~kg}$

\begin{tabular}{ll}
\hline Interventions & 2 arms: \\
& CTL group used general physiotherapy, 5 times per week for 4 weeks ( 300 minutes a week) \\
& EXP group received BWSTT, 5 times per week for 4 weeks ( 300 minutes a week)
\end{tabular}

Outcomes

Outcomes were recorded at baseline, at the end of the intervention phase and at 3-month follow-up FAC, Rivermead Motor Evaluation Gross (RMD1) and total gross function (RMD2), Berg Balance Scale, Barthel Index, walking capacity (6-Minute Walk Test), walking speed (10 metre walk), cadence rate, ratios of right-left step length, muscle activity (EMG)

Notes

Risk of bias

\begin{tabular}{lll}
\hline Bias & Authors' judgement & Support for judgement \\
\hline $\begin{array}{l}\text { Random sequence genera- } \\
\text { tion (selection bias) }\end{array}$ & Unclear risk & Not reported \\
\hline $\begin{array}{l}\text { Allocation concealment } \\
\text { (selection bias) }\end{array}$ & Unclear risk & Not reported \\
\hline $\begin{array}{l}\text { Blinding of outcome as- } \\
\text { sessment (detection bias) }\end{array}$ & Unclear risk & Not reported \\
\hline
\end{tabular}


Deniz 2011 (Continued)

All outcomes

DePaul 2015

RCT
Method of randomisation: permuted block randomisation schedule
Blinding of outcome assessors: stated as 'yes' by the investigator
Adverse events: one or more falls (11 participants in the MLWP and 10 participants in the BWSTT group
had 1 fall;
2 in the MLWP and 4 in the BWSTT group reported multiple falls); new stroke: 3 in MLWP, 1 in BWSTT;
cardiac event: 2 in the BWSTT group
Deaths: 4 ( 2 in the MLWP, 2 in the BWSTT)
Dropouts: 4 ( 0 in EXP group A, 1 in EXP group B, 3 in CTL group)
ITT:yes

Country: Canada
70 participants ( 35 in MLWP, 35 in BWSTT)
Ambulatory at study onset
Mean age: 68 years; (MLWP 66 years, BWSTT 69 years)
Inclusion criteria: $\geq 40$ years old, living in the community, $<12$ months since onset of Ischaemic or
haemorrhagic stroke, able to walk $10 \mathrm{~m}$ without assistance (gait aid allowed), able to follow a 2 -step
verbal command, and independent community ambulation prior to stroke
Exclusion criteria: cognitive impairment (i.e. MMSE score less than age and education norms); severe
visual impairment; lower-extremity amputation; unstable cardiac, medical, or musculoskeletal condi-
tions that would limit treatment participation (determined by physician screening and baseline inter-
view); comfortable gait speed $>1.0 \mathrm{~m} / \mathrm{s}$ without a gait aid

Interventions 2 arms:

1. MLWP group undertook a Motor Learning Walking Program and practiced various overground walking tasks for 40 minutes, 15 sessions over 5 weeks

2. BWSTT group undertook a Body-Weight-Supported Treadmill Training for 30 minutes, 15 sessions over 5 weeks

Outcomes were recorded at 1 week prior to initiating training, within 1 week following completion of
training and 2 months after training
- 5 -m Walk Test (maximum pace)
- 6-Minute Walk Test
- the Functional Balance Test (FBT)
- Activities-specific Balance Confidence Scale
- modified Functional Ambulation Categories
- Stroke Impact Scale
- Life Space Assessment

\section{Notes}

\section{Risk of bias}

\begin{tabular}{lll}
\hline Bias & Authors' judgement & Support for judgement \\
\hline $\begin{array}{l}\text { Random sequence genera- } \\
\text { tion (selection bias) }\end{array}$ & Low risk & Central randomisation \\
\hline $\begin{array}{l}\text { Allocation concealment } \\
\text { (selection bias) }\end{array}$ & Low risk & Central assignment \\
\hline \hline
\end{tabular}


DePaul 2015 (Continued)

Blinding of outcome as- Low risk Blinded physical therapist sessment (detection bias)

All outcomes

Du 2006

RCT, parallel-group design
Method of randomisation: random number table
Allocation concealment: unclear
Blinding of outcome assessors: not stated by the authors
Adverse events: not stated by the authors
Deaths: not stated by the authors
Dropouts: not stated by the authors
ITT: unclear

Country: China
Participants
Ambulatory at study onset: $26 / 61$ participants (43\%) of the EXP group and 22/67 participants (33\%) of
the CTL group
Mean age: 58 to 56 years (CTL and EXP groups, respectively)
Inclusion criteria: $\leq 3$ months after stroke, stable stroke, Brunnstrom stage $\geq 2$
Exclusion criteria: severe cognitive dysfunction, acute myocardial infarction, unstable angina pectoris,
other severe medical conditions of the inner organs

Interventions
CTL group used conventional treatment techniques, 2 times per day for 4 weeks
EXP group used BWSTT in addition to the same training as in the CTL group for the same time and fre-
quency

$\begin{array}{ll}\text { Outcomes } & \text { Outcomes were recorded at baseline and after the end of the intervention phase: } \\ \text { - walking ability (FAC) } \\ \text { - lower limb function (FMA) } \\ \text { - activities in daily living (FIM) }\end{array}$

Notes

\section{Risk of bias}

\begin{tabular}{lll}
\hline Bias & Authors' judgement & Support for judgement \\
\hline $\begin{array}{l}\text { Random sequence genera- } \\
\text { tion (selection bias) }\end{array}$ & Low risk & Random number table \\
\hline $\begin{array}{l}\text { Allocation concealment } \\
\text { (selection bias) }\end{array}$ & High risk & To be confirmed \\
\hline $\begin{array}{l}\text { Blinding of outcome as- } \\
\text { sessment (detection bias) } \\
\text { All outcomes }\end{array}$ & High risk & To be confirmed \\
\hline
\end{tabular}

Duncan 2011

Methods Parallel-group design


Duncan 2011 (Continued)

Participants were randomised to 3 groups using a stratified randomisation procedure

Allocation to groups was concealed

$11.5 \%$ dropouts at the end of the treatment phase

Outcome assessors were not rigorously blinded to group allocation

Country: USA
$\begin{aligned} & \text { Participants participants } \\ & \text { Inclusion criteria: age of } 18 \text { years or older, a stroke within } 45 \text { days before study entry and the ability to } \\ & \text { undergo randomisation within } 2 \text { months after the stroke, residual paresis in the leg affected by stroke, } \\ & \text { the ability to walk } 3 \text { metres with assistance from no more than } 1 \text { person and the ability to follow a 3- } \\ & \text { step command, the treating physician's approval of participation in the study, a self-selected speed for } \\ & \text { walking } 10 \text { metres of less than } 0.8 \text { m per second, and residence in the community by the time of ran- } \\ & \text { domisation } \\ & \text { Exclusion criteria: dependency on assistance in activities of daily living before the stroke, contraindica- } \\ & \text { tions to exercise, pre-existing neurologic disorders, and inability to travel to the treatment site }\end{aligned}$

Interventions

3 groups:

Group 1 (EXP) received training on a treadmill with the use of BWS 2 months after the stroke had occurred (early locomotor training)

Group 2 (EXP) received this training 6 months after the stroke had occurred (late locomotor training)

Group 3 (CTL) participated in an exercise program at home managed by a physical therapist 2 months after the stroke (home-exercise program)

Each intervention included 36 sessions of 90 minutes each for 12 to 16 weeks

\begin{tabular}{|c|c|c|}
\hline Outcomes & \multirow{2}{*}{\multicolumn{2}{|c|}{$\begin{array}{l}\text { The primary outcome was the proportion of participants in each group who had an improvement in } \\
\text { functional walking ability } 1 \text { year after the stroke } \\
\text { Further outcomes were: walking speed; distance walked in } 6 \text { minutes; number of steps walked per day; } \\
\text { Stroke Impact Scale; FMA legs; Berg Balance Scale; Specific Balance Confidence score }\end{array}$}} \\
\hline & & \\
\hline Notes & \multicolumn{2}{|c|}{$\begin{array}{l}\text { We combined the results of both EXP groups (Group } 1 \text { and Group } 2 \text { ) as } 1 \text { group and compared them } \\
\text { with the results of the CTL group (Group } 3 \text { ) }\end{array}$} \\
\hline \multicolumn{3}{|l|}{ Risk of bias } \\
\hline Bias & Authors' judgement & Support for judgement \\
\hline $\begin{array}{l}\text { Random sequence genera- } \\
\text { tion (selection bias) }\end{array}$ & Unclear risk & $\begin{array}{l}\text { Authors reported that participants were randomly assigned to } 1 \text { of } 3 \\
\text { groups. Authors described a stratified randomisation procedure in ratios of } \\
\text { 140:120:120 stratified by severity. The method of randomisation generation } \\
\text { was, however, not described }\end{array}$ \\
\hline $\begin{array}{l}\text { Allocation concealment } \\
\text { (selection bias) }\end{array}$ & Low risk & $\begin{array}{l}\text { The method of allocation concealment was described as: "The study coordina- } \\
\text { tor registers the patient, enters the baseline data into the web based database } \\
\text { system, and then obtains group assignment from the data management and } \\
\text { analysis center." }\end{array}$ \\
\hline
\end{tabular}

Blinding of outcome as-
sessment (detection bias) $\quad$ High risk Per diem therapists did the assessments

All outcomes 
Eich 2004

\begin{tabular}{|c|c|}
\hline Methods & $\begin{array}{l}\text { Parallel-group design } \\
\text { Concealed randomisation of participants to groups by having a person independent of the study ask- } \\
\text { ing the participant to draw a sealed opaque envelope from a box (each envelope contained the group } \\
\text { allocation and there were } 25 \text { EXP and } 25 \text { CTL envelopes) } \\
0 \% \text { dropouts at the end of treatment and } 2 \% \text { dropouts at the end of the follow-up phase } \\
\text { Outcome assessors were blinded to group allocation }\end{array}$ \\
\hline Participants & $\begin{array}{l}25 \text { participants in the EXP group, and } 25 \text { participants in the CTL group } \\
\text { Inclusion criteria: first time supratentorial stroke; less than } 6 \text { weeks post-stroke; aged } 50 \text { to } 75 \text { years; } \\
\text { scores } 50 \text { to } 80 \text { on } 100 \text {-point Barthel Index; able to walk a minimum distance of } 12 \text { metres with either } \\
\text { intermittent help or stand-by assistance; cardiovascular stable; participation in a } 12 \text {-week comprehen- } \\
\text { sive rehabilitation program; no other neurologic or orthopaedic disease impairing walking; able to un- } \\
\text { derstand the purpose and content of the study; written consent }\end{array}$ \\
\hline Interventions & $\begin{array}{l}\text { Treated as inpatients for } 5 \times 30 \text {-minute sessions per week for } 6 \text { weeks } \\
\text { TTBWS (EXP): participants walked on a treadmill with up to } 15 \% \text { of their body weight supported using } \\
\text { a harness; the slope and speed of the treadmill were adjusted to achieve a training heart rate } \\
\text { Regular gait-training (CTL): tone-inhibiting and gait preparatory manoeuvres and walking practice on } \\
\text { the floor and stairs based on Bobath (non-task-oriented 'neurophysiological') }\end{array}$ \\
\hline Outcomes & $\begin{array}{l}\text { Assessed at baseline, after treatment phase, and } 3 \text { months later: } \\
\text { - fast walking speed over } 10 \text { metres with or without a gait aid (supervision and personal assistance was } \\
\text { provided, if required) } \\
\text { - walking endurance - maximum distance walked in } 6 \text { minutes without rest stops, the test was termi- } \\
\text { nated if the participant needed to stop and rest, with or without a gait aid (use of supervision and } \\
\text { personal assistance not reported) } \\
\text { - walking ability using the Rivermead Motor Assessment scale (13-point scale) } \\
\text { - walking quality using an adapted checklist from Los Ranchos Los Amigos Gait Analysis Handbook (41- } \\
\text { point scale) }\end{array}$ \\
\hline
\end{tabular}

Notes

Method of randomisation and the allocation concealment classification were changed based on correspondence from the trialist

\section{Risk of bias}

\begin{tabular}{lll}
\hline Bias & Authors' judgement & Support for judgement \\
\hline $\begin{array}{l}\text { Random sequence genera- } \\
\text { tion (selection bias) }\end{array}$ & Low risk & Using sealed envelopes \\
\hline $\begin{array}{l}\text { Allocation concealment } \\
\text { (selection bias) }\end{array}$ & Low risk & Using sealed envelopes chosen by an independent person \\
\hline $\begin{array}{l}\text { Blinding of outcome as- } \\
\text { sessment (detection bias) } \\
\text { All outcomes }\end{array}$ & Unclear risk & $\begin{array}{l}\text { The primary outcomes were not blinded; the secondary outcomes of walking } \\
\text { ability (Rivermead Motor Assessment scale) and walking quality were blinded }\end{array}$ \\
\hline
\end{tabular}

Franceschini 2009

$\begin{array}{ll}\text { Methods } & \text { RCT } \\ & \text { Method of randomisation: software-generated } \\ & \text { Blinding of outcome assessors: stated as 'yes' by the trialists } \\ & \text { Adverse events: not stated } \\ & \text { Dropouts: } 20 \text { (10 in EXP group, } 10 \text { in CTL group) }\end{array}$


Franceschini 2009 (Continued)

\section{ITT: unclear}

Country: Italy
102 participants (52 in EXP group, 50 in CTL group)
Not ambulatory at study onset
Mean age: 66 to 71 years (CTL and EXP group, respectively)
Inclusion criteria: within 45 days of the onset of hemiparesis caused by right or left ischaemic or haem-
orrhagic stroke, able to control the sitting position on a rigid plane surface with the legs hanging freely
and without the help of the arms for at least 30 seconds; able to control the trunk in the upright po-
sition even with the help of the upper extremities gripping a fixed support or other aid (cane, tripod);
without lower limb spasticity (Ashworth scale 1 ), in stable cardiovascular condition with a low, al-
though slightly greater, risk for vigorous exercise than apparently healthy persons (Class B according to
the American College of Sports Medicine)
Exclusion criteria: significant disability before stroke (modified Rankin Scale 2); significant pre stroke
gait disability (Walking Handicap scale 2) and mild gait impairment at time of enrolment (ability to walk
without aids for at least 3 metres and to walk for more than 6 metres with the aid of a cane or tripod);
participants having done previous treadmill training and/or with a Class C or D exercise risk according
to the American College of Sports Medicine criteria or Class III or IV in the New York Heart Association
classification system; participants with orthopaedic or other disorders causing a gait limitation before
stroke onset
Participants who did not complete the treatment (EXP or CTL) within 5 weeks of study inclusion were
excluded from the analysis

Interventions EXP group received conventional rehabilitative treatment plus gait-training with BWS on a treadmill

CTL group received conventional treatment with overground gait-training only

All participants were treated in 60-minute sessions every weekday for 4 weeks

\begin{tabular}{|c|c|c|}
\hline Outcomes & \multicolumn{2}{|c|}{$\begin{array}{l}\text { Outcome measures were: } \\
\text { - Motricity Index } \\
\text { - Trunk Control test } \\
\text { - Barthel Index } \\
\text { - FAC } \\
\text { - } 10 \text {-metre and 6-Minute Walk Test } \\
\text { - Walking Handicap Scale } \\
\text { Assessments were done at baseline, after } 20 \text { sessions of treatment, } 2 \text { weeks after treatment, and } 6 \\
\text { months after stroke }\end{array}$} \\
\hline \multicolumn{3}{|l|}{ Notes } \\
\hline \multicolumn{3}{|l|}{ Risk of bias } \\
\hline Bias & Authors' judgement & Support for judgement \\
\hline $\begin{array}{l}\text { Random sequence genera- } \\
\text { tion (selection bias) }\end{array}$ & Low risk & $\begin{array}{l}\text { Randomisation scheme was generated by custom-made software that used } \\
\text { the Lehmer algorithm }\end{array}$ \\
\hline $\begin{array}{l}\text { Allocation concealment } \\
\text { (selection bias) }\end{array}$ & Unclear risk & Allocation concealment was not described \\
\hline $\begin{array}{l}\text { Blinding of outcome as- } \\
\text { sessment (detection bias) } \\
\text { All outcomes }\end{array}$ & Low risk & $\begin{array}{l}\text { Assessments were done by therapists and physicians not involved in the treat- } \\
\text { ment of the participant }\end{array}$ \\
\hline
\end{tabular}


Gama 2017

\begin{tabular}{|c|c|}
\hline Methods & $\begin{array}{l}\text { Parallel-group design } \\
\text { Concealment of randomisation unclear } \\
\text { Outcome assessor was not blinded to group allocation }\end{array}$ \\
\hline \multirow[t]{4}{*}{ Participants } & Country: Brazil \\
\hline & $\begin{array}{l}16 \text { participants in the EXP group and } 16 \text { participants in the CTL group } \\
\text { Inclusion criteria: chronic hemiparetic gait after an ischaemic or hemorrhagic stroke, }>6 \text { months from } \\
\text { the stroke event, absence of cardiac (or medical clearance for participation), orthopaedic, or pul- } \\
\text { monary disease or other neurologic impairment that could compromise gait or training, ability to fol- } \\
\text { low } 2 \text {-step verbal commands, and ability to walk } 10 \mathrm{~m} \text { with or without assistance }\end{array}$ \\
\hline & Exclusion criteria: uncontrolled blood pressure \\
\hline & $\begin{array}{l}32 \text { participants after chronic stroke who were able to walk were recruited and randomly allocated to an } \\
\text { experimental or a control group }\end{array}$ \\
\hline \multirow[t]{3}{*}{ Interventions } & $\begin{array}{l}\text { Both the EXP and the CTL groups underwent a maximum of } 45 \text { minutes per day of walking practice with } \\
\text { assistance from } 1 \text { therapist for } 3 \text { days per week, for } 6 \text { weeks ( } 18 \text { sessions) }\end{array}$ \\
\hline & EXP group: involved walking on a treadmill supported in a harness with BWS \\
\hline & CTL group: involved assisted overground walking with BWS \\
\hline \multirow[t]{5}{*}{ Outcomes } & $\begin{array}{l}\text { Time points: } 1 \text { week before training, } 1 \text { week after the last training, and at follow-up } 6 \text { weeks after last } \\
\text { training }\end{array}$ \\
\hline & Outcomes: \\
\hline & - $10 \mathrm{~m}$ walking velocity \\
\hline & - 6 minutes Walking distance \\
\hline & - FIM \\
\hline
\end{tabular}

Notes

\section{Risk of bias}

\begin{tabular}{lll}
\hline Bias & Authors' judgement & Support for judgement \\
\hline $\begin{array}{l}\text { Random sequence genera- } \\
\text { tion (selection bias) }\end{array}$ & Low risk & Computer-based sequence \\
\hline $\begin{array}{l}\text { Allocation concealment } \\
\text { (selection bias) }\end{array}$ & Unclear risk & Not described \\
\hline $\begin{array}{l}\text { Blinding of outcome as- } \\
\text { sessment (detection bias) } \\
\text { All outcomes }\end{array}$ & High risk & Described as not done \\
\hline
\end{tabular}

Gan 2012

$\begin{array}{ll}\text { Methods } & \text { RCT } \\ & \text { Method of randomisation: not stated } \\ & \text { Blinding of outcome assessors: unclear } \\ & \text { Adverse events: not stated } \\ & \text { Deaths: not stated } \\ & \text { Dropouts: unclear }\end{array}$


Gan 2012 (Continued)

$$
\text { ITT: unclear }
$$

\begin{tabular}{ll}
\hline Participants & Country: Philippines \\
& 205 participants (102 in EXP group, 103 in CTL group) \\
& Ambulatory status at study onset: unclear \\
& Mean age: unclear \\
Inclusion criteria: unclear \\
Exclusion criteria: unclear
\end{tabular}

Interventions

Interventions: either to BWS supported overground gait-training or BWS supported treadmill training group

BWS was provided by using an overhead harness system with up to $40 \%$ of their BWS at the beginning of the training

Treadmill speed in the BWS-treadmill group was initially started at $0.5 \mathrm{mph}$

Progression was accomplished by decreasing percentage of BWS or increasing treadmill speed based on gait pattern and endurance

Outcomes $\quad$ Main outcome measures: study outcome measures included:
- balance using the Berg Balance Scale
- cadence
- 10 -metre walking
- speed

Notes Only published as abstract

\section{Risk of bias}

\begin{tabular}{lll}
\hline Bias & Authors' judgement & Support for judgement \\
\hline $\begin{array}{l}\text { Random sequence genera- } \\
\text { tion (selection bias) }\end{array}$ & Unclear risk & Method of random sequence generation not described \\
\hline $\begin{array}{l}\text { Allocation concealment } \\
\text { (selection bias) }\end{array}$ & Unclear risk & Method of allocation concealment not described \\
\hline $\begin{array}{l}\text { Blinding of outcome as- } \\
\text { sessment (detection bias) } \\
\text { All outcomes }\end{array}$ & Unclear risk & Method of blinding not described \\
\hline
\end{tabular}

Globas 2011

\begin{tabular}{ll}
\hline Methods & RCT \\
& Method of randomisation: computer-based \\
& Blinding of outcome assessors: not blinded \\
Adverse events: 1 recurrent stroke (EXP group) \\
Dropouts: 2 (2 in EXP group, 0 in CTL group) \\
ITT: stated by the trialists \\
\hline Participants & $\begin{array}{l}\text { Country: Switzerland and Germany } \\
\text { Ambulatory at study onset } \\
\text { Mean age: } 69 \text { years (both CTL and EXP groups) }\end{array}$ \\
\hline
\end{tabular}


Globas 2011 (Continued)

Inclusion criteria: hemiparetic gait as evaluated by a neurologist with at least 1 clinical sign for paresis, spasticity or circumduction of the affected leg while walking, and the ability to walk on the treadmill at $\geq 0.3 \mathrm{~km} /$ hour for 3 minutes with handrail support

Exclusion criteria: unstable angina pectoris, heart failure (New York Health Association $>1 I^{\circ}$ ), haemodynamically significant valvular dysfunction, peripheral arterial occlusive disease, dementia (MMSE <20), aphasia (unable to follow 2 commands), major depression (CES-D > 16), and other medical conditions precluding participation in aerobic exercise, as well as participants already performing aerobic exercise training for $>20$ minutes per day and $>1$ day per week

\begin{tabular}{ll}
\hline Interventions & $\begin{array}{l}3 \text { months (3 times per week) progressive graded, high-intensity aerobic treadmill exercise (TAEX) or } \\
\text { conventional care physiotherapy }\end{array}$ \\
\hline Outcomes & peak VO ${ }_{2}$ during maximum effort treadmill walking \\
- walking ability measured in 6-minute walks \\
- 10 -Metre Walk Test at comfortable (self-selected) and maximum walking speeds \\
- functional leg strength, the 5-Chair-Rise (5CR) \\
- Berg Balance Scale \\
- self rated mobility and activities for daily living function assessed by the Rivermead Mobility Index \\
(RMI) \\
- physical and mental health measured by the Medical Outcomes Study Short-Form 12 (SF-12)
\end{tabular}

Notes

\section{Risk of bias}

\begin{tabular}{lll}
\hline Bias & Authors' judgement & Support for judgement \\
\hline $\begin{array}{l}\text { Random sequence genera- } \\
\text { tion (selection bias) }\end{array}$ & Low risk & $\begin{array}{l}\text { A computer-based pseudo random number generator and the Moses-Oakford } \\
\text { assignment algorithm were used to develop the randomisation schedule }\end{array}$ \\
\hline
\end{tabular}

\begin{tabular}{|c|c|c|}
\hline $\begin{array}{l}\text { Allocation concealment } \\
\text { (selection bias) }\end{array}$ & Low risk & $\begin{array}{l}\text { The procedure was performed by independent study staff at the Department } \\
\text { of Biostatistics, University of Ulm, Germany }\end{array}$ \\
\hline
\end{tabular}

\begin{tabular}{|c|c|c|}
\hline $\begin{array}{l}\text { Blinding of outcome as- } \\
\text { sessment (detection bias) } \\
\text { All outcomes }\end{array}$ & High risk & No blinding of outcomes was done \\
\hline
\end{tabular}

Hoyer 2012

\begin{tabular}{|c|c|}
\hline Methods & $\begin{array}{l}\text { RCT } \\
\text { Method of randomisation: computer-based } \\
\text { Blinding of outcome assessors: yes } \\
\text { Adverse events: not described } \\
\text { Dropouts: } 0 \\
\text { ITT: not stated by the trialists, probably done because no dropouts were reported }\end{array}$ \\
\hline Participants & $\begin{array}{l}\text { Country: Norway } \\
60 \text { participants ( } 30 \text { in EXP group, } 30 \text { in CTL group) } \\
\text { Not ambulatory at study onset } \\
\text { Mean age: } 52 \text { years (both groups) } \\
\text { Inclusion criteria: admission for a primary rehabilitation stay, mainly < } 6 \text { months after onset of stroke, } \\
\text { use of wheelchair, dependent on assistance for walking with or without walking aids, medically stable, } \\
\text { no neurological or orthopaedic contraindications for walking, and sufficient cognitive capacity to un- } \\
\text { derstand information and instructions }\end{array}$ \\
\hline
\end{tabular}


Hoyer 2012 (Continued)

Exclusion criteria: the participants' need of assistance should not be beyond 1 person for shorter transfer and for taking some steps overground

\begin{tabular}{|c|c|}
\hline Interventions & $\begin{array}{l}2 \text { arms: } \\
\text { Traditional gait-training or treadmill therapy } \\
\text { In the traditional gait-training group, intensive gait-training ( } 30 \text { minutes) and functional training ( } 30 \\
\text { minutes) daily for minimum of } 10 \text { weeks was conducted } \\
\text { In the treadmill therapy, participants walked on a motorised, raised treadmill, secured by a harness } \\
\text { combined with a suspension system releasing body weight; this group received } 30 \text { sessions of TTBWS, } \\
\text { plus conventional gait-training and other functional training for a minimum period of } 10 \text { weeks; TTBWS } \\
\text { was conducted daily for the first } 4 \text { weeks ( } 20 \text { sessions), and then } 1 \text { to } 2 \text { times a week ( } 10 \text { sessions) for } \\
\text { the remaining } 6 \text { weeks; on days without TTBWS, conventional gait-training was conducted; each tread- } \\
\text { mill session lasted for } 30 \text { minutes, including necessary pauses, but excluding equipment preparation } \\
\text { Time for daily training ( } 5 \text { days a week) was the same in the } 2 \text { intervention groups, } 30 \text { minutes for walk- } \\
\text { ing and } 30 \text { minutes for other functional training, including selective training of the trunk and extremi- } \\
\text { ties, balance and transfer, customised to individual deficits and needs } \\
\text { Additional self training, individually or by the staff, was allowed }\end{array}$ \\
\hline
\end{tabular}

\section{Outcomes}

Outcomes were recorded at baseline, after 4 to 6 weeks, and after 10 to 12 weeks

Primary outcomes: walking ability (FAC and EU-walking scale)

Secondary outcomes: walking velocity and steps, walking endurance

Notes

\section{Risk of bias}

\begin{tabular}{lll}
\hline Bias & Authors' judgement & Support for judgement \\
\hline $\begin{array}{l}\text { Random sequence genera- } \\
\text { tion (selection bias) }\end{array}$ & Low risk & 60 numbers concealed in envelopes were prepared by an external statistician \\
\hline $\begin{array}{l}\text { Allocation concealment } \\
\text { (selection bias) }\end{array}$ & Unclear risk & Not described, probably done because concealed envelopes were used \\
\hline $\begin{array}{l}\text { Blinding of outcome as- } \\
\text { sessment (detection bias) } \\
\text { All outcomes }\end{array}$ & Low risk & $\begin{array}{l}\text { A pool of 8 experienced assessors blinded to group allocation were involved in } \\
\text { testing }\end{array}$ \\
\hline
\end{tabular}

Jaffe 2004

\begin{tabular}{ll} 
Methods & $\begin{array}{l}\text { Parallel-group design } \\
\text { Concealed randomisation of participants to groups by using an Excel spreadsheet with group alloca- } \\
\text { tion masked using black cells } \\
15 \% \text { dropouts at the end of the treatment phase and } 15 \% \text { dropouts at the end of the 2-week follow-up } \\
\text { Blinding of outcome assessors to group allocation }\end{array}$ \\
\hline Participants & 11 participants in the EXP group and 12 participants in the CTL group \\
Inclusion criteria: at least 6 months post-stroke; hemiplegia secondary to documented lesion; able to \\
walk independently or with stand-by supervision (with or without a gait aid); asymmetric gait pattern \\
and short step length; 'average' or 'minimal impairment' in all Cognistat test categories; informed con- \\
sent \\
Exclusion criteria: any medical condition that would prevent participation in a training program; in- \\
ability to follow instructions
\end{tabular}


Jaffe 2004 (Continued)

Interventions
Treated as outpatients for $6 \times 1$-hour sessions per week for 2 weeks

Virtual reality and treadmill training (EXP): participants practiced stepping over virtual objects while walking on a treadmill, with a harness to prevent falls (each session consisted of 12 trials of stepping over 10 obstacles)

Overground training (CTL): participants practiced stepping over real objects while walking overground, with a gait belt for safety (each session consisted of 12 trials of stepping over 10 obstacles; task-oriented)

\begin{tabular}{ll}
\hline Outcomes & Assessed at baseline, after treatment phase, and 2 weeks later: \\
- independent preferred walking speed over $6 \mathrm{~m}$ with or without a gait aid (supervision, but not personal \\
assistance, was provided) \\
- independent fast walking speed over $6 \mathrm{~m}$ with or without a gait aid (supervision, but not personal \\
assistance, was provided) \\
- walking endurance - maximum distance walked in 6 minutes with or without a gait aid (supervision, \\
but not personal assistance, was provided) \\
- spatial and temporal gait variables \\
ability to clear obstacles \\
Rotes \\
Ricating of concealed allocation, assessor blinding and dropouts, and the allocation concealment classi- \\
\hline
\end{tabular}

\section{Risk of bias}

Bias Authors' judgement Support for judgement

Random sequence genera- Unclear risk Method not described

tion (selection bias)

$\begin{aligned} & \text { Allocation concealment } \\ & \text { (selection bias) }\end{aligned}$
Unclear risk Unclear concealed randomisation

Blinding of outcome as- Low risk Blinding of outcome assessors to group allocation

sessment (detection bias)

All outcomes

Kang 2012

\begin{tabular}{ll}
\hline Methods & RCT \\
Method of randomisation: sealed envelopes \\
Blinding of outcome assessors: stated as 'yes' by the investigator \\
Adverse events: not stated \\
Dropouts: 2 (2 in EXP groups, 0 in CTL group) \\
ITT: unclear \\
\hline Country: Republic of Korea \\
32 participants (11 in first EXP group, 11 in second EXP group and 10 in CTL group) \\
Ambulatory at study onset \\
Mean age: 56 years (CTL and EXP groups) \\
Inclusion criteria: hemiparetic stroke participants 6 months after diagnosis; participants who could \\
walk on their own for more than 15 minutes; participants without visual disabilities or hemianopia; par- \\
ticipants who had a mini-mental state examination score of 21 or higher; Brunnstrum stage $>4$ \\
Exclusion criteria: cardiovascular problems; orthopaedic and other neurological diseases except stroke \\
for influencing gait
\end{tabular}


Kang 2012 (Continued)
Interventions
3 arms:
1. wore a head-mounted display to receive speed modulated optic flow during treadmill training for 30 minutes
2. treadmill training
3. regular therapy for the same time, 3 times per week for 4 weeks

$\begin{array}{ll}\text { Notes } & \text { We combined the results of both EXP groups (arms } 1 \text { and } 2 \text { ) as } 1 \text { group and compared this group with } \\ \text { the results of the CTL group (arm 3) }\end{array}$
the results of the CTL group (arm 3)

\section{Risk of bias}

\begin{tabular}{lll}
\hline Bias & Authors' judgement & Support for judgement \\
\hline $\begin{array}{l}\text { Random sequence genera- } \\
\text { tion (selection bias) }\end{array}$ & Low risk & Sealed envelopes \\
\hline $\begin{array}{l}\text { Allocation concealment } \\
\text { (selection bias) }\end{array}$ & Low risk & $\begin{array}{l}\text { Independent person who picked one of the sealed envelopes before the start } \\
\text { of the intervention }\end{array}$ \\
\hline $\begin{array}{l}\text { Blinding of outcome as- } \\
\text { sessment (detection bias) } \\
\text { All outcomes }\end{array}$ & Low risk & $\begin{array}{l}\text { Physical therapists other than the treating physical therapists used in this } \\
\text { study for the blinding measurements }\end{array}$ \\
\hline
\end{tabular}

Kim 2011

\begin{tabular}{ll}
\hline Methods & RCT \\
Method of randomisation: not described & Blinding of outcome assessors: no \\
Adverse events: not stated \\
Deaths: none \\
Dropouts: not described \\
ITT: not described \\
\hline
\end{tabular}

Participants Country: Republic of Korea

20 participants in the EXP group and 24 participants in the CTL group

Inclusion criteria: stroke, able to maintain standing independently for 30 seconds and to walk independently more than 30 metres and able to understand and follow instructions

Exclusion criteria: orthopaedic surgery or impairment, Modified Ashworth scale of 2 or more

Interventions 2 arms:

1. EXP group received treadmill training

2. CTL group received lower extremity muscle strength training

Both groups received walking therapy for 30 minutes, 3 times a week for 6 weeks 
Kim 2011 (Continued)

- 10-Metre Walk Test

- Timed Up and Go Test

- Berg Balance Scale

- dynamic mean balance in per cent

Notes

\section{Risk of bias}

\begin{tabular}{lll}
\hline Bias & Authors' judgement & Support for judgement \\
\hline $\begin{array}{l}\text { Random sequence genera- } \\
\text { tion (selection bias) }\end{array}$ & Unclear risk & Method of randomisation not described \\
\hline $\begin{array}{l}\text { Allocation concealment } \\
\text { (selection bias) }\end{array}$ & Unclear risk & Not described, probably not done \\
\hline $\begin{array}{l}\text { Blinding of outcome as- } \\
\text { sessment (detection bias) } \\
\text { All outcomes }\end{array}$ & Unclear risk & Not described, probably not done \\
\hline
\end{tabular}

\section{Kim 2016}

RCT
Method of randomisation: drawing sealed envelopes
Blinding of outcome assessors: stated as 'yes' by the investigator
Adverse events: not stated
Deaths: not stated
Dropouts: 3 ( 0 in VRCA group, 0 in CA group, 3 in control)
ITT: no

Country: Korea
30 participants (10 in VRCA group, 10 in CA group, 10 in Control group)
Ambulatory at study onset
Mean age: 63 years; 64 to 70 years (control and EXP groups, respectively)
Inclusion criteria: hemiplegia participants over six months after stroke, gait speed of less than $0.8 \mathrm{~m} / \mathrm{s}$,
independent ambulation of more than 6 minutes without an assistive device, Mini-Mental State Exami-
nation-Korean $>24$ points
Exclusion criteria: not described

Interventions
$\begin{aligned} & \text { arms: } \\ & \text { 1. VRCA group undertook a virtual reality treadmill training-based community ambulation for } 30 \text { min- } \\ & \text { utes, } 12 \text { sessions, } 3 \text { sessions per week }\end{aligned}$
$\begin{aligned} & \text { 2. CA group undertook a community ambulation training, } 30 \text { minutes per session, } 3 \text { times per week for } \\ & \text { 4 weeks }\end{aligned}$
3. CTL group received general exercise program, $10 \times 30$-minute sessions per week for 4 weeks

\begin{tabular}{ll}
\hline Outcomes & Outcomes were recorded at baseline and after the intervention \\
Timed up and go Test, 6 -minute walk Test, Activities-specific Balance Confidence Scale spatiotemporal \\
parameters (gait velocity, cadence, paretic step length, paretic stride length)
\end{tabular}

\section{Notes}

\section{Risk of bias}

Treadmill training and body weight support for walking after stroke (Review) 
Kim 2016 (Continued)

\begin{tabular}{|c|c|c|}
\hline Bias & Authors' judgement & Support for judgement \\
\hline $\begin{array}{l}\text { Random sequence genera- } \\
\text { tion (selection bias) }\end{array}$ & Unclear risk & Method not described (using sealed envelopes) \\
\hline $\begin{array}{l}\text { Allocation concealment } \\
\text { (selection bias) }\end{array}$ & Low risk & Allocated using sealed envelopes \\
\hline $\begin{array}{l}\text { Blinding of outcome as- } \\
\text { sessment (detection bias) } \\
\text { All outcomes }\end{array}$ & Unclear risk & Blinding not described \\
\hline
\end{tabular}

\section{Kosak 2000}

$\begin{array}{ll}\text { Methods } & \text { Parallel-group design } \\ \text { Participants randomised to groups using a random number table } \\ \text { Concealed allocation to groups by a person independent of the study } \\ 5 \% \text { dropouts at the end of the treatment phase } \\ \text { Blinding of outcome assessors to group allocation }\end{array}$

Participants
Inclusion criteria: no prior stroke; independent with ambulation prior to stroke; no active angina pec-
toris or orthostatic hypertension; free of other neurologic or orthopaedic disorders that might preclude
walking; FIM walking subscore less than or equal to 3 (indicating at least moderate assistance is re-
quired for ambulation); hemiparesis with iliopsoas strength less than or equal to 3 out of 5 (indicating
significant weakness - full range of movement against gravity only); written informed consent

\begin{tabular}{ll}
\hline Interventions & Treated as inpatients for $5 \times 45$-minute sessions per week for an average of 12.5 (SD 4.7) total treatment \\
sessions & \\
& Treadmill training with body weight support (EXP): participants walked on a treadmill and were pro- \\
& vided with manual guidance for weight shifting, leg advancement, and foot placement \\
& Aggressive bracing assisted walking (CTL): participants walked with the assistance of knee-ankle com- \\
bination bracing and a hemi-bar (non-task-oriented - 'orthopaedic')
\end{tabular}

\begin{tabular}{|c|c|}
\hline Outcomes & $\begin{array}{l}\text { Assessed at baseline and after treatment phase: } \\
\text { - preferred walking speed over a 2-minute test period (participants allowed to use gait aids and per- } \\
\text { sonal assistance, if required) } \\
\text { - walking endurance - the distance walked at a preferred speed until the participant indicated fatigue or } \\
\text { they exhibited fatigue-related deterioration in gait (participants allowed to use gait aids and personal } \\
\text { assistance, if required) }\end{array}$ \\
\hline Notes & $\begin{array}{l}\text { Rating of concealed allocation and the allocation concealment classification were changed based on } \\
\text { correspondence from the trialist }\end{array}$ \\
\hline
\end{tabular}

\section{Risk of bias}

\begin{tabular}{lll}
\hline Bias & Authors' judgement & Support for judgement \\
\hline $\begin{array}{l}\text { Random sequence genera- } \\
\text { tion (selection bias) }\end{array}$ & Low risk & Random number table \\
\hline $\begin{array}{l}\text { Allocation concealment } \\
\text { (selection bias) }\end{array}$ & Low risk & Concealed allocation to groups by a person independent of the study \\
\hline
\end{tabular}


Kosak 2000 (Continued)

Blinding of outcome as- Unclear risk Not described sessment (detection bias)

All outcomes

Kuys 2011

$\begin{array}{ll}\text { Methods } & \text { RCT } \\ \text { Method of randomisation: computer-generated random number program } \\ \text { Blinding of outcome assessors: stated as 'yes' by the investigator } \\ \text { Adverse events: none } \\ \text { Dropouts: } 2 \text { (2 in EXP group, } 0 \text { in CTL group) } \\ \text { ITT: ITT used }\end{array}$

Country: Australia
30 participants (15 in EXP group, 15 in CTL group)
Ambulatory at study onset
Mean age: 72 and 63 years (control and EXP group, respectively)
Inclusion criteria: diagnosis of first stroke confirmed by CT scan, were referred for physiotherapy re-
habilitation and scored 2 or more on the walking item of the Motor Assessment Scale (i.e. were able to
walk with stand-by help), were medically stable, were able to understand simple instructions
Exclusion criteria: walking speed was considered normal (> $1.2 \mathrm{~m} / \mathrm{s}$ ), any cardiovascular problems that
limited their participation in rehabilitation, or had other neurological or musculoskeletal conditions af-
fecting their walking

Interventions 2 arms:

1. EXP group walked on the treadmill for 30 minutes (excluding rests), 3 times a week for 6 weeks, at an intensity of $40 \%$ to $60 \%$ heart rate reserve or a Borg Rating of Perceived Exertion of 11 to 14

2. CTL group received usual physiotherapy intervention only

Outcomes

Details of treadmill walking (duration, heart rate reserve, treadmill speed, and distance walked) were recorded for each session:

- comfortable and fast walking speed and walking pattern were quantified from a 10-Metre Walk Test as linear kinematics (step length, cadence) using a GAITRite system and angular kinematic parameters using a two-dimensional web cam kinematic software analysis application, and

- walking capacity was measured using the 6-Minute Walk Test before and after 6 weeks intervention and after 18 weeks follow-up

Notes

\section{Risk of bias}

Bias Authors' judgement Support for judgement

Random sequence genera- Low risk Computer-generated random number program tion (selection bias)

\begin{tabular}{|c|c|c|}
\hline $\begin{array}{l}\text { Allocation concealment } \\
\text { (selection bias) }\end{array}$ & Low risk & $\begin{array}{l}\text { Allocation was concealed from the recruiter through the use of consecutively } \\
\text { numbered envelopes }\end{array}$ \\
\hline
\end{tabular}

\begin{tabular}{ll}
\hline $\begin{array}{l}\text { Blinding of outcome as- } \\
\text { sessment (detection bias) }\end{array} \quad$ Low risk $\quad$ Measures were taken by assessors blinded to group allocation
\end{tabular}
sessment (detection bias)

All outcomes 


$\begin{array}{ll}\text { Methods } & \text { RCT } \\ \text { Method of randomisation: by sealed envelopes } \\ \text { Blinding of outcome assessors: stated as 'yes' by the investigator } \\ \text { Adverse events: not stated } \\ \text { Deaths: no } \\ \text { Dropouts: } 5 \text { ( } 3 \text { in EXP group, } 2 \text { in CTL group) } \\ \text { ITT: unclear } \\ \text { Country: Norway } \\ \text { 39 participants ( } 21 \text { in EXP group, } 18 \text { in CTL group) } \\ \text { Not ambulatory at study onset } \\ \text { Mean age: } 75 \text { and } 74 \text { years (control and EXP group, respectively) } \\ \text { Inclusion criteria: stroke, neurological impairment and age above } 50 \text { years } \\ \text { Exclusion criteria: barriers to taking part in a physical rehabilitation program, insufficient language, an } \\ \text { unstable cardiac status, neurosurgery, and a premorbid history of orthopaedic problems, or any prob- } \\ \text { lems that would prevent a participant from walking }\end{array}$

Interventions
$\begin{aligned} & \text { 1. treadmill training (with handrails to hold on but no body weight or other safety support) } \\ & \text { 2. walking outdoors } \\ & \text { for } 30 \text { minutes } 5 \text { days a week during the inpatient stay until discharge from hospital (length of stay was } \\ & 16 \text { days in EXP group, and } 17 \text { days in CTL group) }\end{aligned}$

Outcomes

Main measures: Six-Minute Walk Test, a 10-Metre Walk Test, and pulse rates at rest and in activity

Notes

\section{Risk of bias}

\begin{tabular}{lll}
\hline Bias & Authors' judgement & Support for judgement \\
\hline $\begin{array}{l}\text { Random sequence genera- } \\
\text { tion (selection bias) }\end{array}$ & Low risk & Sealed envelopes \\
\hline $\begin{array}{l}\text { Allocation concealment } \\
\text { (selection bias) }\end{array}$ & Low risk & By a person not involved; sealed envelopes \\
\hline $\begin{array}{l}\text { Blinding of outcome as- } \\
\text { sessment (detection bias) } \\
\text { All outcomes }\end{array}$ & Low risk & Assessor blinded \\
\hline
\end{tabular}

Laufer 2001

\begin{tabular}{ll}
\hline Methods & Parallel-group design \\
Alternate assignment of participants to groups, therefore allocation to groups not concealed \\
$14 \%$ dropouts at the end of the treatment phase \\
Blinding of outcome assessors to group allocation
\end{tabular}


Laufer 2001 (Continued)

speed of at least $0.2 \mathrm{~km} /$ hour for 2 minutes without rest with minimal to moderate assistance; have begun ambulation training

$\begin{array}{ll}\text { Interventions } & \text { Treated as inpatients for } 5 \text { sessions of up to } 20 \text { minutes per week for } 3 \text { weeks (15 treatment sessions) } \\ \text { Treadmill training (EXP): participants walked on a treadmill at a comfortable speed with a therapist } \\ \text { assisting leg movements; they were permitted use a handrail for external support if required; no body } \\ \text { weight support using a harness was provided } \\ \text { Overground walking (CTL): participants walked on a floor surface using gait aids, assistance, and rest } \\ \text { periods as needed } \\ \text { Assessed at baseline and after treatment phase: } \\ \text { - independent fast walking speed over } 10 \mathrm{~m} \text { (participants allowed to use gait aids and supervision, if } \\ \text { required) } \\ \text { - FAC } \\ \text { - standing balance test } \\ \text { - gait aids used } \\ \text { - temporal characteristics of gait } \\ \text { - stride length } \\ \text { - calf muscle EMG activity }\end{array}$

Notes

\section{Risk of bias}

\begin{tabular}{lll}
\hline Bias & Authors' judgement & Support for judgement \\
\hline $\begin{array}{l}\text { Random sequence genera- } \\
\text { tion (selection bias) }\end{array}$ & High risk & Alternately assigned to groups by order of admittance \\
\hline $\begin{array}{l}\text { Allocation concealment } \\
\text { (selection bias) }\end{array}$ & High risk & Not described, inadequate \\
\hline $\begin{array}{l}\text { Blinding of outcome as- } \\
\text { sessment (detection bias) } \\
\text { All outcomes }\end{array}$ & Low risk & Blinding of outcome assessors to group allocation \\
\hline
\end{tabular}

Liston 2000

\begin{tabular}{ll}
\hline Methods & Cross-over group design \\
Participants randomised to groups by the toss of a coin & Allocation concealment not reported \\
$17 \%$ dropouts at the end of the first treatment phase \\
Blinding of outcome assessors to group allocation
\end{tabular}

$\begin{array}{ll}\text { Interventions } & \text { Treated as inpatients or outpatients for } 3 \times 1 \text {-hour sessions per week for } 4 \text { weeks } \\ & \text { Treadmill training (EXP): participants walked on a treadmill for as long as they felt comfortable; rest } \\ & \text { breaks were allowed; no body weight support was provided using a harness }\end{array}$




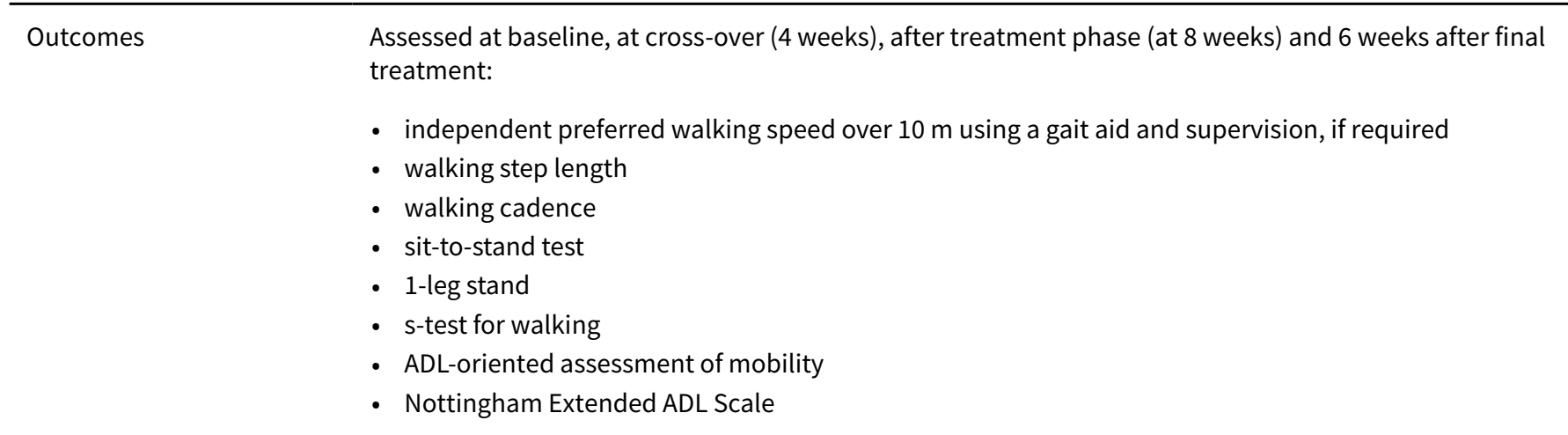

Notes The rating of dropouts was changed based on correspondence from the trialist

Trial treated as a parallel-group design for this review by using the first treatment phase data only

(that is baseline and data before cross-over only)

\section{Risk of bias}

\section{Bias Authors' judgement Support for judgement}

Random sequence genera- Low risk By the toss of a coin

tion (selection bias)

\begin{tabular}{ll}
$\begin{array}{l}\text { Allocation concealment } \\
\text { (selection bias) }\end{array}$ & Unclear risk $\quad$ Not reported \\
\hline
\end{tabular}

Blinding of outcome as- Low risk Blinding of outcome assessors to group allocation

sessment (detection bias)

All outcomes

RCT
Methods of randomisation: computer-based list
Blinding of outcome assessors: stated as 'yes' by the investigator
Adverse events: not stated
Deaths: not stated
Dropouts: 42 (20 in EXP group, 22 in CTL group)
ITT: no

Country: USA
Participants
Ambulatory at study onset
Mean age: 64 and 63 years (CTL and EXP group, respectively)
Inclusion criteria: first clinical ischaemic stroke, older than 45 years of age with chronic hemiparetic
gait 6 or more months after completion of conventional subacute rehabilitation
Exclusion criteria: heart failure, unstable angina, peripheral arterial occlusive disease, dementia
(MMSE $\leq 23$ for those with 9th grade education or more and $\leq 17$ for those with 8th grade education or
less), significant aphasia (unable to follow 2-point commands), untreated major depression (CES-D 16),
and other medical conditions precluding participation in aerobic exercise


1. treadmill training sessions (training goal was $3 \times 40$-minute exercise sessions per week at an aerobic intensity of $60 \%$ of heart rate reserve). Duration and intensity started low (10 to 20 minutes, $40 \%$ to $50 \%$ heart rate reserve) and increased approximately by 5 minutes and $5 \%$ heart rate reserve every 2 weeks, as tolerated

2. stretching sessions (performed 13 supervised traditional stretching movements on a raised mat table with a therapist's assistance) over a 6-month period

\begin{tabular}{lll}
\hline Outcomes & Assessed at baseline, 3, and 6 months: \\
& • maximum walking velocity and $\mathrm{VO}_{2}$ peak during a treadmill stress test \\
\hline Notes & maximum comfortable walking velocity during a 10-metre walk and a 6-Minute Walk Test) \\
\hline Risk of bias & Authors' judgement & Support for judgement \\
\hline Bias & Computer-based list \\
\hline $\begin{array}{l}\text { Random sequence genera- } \\
\text { tion (selection bias) }\end{array}$ & Low risk & \\
\hline $\begin{array}{l}\text { Allocation concealment } \\
\text { (selection bias) }\end{array}$ & Unclear risk & Not described \\
\hline $\begin{array}{l}\text { Blinding of outcome as- } \\
\text { sessment (detection bias) } \\
\begin{array}{l}\text { All outcomes } \\
\hline\end{array}\end{array}$ & Low risk & Blinded assessors \\
\hline
\end{tabular}

MacKay-Lyons 2013

$\begin{array}{ll}\text { Methods } & \text { RCT } \\ \text { Method of randomisation: computer-generated, blocked randomisation } \\ \text { Blinding of outcome assessors: stated as 'yes' by the investigator } \\ \text { Adverse events: not stated } \\ \text { Deaths: not stated } \\ \text { Dropouts: } 5 \text { ( } 2 \text { in EXP group, } 3 \text { in CTL group) } \\ \text { ITT: all analyses were conducted on an ITT basis (that meant carrying the last observation forward for } \\ \text { those lost to follow-up) } \\ \text { Country: Canada } \\ \text { 50 participants (24 in EXP group, } 26 \text { in CTL group) } \\ \text { Ambulatory at study onset } \\ \text { Mean age: } 59 \text { and } 62 \text { years (control and EXP group, respectively) } \\ \text { Inclusion criteria: men and women older than 18 years, within } 1 \text { month of a first ischaemic stroke con- } \\ \text { firmed by neuroimaging, inpatients in the stroke rehabilitation unit, and able to walk } 5 \text { metres with or } \\ \text { without use of ambulatory aids, ankle orthoses or stand-by assistance } \\ \text { Exclusion criteria: contraindications to maximal exercise stress testing, musculoskeletal, or cognitive } \\ \text { limitations that could preclude participation in the program, or involvement in other pharmacological } \\ \text { or physical intervention studies } \\ \text { 2 arms: } \\ \text { 1. body weight-supported treadmill training + usual care } \\ \text { 2. usual care } \\ \text { Interventions }\end{array}$


MacKay-Lyons 2013 (Continued)

All individuals participated in 60-minute physiotherapy sessions 5 times weekly as inpatients for 6 weeks and 3 times weekly as outpatients for another 6 weeks for a total of 48 sessions. Substitute sessions for missed appointments were provided

\begin{tabular}{|c|c|}
\hline Outcomes & $\begin{array}{l}\text { Assessments were done at baseline, post-training, at } 6 \text { and } 12 \text {-month follow- } 4 \\
\text { - peak oxygen consumption, } \mathrm{VO}_{2} \text { peak } \\
\text { - } \text { walking ability (6-Minute Walk Test and } 10 \text {-metre walk) } \\
\text { - Berg Balance Scale } \\
\text { - motor impairment (Chedoke-McMaster Stages of Recovery, Leg and Foot) }\end{array}$ \\
\hline
\end{tabular}

Notes

\section{Risk of bias}

\begin{tabular}{lll}
\hline Bias & Authors' judgement & Support for judgement \\
\hline $\begin{array}{l}\text { Random sequence genera- } \\
\text { tion (selection bias) }\end{array}$ & Low risk & Computer-generated, blocked randomisation \\
\hline $\begin{array}{l}\text { Allocation concealment } \\
\text { (selection bias) }\end{array}$ & Low risk & $\begin{array}{l}\text { A person not involved in the study prepared and safeguarded individual, } \\
\text { opaque sealed envelopes containing group and physiotherapist allocation, } \\
\text { which were opened after completion of the baseline assessment }\end{array}$ \\
\hline $\begin{array}{l}\text { Blinding of outcome as- } \\
\text { sessment (detection bias) } \\
\text { All outcomes }\end{array}$ & Low risk & $\begin{array}{l}\text { All outcome assessments were conducted by a blinded assessor located off- } \\
\text { site }\end{array}$ \\
\hline
\end{tabular}

Macko 2005

\begin{tabular}{|c|c|}
\hline Methods & $\begin{array}{l}\text { Parallel-group design } \\
\text { Participants randomised to groups using a computer-generated randomisation scheme that was strat- } \\
\text { ified by walking speed (less than } 0.44 \mathrm{~m} / \mathrm{s} \text { and more than or equal to } 0.44 \mathrm{~m} / \mathrm{s} \text { ) and age (less than } 65 \\
\text { years and more than or equal to } 65 \text { years) } \\
\text { Concealed allocation to groups not reported } \\
26 \% \text { dropouts at the end of the treatment phase } \\
\text { Blinding of outcome assessors to group allocation for gait and balance outcomes (i.e. outcomes 1, 2, 3, } \\
\text { and 6) }\end{array}$ \\
\hline Participants & $\begin{array}{l}32 \text { participants in the EXP group and } 29 \text { participants in the CTL group } \\
\text { Inclusion criteria: chronic ischaemic stroke (less than } 6 \text { months); residual mild to moderate hemiplegic } \\
\text { gait deficits; completion of all conventional physiotherapy; aged } 45 \text { years or more; (5) independently } \\
\text { ambulant with or without a gait aid or stand-by help } \\
\text { Exclusion criteria: heart failure, unstable angina, peripheral arterial occlusive disease; aphasia (inabili- } \\
\text { ty to follow 2-point commands); dementia; untreated major depression; other medical conditions pre- } \\
\text { cluding aerobic exercise }\end{array}$ \\
\hline
\end{tabular}

Interventions

Treated as outpatients for $3 \times 40$-minute sessions per week for 6 months

Treadmill training (EXP): participants walked on a treadmill to achieve a target aerobic intensity of $60 \%$ to $70 \%$ heart rate reserve (progressive aerobic training); no body weight support was provided using a harness

Conventional physiotherapy (CTL): participants completed a supervised stretching and low-intensity walking program (5 minutes walking on a treadmill at 30\% to $40 \%$ heart rate reserve without body weight support; task-oriented) 
- independent self-selected walking speed over 30 feet (participants allowed to use gait aids and supervision, if required)

- independent fastest comfortable walking speed over 30 feet (participants allowed to use gait aids and supervision, if required)

- walking endurance - maximum distance covered in 6 minutes using preferred gait aid

- peak exercise capacity

- rate of oxygen consumption during submaximal effort treadmill walking (economy of gait)

- balance using an instrumented balance assessment system

Notes

Method of randomisation and rating of assessor blinding were changed based on correspondence from the trialist

Obtained unpublished data by correspondence with the trialists

\section{Risk of bias}

\section{Bias}

Authors' judgement Support for judgement

Random sequence genera- Low risk Computer-generated randomisation scheme tion (selection bias)

Allocation concealment Unclear risk Not reported

(selection bias)

Blinding of outcome as- Low risk sessment (detection bias)

Blinding of outcome assessors to group allocation for gait and balance out-

All outcomes comes (i.e. outcomes 1, 2, 3, and 6)

Mao 2015

$\begin{array}{ll}\text { Methods } & \text { RCT } \\ \text { Method of randomisation: not described } \\ \text { Blinding of outcome assessors: stated as 'yes' by the investigator } \\ \text { Adverse events: not stated } \\ \text { Deaths: not stated } \\ \text { Dropouts: } 5 \text { (3 BWSTT group, } 2 \text { CT group) } \\ \text { ITT: unclear }\end{array}$

Participants Country: China

29 participants (15 BWSTT group, 14 CT group)

Not ambulatory at study onset

Mean age: 60 years

Inclusion criteria: first stroke, unilateral hemiparesis for no more than 3 months resulting, abnormal $10 \mathrm{~m}$ walk time according to age, MMSE score $\geq 27$, average modified Ashworth scale score at hip, knee, and ankle $\leq 2$

Exclusion criteria: presence of significant medical complications or unstable vital signs

Interventions 2 arms:

1. BWSTT group received body weight-supported treadmill training 20 to 40 minutes 5 times per week for 3 weeks

2. CT group underwent conventional overground walking for same amount of time 
Mao 2015 (Continued)

- kinematic parameters (hip flexion, knee flexion, ankle dorsiflexion, hip extension, knee extension, ankle plantarflexion)

- spatiotemporal parameters (cadence, stride length, stride time, step length, step time, gait speed)

- Fugl-Meyer Lower Extremity Assessment

- Brunel Balance Assessment

Notes

\section{Risk of bias}

Bias Authors' judgement Support for judgement

Random sequence genera- Unclear risk Method not described

tion (selection bias)

$\begin{aligned} & \text { Allocation concealment } \\ & \text { (selection bias) }\end{aligned}$
Unclear risk $\quad$ Allocation not described

\begin{tabular}{lll}
\hline Blinding of outcome as- & High risk & No blinding \\
sessment (detection bias) & \\
All outcomes & \\
\hline
\end{tabular}

Mehrberg 2001

\begin{tabular}{ll}
\hline Methods & RCT \\
& Method of randomisation: not stated \\
& Blinding of outcome assessors: not stated \\
& Adverse events: not stated \\
& Deaths: not stated \\
& Dropouts: not stated \\
ITT: unclear
\end{tabular}

Country: USA
21 participants (9 in EXP group, 11 in CTL group; according to the authors, 1 participant appears to be
missing)
Ambulatory status at study onset unclear
Mean age: unclear
Inclusion criteria: severe hemiparetic participants after stroke (defined as inability to raise and hold af-
fected leg)
Exclusion criteria: not stated

\begin{tabular}{ll}
\hline Interventions & 2 arms: \\
& $\begin{array}{l}\text { 1. body weight-supported walking (no treadmill) } \\
\text { 2. traditional physical therapy } \\
1 \text { hour per day for } 3 \text { weeks }\end{array}$
\end{tabular}

\begin{tabular}{ll}
\hline Outcomes & Tinetti Balance Scale \\
& Functional Ambulation Categories \\
& Scandinavian Stroke Scale
\end{tabular}


Mehrberg 2001 (Continued)

Risk of bias

\begin{tabular}{lll}
\hline Bias & Authors' judgement & Support for judgement \\
\hline $\begin{array}{l}\text { Random sequence genera- } \\
\text { tion (selection bias) }\end{array}$ & Unclear risk & Not described \\
\hline $\begin{array}{l}\text { Allocation concealment } \\
\text { (selection bias) }\end{array}$ & Unclear risk & Not described \\
\hline $\begin{array}{l}\text { Blinding of outcome as- } \\
\text { sessment (detection bias) } \\
\text { All outcomes }\end{array}$ & Unclear risk & Not described \\
\hline
\end{tabular}

\section{Middleton 2014}

Rethods
Method of randomisation: drawing concealed envelopes
Blinding of outcome assessors: stated as 'yes' by the investigator
Adverse events: not stated
Deaths: not stated
Dropouts: 12 (8 in intervention group, 4 in control group)
ITT: no

$\begin{array}{ll}\text { Participants } & \text { Country: USA } \\ & 50 \text { participants (27 intervention group, } 23 \text { control group) } \\ & \text { Not ambulatory at study onset } \\ & \text { Mean age: } 61 \text { years; (range } 23 \text { to } 86 \text { years in control and intervention groups) }\end{array}$

Inclusion criteria: age $\geq 18$ years, presence of unilateral hemiplegia, ability to follow 3-step commands, sit independently without back or arm support for 5 minutes, stand without support of assistance devices for 5 minutes with no more than minimal assistance, walk 20 feet with occasional moderate help for balance, independently advance assistance devices and bilateral lower extremity during ambulation

Exclusion criteria: unable to ambulate 150 feet before stroke, receiving therapy for balance, mobility, and/or gait, significant health risk, serious COPD or oxygen dependence, weight-bearing restrictions, lower extremity amputation, nonhealing lower extremity, severe visual or hearing impairment, significant psychiatric illness, life expectancy < 1 year, severe contracture of lower extremity, deep venous thrombosis or pulmonary embolism within 6 months, uncontrollable diabetes with recent weight loss, diabetic coma or frequent insulin reactions, severe systolic hypertension, history of seizure disorder, neurological conditions other than stroke, severe pain

Interventions 2 arms:

1. Intervention group (BWSTT) undertook gait-training on a treadmill with comfortable speed for 60 minutes and 120 minutes training for balance, strength, coordination and range of motion for 10 consecutive weekdays (total of 30 hours)

2. Experimental group (OGT) received an overground gait-training including training for balance, strength, coordination and range of motion, $3 \mathrm{~h}$ for 10 consecutive weekdays (total of 30 hours)

\section{Outcomes}

Outcomes were recorded at baseline ( 2 days before pretest), pretest ( 1 day before intervention), posttest (1 day after intervention), and follow-up (101 days after completion of intervention)

- Stroke Impact Scale

- Fugl-Meyer Scale Lower Extremity subscale

- Timed Up and Go

- Single limb stance 
Middleton 2014 (Continued)

- Activities-specific Balance Confidence Scale

Notes

\section{Risk of bias}

\begin{tabular}{lll}
\hline Bias & Authors' judgement & Support for judgement \\
\hline $\begin{array}{l}\text { Random sequence genera- } \\
\text { tion (selection bias) }\end{array}$ & High risk & Unclear randomisation procedure author stated: "randomised and matched" \\
\hline $\begin{array}{l}\text { Allocation concealment } \\
\text { (selection bias) }\end{array}$ & High risk & Unclear allocation author stated: "rolling approach to enrolment" \\
\hline $\begin{array}{l}\text { Blinding of outcome as- } \\
\text { sessment (detection bias) } \\
\text { All outcomes }\end{array}$ & Low risk & Blinded rater \\
\hline
\end{tabular}

Moore 2010

RCT with baseline period, followed by cross-over design
Method of randomisation: not stated
Blinding of outcome assessors: stated as 'yes' by the investigator
Adverse events: not stated
Deaths: not stated
Dropouts: 10 (unclear in which period/group)
ITT: unclear

\begin{tabular}{ll}
\hline Participants & Country: USA \\
& 30 participants (probably 15 in EXP group, 15 in CTL group) \\
Ambulatory at study onset & Mean age: 57 and 67 years (CTL and EXP group, respectively) \\
Inclusion criteria: $\leq 3$ months after stroke, ability to stand or walk 5 metres \\
Exclusion criteria: orthopaedic problems, contractures, NYHA III-IV \\
\hline Interventions \\
20/30 participants with chronic stroke completed a repeated baseline measure with clinical physiother- \\
apy; afterwards participants were randomised in a cross-over trial and received 4 weeks of intensive lo- \\
comotor training (A) or 4 weeks of no intervention (B) before cross over
\end{tabular}

Outcomes

Outcome measures included clinical and physiological (metabolic) measures of walking overground and on a treadmill, and measures of daily stepping activity in the home and community, including during clinical physical therapy and subsequent locomotor therapy sessions

\footnotetext{
Notes
}

\section{Risk of bias}

\begin{tabular}{lll}
\hline Bias & Authors' judgement & Support for judgement \\
\hline $\begin{array}{l}\text { Random sequence genera- } \\
\text { tion (selection bias) }\end{array}$ & Unclear risk & Method of randomisation not stated \\
\hline $\begin{array}{l}\text { Allocation concealment } \\
\text { (selection bias) }\end{array}$ & Unclear risk & Method not stated \\
\hline
\end{tabular}


Moore 2010 (Continued)

$\begin{array}{lll}\text { Blinding of outcome as- } & \text { Unclear risk } & \text { Not stated } \\ \text { sessment (detection bias) } & \end{array}$

All outcomes

Nilsson 2001

\begin{tabular}{|c|c|}
\hline Methods & $\begin{array}{l}\text { Parallel-group design } \\
\text { Participants randomised to groups using a random number computer program } \\
\text { Concealed allocation to groups using sealed, opaque, and consecutively numbered envelopes } \\
10 \% \text { dropouts at the end of the treatment phase, } 18 \% \text { dropouts at the } 10 \text {-month follow-up } \\
\text { Blinding of outcome assessors to group allocation }\end{array}$ \\
\hline Participants & $\begin{array}{l}36 \text { participants in the EXP group and } 37 \text { participants in the CTL group } \\
\text { Inclusion criteria: first stroke with residual hemiparesis; aged less than } 70 \text { years; onset of stroke no } \\
\text { more than } 8 \text { weeks prior to recruitment; take longer than } 14 \text { seconds to walk } 10 \text { metres; informed con- } \\
\text { sent } \\
\text { Exclusion criteria: participants with heart disease, psychiatric illness or incapable of co-operating; par- } \\
\text { ticipants with other severe disabilities (e.g. rheumatoid arthritis) that might hinder training; partici- } \\
\text { pants participating in other studies }\end{array}$ \\
\hline
\end{tabular}

Interventions

Treated as inpatients for $5 \times 30$-minute sessions per week for the duration of inpatient rehabilitation Treadmill training with body weight support (EXP): participants walked on a treadmill with up to 2 therapists assisting leg movements, they were permitted to use a handrail for external support, if required

Overground walking training (CTL): participants practiced walking on a floor surface based on Motor Relearning Program guidelines

Outcomes

Assessed at baseline, after treatment phase (when discharged from inpatient rehabilitation), and 10 months after stroke:

- preferred walking speed over 10 metres (participants allowed to use gait aids and personal assistance, if required)

- $F A C$

- FIM

- FMA

- Berg Balance Scale

Notes Allocation concealment classification was changed based on correspondence from the trialist

Data divided into 2 comparisons, see Nilsson 2001a and Nilsson 2001b

\section{Risk of bias}

\begin{tabular}{lll}
\hline Bias & Authors' judgement & Support for judgement \\
\hline $\begin{array}{l}\text { Random sequence genera- } \\
\text { tion (selection bias) }\end{array}$ & Low risk & Random number computer program \\
\hline $\begin{array}{l}\text { Allocation concealment } \\
\text { (selection bias) }\end{array}$ & Low risk & Sealed, opaque, and consecutively numbered envelopes \\
\hline $\begin{array}{l}\text { Blinding of outcome as- } \\
\text { sessment (detection bias) } \\
\text { All outcomes }\end{array}$ & Low risk & Blinding was done \\
\hline
\end{tabular}


Nilsson 2001a

\begin{tabular}{ll}
\hline Methods & See Nilsson 2001 \\
\hline Participants & See Nilsson 2001 \\
\hline Interventions & See Nilsson 2001 \\
\hline Outcomes & See Nilsson 2001 \\
\hline Notes & $\begin{array}{l}\text { For Nilsson 2001a, data from the } 54 \text { participants who were dependent walkers at the start of treatment } \\
\text { were used (26 EXP and 28 CTL); these walking dependency data were obtained through correspon- } \\
\text { dence with the authors }\end{array}$ \\
\hline
\end{tabular}

Nilsson 2001b

\begin{tabular}{ll}
\hline Methods & See Nilsson 2001 \\
\hline Participants & See Nilsson 2001 \\
\hline Interventions & See Nilsson 2001 \\
\hline Outcomes & See Nilsson 2001 \\
\hline Notes & $\begin{array}{l}\text { For Nilsson 2001b, data from the 19 participants who were independent walkers at the start of treat- } \\
\text { ment were used (10 EXP and 9 CTL); these walking dependency data were obtained through correspon- } \\
\text { dence with the authors }\end{array}$ \\
\hline
\end{tabular}

\section{Olawale 2009}

$\begin{array}{ll}\text { Methods } & \text { RCT } \\ & \text { Method of randomisation: not described } \\ & \text { Blinding of outcome assessors: unclear } \\ & \text { Adverse events: not reported } \\ \text { Deaths: not reported } \\ \text { Dropouts: } 7 \text { (2 in EXP group, } 5 \text { in CTL group) } \\ \text { ITT: no }\end{array}$

Participants
Country: Nigeria
Ambulatory at study onset: yes
Mean age: 57 years (CTL and EXP group respectively)
Inclusion criteria: stroke $>3$ months but < 24 months prior to enrolment, ability to walk 10 metres inde-
pendently without the help of assistive devices, written informed consent
Exclusion criteria: not reported
3 arms:
1. CTL group 1 used standard physiotherapy, 3 times a week for 12 weeks (3 hours a week)
2. CTL group 2 used standard physiotherapy including overground walking exercises for the same time
and frequency
3. EXP group 1 used treadmill training for the same time and frequency


Olawale 2009 (Continued)

Outcomes Outcomes were recorded at baseline, at 4, 8, and after 12 weeks (at the end of the intervention phase) Outcomes: walking speed (10-Metre Walk Test), walking capacity (6-Minute Walk Test)

Notes

\section{Risk of bias}

Bias Authors' judgement Support for judgement

Random sequence genera- Unclear risk Not described

tion (selection bias)

\begin{tabular}{l}
$\begin{array}{l}\text { Allocation concealment } \\
\text { (selection bias) }\end{array}$ \\
\hline
\end{tabular}

Blinding of outcome as- Unclear risk Not described

sessment (detection bias)

All outcomes

\section{Park 2013}

\begin{tabular}{|c|c|}
\hline \multirow[t]{4}{*}{ Methods } & $\begin{array}{l}\text { RCT } \\
\text { Method of randomisation: selecting card from box containing two cards }\end{array}$ \\
\hline & Blinding of outcome assessors: not mentioned \\
\hline & $\begin{array}{l}\text { Adverse events: not stated } \\
\text { Deaths: not stated } \\
\text { Dropouts: not reported }\end{array}$ \\
\hline & ITT: not stated \\
\hline \multirow[t]{2}{*}{ Participants } & $\begin{array}{l}\text { Country: Korea } \\
40 \text { participants ( } 20 \text { in TGT, } 20 \text { in OGT, stratified into } n=10 \text { slow walking and } n=10 \text { fast walking per } \\
\text { group ) }\end{array}$ \\
\hline & $\begin{array}{l}\text { Ambulatory at study onset } \\
\text { Mean age: } 53 \text { years (TGT group slow walking } n=52 \text { and fast walking } n=53 \text { years and OGT slow walking } \\
n=51 \text { and fast walking } n=55 \text { years) } \\
\text { Inclusion criteria: onset of stroke } 6 \text { months or more prior to the study; ability to walk for } 10 \text { mor more } \\
\text { without any aid; } \geq 23 \text { points on the Korean version of the MMSE; no other neurological or orthopaedic } \\
\text { lesions; consent to participation } \\
\text { Exclusion criteria: not reported }\end{array}$ \\
\hline
\end{tabular}

Interventions

2 intervention arms:

1. OGT group undertook overground gait-training for 30 mins twice a day for 5 days

2. TGT group received treadmill gait-training with increased speed for same amount of time

\begin{tabular}{ll}
\hline Outcomes & Outcomes were recorded at baseline and after intervention \\
& - 10 -m walking time \\
- 6-min walking distance & - Berg Balance Scale \\
\hline Notes & \\
\hline
\end{tabular}


Park 2013 (Continued)

Risk of bias

\begin{tabular}{lll}
\hline Bias & Authors' judgement & Support for judgement \\
\hline $\begin{array}{l}\text { Random sequence genera- } \\
\text { tion (selection bias) }\end{array}$ & Low risk & Selecting a card from a box containing two cards \\
\hline $\begin{array}{l}\text { Allocation concealment } \\
\text { (selection bias) }\end{array}$ & Unclear risk & Selecting a card from a box containing two cards (the concealment is unclear) \\
\hline $\begin{array}{l}\text { Blinding of outcome as- } \\
\text { sessment (detection bias) } \\
\text { All outcomes }\end{array}$ & High risk & No blinding \\
\hline
\end{tabular}

\section{Park 2015}

\begin{tabular}{ll}
\hline Methods & RCT \\
Method of randomisation: not mentioned \\
Blinding of outcome assessors: not stated \\
Adverse events: not stated \\
Deaths: not stated \\
Dropouts: not stated \\
ITT: not stated
\end{tabular}

Country: Korea
19 participants (9 TRAS group, 10 ORAS group )
Mean age: 53 years (51 years TRAS group, 53 years ORAS group)
Inclusion criteria: > 6 months and < 2 years after the onset of stroke, walk for 10 minutes or longer on
a treadmill, absence of neurotic diseases and abnormal vestibular function, no orthopaedic problems
that affect walking, understanding of researchers' instructions, no blood pressure, pulse, or breathing
problems after 6 minutes of walking
Exclusion criteria: other neurologic conditions that would interfere with walking, receiving other tread-
mill gait-training

Interventions 2 arms:

1. TRAS group undertook treadmill walking training with rhythmic auditory stimulation 30 minutes, 5 times per week for 3 weeks

2. ORAS group received overground walking training with rhythmic auditory stimulation for the same amount of time

Outcomes were recorded at baseline and after the intervention
- spatiotemporal parameters (walking speed, step cycle, step length affected and unaffected lower ex-
tremity)
- 6 -minute walking test
- Functional Gait Assessment

Notes

\section{Risk of bias}


Park 2015 (Continued)

Bias Authors' judgement Support for judgement

Random sequence genera- High risk Method of pairing participants with similar physical and balancing abilities
tion (selection bias)

Allocation concealment $\quad$ High risk Method of pairing participants with similar physical and balancing abilities
(selection bias)

\begin{tabular}{|c|c|c|}
\hline $\begin{array}{l}\text { Blinding of outcome as- } \\
\text { sessment (detection bias) } \\
\text { All outcomes }\end{array}$ & High risk & No blinding was done \\
\hline
\end{tabular}

Pohl 2002

$\begin{array}{ll}\text { Methods } & \text { Parallel-group design } \\ \text { Participants randomised to groups (block randomisation with participants stratified for walking } \\ \text { speed) } \\ \text { Concealed allocation to groups using sealed, opaque envelopes } \\ \text { 13\% dropouts at the end of the treatment phase } \\ \text { Blinding of outcome assessors to group allocation }\end{array}$

$\begin{array}{ll}\text { Participants } & 22 \text { participants in the EXP } 1 \text { group, } 22 \text { participants in the EXP } 2 \text { group and } 25 \text { participants in the CTL } \\ \text { group } & \text { Inclusion criteria: hemiparesis caused by ischaemic stroke; impaired gait (takes } 5 \text { to } 60 \text { seconds to walk } \\ & 10 \text { metres); hemiparesis more than } 4 \text { weeks; no or slight spasticity (0 or } 1 \text { on the Ashworth scale); able } \\ \text { to walk without assistance (FAC of } 3 \text { or more); informed consent } \\ \text { Exclusion criteria: previous treadmill training; class C or D exercise risk (American College of Sports } \\ \text { Medicine Guidelines); cognitive deficits (less than } 26 \text { out of } 30 \text { on Mini Mental State Examination); } \\ \text { movement disorders, orthopaedic or other gait influencing disease }\end{array}$

Interventions

Treated as inpatients for $3 \times 30$-minutes sessions (EXP 1 and EXP 2) or 45-minute sessions (CTL) per week for 4 weeks

Speed-dependent treadmill training with body weight support (EXP 1): participants walked on a treadmill without therapist assistance, speed was progressed using an aggressive protocol Limited progressive treadmill training with body weight support (EXP 2): participants walked on a treadmill with therapists assisting the walking cycle, speed was progressed using conservative protocol Conventional gait therapy (CTL): traditional physiotherapy based on neurophysiological techniques

\begin{tabular}{ll}
\hline Outcomes & Assessed at baseline and after treatment phase: \\
- independent preferred walking speed over $10 \mathrm{~m}$ using gait aids, if required \\
- FAC \\
- cadence \\
stride length \\
The rating of concealed allocation and the allocation concealment classification were changed based \\
on correspondence from the trialist \\
In the update of 2005, the data from this study were divided into 2 comparisons: half of the control \\
group data were used for each comparison. According to Chapter 16.5 .4 of the Cochrane Handbook for \\
Systematic Reviews of Interventions (Higgins 2011), we combined both treadmill groups, group LTT and \\
group STT together to one treadmill group (to create a single pair-wise comparison) and compared it \\
with the control group \\
We used raw data provided by the trialists
\end{tabular}


Pohl 2002 (Continued)

Risk of bias

\begin{tabular}{lll}
\hline Bias & Authors' judgement & Support for judgement \\
\hline $\begin{array}{l}\text { Random sequence genera- } \\
\text { tion (selection bias) }\end{array}$ & Unclear risk & Not described \\
\hline $\begin{array}{l}\text { Allocation concealment } \\
\text { (selection bias) }\end{array}$ & Unclear risk & Not described \\
\hline $\begin{array}{l}\text { Blinding of outcome as- } \\
\text { sessment (detection bias) } \\
\text { All outcomes }\end{array}$ & Low risk & Outcome assessors were blinded \\
\hline
\end{tabular}

Ribeiro 2013

Quasi-RCT
Methods of randomisation: one by one after enrolment in study
Blinding of outcome assessors: stated as 'yes' by the investigator
Adverse events: not stated
Deaths: not stated
Dropouts: 6 (4 PNF group, 2 TPBWS group )
ITT: no

\title{
Participants
}

\author{
Country: Brazil \\ 25 participants ( $n=12$ PFN group and $n=13$ TPBWS group)
}

Ambulatory at study onset

Mean age: 57 years (range 40 to 70 in both groups)

Inclusion criteria: age 40 to 70 years, chronic stroke ( $\geq 6$ months) with hemiparesis, modified Ashworth scale lower extremity 0 to 1 points, Functional Ambulatory Categories 3 to 5 , no signs of cardiac alterations, no other neurological or orthopaedic disease interfering with gait, independently walk $10 \mathrm{~m}$ without assistive devices or orthotics at paretic leg, follow simple verbal commands

Exclusion criteria: age-adjusted heart rate exceeded $75 \%$, fear of falling on treadmill

2 arms:
$\begin{aligned} & \text { 1. PNF group underwent gait-training base on PNF } 30 \text { minutes } 3 \text { times per week for } 4 \text { weeks } \\ & \text { 2. TPBWS group received treadmill walking training with comfortable speed for same amount of time }\end{aligned}$

Outcomes

Outcomes were recorded at baseline and after the intervention

- Stroke Rehabilitation Assessment of Movement

- Functional Ambulatory Categories

- Functional Independent Measure (motoric parts)

- spatiotemporal and kinematic parameters (walking speed, stride length, double-support time, symmetry ratio, max knee and hip flexion, max knee extension, plantarflexion and dorsiflexion)

Notes 
Ribeiro 2013 (Continued)

Risk of bias

\begin{tabular}{lll}
\hline Bias & Authors' judgement & Support for judgement \\
\hline $\begin{array}{l}\text { Random sequence genera- } \\
\text { tion (selection bias) }\end{array}$ & High risk & $\begin{array}{l}\text { Stated as randomised, but participants were according to authors 'selected } \\
\text { consecutively, one by one, according to when they enrolled' }\end{array}$ \\
\hline $\begin{array}{l}\text { Allocation concealment } \\
\text { (selection bias) }\end{array}$ & High risk & 'Selected consecutively, one by one, according to when they enrolled' \\
\hline $\begin{array}{l}\text { Blinding of outcome as- } \\
\text { sessment (detection bias) } \\
\text { All outcomes }\end{array}$ & High risk & No blinding \\
\hline
\end{tabular}

\section{Richards 1993}

Parallel-group design
Participants randomised to groups using a stratified block randomisation scheme
Concealed allocation to groups not reported
$15 \%$ dropouts at the end of the treatment phase, number of dropouts not reported at 3 and 6-month
follow-up
Blinding of outcome assessors to group allocation

Participants 10 participants in the EXP group, 8 participants in the CTL 1 group and 9 participants in the CTL 2 group

Nonambulatory at study onset

Inclusion criteria: resident within $50 \mathrm{~km}$ of Quebec; aged 40 to 80 years; less than 7 days after onset of first stroke; clinically identifiable middle cerebral artery syndrome of thromboembolic origin involving subcortical structures confirmed by $\mathrm{CT}$; under medical supervision of study neurologists; informed consent; middle-band disability according to Garraway (i.e. excluded participants independent in ambulation as well as those who were unconscious)

Exclusion criteria: other neurological problems; major medical problems that would incapacitate functional capacity (participants independent in ambulation were excluded)

$\begin{array}{ll}\text { Interventions } & \text { Treated as inpatients for } 6 \text { weeks for a mean of 1.74 (SD 0.15) (EXP), } 1.79 \text { (SD 0.10) (CTL 1) and 0.72 (SD } \\ \text { 0.10) (CTL 2) hours per day } \\ \text { Early intensive task-oriented physiotherapy (EXP): treatment started as early as possible after stroke } \\ \text { and included treadmill training (no body weight support was provided using a harness), tilt table exer- } \\ \text { cises and resisted exercises using isokinetic equipment } \\ \text { Early intensive traditional physiotherapy (CTL 1): treatment started as early as possible after stroke } \\ \text { and included traditional physiotherapy based on neurophysiological techniques } \\ \text { Delayed non-intensive traditional physiotherapy (CTL 2): treatment started later after stroke and in- } \\ \text { cluded less intense traditional physiotherapy based on neurophysiological techniques } \\ \text { Assessed at baseline, after treatment phase, and 3 and } 6 \text { months later: } \\ \text { - walking speed over } 4 \text { metres (personal assistance could be used, but speed of test (preferred or fast), } \\ \text { - supervision and gait aid use not reported) } \\ \text { - } 15 \text {-item Barthel Index } \\ \text { - FMA }\end{array}$

\begin{tabular}{|c|c|}
\hline Notes & $\begin{array}{l}3 \text { and 6-month follow-up data not reported } \\
\text { We chose to compare the EXP and CTL } 1 \text { groups only for this review because they had the same intensi- } \\
\text { ty and starting time of therapy }\end{array}$ \\
\hline
\end{tabular}


Richards 1993 (Continued)

Risk of bias

\begin{tabular}{lll}
\hline Bias & Authors' judgement & Support for judgement \\
\hline $\begin{array}{l}\text { Random sequence genera- } \\
\text { tion (selection bias) }\end{array}$ & Unclear risk & Not described \\
\hline $\begin{array}{l}\text { Allocation concealment } \\
\text { (selection bias) }\end{array}$ & Unclear risk & Not described \\
\hline $\begin{array}{l}\text { Blinding of outcome as- } \\
\text { sessment (detection bias) } \\
\text { All outcomes }\end{array}$ & Unclear risk & Unclear if evaluators were blind to group allocation \\
\hline
\end{tabular}

\section{Richards 2004}

\begin{tabular}{ll}
\hline Methods & RCT \\
Method of randomisation: stratified randomisation with random permuted blocks and random block \\
size \\
Blinding of outcome assessors: yes \\
Adverse events: not reported \\
Deaths: not reported \\
Dropouts: 15 (7 in EXP group, 8 in CTL group) \\
ITT:yes
\end{tabular}

Country: Canada
Participants participants (32 in EXP group, 31 in CTL group)
Ambulatory at study onset
Mean age: 61 and 63 years (CTL and EXP group, respectively)
Inclusion criteria: age between 30 and 89 years, with first or second episode of ischaemic stroke with
residual deficit, Barthel Ambulation Subscore $\geq 10$, gait speed between 0.1 and $0.6 \mathrm{~m} / \mathrm{s}$
Exclusion criteria: haemorrhagic stroke, inability to understand and follow verbal instructions, major
medical problems (diabetes, cancer, aphasia, orthopaedic disorders) interfering with the intervention

Interventions 2 arms:

1. CTL group received physiotherapy in an eclectic approach, 5 times per week for 8 weeks ( 5 hours per week)

2. EXP group received treadmill training without body weight support, reciprocal stepping and limb loading for the same time and frequency

$\begin{array}{ll}\text { Outcomes } & \text { Outcomes were recorded at baseline, at the end of the intervention phase, and } 3 \text { months later } \\ \text { Primary outcomes: gait speed by walking } 5 \text { metres, } 10 \text { metres, or } 30 \text { metres at preferred speed } \\ \text { Secondary outcomes: lower extremity function (FMA), Timed Up and Go, Functional Independence } \\ \text { (Barthel Ambulation Subscore) }\end{array}$

Notes Contamination addressed in the study design by issues of location and personnel

\section{Risk of bias}

\begin{tabular}{lll}
\hline Bias & Authors' judgement & Support for judgement \\
\hline $\begin{array}{l}\text { Random sequence genera- } \\
\text { tion (selection bias) }\end{array}$ & Low risk & Stratified randomisation with random permuted blocks and random block size \\
\hline
\end{tabular}


Richards 2004 (Continued)

\begin{tabular}{l}
$\begin{array}{l}\text { Allocation concealment } \\
\text { (selection bias) }\end{array}$ Low risk After randomisation, treating therapists were informed about assignment \\
\hline
\end{tabular}

$\begin{array}{ll}\text { Methods } & \text { Cross-over group design } \\ \text { Participants randomised to groups (method of randomisation and concealment not stated) } & 0 \% \text { dropouts at the end of the first treatment phase } \\ \text { Blinding of outcome assessors to group allocation not reported }\end{array}$

$\begin{array}{ll}\text { Participants } & 15 \text { participants allocated to the EXP then CTL order, and } 15 \text { participants allocated to the CTL then EXP } \\ & \text { order } \\ & \text { Inclusion criteria: hemiparesis; stroke (infarct or haemorrhage); at least } 4 \text { weeks post-stroke; not able } \\ & \text { to walk; able to stand for } 20 \text { seconds } \\ & \text { Exclusion criteria: cardiovascular problems or infections, with a decrease in general health }\end{array}$

Treated as inpatients for $5 \times 1$-hour sessions per week for 3 weeks
Treadmill training with body weight support (EXP): participants walked on a treadmill with partial
body weight support provided by a harness for 30 minutes plus completed 30 minutes of usual physio-
therapy per day
Usual physiotherapy $(\mathrm{CTL})$ : participants completed $2 \times 30$-minute sessions of usual physiotherapy per
day

Assessed at baseline, at cross-over ( 3 weeks) and after treatment phase (at 6 weeks):
- RMAS
- walking speed over $10 \mathrm{~m}$ (item 6 of the RMAS) (the speed of test (preferred or fast), personal assistance,
supervision and gait aid use were not reported)
- a unique gait scale based on clinical assessment
is baseline and data before cross-over only)

\section{Risk of bias}

\begin{tabular}{lll}
\hline Bias & Authors' judgement & Support for judgement \\
\hline $\begin{array}{l}\text { Random sequence genera- } \\
\text { tion (selection bias) }\end{array}$ & Unclear risk & Not described \\
\hline $\begin{array}{l}\text { Allocation concealment } \\
\text { (selection bias) }\end{array}$ & Unclear risk & Not described \\
\hline $\begin{array}{l}\text { Blinding of outcome as- } \\
\text { sessment (detection bias) } \\
\text { All outcomes }\end{array}$ & Unclear risk & Not described \\
\hline
\end{tabular}

Smith 2008

\begin{tabular}{ll}
\hline Methods RCT \\
\hline
\end{tabular}


Smith 2008 (Continued)

Method of randomisation: modified random assignment, matched-pair CTL group design; stratified regarding (1) motor impairment (measured by FMA) and (2) side of hemiparesis

Blinding of outcome assessors: no

Adverse events: not reported

Deaths: not reported

Dropouts: not reported

ITT: unclear

Country: USA
20 participants (10 in EXP group, 10 in CTL group)
Ambulatory at study onset: yes
Mean age: 56 and 58 years (CTL and EXP group, respectively)
Inclusion criteria: informed consent, ischaemic stroke in the distribution of the middle cerebral artery
$<3$ months, but > 2 years prior to study enrolment, walking slower than prior to the stroke
Exclusion criteria: cognitive impairment, inability to ambulate, concomitant pathology interfering with
treadmill walking

Interventions 2 arms:

1. CTL group received weekly telephone calls, asking about the quality of the participant's week and encouraging them to record life events in a log

2. EXP group additionally received treadmill training 12 times per month (mean intensity: 1 hour per week)

Outcomes

Outcomes were recorded at baseline, at the end of the intervention phase, and at 6-week follow-up

Outcomes: depression (Beck Depression Inventory); Stroke Impact Scale (SIS)

Notes

\section{Risk of bias}

\begin{tabular}{lll}
\hline Bias & Authors' judgement & Support for judgement \\
\hline $\begin{array}{l}\text { Random sequence genera- } \\
\text { tion (selection bias) }\end{array}$ & Unclear risk & Not described \\
\hline $\begin{array}{l}\text { Allocation concealment } \\
\text { (selection bias) }\end{array}$ & Unclear risk & Not described \\
\hline $\begin{array}{l}\text { Blinding of outcome as- } \\
\text { sessment (detection bias) } \\
\text { All outcomes }\end{array}$ & High risk & Outcome assessor was not blinded \\
\hline
\end{tabular}

\section{Srivastava 2016}

$\begin{array}{ll}\text { Methods } & \text { RCT } \\ \text { Method of randomisation: table of random numbers } \\ \text { Blinding of outcome assessors: stated as 'yes' by the investigator } \\ \text { Adverse events: no } \\ \text { Deaths: not stated } \\ \text { Dropouts: } 23 \text { (13 in group 2 and 3, } 10 \text { in group 1) } \\ \text { ITT: unclear }\end{array}$

$\begin{array}{ll}\text { Participants } & \text { Country: India } \\ & 45 \text { participants (group } 1 n=15 \text {, group } 2 n=15 \text {, and group } 3 n=15 \text { ) }\end{array}$


Srivastava 2016 (Continued)

Not ambulatory at study onset

Mean age: 46 years ( 24 to 65 years in all groups)

Inclusion criteria: first clinical episode of stroke due to an Ischaemic or haemorrhagic supratentorial lesion; right or left hemiparesis, age 16 to 65 years, duration of hemiparesis > 3 months; impaired ability to walk independently or need for one person to help with balance and coordination (Functional Ambulation Category II-IV).

Exclusion criteria: recurrent stroke, receptive aphasia with inadequate comprehension to understand and follow the training schedule, MMSE score $<23$, score $<12$ on the 24-item Hamilton Rating Scale for Depression, movement disorders interfering with training, recent myocardial infarction ( $<6$ months), ischaemia or angina at rest or during exercise, orthopaedic conditions

Interventions
$\begin{aligned} & \text { 1. group } 1 \text { received overground task-oriented gait-training } \\ & \text { 2. group } 2 \text { received gait-training on a treadmill without bodyweight support (full weight bearing) } \\ & \text { 3. group } 3 \text { received gait-training on a treadmill with partial bodyweight support (40\% unweighting of } \\ & \text { body weight) all groups trained } 30 \text { mins per day, } 5 \text { day per week for } 4 \text { weeks }\end{aligned}$

Outcomes

Outcomes were recorded at baseline, immediately after the intervention, and after 3 months

- Scandinavian Stroke Scale

- Functional ambulation category

- walking speed

- walking endurance

Notes

\section{Risk of bias}

\begin{tabular}{lll}
\hline Bias & Authors' judgement & Support for judgement \\
\hline $\begin{array}{l}\text { Random sequence genera- } \\
\text { tion (selection bias) }\end{array}$ & Low risk & Table of random numbers \\
\hline $\begin{array}{l}\text { Allocation concealment } \\
\text { (selection bias) }\end{array}$ & Unclear risk & Not described \\
\hline $\begin{array}{l}\text { Blinding of outcome as- } \\
\text { sessment (detection bias) } \\
\text { All outcomes }\end{array}$ & Low risk & Blinded assessor \\
\hline
\end{tabular}

Sullivan 2007

RCT, parallel-group design
Method of randomisation: stratified block randomisation (block size not stated)
Blinding of outcome assessors: yes
Adverse events: 21 cumulative adverse events in 18 participants until follow-up
Deaths: none
Dropouts: 9 until follow-up (6 in EXP group, 3 in CTL group)
ITT: yes, last observation carried forward for primary outcomes

Participants Country: USA

80 participants (60 in EXP group, 20 in CTL group)

Ambulatory at study onset: yes

Mean age: 63 and 60 years (CTL and EXP group, respectively) 
Sullivan 2007 (Continued)

Inclusion criteria: aged 18 and above, ischaemic or haemorrhagic stroke confirmed by CT, MRI or clinical criteria, 4 to 60 months post-stroke, ambulate at least 10 metres with assistive or orthotic device, FAC 2 or above, walking speed $\leq 1 \mathrm{~m} / \mathrm{s}$, informed consent, approval of primary care physician Exclusion criteria: serious medical conditions interfering with the study protocol such as high blood pressure, high resting heart rate, lower limb orthopaedic conditions, recent botulinum toxin injections, recent baclofen delivery, MMSE score < 24, co-interventions aiming at gait-training or lower extremity strengthening, prior enrolment to similar studies, plans to move out of the area of study centres during the next year

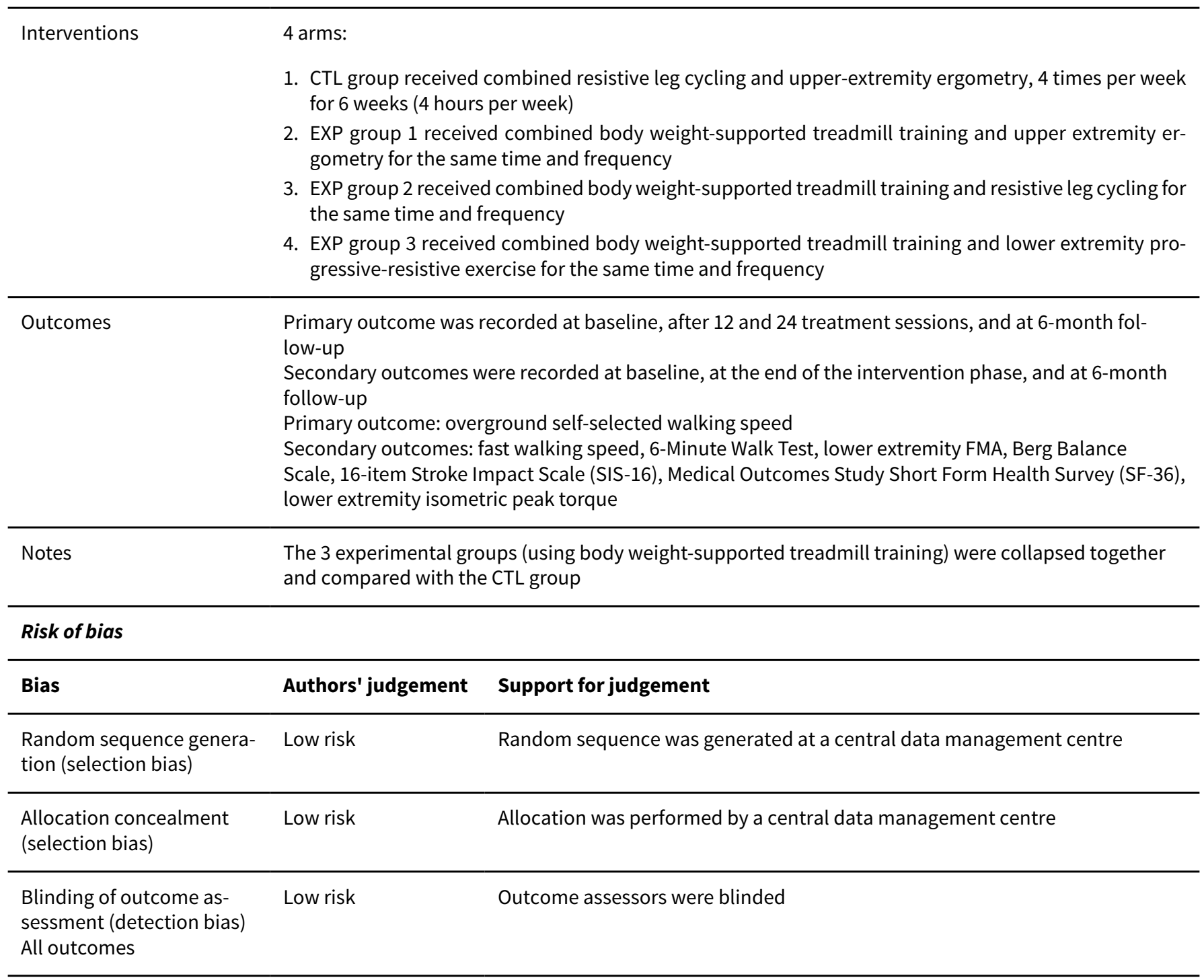

\section{Suputtitada 2004}

$\begin{array}{ll}\text { Methods } & \text { RCT, parallel-group design } \\ & \text { Method of randomisation: block randomisation (block size of 4) } \\ \text { Blinding of outcome assessors: yes } & \text { Adverse events: not reported } \\ \text { Deaths: not reported } \\ \text { Dropouts: not reported } \\ \text { ITT: unclear }\end{array}$

Participants Country: Thailand


Suputtitada 2004 (Continued)

48 participants (24 in EXP group, 24 in CTL group)

Ambulatory at study onset: yes

Mean age: 65 and 61 years (CTL and EXP group, respectively)

Inclusion criteria: stroke $\geq 6$ months prior to enrolment, able to sit at the edge of the bed independent-

ly, independent ambulation with or without gait aids, being able to communicate with therapists, in-

formed consent

Exclusion criteria: cardiac risk factors, hyperkinetic movement disorders, using orthoses or prostheses, training less than 2 consecutive weeks

\begin{tabular}{|c|c|c|}
\hline Interventions & \multicolumn{2}{|c|}{$\begin{array}{l}\text { 2 arms: } \\
\text { 1. CTL group received overground walking, } 7 \text { times per week for } 4 \text { weeks ( } 2.9 \text { hours per week) } \\
\text { 2. EXP group received body weight-supported treadmill training for the same time and frequency }\end{array}$} \\
\hline Outcomes & \multicolumn{2}{|c|}{$\begin{array}{l}\text { Outcomes were recorded at baseline and the end of the intervention phase } \\
\text { Measures of timed gait (10-Metre Walk Test); balance ability (Berg Balance Scale) }\end{array}$} \\
\hline \multicolumn{3}{|l|}{ Notes } \\
\hline \multicolumn{3}{|l|}{ Risk of bias } \\
\hline Bias & Authors' judgement & Support for judgement \\
\hline $\begin{array}{l}\text { Random sequence genera- } \\
\text { tion (selection bias) }\end{array}$ & Unclear risk & Not described \\
\hline $\begin{array}{l}\text { Allocation concealment } \\
\text { (selection bias) }\end{array}$ & Unclear risk & Not described \\
\hline $\begin{array}{l}\text { Blinding of outcome as- } \\
\text { sessment (detection bias) } \\
\text { All outcomes }\end{array}$ & Low risk & Outcome assessor was blinded \\
\hline
\end{tabular}

Takami 2010

$\begin{array}{ll}\text { Methods } & \text { RCT } \\ & \text { Method of randomisation: drawing envelopes containing a lot } \\ \text { Blinding of outcome assessors: not described } \\ \text { Adverse events: not reported } \\ \text { Deaths: not reported } \\ \text { Dropouts: } 3 \text { (1 in EXP group 1, } 2 \text { in EXP group 2, none in the CTL group) } \\ \text { ITT: unclear } \\ \text { Country: Japan } \\ \text { 36 participants (12 in EXP group 1, 12 in EXP group 2, 12 in CTL group) } \\ \text { Ambulatory at study onset: yes } \\ \text { Mean age: } 67 / 71 / 66 \text { years (CTL and EXP groups } 1 \text { and 2, respectively) } \\ \text { Inclusion criteria: receive physical therapy, being able to walk } 10 \text { metres unassisted, less than } 5 \text { weeks } \\ \text { post-stroke, FIM-L score } \leq 5, \text { perfect score on the Berg Balance Scale (BBS) or the Rivermead Mobility In- } \\ \text { dex (RMI) } \\ \text { Exclusion criteria: time to complete 10-Metre Walk Test < 4 sec, factors interfering with the study like } \\ \text { parkinsonism, dementia, severe communication disorders, and orthopaedic conditions }\end{array}$


Takami 2010 (Continued)

1. CTL group received conventional physiotherapy including overground walking, 6 times per week for 3 weeks ( 4 hours per week) plus ADL training 5 times per week for 3 weeks ( 3.3 hours)

2. EXP group 1 received control intervention 6 times per week for 3 weeks ( 3 hours per week) and additional body weight-supported treadmill training in forward direction 6 times per week for 3 weeks (1 hour per week)

3. EXP group 2 received control intervention 6 times per week for 3 weeks ( 3 hours per week) and additional body weight-supported treadmill training in backward direction 6 times per week for 3 weeks (1 hour per week)

Primary outcomes were recorded at baseline and once weekly during the 3-week intervention phase
Primary outcomes: balance ability (BBS), RMI, 10-metre maximum walking speed, walk ratios during
10 metres of forward walking, and 5 metres of backward walking
Secondary outcomes: Motricity Index, Functional Independence Measure Locomotor (FIM-L), modified
Borg scale

Notes Both EXP groups (using body weight-supported treadmill training) were collapsed together and compared with the CTL group

\section{Risk of bias}

\begin{tabular}{lll}
\hline Bias & Authors' judgement & Support for judgement \\
\hline $\begin{array}{l}\text { Random sequence genera- } \\
\text { tion (selection bias) }\end{array}$ & Unclear risk & Not described \\
\hline $\begin{array}{l}\text { Allocation concealment } \\
\text { (selection bias) }\end{array}$ & Low risk & Quote: "[subjects] were randomly allocated [...] using an envelope method." \\
\hline $\begin{array}{l}\text { Blinding of outcome as- } \\
\text { sessment (detection bias) } \\
\text { All outcomes }\end{array}$ & Unclear risk & $\begin{array}{l}\text { Not clearly described by the authors, however (quote:) "....a physical therapist } \\
\text { measured the required time and number of steps [of measures of timed gait]." }\end{array}$ \\
\hline
\end{tabular}

\section{Toledano-Zarhi 2011}

\begin{tabular}{ll}
\hline Methods & RCT, parallel-group design \\
Method of randomisation: not described \\
Blinding of outcome assessors: not described \\
Adverse events: none \\
Deaths: none \\
Dropouts: 1 in EXP group \\
ITT: yes \\
Country: Israel \\
28 participants (14 in EXP group, 14 in CTL group) \\
Ambulatory at study onset: yes \\
Mean age: 65 years \\
Inclusion criteria: ischaemic stroke within 1 to 3 weeks before the trial, modified Rankin scale $\leq 2$ \\
Exclusion criteria: systolic blood pressure $\geq 200$ mm Hg, diastolic blood pressure $\geq 110 \mathrm{~mm}$ Hg, unsta- \\
ble heart conditions, dementia, age $\geq 80$ years \\
2 arms: \\
1. CTL group received a home exercise booklet with included instructions for flexibility and muscle \\
strength exercises
\end{tabular}


Toledano-Zarhi 2011 (Continued)

2. EXP group received supervised exercise program including treadmill training twice per week for 6 weeks (180 minutes per week exercise training, including 70 to 110 minutes per week treadmill training) additionally to the control intervention

\begin{tabular}{|c|c|}
\hline Outcomes & $\begin{array}{l}\text { Outcomes were recorded at baseline and at the end of the } \\
\text { - gait endurance (6-Minute Walk Test) } \\
\text { - dynamic balance (four square step test) } \\
\text { - stairs ascending (seconds) } \\
\text { - stair descending (seconds) } \\
\text { - modified Bruce test: exercise duration (minutes) } \\
\text { - modified Bruce test: exercise (metabolic equivalents) } \\
\text { - heart rate rest (beats per minute) } \\
\text { - heart rate work (beats per minute) } \\
\text { - blood pressure rest systolic } \\
\text { - blood pressure rest diastolic } \\
\text { - blood pressure work systolic } \\
\text { - blood pressure work diastolic }\end{array}$ \\
\hline
\end{tabular}

Notes

\section{Risk of bias}

\begin{tabular}{lll}
\hline Bias & Authors' judgement & Support for judgement \\
\hline $\begin{array}{l}\text { Random sequence genera- } \\
\text { tion (selection bias) }\end{array}$ & Unclear risk & Not described \\
\hline $\begin{array}{l}\text { Allocation concealment } \\
\text { (selection bias) }\end{array}$ & Unclear risk & Not described \\
\hline $\begin{array}{l}\text { Blinding of outcome as- } \\
\text { sessment (detection bias) } \\
\text { All outcomes }\end{array}$ & Unclear risk & Not described \\
\hline
\end{tabular}

Visintin 1998

$\begin{array}{ll}\text { Methods } & \text { Parallel-group design } \\ \text { Participants randomised to groups using a stratified block randomisation scheme } \\ \text { Allocation was concealed using sealed and numbered envelopes } \\ 21 \% \text { dropouts at the end of the treatment phase, } 48 \% \text { dropouts at the 3-month follow-up } \\ \text { Blinding of outcome assessors to group allocation }\end{array}$

Participants
Inclusion criteria: admitted to the Jewish Rehabilitation Hospital for physical rehabilitation after
stroke; abnormal gait; no severe cardiac problems; no comorbid conditions contraindicating treadmill
training; not cerebellar, bilateral or brain stem stroke; able to understand simple commands; anticipat-
ed length of stay of at least 4 weeks; onset of stroke no more than 6 months prior to recruitment; able
to ambulate pre-stroke; first admission during study period; treadmill training time slot available; in-
formed consent

Interventions

Treated as inpatients for 4 × 20-minute session per week for 6 weeks

Treadmill training with body weight support (EXP): participants walked on a treadmill with partial body weight support using a harness and the assistance of 1 to 2 therapists 
Visintin 1998 (Continued)

Treadmill training only (CTL): participants walked on a treadmill with the assistance of 1 to 2 therapists; no body weight support was provided using a harness

\begin{tabular}{|c|c|c|}
\hline Outcomes & \multicolumn{2}{|c|}{$\begin{array}{l}\text { Assessed at baseline, after treatment phase, and } 3 \text { months later: } \\
\text { - preferred walking speed over } 3 \mathrm{~m} \text { (personal assistance and gait aids could be used) } \\
\text { - walking endurance - maximum distance walked up to a maximum of } 320 \mathrm{~m} \text { (personal assistance and } \\
\text { gait aids could be used) } \\
\text { - Berg Balance Scale } \\
\text { - Stroke Rehabilitation Assessment of Movement }\end{array}$} \\
\hline Notes & \multicolumn{2}{|c|}{$\begin{array}{l}\text { The rating of concealed allocation and the allocation concealment classification were changed based } \\
\text { on correspondence from the trialist } \\
\text { Data divided into } 2 \text { comparisons, see Visintin 1998a and Visintin 1998b }\end{array}$} \\
\hline \multicolumn{3}{|l|}{ Risk of bias } \\
\hline Bias & Authors' judgement & Support for judgement \\
\hline $\begin{array}{l}\text { Random sequence genera- } \\
\text { tion (selection bias) }\end{array}$ & Low risk & Drawing lots out of a box \\
\hline $\begin{array}{l}\text { Allocation concealment } \\
\text { (selection bias) }\end{array}$ & Low risk & Allocation was concealed using sealed and numbered envelopes \\
\hline $\begin{array}{l}\text { Blinding of outcome as- } \\
\text { sessment (detection bias) } \\
\text { All outcomes }\end{array}$ & Low risk & Outcome assessors were blind to group allocation \\
\hline
\end{tabular}

Visintin 1998a

\begin{tabular}{ll}
\hline Methods & See Visintin 1998 \\
\hline Participants & See Visintin 1998 \\
\hline Interventions & See Visintin 1998 \\
\hline Outcomes & See Visintin 1998 \\
\hline Notes & $\begin{array}{l}\text { For Visintin 1998a, data from the } 59 \text { participants who were dependent walkers at the start of treatment } \\
\text { and who did not drop out before the end of the treatment phase were used (33 EXP and } 26 \text { CTL); these } \\
\text { walking dependency data were obtained through correspondence with the authors }\end{array}$ \\
\hline
\end{tabular}

\section{Risk of bias}

\begin{tabular}{lll}
\hline Bias & Authors' judgement & Support for judgement \\
\hline $\begin{array}{l}\text { Random sequence genera- } \\
\text { tion (selection bias) }\end{array}$ & Low risk & Drawing lots out of a box \\
\hline $\begin{array}{l}\text { Allocation concealment } \\
\text { (selection bias) }\end{array}$ & Low risk & Allocation was concealed using sealed and numbered envelopes \\
\hline $\begin{array}{l}\text { Blinding of outcome as- } \\
\text { sessment (detection bias) }\end{array}$ & Low risk & Outcome assessors were blind to group allocation \\
\end{tabular}


Visintin 1998a (Continued)

All outcomes

Visintin 1998b

\begin{tabular}{ll}
\hline Methods & See Visintin 1998 \\
\hline Participants & See Visintin 1998 \\
\hline Interventions & See Visintin 1998 \\
\hline Outcomes & See Visintin 1998 \\
\hline Notes & $\begin{array}{l}\text { For Visintin 1998b, data from the } 20 \text { participants who were independent walkers at the start of treat- } \\
\text { ment and who did not drop out before the end of the treatment phase were used (10 EXP and } 10 \mathrm{CTL}) ; \\
\text { these walking dependency data were obtained through correspondence with the authors }\end{array}$ \\
\hline
\end{tabular}

\section{Risk of bias}

\begin{tabular}{lll}
\hline Bias & Authors' judgement & Support for judgement \\
\hline $\begin{array}{l}\text { Random sequence genera- } \\
\text { tion (selection bias) }\end{array}$ & Low risk & Drawing lots out of a box \\
\hline $\begin{array}{l}\text { Allocation concealment } \\
\text { (selection bias) }\end{array}$ & Low risk & Allocation was concealed using sealed and numbered envelopes \\
\hline $\begin{array}{l}\text { Blinding of outcome as- } \\
\text { sessment (detection bias) } \\
\text { All outcomes }\end{array}$ & Low risk & Outcome assessors were blind to group allocation \\
\hline
\end{tabular}

Weng 2004

RCT, parallel-group design
Method of randomisation: stratified randomisation, generation of random sequence not stated
Allocation concealment: not described
Blinding of outcome assessors: unclear
Adverse events: none
Deaths: none
Dropouts: 5 ( 2 in EXP group, 3 in CTL group)
ITT: no

Participants

Country: China

50 participants (25 in EXP group, 25 in CTL group)

Ambulatory at study onset: yes $(F A C \geq 3)$

Mean age: 55 years (CTL and EXP group)

Inclusion criteria: comply with the Fourth National Stroke diagnostic criteria; stable disease, blood pressure and heart rate control in the normal range, lower extremity Brunnstrom stage $\geq 2$, lower ex- 
Weng 2004 (Continued)

tremity limb paralysis without severe clonus and joint stiffness (Ashworth scale $\leq 2$ ), participants being able to walk more than 10 metres independently or under supervision and without the help of assistive devices, walking speed $\geq 0.17 \mathrm{~m} / \mathrm{s}$

Exclusion criteria: history of myocardial infarction, severe ventricular arrhythmias, chronic heart failure; lower extremity total joint replacement or severe arthritis, recurrent stroke, other severe conditions

Interventions

2 arms, treated as inpatients:

1. CTL group received 5 daily sessions of 20 minutes conventional training for 4 weeks

2. EXP group received 5 daily sessions of 20 minutes of body weight-supported treadmill training for 4 weeks

Outcomes

Outcomes were assessed at baseline and at the end of the intervention phase:

- lower limb function (lower extremity FMA)

- balance ability (Berg Balance Scale)

- ADL-performance (FIM)

- ambulation (FAC)

- maximal walking speed

Notes

\section{Risk of bias}

\begin{tabular}{lll}
\hline Bias & Authors' judgement & Support for judgement \\
\hline $\begin{array}{l}\text { Random sequence genera- } \\
\text { tion (selection bias) }\end{array}$ & Unclear risk & Not described \\
\hline $\begin{array}{l}\text { Allocation concealment } \\
\text { (selection bias) }\end{array}$ & Unclear risk & Not described \\
\hline $\begin{array}{l}\text { Blinding of outcome as- } \\
\text { sessment (detection bias) } \\
\text { All outcomes }\end{array}$ & Unclear risk & Not described \\
\hline
\end{tabular}

\section{Weng 2006}

Methods

RCT, parallel-group design

Method of randomisation: random number table

Allocation concealment: sealed envelopes

Blinding of outcome assessors: unclear

Adverse events: not stated by the authors

Deaths: not stated by the authors

Dropouts: unclear

ITT: unclear

$\begin{array}{ll}\text { Participants } & \text { Country: China } \\ & 26 \text { participants (13 in EXP group, } 13 \text { in CTL group) }\end{array}$


Weng 2006 (Continued)

Ambulatory at study onset: able to walk 10 metres without aids

Mean age: 50 and 51 years (CTL and EXP group, respectively)

Inclusion criteria: comply with the Fourth National Stroke diagnostic criteria; stable disease, blood pressure and heart rate control in the normal range, lower extremity Brunnstrom stage $\geq 2$, lower extremity limb paralysis without severe clonus and joint stiffness (Ashworth scale $\leq 2$ ), participants being able to walk more than $10 \mathrm{~m}$ independently and without the help of assistive devices

Exclusion criteria: history of myocardial infarction, severe ventricular arrhythmias, chronic heart failure, lower extremity total joint replacement or severe arthritis, recurrent stroke, other severe conditions

Interventions
$\begin{aligned} & \text { 1. CTL group received } 5 \text { daily sessions of } 60 \text { minutes conventional training for } 3 \text { weeks } \\ & \text { 2. EXP group received } 5 \text { daily sessions of } 30 \text { minutes conventional training and } 30 \text { minutes of additional } \\ & \text { backward walking with body weight support on a treadmill for } 3 \text { weeks }\end{aligned}$

Outcomes

Outcomes were assessed at baseline and at 3 weeks follow-up:

- lower extremity FMA

- Berg Balance Scale

Notes

\section{Risk of bias}

\begin{tabular}{lll}
\hline Bias & Authors' judgement & Support for judgement \\
\hline $\begin{array}{l}\text { Random sequence genera- } \\
\text { tion (selection bias) }\end{array}$ & Low risk & Random number table \\
\hline $\begin{array}{l}\text { Allocation concealment } \\
\text { (selection bias) }\end{array}$ & Low risk & Sealed envelopes \\
\hline $\begin{array}{l}\text { Blinding of outcome as- } \\
\text { sessment (detection bias) } \\
\text { All outcomes }\end{array}$ & Unclear risk & Not described \\
\hline
\end{tabular}

Werner 2002a

\begin{tabular}{ll} 
Methods & $\begin{array}{l}\text { Cross-over group design } \\
\text { Participants randomised to groups (group allocation in envelopes that were drawn by an independent } \\
\text { person) } \\
0 \% \text { dropouts at the end of the first treatment phase } \\
\text { Blinding of outcome assessors to group allocation }\end{array}$ \\
\hline Participants & $\begin{array}{l}15 \text { participants allocated to the EXP then CTL order, and } 15 \text { participants allocated to the CTL then EXP } \\
\text { order } \\
\text { Inclusion criteria: first stroke; supratentorial lesion; } 4 \text { to } 12 \text { weeks post-stroke; aged less than } 75 \text { years; } \\
\text { not able to walk (FAC of } 2 \text { or less); able to sit unsupported on the edge of a bed; able to stand for at least } \\
10 \text { seconds with help; written informed consent } \\
\text { Exclusion criteria: hip and knee extension deficit of more than } 20 \text { degrees; passive dorsiflexion of the } \\
\text { affected ankle to less than a neutral position; severe impairment of cognition or communication; ev- } \\
\text { idence of cardiac ischaemia, arrhythmia, decompression or heart failure; feeling of 'overexertion' or } \\
\text { heart rate exceeding the age-predicted maximum (i.e. } 190 \text { beats/minute minus age) during training; }\end{array}$
\end{tabular}


Werner 2002a (Continued)

resting systolic blood pressure exceeding $200 \mathrm{~mm} \mathrm{Hg}$ at rest or dropping by more than $10 \mathrm{~mm} \mathrm{Hg}$ with increasing workload

\begin{tabular}{ll}
\hline Interventions & Treated as inpatients for 5 x 15 to 20 -minute sessions per week for 2 weeks \\
$\begin{array}{l}\text { 1. Treadmill training with body weight support (EXP): participants walked on a treadmill with partial } \\
\text { body weight support provided by a harness }\end{array}$ \\
$\begin{array}{l}\text { 2. GaitTrainer with body weight support (CTL): participants walked on a GaitTrainer with partial body } \\
\text { weight support provided by a harness }\end{array}$ \\
\hline Outcomes \\
$\begin{array}{l}\text { This was an A-B-A (or B-A-B) design, so participants were assessed at baseline, at first cross-over ( } 2 \\
\text { - FAC } \\
\text { - fast walking speed over } 10 \text { m with personal assistance and gait aids, if required } \\
\text { - RMAS }\end{array}$
\end{tabular}

Notes number of dropouts was changed based on correspondence with the trialists
Trial treated as a parallel-group design for this review by using the first treatment phase data only (that
is, baseline and data from the first phase of the cross-over trial only)

\section{Risk of bias}

\begin{tabular}{lll}
\hline Bias & Authors' judgement & Support for judgement \\
\hline $\begin{array}{l}\text { Random sequence genera- } \\
\text { tion (selection bias) }\end{array}$ & Low risk & Lots with sealed opaque envelopes that were drawn by an independent person \\
\hline $\begin{array}{l}\text { Allocation concealment } \\
\text { (selection bias) }\end{array}$ & Low risk & Sealed opaque envelopes that were drawn by an independent person \\
\hline $\begin{array}{l}\text { Blinding of outcome as- } \\
\text { sessment (detection bias) } \\
\text { All outcomes }\end{array}$ & Unclear risk & Unclear if outcome assessors were blinded to group assignment \\
\hline
\end{tabular}

\section{Yang 2010}

\begin{tabular}{ll}
\hline Methods & RCT in parallel-group design \\
& Method of randomisation: drawing lots out of an envelope \\
& Blinding of outcome assessors: yes \\
Adverse events: not reported & Deaths: none \\
Dropouts: none \\
ITT: yes
\end{tabular}


Yang 2010 (Continued)

1. EXP group 1 with participants $<6$ months post-stroke received body weight-supported treadmill training for 30 minutes followed by 20 minutes general exercise program, 3 times per week for 4 weeks (150 minutes per week)

2. CTL group 1 with participants $<6$ months post-stroke received the general exercise program for 50 minutes, 3 times per week for 4 weeks ( 150 minutes per week)

3. EXP group 2 with participants $>12$ months post-stroke received body weight-supported treadmill training for 30 minutes followed by 20 minutes general exercise program, 3 times per week for 4 weeks (150 minutes per week)

4. CTL group 2 with participants $>12$ months post-stroke received the general exercise program for 50 minutes, 3 times per week for 4 weeks (150 minutes per week)

\begin{tabular}{ll}
\hline Outcomes & Outcomes were recorded at baseline and at the end of the intervention phase \\
Primary outcomes: motor threshold and cortical map size \\
Secondary outcomes: lower limb function (FMA)
\end{tabular}

Notes

We combined the experimental groups and compared them with the combined controlled groups

\section{Risk of bias}

Bias Authors' judgement Support for judgement

Random sequence genera- Unclear risk Not described

tion (selection bias)

Allocation concealment $\quad$ Low risk Drawing lots out of an envelope
(selection bias)

Blinding of outcome as- Low risk Outcome assessor was blinded

sessment (detection bias)

All outcomes

\section{Yen 2008}

Rethods
Method of randomisation: described that an independent person selected 1 of the sealed envelopes
containing allocation
Adverse events: not stated
Deaths: none
Dropouts: none
ITT: yes

Country: Taiwan
Participants
Ambarticipants ( 7 in EXP group, 7 in CTL group)
Mean age: 56 and 57 years (CTL and EXP group, respectively)
Inclusion criteria: unilateral stroke with unilateral hemiparesis, $\geq 6$ months post-stroke, ability to walk
at least 10 metres independently with or without assistance, no severe cognitive impairment, stable
medical condition
Exclusion criteria: history of seizure, any orthopaedic or neurological conditions interfering with the
study, cardiac problems/pacemaker, metallic implants in the head, walk with normal gait pattern, in-
ability to walk pre-stroke

Interventions 2 arms:

1. CTL group used general physiotherapy, 2 to 5 times per week for 4 weeks ( 100 to 250 minutes per week) 
Yen 2008 (Continued)

2. EXP group, additionally to the control intervention, received 12 additional sessions of BWSTT, 3 times per week for 4 weeks ( 90 minutes per week)

\begin{tabular}{lll}
\hline Outcomes & Outcomes were recorded at baseline and at the end of the intervention phase \\
& $\begin{array}{l}\text { • } \\
\text { - } \begin{array}{l}\text { galance performance (Berg Balance Scale) } \\
\text { corticomotor activity }\end{array}\end{array}$ \\
\hline Notes & & \\
\hline Risk of bias & Authors' judgement & Support for judgement \\
\hline Bias & Low risk & Independent person selected one of the sealed envelopes containing a lot \\
\hline $\begin{array}{l}\text { Random sequence genera- } \\
\text { tion (selection bias) }\end{array}$ & Low risk & Independent person selected one of the sealed envelopes containing a lot \\
\hline $\begin{array}{l}\text { Allocation concealment } \\
\text { (selection bias) }\end{array}$ & High risk & Outcome assessor was not blinded \\
\hline $\begin{array}{l}\text { Blinding of outcome as- } \\
\text { sessment (detection bias) } \\
\text { All outcomes }\end{array}$ & & \\
\hline
\end{tabular}

\section{Zhang 2008}

Rethods parallel-group design
Method of randomisation: no details described by the authors
Allocation concealment: no details described by the authors
Blinding of outcome assessors: no blinding
Adverse events: not stated by the authors
Deaths: not stated by the authors
Dropouts: not clearly stated by the authors
ITT: unclear

Participants

Country: China

39 participants (19 in EXP group, 20 in CTL group)

Ambulatory at study onset: not stated by the authors

Mean age: 63 years (CTL and EXP group, respectively)

Inclusion criteria: ischaemic or haemorrhagic stroke confirmed by CT or MRI; aged 52 to 70 years; stable vital signs, conscious, being able to adhere to instructions; lower limb dysfunction Brunnstrom stage 2; blood pressure $>140 / 90 \mathrm{~mm} \mathrm{Hg}$, no myocardial infarction or angina pectoris

Exclusion criteria: not stated by the authors

Interventions
1. CTL group used conventional physical therapy (treatment dosage not stated)


2. EXP group received conventional physical therapy and additional BWSTT for $5 \times 30$-minute sessions, 8 weeks, started with $40 \%$ weight-bearing relief and $0.2 \mathrm{~km} /$ hour and was gradually decreased or increased, respectively

\begin{tabular}{|c|c|}
\hline Outcomes & Outcomes were assessed at baseline and at the end of the int \\
\hline Uutcomes & $\begin{array}{l}\text { - ankle dorsiflexion (tibialis anterior muscle) EMG activity } \\
\text { - } \text { ankle plantarflexion (gastrocnemius muscle) EMG activity } \\
\text { - contraction ratio of agonist and antagonist }\end{array}$ \\
\hline
\end{tabular}

\section{Notes}

\section{Risk of bias}

\begin{tabular}{lll}
\hline Bias & Authors' judgement & Support for judgement \\
\hline $\begin{array}{l}\text { Random sequence genera- } \\
\text { tion (selection bias) }\end{array}$ & Unclear risk & Not described \\
\hline $\begin{array}{l}\text { Allocation concealment } \\
\text { (selection bias) }\end{array}$ & Unclear risk & Not described \\
\hline $\begin{array}{l}\text { Blinding of outcome as- } \\
\text { sessment (detection bias) } \\
\text { All outcomes }\end{array}$ & Unclear risk & Not described \\
\hline
\end{tabular}

\section{Zhu 2004}

Rethods parallel-group design
Method of randomisation: random number table
Allocation concealment: unclear
Blinding of outcome assessors: no
Adverse events: not reported by the authors
Dropouts: none, all participants completed the study
ITT: yes
Country: China
20 participants (10 in EXP group, 10 in CTL group)
Ambulatory at study onset: not stated by the authors
Mean age: 58 and 57 years (CTL and EXP group, respectively)
Inclusion criteria: aged 30 to 80 years; ischaemic or haemorrhagic stroke; confirmed by CT or MRI; not
able to walk (FAC of 2 or less); being able to stand up without help; MMSE $\geq 21$ points
Exclusion criteria: other conditions than stroke affecting ambulation, such as history of spinal cord in-
jury or amputation; myocardial infarction; severe heart failure; poor kidney function; uncontrolled dia-
betes mellitus; activated rheumatic diseases; MMSE < 21 points; body weight $\geq 110$ kg

Interventions 2 arms, treated as inpatients: 
Zhu 2004 (Continued)

1. treadmill training with body weight support (EXP): participants walked on the Pneu-weight system 5 sessions per week for 4 weeks (duration of sessions not stated), therapy (duration, body weight support) was tailored to the participants individual capabilities

2. traditional gait-training (CTL): conventional functional gait-training 5 sessions per week for 4 weeks (duration of sessions not stated)

Assessed at baseline and at the end of the intervention phase:
- walking ability (FAC)
- balance ability (BBS)
The following outcomes were measured by footprint analysis:
- ipsilateral stepping length
- contralateral stepping length
- contralateral stride
- ipsilateral stride
- contralateral step angle
- ipsilateral step angle
- cadence
- step width
- walking speed

\section{Notes}

\section{Risk of bias}

\begin{tabular}{lll}
\hline Bias & Authors' judgement & Support for judgement \\
\hline $\begin{array}{l}\text { Random sequence genera- } \\
\text { tion (selection bias) }\end{array}$ & Low risk & Random number table \\
\hline $\begin{array}{l}\text { Allocation concealment } \\
\text { (selection bias) }\end{array}$ & Unclear risk & Not described \\
\hline $\begin{array}{l}\text { Blinding of outcome as- } \\
\text { sessment (detection bias) } \\
\text { All outcomes }\end{array}$ & High risk & Outcome assessor was not blinded \\
\hline
\end{tabular}

ADL: activities of daily living

BBS: Berg Balance Scale

BWS: body weight support

BWSTT: body weight-supported treadmill training

$\mathrm{CT}$ : computed tomography

CTL: control

EMG: electromyographic activity

EXP: experimental

FAC: Functional Ambulation Category

FIM: Functional Independence Measure

FMA: Fugl-Meyer Assessment

GT: Gait trainer

ICF: international classification of functioning

ITT: intention-to-treat

$\mathrm{km} / \mathrm{hr}$ : kilometres per hour

LTT: limited progressive treadmill training

max: maximum

$\mathrm{m} / \mathrm{min}$ : metre per minute

$\mathrm{m} / \mathrm{s}$ : metre per second 
MMSE: Mini Mental State Examination

MRI: magnetic resonance imaging

NYHA: New York Heart Association

PNF: Proprioceptive Neuromuscular Facilitation

$\mathrm{RCT}$ : randomised controlled trial

RMAS: Rivermead Motor Assessment Scale

RMI: Rivermead Mobility Index

SD: standard deviation

SF-12: short form 12-item (for measuring health-related quality of life)

SF-36: short form 36-item (for measuring health-related quality of life)

SIS: stroke impact scale

STT: speed-dependent treadmill training

TBC: to be confirmed

TTBWS: treadmill training with body weight support

VO2: volume of oxygen consumption

Characteristics of excluded studies [ordered by study ID]

\begin{tabular}{|c|c|}
\hline Study & Reason for exclusion \\
\hline Aschbacher 2006 & Irrelevant intervention: electromechanical device training \\
\hline Bayat 2005 & Described only a single-session application of treadmill training \\
\hline Bleckert 2006 & Both groups received treadmill training and differed only in the speed of the treadmill \\
\hline Blennerhassett 2004 & Irrelevant intervention: circuit class training \\
\hline Borsje 2003 & Correspondence with the author revealed that the trial was abandoned \\
\hline Brissot 2006 & Investigated electromechanically assisted gait-training \\
\hline Caldwell 2000 & $\begin{array}{l}\text { Correspondence with the author revealed that the trial was abandoned after the recruitment of on- } \\
\text { ly } 5 \text { participants (each allocated to } 1 \text { of } 3 \text { treatment groups) }\end{array}$ \\
\hline Daly 2004 & $\begin{array}{l}\text { Both groups received treadmill training; the parameter that was experimentally manipulated was } \\
\text { electrical stimulation }\end{array}$ \\
\hline Daly 2011 & $\begin{array}{l}\text { Both groups received treadmill training and differed only by means of functional electrical stimula- } \\
\text { tion }\end{array}$ \\
\hline Dean 2000 & Irrelevant intervention: circuit class training \\
\hline DEGAS 2007 & Irrelevant intervention: electromechanical device training \\
\hline Dias 2007 & Irrelevant intervention: electromechanical device training \\
\hline Druzbicki 2016 & Control group also received treadmill training \\
\hline English 2007 & Irrelevant intervention: circuit class training \\
\hline Fisher 2008 & Irrelevant intervention: electromechanical device training \\
\hline Forrester 2004 & Evaluated a single treatment session, not a full course of treatment \\
\hline Freivogel 2009 & $\begin{array}{l}\text { Mixed population of participants with traumatic brain injury, spinal cord injury, and stroke; only } 2 \\
\text { out of } 16 \text { included participants had a stroke }\end{array}$ \\
\hline
\end{tabular}




\begin{tabular}{|c|c|}
\hline Study & Reason for exclusion \\
\hline Globokar 2005 & Irrelevant intervention: electromechanical device training \\
\hline Hidler 2009 & Irrelevant intervention: electromechanical device training \\
\hline Hornby 2008 & Irrelevant intervention: robotic device training \\
\hline Husemann 2007 & Irrelevant intervention: electromechanical device training \\
\hline Jang 2005 & Irrelevant intervention: electromechanical device training \\
\hline Jeong 2008 & Irrelevant intervention: electromechanical device training \\
\hline Khanna 2003 & $\begin{array}{l}\text { Correspondence with the author revealed that the trial was abandoned before the commencement } \\
\text { of recruitment }\end{array}$ \\
\hline Kim 2001 & Irrelevant intervention: electromechanical device training \\
\hline Kim 2008 & Irrelevant intervention: electromechanical device training \\
\hline Kovrazhkina 2009 & Irrelevant intervention: electromechanical device training \\
\hline Kwakkel 1999 & $\begin{array}{l}\text { Correspondence with the author revealed that less than } 20 \% \text { of participants in the EXP group par- } \\
\text { ticipated in treadmill training (i.e. only } 6 \text { out of } 31 \text { participants) }\end{array}$ \\
\hline Langhammer 2000 & $\begin{array}{l}\text { Correspondence with the author revealed that treadmill training (with or without body weight sup- } \\
\text { port) was not used in either group }\end{array}$ \\
\hline Langhammer 2007 & Fewer than $20 \%$ of participants in the EXP group received treadmill training \\
\hline Lau 2010 & Both groups received treadmill training which differed only by speed \\
\hline Lee 2013 & Both groups received treadmill training \\
\hline Lindquist 2011 & Quasi-experimental study, without randomisation \\
\hline Macko 2006 & Both groups received treadmill training which differed only by duration and speed \\
\hline Mayr 2007 & EXP group used an electromechanical device on a treadmill \\
\hline Mayr 2008 & Irrelevant intervention: electromechanical device training \\
\hline McCain 2008 & Not an RCT \\
\hline Michael 2011 & Not a randomised controlled trial \\
\hline NCT00018421 & Investigated cardiovascular fitness and energy expenditure \\
\hline NCT00108030 & compared BWS + TT with BWS + TT plus power training \\
\hline NCT00284115 & Investigated electromechanical-assisted gait-training \\
\hline NCT00612300 & Irrelevant intervention: electromechanical device training \\
\hline NCT00891514 & Investigated aerobic exercise and inflammation \\
\hline
\end{tabular}




\begin{tabular}{|c|c|}
\hline Study & Reason for exclusion \\
\hline NCT01146587 & Suspended \\
\hline NCT01337960 & Evaluated ankle robot \\
\hline NCT01674790 & Assessed cognition \\
\hline NCT02043574 & Measured energy expenditure \\
\hline NCT02680496 & Measured energy consumption and cardiorespiratory load during walking \\
\hline NCT02735148 & Investigated robot-assisted device (Lokomat) \\
\hline NCT02798237 & Not yet recruiting \\
\hline NCT02956096 & Not yet recruiting \\
\hline NCT03006731 & Not yet recruiting \\
\hline NCT03056287 & Not yet recruiting \\
\hline Pang 2010 & Not an RCT \\
\hline Park 2012 & $\begin{array}{l}\text { Both groups received treadmill training and differed only in the setting (underwater treadmill ver- } \\
\text { sus overground treadmill) }\end{array}$ \\
\hline Peurala 2005 & Did not use treadmill training \\
\hline Peurala 2009 & Irrelevant intervention: electromechanical device training \\
\hline Ploughman 2008 & Evaluation of a single treatment session \\
\hline Rimmer 2000 & $\begin{array}{l}\text { Correspondence with the author revealed that only one-third of participants in the EXP group par- } \\
\text { ticipated in treadmill training }\end{array}$ \\
\hline Salbach 2004 & Irrelevant intervention: circuit class training \\
\hline Saltuari 2004 & Irrelevant intervention: electromechanical device training \\
\hline Schwartz 2009 & Irrelevant intervention: electromechanical device training \\
\hline Shafshak 2012 & $\begin{array}{l}\text { All groups received treadmill training with partial body weight support: the parameter that was ex- } \\
\text { perimentally manipulated was upper limb swinging }\end{array}$ \\
\hline Sullivan 2002 & $\begin{array}{l}\text { All groups received treadmill training with partial body weight support; the parameter that was ex- } \\
\text { perimentally manipulated was treadmill speed }\end{array}$ \\
\hline Tong 2006 & Irrelevant intervention: electromechanical device training \\
\hline Trueblood 2001 & $\begin{array}{l}\text { A non-random process was used to allocate participants to groups in Part II and Part III } \\
\text { Participants chose which treatment they would receive }\end{array}$ \\
\hline Tsai 2004 & $\begin{array}{l}\text { All groups received treadmill training (without partial body weight support); the parameters that } \\
\text { were experimentally manipulated were walking direction and treadmill slope }\end{array}$ \\
\hline
\end{tabular}




\begin{tabular}{ll}
\hline Study & Reason for exclusion \\
\hline Tsang 2012 & Irrelevant outcome: echocardiography \\
\hline Werner 2002b & $\begin{array}{l}\text { Both groups received treadmill training with body weight support; the parameter that was experi- } \\
\text { mentally manipulated was 'conventional' physiotherapy gait-training }\end{array}$ \\
\hline Westlake 2009 & Used robot-assisted training (Lokomat) \\
\hline Yagura 2006 & $\begin{array}{l}\text { Both groups received treadmill training with body weight support; the parameter that was experi- } \\
\text { mentally manipulated was therapeutic facilitation }\end{array}$ \\
\hline Yang 2008 & $\begin{array}{l}\text { Both groups received treadmill training and differed only by the EXP group receiving virtual reality } \\
\text { as well }\end{array}$ \\
\hline
\end{tabular}

EXP: experimental

$\mathrm{RCT}$ : randomised controlled trial

Characteristics of studies awaiting assessment [ordered by study ID]

Baer 2009

$\begin{array}{ll}\text { Methods } & \text { Method: multicentre RCT } \\ & \text { Method of randomisation: stratified randomisation based on side of lesion and initial FAC score } \\ & \text { Blinding of outcome assessors: not described } \\ & \text { Adverse events: not stated } \\ & \text { Deaths: not stated } \\ & \text { Dropouts: } 8 \text { during intervention phase } \\ & \text { ITT: unclear }\end{array}$

Country: UK
77 people with subacute stroke within 3 months of stroke onset
Ambulatory at study onset: not described
Inclusion criteria: stroke as defined by WHO; age over 18 ; medically stable; 1 minute standing bal-
ance (with or without support), ability to understand and follow verbal instructions

\section{2 arms:}

1. CTL group received "normal gait re-education" for 8 weeks, at least 3 times per week

2. EXP group received gait re-education by treadmill training for 8 weeks, at least 3 times per week

\begin{tabular}{ll}
\hline Outcomes & Outcomes were recorded at baseline and after 8 weeks of therapy: \\
& Measures of timed gait (10-Metre Walk Test) \\
& - Motor Assessment Scale \\
& - FAC \\
& - gait capacity (6-Minute Walk Test) \\
& - ADL (Barthel Index) \\
& - modified Rivermead Mobility Index \\
& - Timed Up and Go \\
& - Stroke Impact Scale
\end{tabular}


Bartloff 2009

\begin{tabular}{ll}
\hline Methods & Unclear \\
\hline Participants & Unclear \\
\hline Interventions & Unclear \\
\hline Outcomes & Unclear \\
\hline
\end{tabular}

Notes

Mokrusch 2004

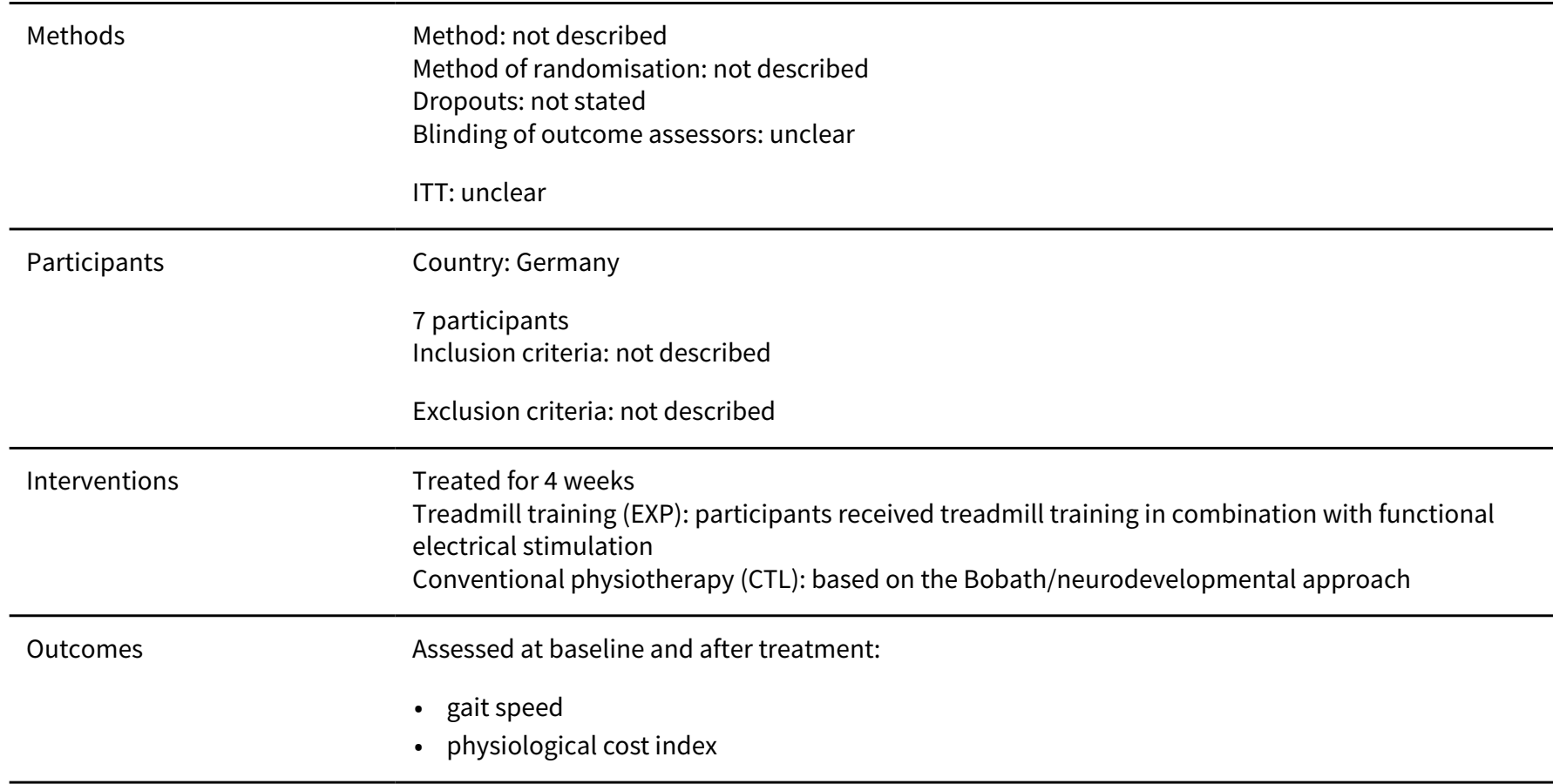

Notes Characteristics derived from conference abstract

\section{Muller 2004}

\begin{tabular}{ll}
\hline Methods & Method: not described \\
& Method of randomisation: not described \\
& Drop outs:not stated \\
Blinding of outcome assessors: unclear \\
ITT: unclear
\end{tabular}

\section{Participants}

\section{Country: Germany}

50 participants in the EXP group, 44 participants in the CTL group Ambulatory at study onset: unclear

Inclusion criteria: not clearly described, quote "stroke and spinal patients" 
Muller 2004 (Continued)

Exclusion criteria: not described

\section{Interventions Treatment duration: unknown}

Treadmill training (EXP): participants received treadmill training for 45 minutes per session

Electromechanical assisted gait-training (CTL): using the Lokomat on a treadmill for 45 minutes per session

Outcomes Assessed at baseline and after treatment :

1. effective training time

2. gait endurance (distance walked in therapy sessions)

Notes Characteristics derived from conference abstract

\section{Methods}

Methods

\begin{tabular}{ll}
\hline Methods & Method: RCT, parallel assignment \\
& Method of randomisation: not described \\
& Blinding of outcome assessors: yes \\
ITT: unclear
\end{tabular}

\section{Country: USA}

56 people with chronic stroke

Ambulatory at study onset: yes

Inclusion criteria: subacute (<6 months) stroke; 18 to 75 years old; history of unilateral, supratentorial, ischaemic or haemorrhagic stroke; being able to walk 10 metres without physical assistance; gait speed less than or equal to $0.8 \mathrm{~m} / \mathrm{s}$; medical clearance

Exclusion criteria: significant cardiorespiratory or metabolic disease that may limit exercise participation; weight limit > $113 \mathrm{~kg}$; history of previous orthopaedic or neurological conditions which may impair walking; MMSE $<23$

Exclusion for transcranial magnetic stimulation (TMS): pacemaker, metal implants in the head region, history of epilepsy or seizures, skull fractures or skull deficits, concussion within the last 6 months, unexplained recurring headaches, medications that lower seizure threshold, pregnancy

Exclusion for the MRI: aneurysm clip or coil, metal or wire implants, heart valve prosthesis

1. CTL group will receive conventional physiotherapy for 8 weeks, at least 3 times per week

2. EXP group will receive locomotor training including treadmill training, overground walking training, overground walking training and stair climbing for 8 weeks, 5 times per week (200 minutes per week)

Outcomes

Primary outcomes will be assessed at baseline, at the end of the intervention phase at 8 weeks, and at 3-month follow-up:

- gait speed (change in 10-Metre Walk Test)

Secondary outcomes will be assessed at baseline, at the end of the intervention phase at 8 weeks, and at 2-month follow-up:

- change in 6-Minute Walk Test 
NCT01789853 (Continued)

- change in Berg Balance Scale

\section{Notes}

\section{NCT02619110}

Methods Method: not described

Method of randomisation: not described

Dropouts: not stated

Blinding of outcome assessors: not blinded

ITT: unclear

People after chronic stroke
$\begin{array}{ll}\text { Inclusion criteria: } \\ \text { - }\end{array}$
$\begin{aligned} & \text { this experiment recruited participants with chronic stroke more than } 6 \text { months, whose level of } \\ & \text { assistive devices }\end{aligned}$

Exclusion criteria: unclear

Interventions

- EXP: backward walking treadmill training participants received 30 minutes backward walking treadmill training per week for 4 weeks

- CTL: conventional physical therapy participants received 30 minutes traditional physical therapy 3 times per week for 4 weeks
After 4 weeks:

- Berg Balance Scale

- Timed 10-Meter Walk Test

- 6-minute walk test

- Up and Go test (TUG)

\section{Notes}

\section{Opara 2016}

\begin{tabular}{|c|c|}
\hline Methods & $\begin{array}{l}\text { Method of randomisation: not described } \\
\text { Dropouts: not stated } \\
\text { Blinding of outcome assessors: not blinded } \\
\text { ITT: unclear }\end{array}$ \\
\hline Participants & $\begin{array}{l}60 \text { people after stroke, including those with hemiparesis } \\
\text { Inclusion criteria: up to } 3 \text { months after stroke with limited gait function } \\
\text { Exclusion criteria: unclear }\end{array}$ \\
\hline Interventions & $\begin{array}{l}\text { - EXP: treadmill training with BWS (consisted of } 30 \text { participants who applied exercises using a de- } \\
\text { vice that enables partial body weight support - UnWeighing System) } 4 \text { weeks, } 5 \text { days a week, for } \\
30 \text { minutes per day, body weight support was } 30 \% \text {, speed of the treadmill was between } 1 \text { and } 4.2 \\
\mathrm{~km} / \mathrm{h} \text {, an average of } 1.5 \mathrm{~km} / \mathrm{h} \\
\text { - } \mathrm{CTL} \text { : walking training was carried out using traditional methods }\end{array}$ \\
\hline
\end{tabular}


Opara 2016 (Continued)

Outcomes
Time points of assessment: after 4 weeks of training

- 10-Meter Walk Test

- Functional Index "Repty"

- Timed Up and Go Test, P

- Functional Ambulatory Category

Notes Information provided in part by the primary investigator

Shintani 2005

\begin{tabular}{ll}
\hline Methods & Unclear \\
\hline Participants & Unclear \\
\hline Interventions & Unclear \\
\hline Outcomes & Unclear \\
\hline
\end{tabular}

Notes

Stephenson 2004

\begin{tabular}{lc}
\hline Methods & Unclear \\
\hline Participants & Unclear \\
\hline Interventions & Unclear \\
\hline Outcomes & Unclear \\
\hline
\end{tabular}

\section{Notes}

\section{Thompson 2006}

\begin{tabular}{ll}
\hline Methods & RCT \\
Method of randomisation: not described \\
Blinding of outcome assessors: not described \\
Adverse events: not stated \\
Deaths: not stated \\
Dropouts: not stated \\
ITT: not stated
\end{tabular}

$\begin{array}{ll}\text { Participants } & \text { Country: USA } \\ & 22 \text { participants } \\ & \text { Ambulatory at study onset: not stated } \\ \text { Mean age: } 58 \text { years } \\ \text { Inclusion criteria: not stated } \\ \text { Exclusion criteria: not stated }\end{array}$

3 arms:

Treadmill training and body weight support for walking after stroke (Review) 
1. CTL: overground walking at a self-selected speed, 2 times per week for 4 weeks (40 minutes per week)

2. EXP 1: body weight-supported treadmill training at self-selected speed, 2 times per week for 4 weeks (40 minutes per week)

3. EXP 2: body weight-supported treadmill training at fast speed, 2 times per week for 4 weeks (40 minutes per week)

Outcomes

Outcomes were recorded at baseline, post intervention, and after 1-month and 6-month follow-up:

- lower limb function (Fugl-Meyer Assessment)

- ADL performance (Barthel-Index)

- gait endurance (6-Minute Walk Test)

- measures of timed gait (10-Metre Walk Test)

Notes Abstract only

Venkadesan 2009

$\begin{array}{ll}\text { Methods } & \text { Method: not described } \\ & \text { Method of randomisation: not described } \\ \text { Dropouts: not stated } \\ \text { Blinding of outcome assessors: unclear } \\ \text { ITT: unclear }\end{array}$

ITT: unclear

Country: India
10 participants in the EXP group, 10 participants in the CTL group
Ambulatory at study onset: yes
Inclusion criteria: not described
Exclusion criteria: not described

Interventions Treatment duration: unknown

Treadmill training (EXP): participants received treadmill training and conventional gait-training

Conventional gait-training (CTL): participants received conventional gait-training alone

\begin{tabular}{ll}
\hline Outcomes & Time points of assessments unknown: \\
& $\bullet$ cadence \\
& - stride length \\
\hline Notes & Characteristics derived from abstract \\
\hline
\end{tabular}

\begin{tabular}{ll} 
Xiao 2014 & \\
\hline Methods & Unclear \\
\hline Participants & Unclear \\
\hline Interventions & Unclear \\
\hline
\end{tabular}


Xiao 2014 (Continued)

Outcomes

Unclear

\section{Notes}

Xu 2008

\begin{tabular}{ll}
\hline Methods & Method: not described \\
& Method of randomisation: not described \\
Dropouts: not stated & Blinding of outcome assessors: unclear \\
& ITT: unclear \\
\hline Participants & Country: China \\
& 36 participants in the EXP group, 40 participants in the CTL group \\
& Ambulatory at study onset: not described \\
Inclusion criteria: not described \\
Exclusion criteria: not described \\
\hline Interventions & Preatment duration: unknown \\
& Underwater gait-training (CTL): participants received underwater gait-training \\
\hline Outcomes & Time points of assessments unknown: \\
\hline improvement of walking ability (outcome measure: unknown)
\end{tabular}

Yang 2007

\begin{tabular}{|c|c|}
\hline \multirow[t]{2}{*}{ Methods } & Method: RCT, parallel group design \\
\hline & $\begin{array}{l}\text { Method of randomisation: not described } \\
\text { Blinding of outcome assessors: not described } \\
\text { Adverse events: not stated } \\
\text { Deaths: not stated } \\
\text { Dropouts: not stated } \\
\text { ITT: unclear }\end{array}$ \\
\hline
\end{tabular}

\section{Participants}

Country: Taiwan

13 participants in the EXP group and 13 in the CTL group

Ambulatory at study onset: not described

Inclusion criteria: hemiparetic gait disturbances and coronary artery disease

Exclusion criteria: not stated

1. EXP group received aerobic treadmill exercise for 6 months 
Yang 2007 (Continued)

2. CTL group received no intervention

Outcomes were recorded at baseline and after 4 weeks of therapy:
- aerobic capacity (symptom limited exercise test)
- ADL (Barthel Index)

Notes

Characteristics derived from conference abstract

Zielke 2003

\begin{tabular}{ll}
\hline Methods & Unclear \\
\hline Participants & $\begin{array}{l}5 \text { participants will be recruited for the EXP group and } 5 \text { participants for the CTL group } \\
\text { Inclusion criteria: admitted to inpatient stroke unit between } 2 \text { and } 30 \text { days following stroke; single } \\
\text { infarct stroke confirmed by MRI or CT scan; aged } 50 \text { to } 75 \text { years; no orthopaedic or additional neu- } \\
\text { rologic conditions that impair ambulation (independent walker, with or without a gait aid, before } \\
\text { the stroke); no history of previous stroke (based on medical chart review); no cardiac, respiratory, } \\
\text { or other medical condition that might interfere with the treatment protocol; able to follow instruc- } \\
\text { tions (no significant cognitive or communication deficits); scores at least } 1 \text { out of } 5 \text { on manual mus- } \\
\text { cle testing of the hip flexors }\end{array}$ \\
\hline $\begin{array}{l}\text { Treated for } 3 \text { sessions per week for } 2 \text { weeks } \\
\text { Treadmill training (EXP): participants will walk on a treadmill with partial body weight support us- } \\
\text { ing a harness } \\
\text { Overground walking training (CTL): participants will complete overground walking training }\end{array}$ \\
$\begin{array}{l}\text { Assessed at baseline, and after the treatment (2 weeks): } \\
\text { 1. Berg Balance Scale } \\
\text { 2. walking speed } \\
\text { 3. gait portion of the Tinetti assessment } \\
\text { 4. FIM - gait score }\end{array}$
\end{tabular}

Notes

ADL: activities of daily living

BWS: body weight-support

BWSTT: body weight-supported treadmill training

CTL: control

EMG: electromyographic activity

EXP: experimental

FAC: Functional Ambulation Categories

FIM: Functional Independence Measure

ITT: intention-to-treat

MMSE: Mini Mental State Examination

MRI: magnetic resonance imaging

$\mathrm{RCT}$ : randomised controlled trial

TMS: transcranial magnetic stimulation

TUG: timed up-and-go-test

WHO: World Health Organization

Characteristics of ongoing studies [ordered by study ID] 
Trial name or title population
Aerobic exercise to improve cardiovascular and neurological health outcomes in the chronic stroke

population

Method: RCT, parallel group design

Method of randomisation: secure web-based computer generation, stratified according to age $(<65$ versus $>65$ ) and mobility (the 6 -Minute Walk Test, $<160$ metres versus $>160$ metres)

Blinding of outcome assessors: yes

ITT: unclear
Country: Australia

Target sample size: 150 participants

Ambulatory at study onset: not described

Inclusion criteria: aged between 45 and 80 years, diagnosis of first or recurrent stroke, haemorrhage or infarct at least 6 months prior to study entry

Exclusion criteria: unable to participate in an exercise program due to medical conditions such as heart failure, unstable angina, dementia, and receptive aphasia, participants on beta-blockers, participants already participating in a supervised aerobic exercise program, participants who have epilepsy, metallic implants in the skull or cardiac pacemakers (exclusion from the transcranial magnetic stimulation)
2 arms:

- EXP group received aerobic treadmill exercise 3 times per week for 12 weeks

- CTL group received usual care 3 times per week for 12 weeks
Outcomes were recorded at baseline, at the end of the 12-week intervention period, and at 6 months follow-up:

Primary outcome: peak oxygen uptake $\left(\mathrm{VO}_{2}\right.$ peak $)$

Secondary outcomes:

- Timed Up and Go Test, 6-Minute Walk Test, gait velocity, Sit-to-Stand Test

- cognitive function (the Stroop Test, verbal fluency, trail making tests A and B, Rey Auditory Verbal learning test, digit span backwards and forwards, spatial span test, a clock drawing task test, inspection time, Paced Auditory Serial Addition Test)

- cerebral blood flow and vessel reactivity (Doppler sonography)

- quality of life (Assessment of Quality of Life tool)

- cost-effectiveness and cost utility using the AQoL to calculate quality adjusted life years (QALYS)

- response to stimulation of the motor cortex to induce plasticity (repetitive transcranial magnetic stimulation)

\section{August 2009}

Dr Michelle McDonnell

School of Nursing and Midwifery GPO Box 2471 Adelaide SA 5001, Australia

Email: michelle.mcdonnell@unisa.edu.au

Notes 


\section{ISRCTN50586966}

\begin{tabular}{|c|c|}
\hline Trial name or title & Improving community walking after a stroke, a new approach \\
\hline \multirow[t]{2}{*}{ Methods } & Method: pilot RCT \\
\hline & $\begin{array}{l}\text { Method of randomisation: not described } \\
\text { Blinding of outcome assessors: not described } \\
\text { ITT: unclear }\end{array}$ \\
\hline \multirow[t]{5}{*}{ Participants } & Country: UK \\
\hline & 50 people with chronic stroke \\
\hline & Ambulatory at study onset: yes \\
\hline & $\begin{array}{l}\text { Inclusion criteria: more than } 6 \text { months after first ischaemic stroke; reduced gait capacity (6-Minute } \\
\text { Walk Test); being able to perform a simple reciprocal bilateral foot tapping task and to walk safely } \\
\text { on a treadmill; informed consent }\end{array}$ \\
\hline & $\begin{array}{l}\text { Exclusion criteria: high risk of psychosis; severe aphasia; history of previous stroke; other known } \\
\text { contraindication to safe participation; contraindication to MRI }\end{array}$ \\
\hline \multirow[t]{3}{*}{ Interventions } & 2 arms: \\
\hline & - CTL group will receive 24 sessions of 45 minutes of aerobic walking training \\
\hline & $\begin{array}{l}\text { EXP group will receive implicit dual task-training during body weight-supported treadmill training } \\
\text { for } 24 \text { sessions of } 45 \text { minutes }\end{array}$ \\
\hline \multirow[t]{6}{*}{ Outcomes } & Outcomes will be assessed at 0,10 , and 20 weeks: \\
\hline & - community mobility \\
\hline & - health and well-being \\
\hline & - changes in walking performance (temporal spatial parameters, walking endurance) \\
\hline & - adherence to training \\
\hline & - brain activation changes \\
\hline
\end{tabular}

\begin{tabular}{|c|c|}
\hline Starting date & February 2013 \\
\hline Contact information & $\begin{array}{l}\text { Prof Helen Dawes } \\
\text { Oxford Brookes University, Movement Science Group, School of Life } \\
\text { Email: hdawes@brookes.ac.uk }\end{array}$ \\
\hline Notes & $\begin{array}{l}16 \text { January 2017: The following changes have been made to the record: } \\
\text { - the scientific title, secondary outcome measures, publication and dissemination plan, IPD sharing } \\
\text { plan, ORCID ID, plain English summary and trial participating centres have been added } \\
\text { - the overall trial dates have been updated from } 30 / 01 / 2013 \text { to } 30 / 12 / 2014 \text { to } 01 / 08 / 2011 \text { to } \\
31 / 08 / 2016 \\
\text { - information about the randomisation process and length of training sessions have been added to } \\
\text { the interventions section }\end{array}$ \\
\hline
\end{tabular}

Lennihan 2003

\begin{tabular}{ll}
\hline Trial name or title & Treadmill with partial body weight support versus conventional gait-training after stroke \\
\hline Methods & Unclear \\
\hline
\end{tabular}


Lennihan 2003 (Continued)

Participants

42 participants will be recruited for the EXP group and 41 participants for the CTL group Inclusion criteria: within 30 days of first stroke; hemiparesis; dependent on supervision or physical assistance from at least 1 person to walk; not ataxic

$\begin{array}{ll}\text { Interventions } & \text { Treated as inpatients for } 12 \times 30 \text {-minute per day sessions over } 3 \text { weeks } \\ \text { Treadmill training }(E X P) \text { : participants will walk on a treadmill with partial body weight supp } \\ \text { ing a harness } \\ \text { Conventional physiotherapy (CTL): participants will participate in conventional physiothera } \\ \text { (standing, walking, sit-to-stand, and standing and walking with activity) } \\ \text { Assessed } 90 \text { days after stroke: } \\ \text { - walking speed } \\ \text { - walking endurance - maximum distance covered in } 6 \text { minutes using preferred gait aid } \\ \text { - FIM } \\ \text { - National Institute of Health Stroke Scale score } \\ \text { - Fugl-Meyer Assessment leg motor score } \\ \text { - Tinetti score }\end{array}$

\begin{tabular}{ll}
\hline Starting date & Unknown \\
\hline Contact information & Unknown \\
\hline Notes & Characteristics derived from conference abstract \\
\hline
\end{tabular}

Malagoni 2014

\begin{tabular}{ll}
\hline Trial name or title & Challenging or low-intensity to improve mobility \\
\hline Methods & Unclear \\
\hline Participants & $\begin{array}{l}\text { 8 adults with chronic stroke }>6 \text { months ( } M=7 \text {, age }=71 \pm 11 \text { years, hemiplegia } n=6) \text { were ran- } \\
\text { domised }\end{array}$ \\
\hline Interventions & $\begin{array}{l}\text { EXP: 'treadmill walking strength training' intervention, based on moderate-intensity treadmill } \\
\text { walking (4-weeks) and lower limbs muscle strength training with gym machines (4-weeks) }\end{array}$ \\
& $\begin{array}{l}\text { CTL: 'ground walking-power training' program combining interval low-intensity ground walking (4- } \\
\text { weeks) and lower limbs muscle power training performed with wearable weights (4-weeks) }\end{array}$ \\
& Each intervention was performed 3 times per week for 8 weeks, for a total of 24 sessions \\
\hline Outcomes & $\begin{array}{l}\text { The 6-minute walking distance, up-and-go time, } 10 \text { m time, 5-sit-to-stand-to-sit time, balance score } \\
\text { (Berg Balance Scale) maximal strength and peak power of quadriceps and biceps femoris (Kg and } \\
\text { Watts, respectively determined by force-velocity curve by the linear encoder MuscleLab, Roma, } \\
\text { Italy), were measured before and after } 8 \text { weeks }\end{array}$
\end{tabular}

Starting date

Contact information

Notes

All participants completed the program. Both treatments showed improvements, although not significant, for all parameters. CTL showed significant improvement compared to EXP for 5STS $(P=$ $0.021)$, 10MWT $(P=0.043)$, maximal strength of biceps femoris for all legs $(P=0.037)$, peak power for quadriceps $(P=0.021)$ and for all legs $(P=0.006)$ 
Trial name or title

Methods
Task-oriented training for stroke: impact on function mobility

\author{
Method: RCT, parallel assignment \\ Method of randomisation: not described \\ Blinding of outcome assessors: no \\ ITT: no
}

\begin{abstract}
Participants
Country: USA

60 people with stroke

Ambulatory at study onset: yes

Inclusion criteria: stroke $>6$ months prior with residual hemiparetic gait in women or men aged 40 to 85 years, completion of all regular post-stroke physical therapy, adequate language and neurocognitive function to participate in testing and training and to give adequate informed consent, able to rise from a chair unaided and able to walk 10 metres without human assistance

Exclusion criteria: regular structured aerobic exercise ( $>2 x$ week), raised alcohol consumption by self-report, clinical history of severe heart conditions, peripheral arterial obstructive disease with claudication, major orthopaedic, chronic pain or non-stroke neuromuscular disorders restricting exercise, pulmonary or renal failure, poorly controlled hypertension (> 190/110) measured on at least 2 separate occasions, recent hospitalisation for severe disease or surgery, severe or global receptive aphasia which confounds reliable testing and training, untreated major depression as documented by a CES-D score of $>16$ and confirmed by clinical interview, pregnancy
\end{abstract}

Interventions 2 arms:

- CTL group will receive a low-intensity lifestyle intervention (group exercises incorporating balance, co-ordination and strength) (time frame not described)

- EXP group will receive a high-intensity treadmill walking program (time frame not described)

\begin{tabular}{ll}
\hline Outcomes & Outcomes will be assessed at baseline and at 3 months: \\
& Primary outcomes: economy of gait \\
& Secondary outcomes: \\
& • muscular strength \\
& • muscular endurance \\
\hline Starting date & July 2011 \\
\hline Contact information & Alyssa D Stookey, PhD MS \\
\hline Email: alyssa.stookey@va.gov
\end{tabular}

\title{
NCT01392391
}

\begin{tabular}{ll}
\hline Trial name or title & Exercise for subacute stroke patients in Jamaica \\
\hline Methods & Method: RCT, parallel assignment \\
\hline
\end{tabular}


NCT01392391 (Continued)

Method of randomisation: stratified based on glucose tolerance (normal versus abnormal) and gait deficit severity

Blinding of outcome assessors: no

ITT: unclear

Participants

Country: Jamaica

150 people with chronic stroke

Ambulatory at study onset: unclear

Inclusion criteria: ischaemic stroke within 2 months; BMI of 18 to $40 \mathrm{~kg} / \mathrm{m}^{2}$; being able to walk 3 minutes with handrails, assistive device or stand-by aid

Exclusion criteria: actively exercising for $>30$ minutes per day for 5 days per week; increased alcohol consumption; active abuse of other illegal and illicit drugs; history of severe cardiac conditions; history of (1) peripheral arterial disease with vascular claudication making exercise challenging, (2) orthopaedic or chronic pain condition(s) restricting exercise, (3) pulmonary or renal failure, (4) active cancer, (5) untreated poorly controlled hypertension measured on at least 2 occasions (greater than 160/100), (6) HIV-AIDS or other known inflammatory responses, (7) sickle cell anaemia, (8) medications: heparin, warfarin, Lovenox or oral steroids, (9) currently pregnant, (10) history of type 1 diabetes or insulin dependent type 2 diabetes, (11) poorly controlled type 2 diabetes (HbA1C > 10), (12) dementia (MMSE score $<23$ or $<17$ if education level at or below 8th grade) and clinical confirmation by clinical evaluation, (13) severe receptive or global aphasia that confounds testing and/or training, operationally defined as unable to follow 2-point commands, (14) hemiparetic gait from a prior stroke preceding the index stroke defining eligibility (more than one stroke), (15) neurologic disorder restricting exercise such as Parkinson's or myopathy, (16) untreated major depression (CES-D > 16 or clinical confirmation), (17) muscular disorder(s) restricting exercise; muscle biopsy exclusion criteria: (1) anticoagulation therapy with heparin, warfarin or Lovenox (antiplatelet therapy is permitted), (2) bleeding disorder

- CTL group will receive best medical stroke care 'Get with the guidelines' for Jamaica for 6 months

- EXP group, in addition to the control intervention, will receive treadmill training for 6 months, 3 times per week (18 to 90 minutes per week) and group dynamic balance exercise

Outcomes

Outcomes will be assessed at baseline and at the end of the intervention phase at 6 months:

Primary outcomes:

- thigh and abdominal muscle and fat

- whole body protein and skeletal muscle synthesis and breakdown (serial blood sampling and pre-/post-muscle biopsies in the fasted and fed state)

- muscle myosin heavy chain isoform proportions (muscle biopsy)

- leg strength (1 repetitive maximum strength for leg extension, quadriceps, and hamstring muscles)

- fitness $\left(\mathrm{VO}_{2}\right.$ peak testing with open circuit spirometry)

- glucose tolerance (2-hour oral glucose tolerance test with serial blood sampling every 30 minutes for glucose and insulin)

Secondary outcomes:

- muscle TNF alpha (muscle biopsy)

- mobility and balance (National Institutes of Health Stroke Scale, modified Ashworth, timed walks, Short Physical Performance Battery, Berg Balance Scale)

Starting date July 2011


NCT01392391 (Continued)

Email:rmacko@grecc.umaryland.edu

Notes

\section{NCT01600391}

\begin{tabular}{ll}
\hline Trial name or title & Visual cues for gait training post stroke \\
\hline Methods & Method: RCT, parallel assignment \\
Method of randomisation: not described & Blinding of outcome assessors: yes \\
ITT: unclear & Country: Australia \\
& Target sample size: 60 people with stroke \\
Ambulatory at study onset: yes & Inclusion criteria: diagnosis of stroke; being able to walk 10 metres with or without assistance; \\
residual paresis in the lower limb (Fugl-Meyer lower limb score less than 34), informed written con- \\
sent \\
Exclusion criteria: gait speed more than 0.8 m/s; participants with a premorbid (retrospective) \\
modified Rankin Scale score of greater than 3; gait deficits attributable to nonstroke pathology; \\
visual impairments preventing use of visual cue training (as assessed by Apple Cancellation test), \\
concurrent progressive neurologic disorder, acute coronary syndrome, severe heart failure, con- \\
firmed or suspected lower-limb fracture preventing mobilisation, those requiring palliative care, in- \\
ability to follow a 3-step command (as assessed by Modified MMSE)
\end{tabular}

- Active comparator: usual care group will receive task-specific overground walking rehabilitation for 8 weeks, 2 times per week (120 minutes per week)

- EXP: overground visual cue training group will receive overground walking rehabilitation with visual cues for 8 weeks, 2 times per week (120 minutes per week)

- EXP: treadmill visual cue training group will receive treadmill training with visual cues for 8 weeks, 2 times per week (120 minutes per week)

Outcomes will be assessed at baseline, at the end of the intervention phase, and at 3-month follow-up:

Primary outcome: participant enrolment, recruitment, and retention

Secondary outcomes:

- 180 degree turn (time taken (s) and number of steps (\#) to complete a 180 degree turn)

- gait adaptability (the number of times participants fail to hit stepping targets when these are presented unpredictably in timing and location will be used to indicate the ability to adapt the straight gait pattern according to environmental demands)

- Timed Up and Go (TUG) test (7 metres)

- Fugl-Meyer Lower Limb Motor Assessment

- Berg Balance Scale

- Falls Efficacy Scale

- health-related quality of life (SF-12)

- $F A C$ 
NCT01600391 (Continued)

- gait speed (10-metre walk)

\begin{tabular}{ll}
\hline Starting date & May 2012 \\
\hline Contact information & Trudy A Pelton, MRes \\
& Email: t.a.pelton@bham.ac.uk \\
& Kristen Hollands, PhD \\
& Email: k.hollands@salford.ac.uk
\end{tabular}

Notes

\begin{tabular}{ll}
\hline Trial name or title & Robot walking rehabilitation in stroke patients \\
\hline Methods & RCT with 3 arms \\
\hline Participants & $\begin{array}{l}\text { Inclusion criteria: between the ages of } 18 \text { and } 95 \text { years, able to walk } 25 \text { feet unassisted or with as- } \\
\text { sistance, first acute event of cerebrovascular stroke, unilateral paresis, ability to understand and } \\
\text { follow simple instructions, ability to walk without assistance before stroke, endurance sufficient to } \\
\text { stand at least } 20 \text { minutes unassisted per participant report } \\
\text { Exclusion criteria: unable to understand instructions required by the study (Informed Consent Test } \\
\text { of Comprehension), medical or neurological comorbidities that might contribute to significant gait } \\
\text { dysfunction, uncontrolled hypertension }>190 / 110 \text { mm Hg, significant symptoms of orthostasis } \\
\text { when standing up, circulatory problems, history of vascular claudication or significant (+ 3) pitting } \\
\text { oedema, lower extremity injuries or joint problems (hip or leg) that limit range of motion or func- } \\
\text { tion or cause pain with movement, bilateral impairment, severe sensory deficits in the paretic up- } \\
\text { per limb, cognitive impairment or behavioural dysfunction that would influence the ability to com- } \\
\text { prehend or participate in the study, women who are pregnant or lactating or both }\end{array}$
\end{tabular}

Interventions

EXP group: robot G-EO: each participant will be asked to perform 15 sessions ( 3 to 5 days a week for 4 up to 5 weeks) consisting of a treatment cycle using the GE-O system device, according to individually tailored exercise scheduling

CTL group: treadmill training: each participant will be asked to perform 15 sessions ( 3 to 5 days a week for 4 up to 5 weeks) consisting of a treatment cycle using the treadmill system device, according to individually tailored exercise scheduling

CTL group: ground treatment: Ground Control Group: each participant will be asked to perform 15 sessions ( 3 to 5 days a week for 4 up to 5 weeks) of traditional lower limb physiotherapy

This review will only analyse 1 control group compared to the other

Outcomes

Outcomes will be assessed at baseline and at 6 months follow-up:

Primary outcomes: 6-Minute Walk Test

Secondary outcomes:

- Fugl-Meyer Assessment (lower limb)

- Borg scale

- gait parameters with EMG

- FAC

- Walk Handicap Scale 
NCT01678547 (Continued)

Email: patrizio.sale@gmail.com

Contact: Marco Franceschini, MD

Email: marco.franceschini@sanraffaele.it

Notes

Estimated enrolment: 90

Estimated study completion date: September 2015

Estimated primary completion date: August 2014 (final data collection date for primary outcome measure)

\section{NCT01777113}

Trial name or title

Methods
High-intensity interval training in chronic stroke patients

Method: RCT

Method of randomisation: not described

Blinding of outcome assessors: yes

ITT: unclear

\begin{tabular}{|c|c|}
\hline \multirow[t]{5}{*}{ Participants } & Country: Italy \\
\hline & Target sample size: 100 people with stroke \\
\hline & Ambulatory at study onset: not described \\
\hline & $\begin{array}{l}\text { Inclusion criteria: diagnosis of ischaemic or haemorrhagic stroke, confirmed by MRI or CT at least } \\
6 \text { months before the onset of the study; ability to walk in the treadmill at }>0.3 \mathrm{~km} / \text { hour for } 3 \mathrm{~min} \text { - } \\
\text { utes with handrail support; be able to give informed consent and be motivated to participate in 3- } \\
\text { month intensive physical fitness training }\end{array}$ \\
\hline & $\begin{array}{l}\text { Exclusion criteria: MMSE < 20; unstable angina pectoris; unstable cardiac conditions; complex ven- } \\
\text { tricular arrhythmia; resting systolic blood pressure > } 200 \mathrm{~mm} \mathrm{Hg} \text {, resting diastolic blood pressure } \\
>100 \mathrm{~mm} \mathrm{Hg} \text {; aphasia (unable to follow } 2 \text { commands); other medical conditions precluding partici- } \\
\text { pation in aerobic exercise }\end{array}$ \\
\hline \multirow[t]{4}{*}{ Interventions } & 3 arms: \\
\hline & - EXP group 1 will receive high-intensity treadmill training for 12 weeks \\
\hline & - EXP group 2 will receive high-intensity strength training for 12 weeks \\
\hline & $\begin{array}{l}\text { - Active comparator group will receive conventional training consisting of group mobility, balance, } \\
\text { and stretching exercises for } 12 \text { weeks }\end{array}$ \\
\hline \multirow[t]{12}{*}{ Outcomes } & $\begin{array}{l}\text { Primary outcome will be assessed at baseline and at the end of the intervention phase at } 12 \text { weeks: } \\
\text { 6-Minute Walk Test }\end{array}$ \\
\hline & Secondary outcomes: \\
\hline & - 10-Metre Walk Test \\
\hline & - Timed Up and Go Test \\
\hline & - gait analysis \\
\hline & - strength (isokinetic dynamometer) \\
\hline & - arterial - venous oxygen difference (Near Infrared Spectroscopy) \\
\hline & - cardiac output (Portapres) \\
\hline & - Oxygen Uptake Efficiency Slope \\
\hline & - Specific Balance Confidence Scale \\
\hline & - SF-36 Health Survey Questionnaire \\
\hline & - Stroke Impact scale \\
\hline
\end{tabular}


NCT01777113 (Continued)

- peak oxygen consumption $\left(\mathrm{VO}_{2}\right.$ peak)

- walking energy cost

\begin{tabular}{ll}
\hline Starting date & March 2013 \\
\hline Contact information & $\begin{array}{l}\text { Nicola Smania } \\
\text { Email: nicola.smania@univr.it }\end{array}$ \\
\hline Notes & \\
\hline
\end{tabular}

\section{NCT02108912}

\begin{tabular}{ll}
\hline Trial name or title & Metabolic costs of walking post stroke \\
\hline Methods & Method: pilot RCT \\
& Method of randomisation: not described \\
& Blinding of outcome assessors: not described \\
ITT: unclear
\end{tabular}

\section{Participants}

\section{Country: USA}

30 people with chronic stroke

Ambulatory at study onset: unclear

Inclusion criteria:

- confirmed diagnosis of recent cerebrovascular accident (less than 6 weeks post-strokeat the time of admission to inpatient rehabilitation)

- able to give informed consent independently or have family member or other authorized surrogate available to give consent

- first time stroke OR complete gait recovery from prior stroke

- sufficient support at home to participate in home-based fitness training program

- transportation to University of Texas Southwestern Medical Center Gait Disorders Clinic for therapy and testing

- ability to follow one-part commands

Exclusion criteria:

- not ambulatory before onset of stroke (at time of admission to inpatient rehabilitation)

- bilateral stroke

- presence of severe cardiac problems (heart failure (New York Heart Association > Class 2), unstable or exercise-induced angina)

- other comorbidities which could affect gait-training (i.e. amputation, spinal cord injury, traumatic brain injury, etc.)

- recent myocardial infarct (within 4 weeks of date of inpatient rehabilitation admission)

- any uncontrolled health condition for which exercise is contraindicated

- severe lower extremity joint disease/pathology that would interfere with gait-training

- participants - with body mass index (BMI) greater than 40

- significant cognitive impairment (less than 2 on the FIM cognitive subscale)

- age greater than 80 years or less than 18 years

- able to complete 5 or more full heel raises with the affected ankle in standing with the knee extended with no more than one or two fingers on support surface for balance 
NCT02108912 (Continued)

- CTL: traditional outpatient therapy

- EXP: treadmill outpatient therapy

\begin{tabular}{ll}
\hline Outcomes & Primary outcome: \\
& - maximum exercise tolerance \\
& Secondary outcome will be assessed at enrolment, week 9, week 17, and week 25: \\
& - 6 -Minute Walk Test \\
\hline Starting date & March 2014 \\
\hline Contact information & Karen J McCain, DPT \\
& University of Texas Southwestern Medical Center \\
\hline
\end{tabular}

Notes

\section{NCT02550015}

Trial name or title

Methods
High intensity interval training after stroke

Method: RCT

Method of randomisation: not described

Blinding of outcome assessors: not described

ITT: unclear

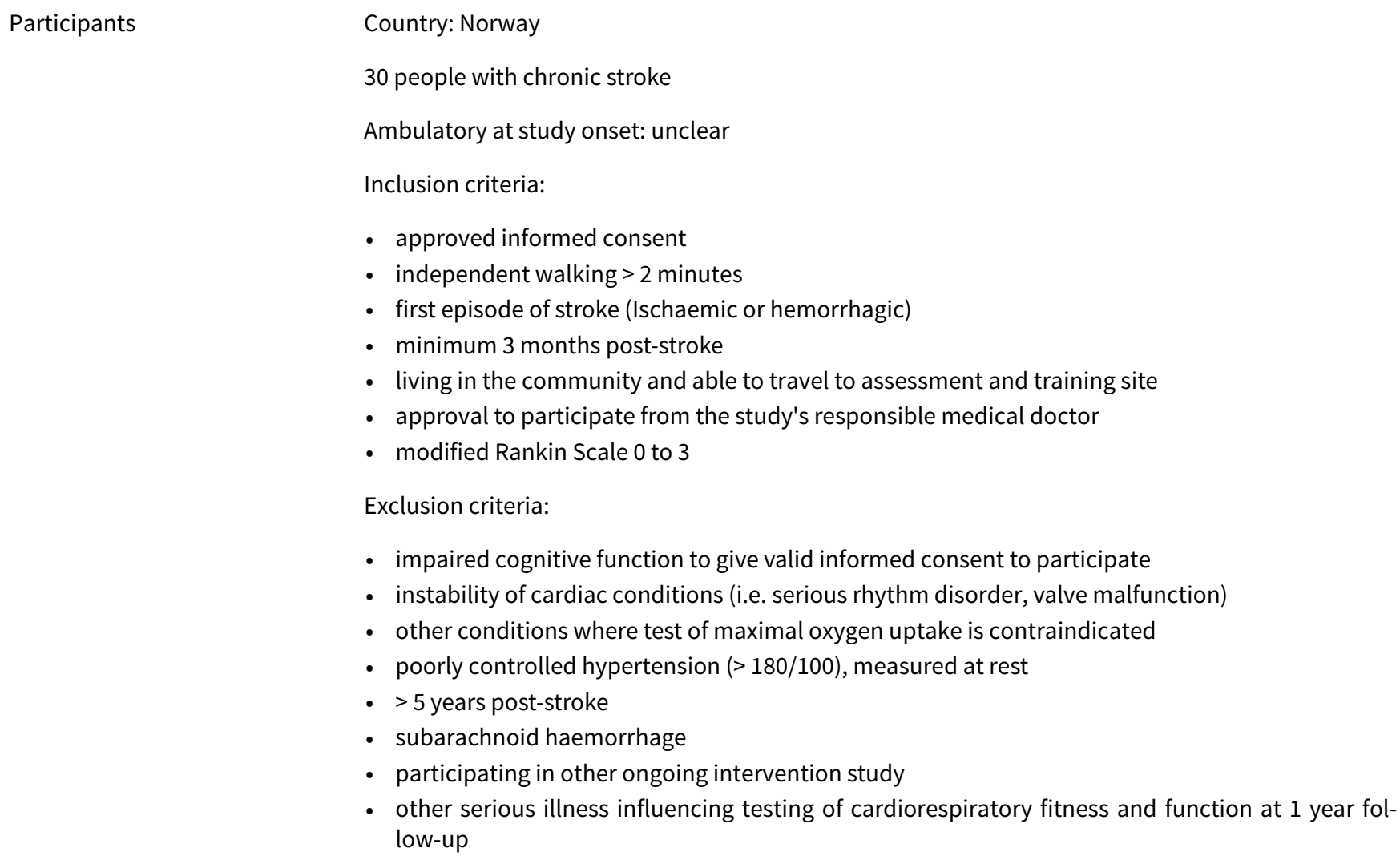

Participants

Country: Norway

30 people with chronic stroke

Ambulatory at study onset: unclear

Inclusion criteria:

- approved informed consent

- independent walking > 2 minutes

- first episode of stroke (Ischaemic or hemorrhagic)

- minimum 3 months post-stroke

- living in the community and able to travel to assessment and training site

- approval to participate from the study's responsible medical doctor

- modified Rankin Scale 0 to 3

Exclusion criteria:

- impaired cognitive function to give valid informed consent to participate

- instability of cardiac conditions (i.e. serious rhythm disorder, valve malfunction)

- other conditions where test of maximal oxygen uptake is contraindicated

- poorly controlled hypertension (>180/100), measured at rest

- > 5 years post-stroke

- subarachnoid haemorrhage

- participating in other ongoing intervention study

- other serious illness influencing testing of cardiorespiratory fitness and function at 1 year follow-up 
NCT02550015 (Continued)

Interventions 2 arms:
- EXP: high intensity interval training (uphill treadmill walking $4 \times 4$ min at 90 to $95 \%$ of peak heart rate) 3 times weekly for 8 weeks

- CTL: standard care

Standard clinical follow-up care, including general information about importance of physical activity as part of a healthy lifestyle

\begin{tabular}{ll}
\hline Starting date & September 2015 \\
\hline Contact information & Torunn Askim, PhD \\
& Norwegian University of Science and Technology \\
& Contact: Tor Ivar Gjellesvik tor.i.gjellesvik@ntnu.no \\
\hline
\end{tabular}

Notes

10MWT: 10 meters walk test

5STS: five time sit-to-stand

6MWD: six minute walk distance

BMI: body mass index

BWS: body weight support

BWSTT: body weight-supported treadmill training

CES-D: Center for Epidemiologic Studies Depression Scale

$\mathrm{CT}$ : computed tomography

CTL: control

CVA: cerebrovascular accident

DPT: academic title (Doctor of Physical therapy)

EMG: Electromyography

EXP: experimental

FAC: Functional Ambulation Categories

FIM: Functional Independence Measure

G-EO: the G-EO System is a brand name of a robotic gait trainer

IPD: individual patient data

ITT: intention-to-treat

M: male

MMSE: Mini Mental State Examination

MRI: magnetic resonance imaging

ORCID: Open Researcher and Contributor identification

QALY: quality adjusted life years

$\mathrm{RCT}$ : randomised controlled trial

SF-36: short form 36

TNF: tumor necrosis factor

TUG: timed-up-and-go-test

$\mathrm{VO}_{2}$ : volume of oxygen consumption 
DATA AND ANALYSES

Comparison 1. Treadmill (with or without body weight support) versus other intervention

\begin{tabular}{|c|c|c|c|c|}
\hline Outcome or subgroup title & No. of studies & $\begin{array}{l}\text { No. of partici- } \\
\text { pants }\end{array}$ & Statistical method & Effect size \\
\hline $\begin{array}{l}1 \text { Walking speed }(\mathrm{m} / \mathrm{s}) \text { at end of treat- } \\
\text { ment }\end{array}$ & 47 & 2323 & $\begin{array}{l}\text { Mean Difference (IV, Random, } \\
95 \% \mathrm{CI} \text { ) }\end{array}$ & $0.06[0.03,0.09]$ \\
\hline $\begin{array}{l}1.1 \text { dependent in walking at start of } \\
\text { treatment }\end{array}$ & 9 & 752 & $\begin{array}{l}\text { Mean Difference (IV, Random, } \\
95 \% \mathrm{CI})\end{array}$ & $-0.01[-0.06,0.03]$ \\
\hline $\begin{array}{l}1.2 \text { independent in walking at start of } \\
\text { treatment }\end{array}$ & 38 & 1571 & $\begin{array}{l}\text { Mean Difference (IV, Random, } \\
95 \% \mathrm{CI})\end{array}$ & $0.08[0.05,0.12]$ \\
\hline $\begin{array}{l}2 \text { Walking endurance }(\mathrm{m}) \text { at end of } \\
\text { treatment }\end{array}$ & 28 & 1680 & $\begin{array}{l}\text { Mean Difference (IV, Random, } \\
95 \% \mathrm{CI})\end{array}$ & $14.19[2.92,25.46]$ \\
\hline $\begin{array}{l}2.1 \text { dependent in walking at start of } \\
\text { treatment }\end{array}$ & 5 & 639 & $\begin{array}{l}\text { Mean Difference (IV, Random, } \\
95 \% \mathrm{CI} \text { ) }\end{array}$ & $\begin{array}{l}-5.09[-23.41 \\
13.22]\end{array}$ \\
\hline $\begin{array}{l}2.2 \text { independent in walking at start of } \\
\text { treatment }\end{array}$ & 23 & 1041 & $\begin{array}{l}\text { Mean Difference (IV, Random, } \\
95 \% \mathrm{CI})\end{array}$ & $19.72[6.61,32.83]$ \\
\hline
\end{tabular}

Analysis 1.1. Comparison 1 Treadmill (with or without body weight support) versus other intervention, Outcome 1 Walking speed $(\mathrm{m} / \mathrm{s})$ at end of treatment.

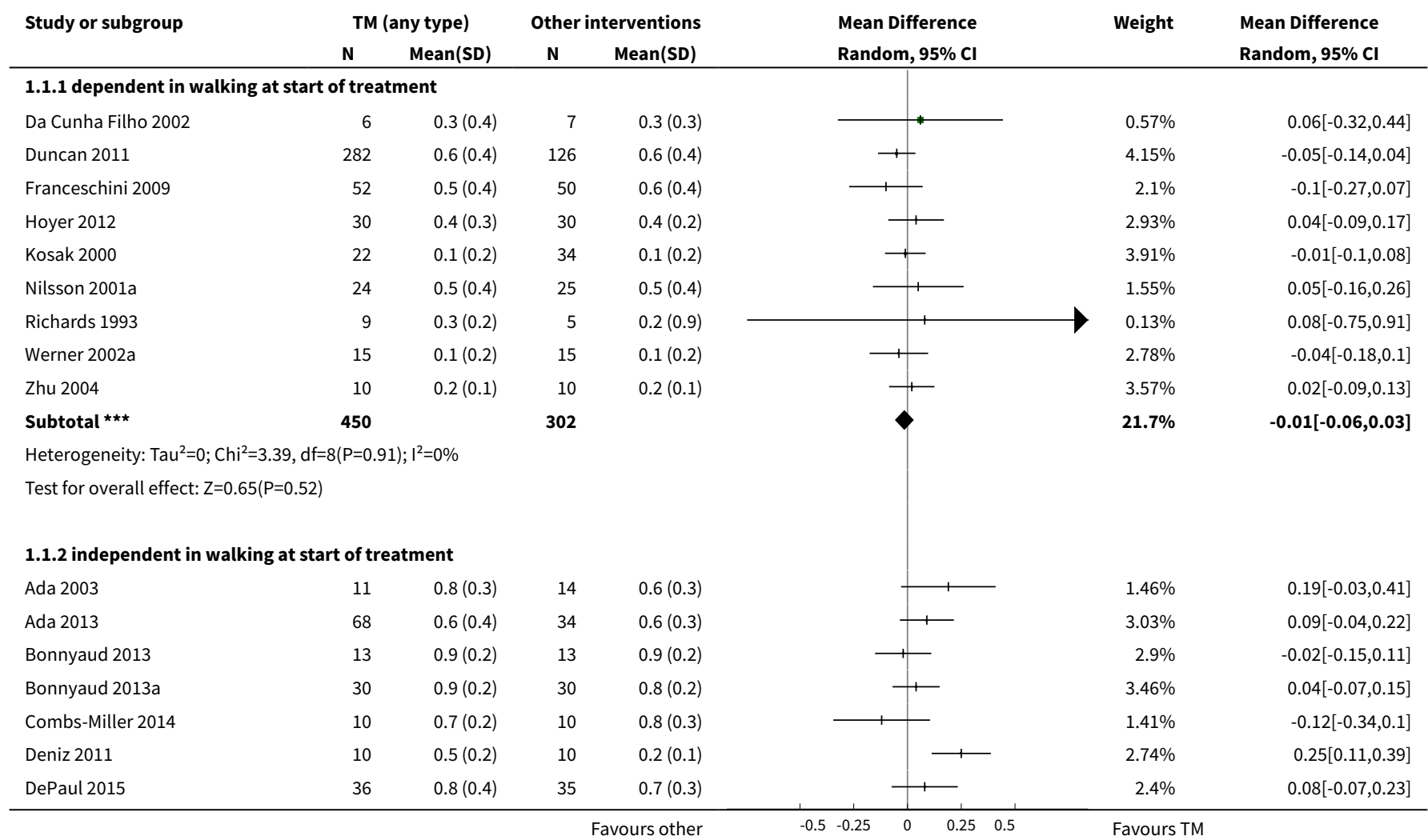




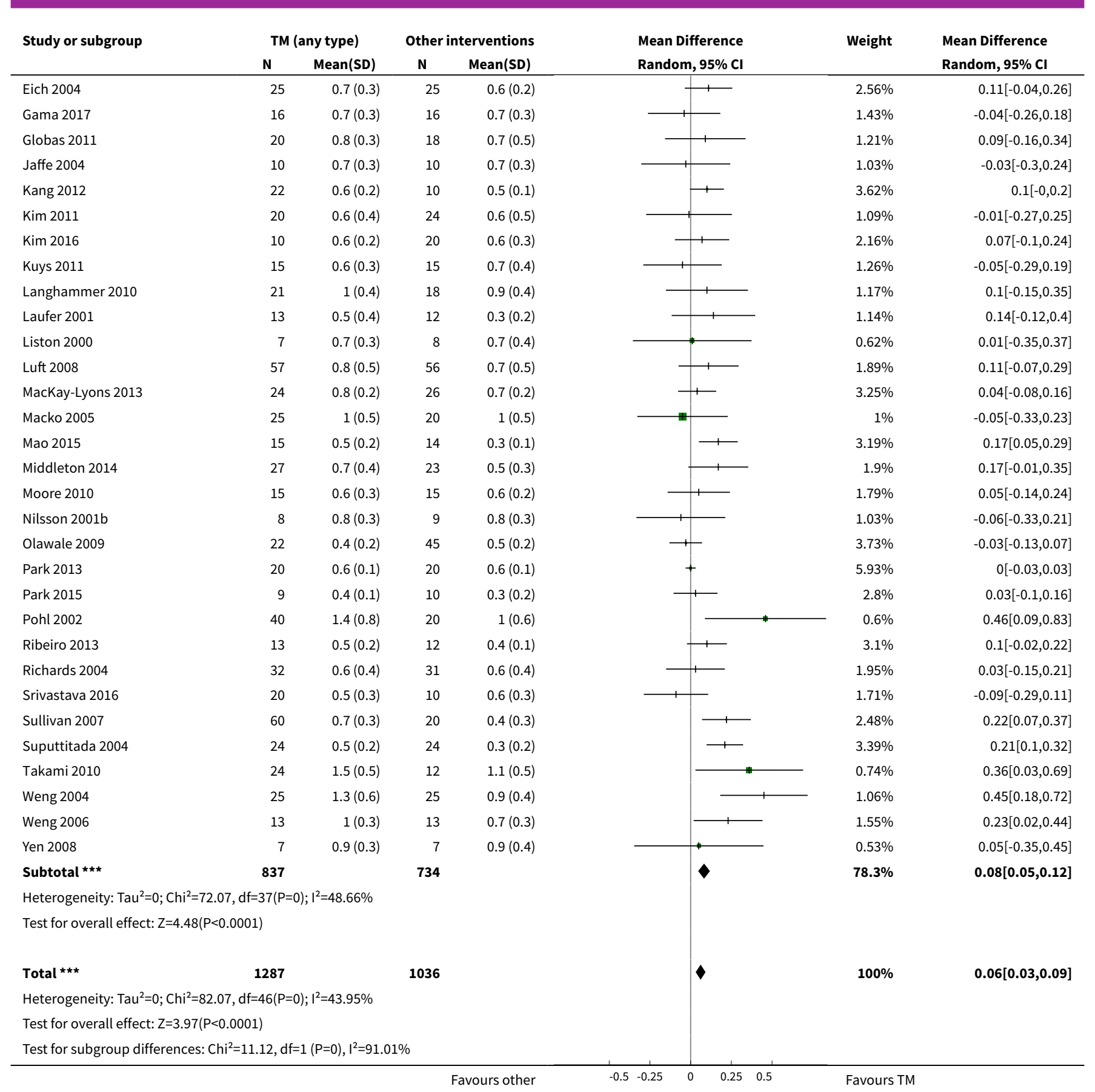

Analysis 1.2. Comparison 1 Treadmill (with or without body weight support) versus other intervention, Outcome 2 Walking endurance $(\mathrm{m})$ at end of treatment.

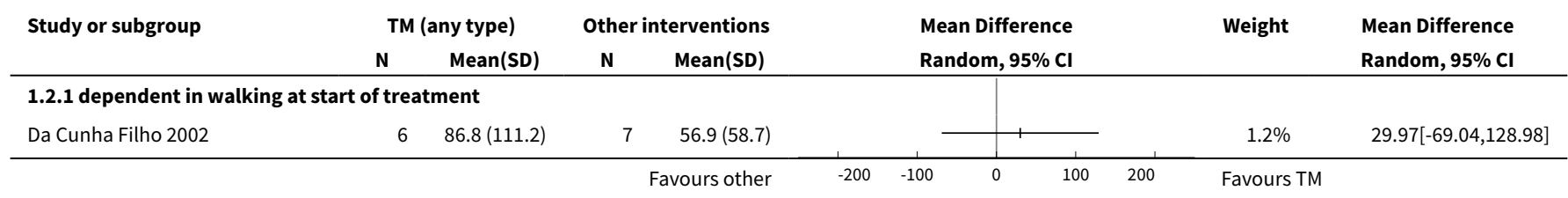




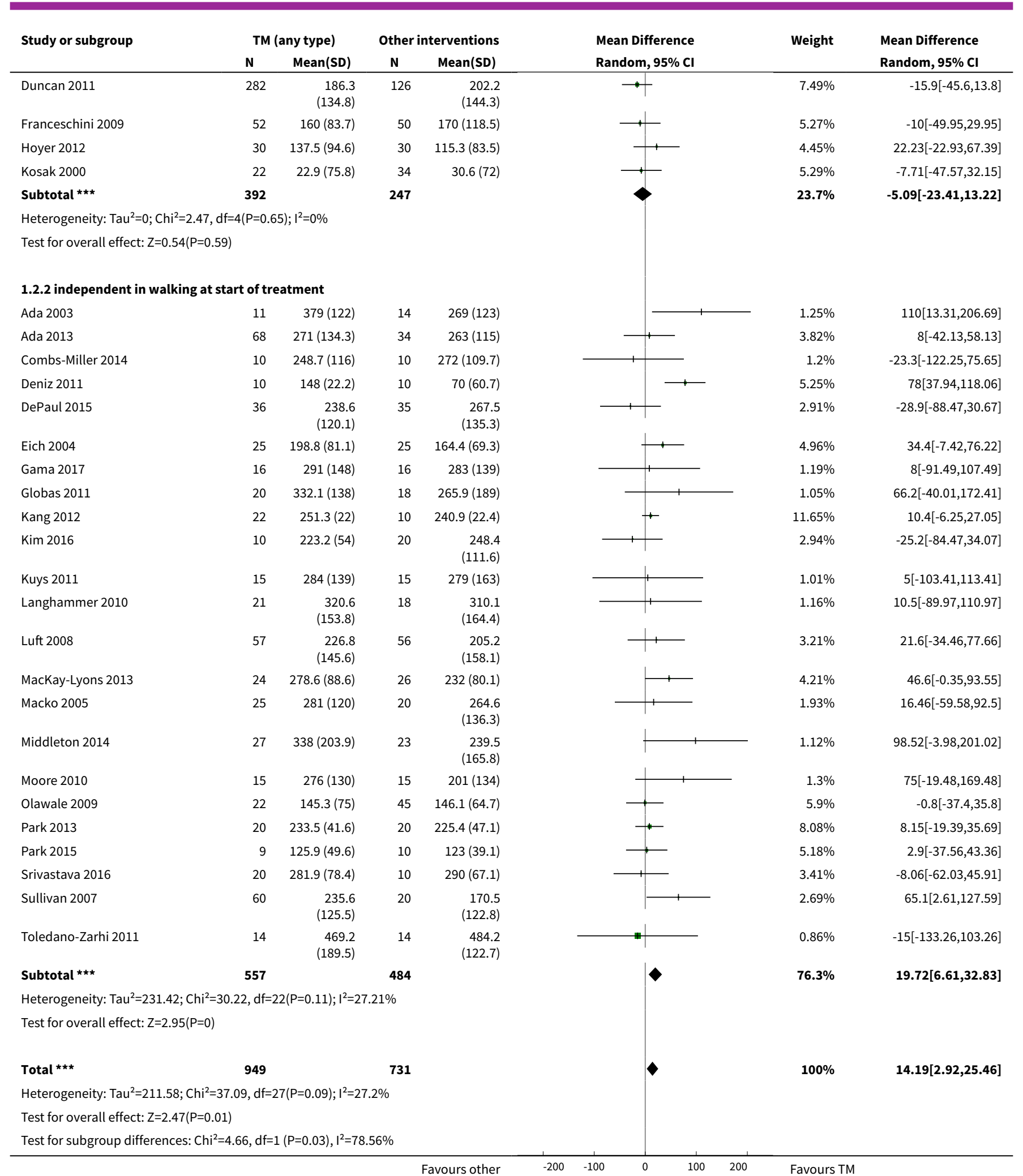


Comparison 2. Treadmill and body weight support versus other interventions

\begin{tabular}{|c|c|c|c|c|}
\hline Outcome or subgroup title & No. of studies & $\begin{array}{l}\text { No. of partici- } \\
\text { pants }\end{array}$ & Statistical method & Effect size \\
\hline $\begin{array}{l}1 \text { Dependence on personal assistance } \\
\text { to walk at end of treatment }\end{array}$ & 19 & 1210 & $\begin{array}{l}\text { Risk Difference (M-H, Ran- } \\
\text { dom, } 95 \% \mathrm{Cl})\end{array}$ & $-0.00[-0.02,0.02]$ \\
\hline $\begin{array}{l}1.1 \text { dependent in walking at start of } \\
\text { treatment }\end{array}$ & 8 & 814 & $\begin{array}{l}\text { Risk Difference (M-H, Ran- } \\
\text { dom, } 95 \% \mathrm{Cl})\end{array}$ & $-0.00[-0.03,0.03]$ \\
\hline $\begin{array}{l}1.2 \text { independent in walking at start of } \\
\text { treatment }\end{array}$ & 11 & 396 & $\begin{array}{l}\text { Risk Difference (M-H, Ran- } \\
\text { dom, } 95 \% \mathrm{Cl})\end{array}$ & $0.0[-0.03,0.03]$ \\
\hline $\begin{array}{l}2 \text { Walking speed }(\mathrm{m} / \mathrm{s}) \text { at end of treat- } \\
\text { ment }\end{array}$ & 26 & 1410 & $\begin{array}{l}\text { Mean Difference (IV, Random, } \\
95 \% \mathrm{CI} \text { ) }\end{array}$ & $0.07[0.02,0.11]$ \\
\hline $\begin{array}{l}2.1 \text { dependent in walking at start of } \\
\text { treatment }\end{array}$ & 8 & 738 & $\begin{array}{l}\text { Mean Difference (IV, Random, } \\
95 \% \mathrm{CI} \text { ) }\end{array}$ & $-0.01[-0.06,0.03]$ \\
\hline $\begin{array}{l}2.2 \text { independent in walking at start of } \\
\text { treatment }\end{array}$ & 18 & 672 & $\begin{array}{l}\text { Mean Difference (IV, Random, } \\
95 \% \mathrm{CI} \text { ) }\end{array}$ & $0.11[0.06,0.17]$ \\
\hline $\begin{array}{l}3 \text { Walking endurance }(\mathrm{m}) \text { at end of } \\
\text { treatment }\end{array}$ & 15 & 1062 & $\begin{array}{l}\text { Mean Difference (IV, Random, } \\
95 \% \mathrm{CI} \text { ) }\end{array}$ & $20.79[0.43,41.14]$ \\
\hline $\begin{array}{l}3.1 \text { dependent in walking at start of } \\
\text { treatment }\end{array}$ & 5 & 639 & $\begin{array}{l}\text { Mean Difference (IV, Random, } \\
95 \% \mathrm{CI} \text { ) }\end{array}$ & $\begin{array}{l}-5.09[-23.41 \\
13.22]\end{array}$ \\
\hline $\begin{array}{l}3.2 \text { independent in walking at start of } \\
\text { treatment }\end{array}$ & 10 & 423 & $\begin{array}{l}\text { Mean Difference (IV, Random, } \\
95 \% \mathrm{CI} \text { ) }\end{array}$ & $\begin{array}{l}36.91[11.14 \\
62.68]\end{array}$ \\
\hline $\begin{array}{l}4 \text { Dependence on personal assistance } \\
\text { to walk at end of scheduled follow-up }\end{array}$ & 5 & 285 & $\begin{array}{l}\text { Risk Difference (M-H, Ran- } \\
\text { dom, } 95 \% \mathrm{Cl})\end{array}$ & $-0.00[-0.05,0.04]$ \\
\hline $\begin{array}{l}4.1 \text { dependent in walking at start of } \\
\text { treatment }\end{array}$ & 2 & 170 & $\begin{array}{l}\text { Risk Difference (M-H, Ran- } \\
\text { dom, } 95 \% \mathrm{Cl})\end{array}$ & $-0.02[-0.18,0.15]$ \\
\hline $\begin{array}{l}4.2 \text { independent in walking at start of } \\
\text { treatment }\end{array}$ & 3 & 115 & $\begin{array}{l}\text { Risk Difference (M-H, Ran- } \\
\text { dom, } 95 \% \mathrm{Cl})\end{array}$ & $0.0[-0.05,0.05]$ \\
\hline $\begin{array}{l}5 \text { Walking speed }(\mathrm{m} / \mathrm{s}) \text { at end of } \\
\text { scheduled follow-up }\end{array}$ & 12 & 944 & $\begin{array}{l}\text { Mean Difference (IV, Random, } \\
95 \% \mathrm{CI} \text { ) }\end{array}$ & $0.03[-0.05,0.10]$ \\
\hline $\begin{array}{l}5.1 \text { dependent in walking at start of } \\
\text { treatment }\end{array}$ & 3 & 556 & $\begin{array}{l}\text { Mean Difference (IV, Random, } \\
95 \% \mathrm{CI} \text { ) }\end{array}$ & $-0.05[-0.13,0.03]$ \\
\hline $\begin{array}{l}5.2 \text { independent in walking at start of } \\
\text { treatment }\end{array}$ & 9 & 388 & $\begin{array}{l}\text { Mean Difference (IV, Random, } \\
95 \% \mathrm{CI} \text { ) }\end{array}$ & $0.06[-0.03,0.15]$ \\
\hline $\begin{array}{l}6 \text { Walking endurance }(m) \text { at end of } \\
\text { scheduled follow-up }\end{array}$ & 10 & 882 & $\begin{array}{l}\text { Mean Difference (IV, Random, } \\
95 \% \mathrm{CI} \text { ) }\end{array}$ & $21.64[-4.70,47.98]$ \\
\hline $\begin{array}{l}6.1 \text { dependent in walking at start of } \\
\text { treatment }\end{array}$ & 2 & 510 & $\begin{array}{l}\text { Mean Difference (IV, Random, } \\
95 \% \mathrm{CI} \text { ) }\end{array}$ & $\begin{array}{l}-6.78[-34.57 \\
21.02]\end{array}$ \\
\hline $\begin{array}{l}6.2 \text { independent in walking at start of } \\
\text { treatment }\end{array}$ & 8 & 372 & $\begin{array}{l}\text { Mean Difference (IV, Random, } \\
95 \% \mathrm{CI} \text { ) }\end{array}$ & $31.55[0.57,62.53]$ \\
\hline
\end{tabular}


Analysis 2.1. Comparison 2 Treadmill and body weight support versus other interventions, Outcome 1 Dependence on personal assistance to walk at end of treatment.

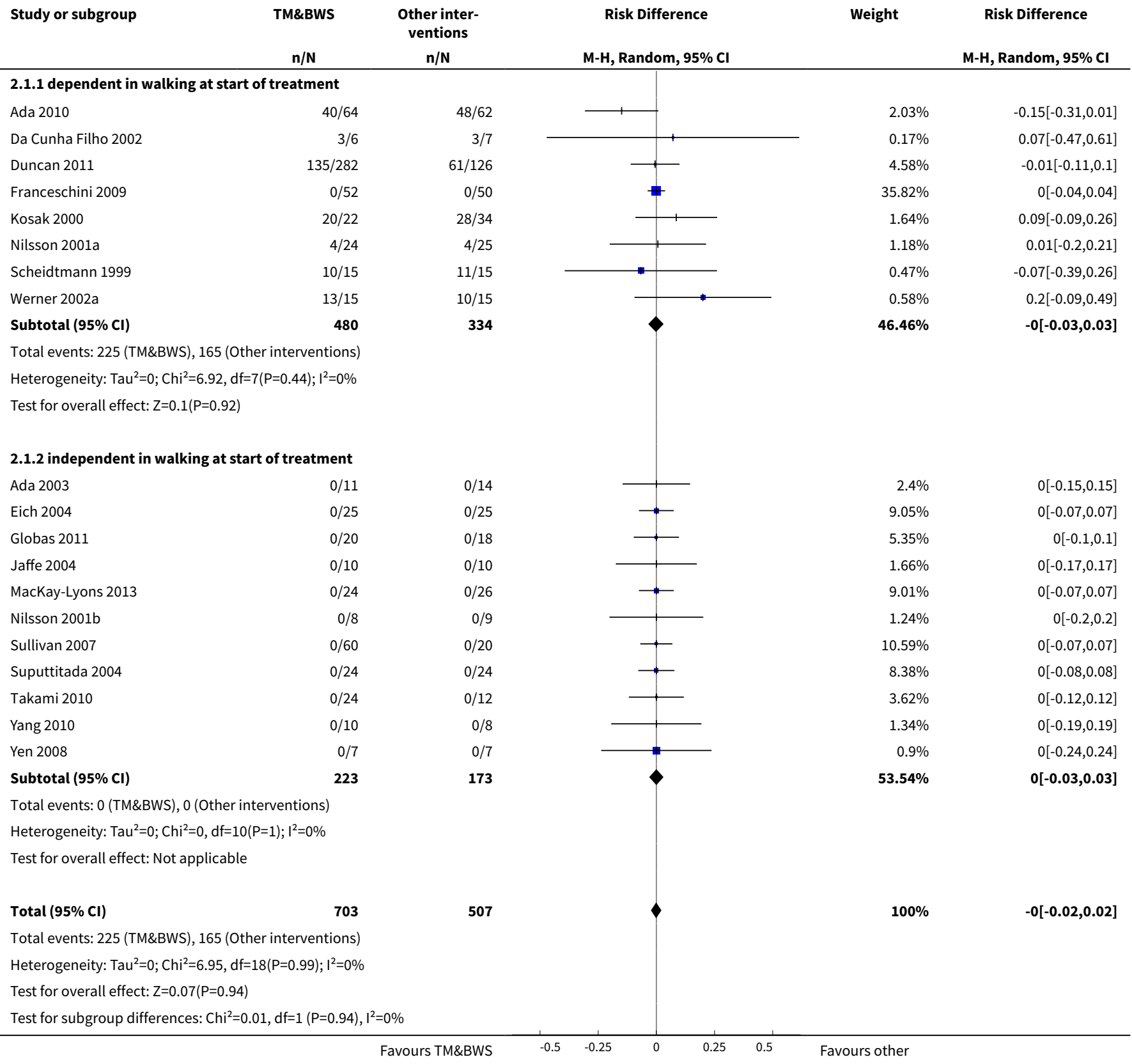

Analysis 2.2. Comparison 2 Treadmill and body weight support versus other interventions, Outcome 2 Walking speed $(\mathrm{m} / \mathrm{s})$ at end of treatment.

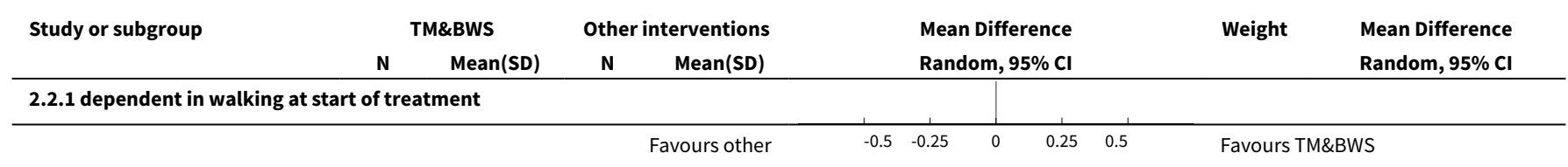




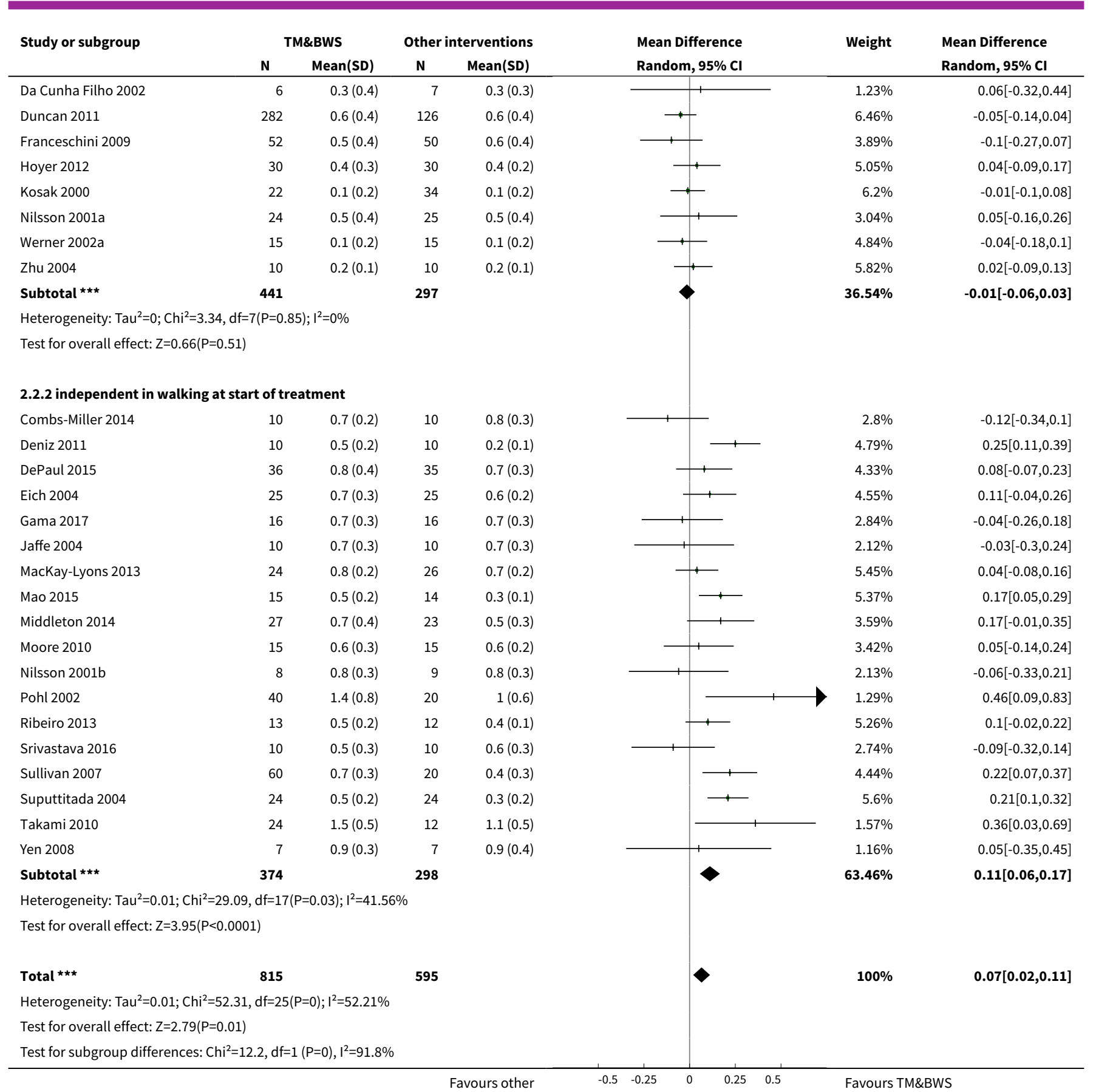

Analysis 2.3. Comparison 2 Treadmill and body weight support versus other interventions, Outcome 3 Walking endurance $(m)$ at end of treatment.

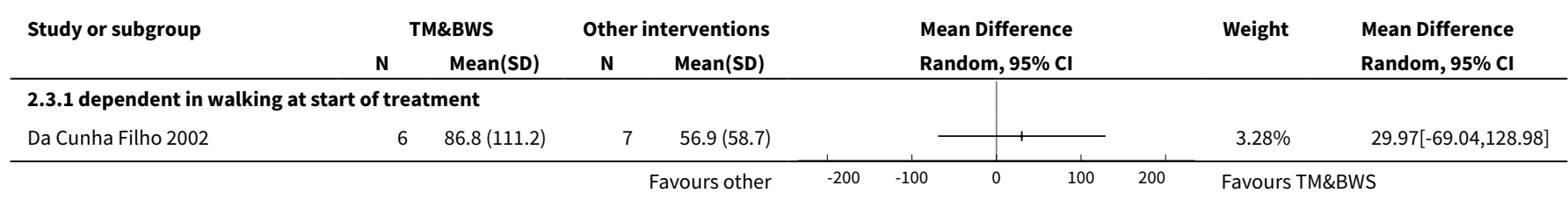




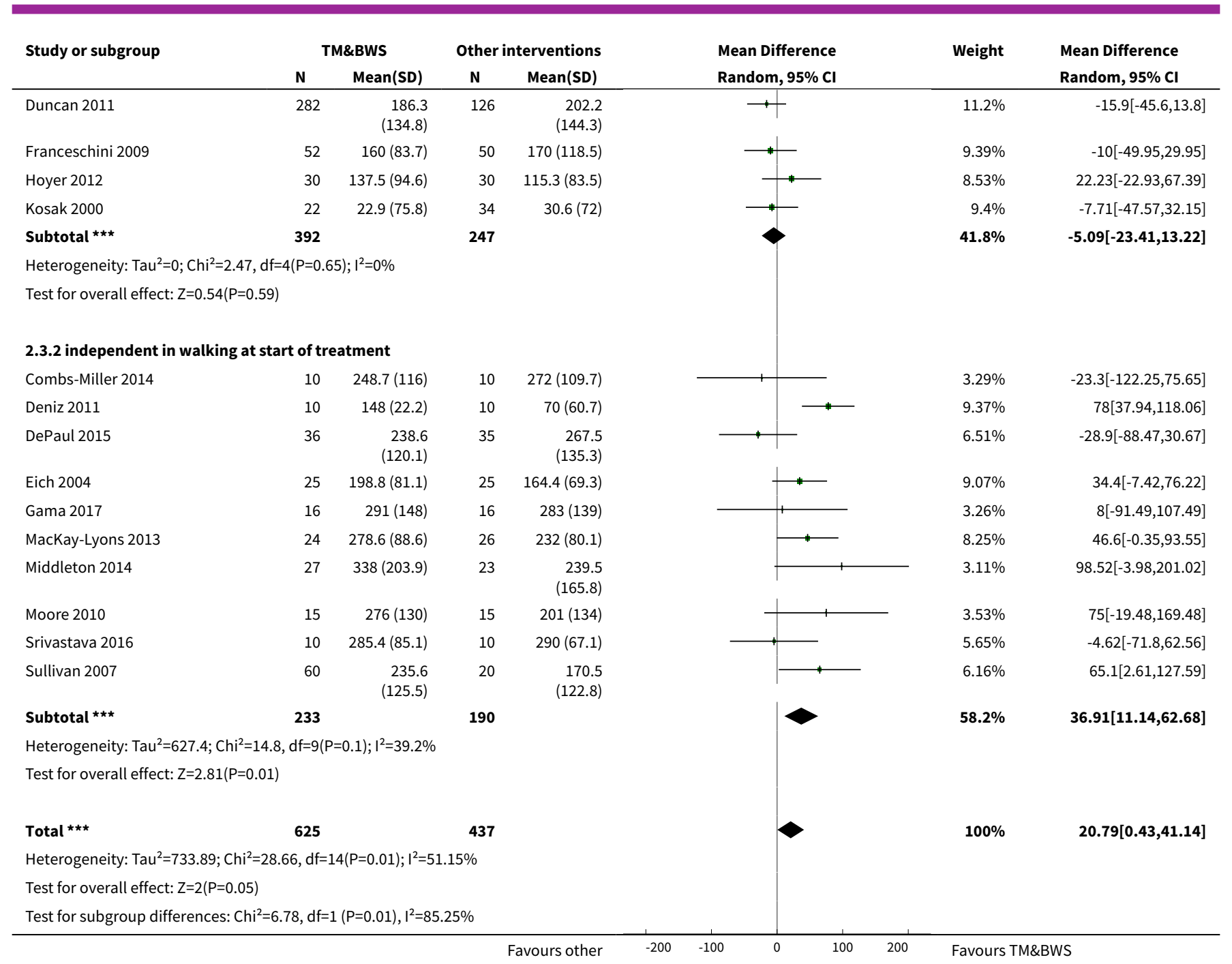

\section{Analysis 2.4. Comparison 2 Treadmill and body weight support versus other interventions, Outcome 4 Dependence on personal assistance to walk at end of scheduled follow-up.}

\begin{tabular}{|c|c|c|c|c|c|}
\hline \multirow[t]{2}{*}{ Study or subgroup } & TM\&BWS & $\begin{array}{l}\text { other inter- } \\
\text { ventions }\end{array}$ & Risk Difference & \multirow[t]{2}{*}{ Weight } & \multirow{2}{*}{$\begin{array}{c}\text { Risk Difference } \\
\text { M-H, Random, } 95 \% \mathrm{CI}\end{array}$} \\
\hline & $\mathrm{n} / \mathrm{N}$ & $n / N$ & M-H, Random, $95 \% \mathrm{Cl}$ & & \\
\hline \multicolumn{3}{|c|}{ 2.4.1 dependent in walking at start of treatment } & & & \\
\hline Ada 2010 & $21 / 64$ & $26 / 62$ & $\longrightarrow$ & $8.1 \%$ & $-0.09[-0.26,0.08]$ \\
\hline Nilsson 2001a & $3 / 20$ & $2 / 24$ & + & $6.25 \%$ & $0.07[-0.12,0.26]$ \\
\hline Subtotal $(95 \% \mathrm{Cl})$ & 84 & 86 & & $14.35 \%$ & $-0.02[-0.18,0.15]$ \\
\hline \multicolumn{6}{|c|}{ Heterogeneity: $\mathrm{Tau}^{2}=0.01 ; \mathrm{Chi}^{2}=1.66, \mathrm{df}=1(\mathrm{P}=0.2) ; \mathrm{I}^{2}=39.86 \%$} \\
\hline \multicolumn{6}{|c|}{ Test for overall effect: $\mathrm{Z}=0.22(\mathrm{P}=0.83)$} \\
\hline \multicolumn{6}{|c|}{ 2.4.2 independent in walking at start of treatment } \\
\hline Eich 2004 & $0 / 24$ & $0 / 25$ & & $39.56 \%$ & $0[-0.08,0.08]$ \\
\hline MacKay-Lyons 2013 & $0 / 24$ & $0 / 26$ & + & $40.98 \%$ & $0[-0.07,0.07]$ \\
\hline
\end{tabular}




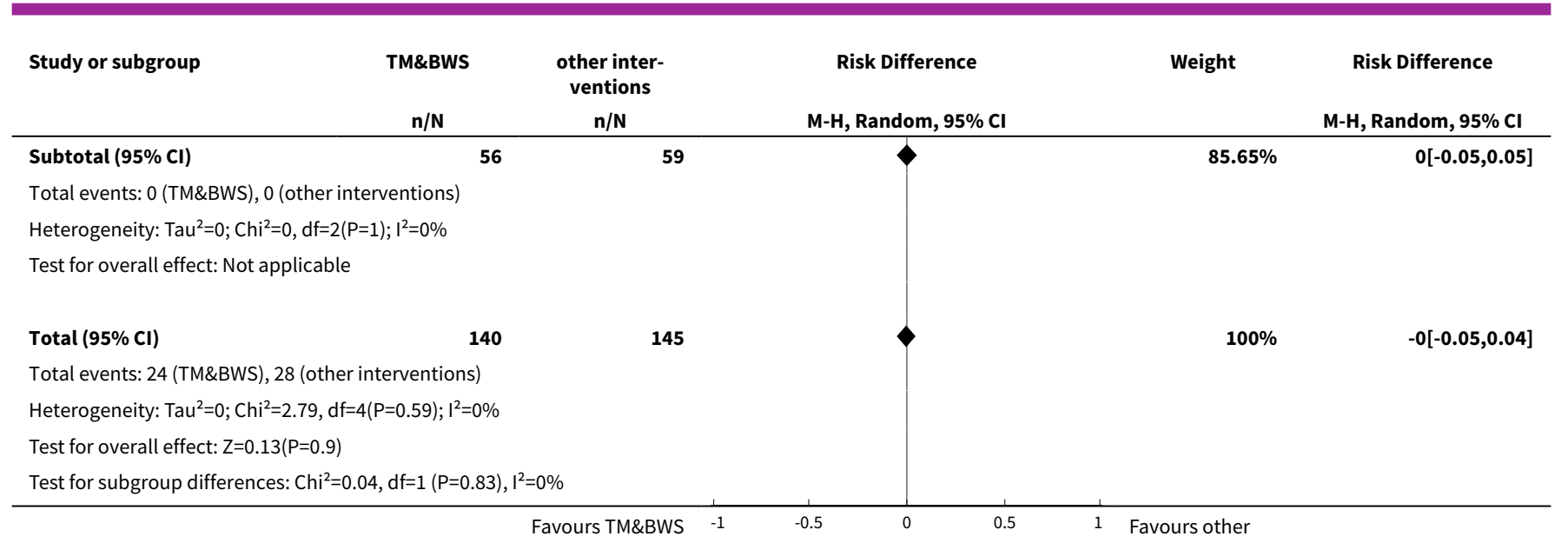

Analysis 2.5. Comparison 2 Treadmill and body weight support versus other interventions, Outcome 5 Walking speed $(\mathrm{m} / \mathrm{s})$ at end of scheduled follow-up.

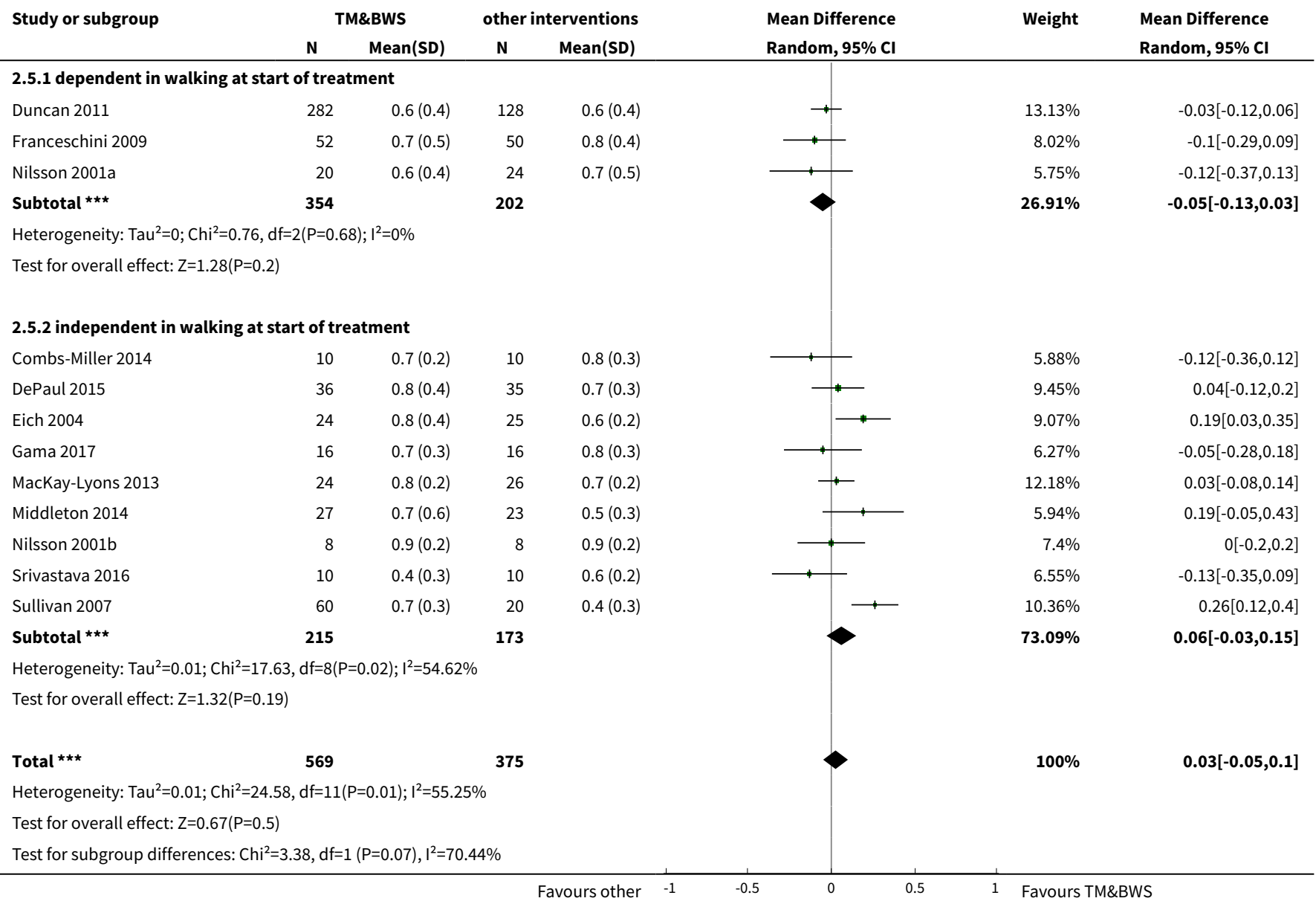


Analysis 2.6. Comparison 2 Treadmill and body weight support versus other interventions, Outcome 6 Walking endurance $(m)$ at end of scheduled follow-up.

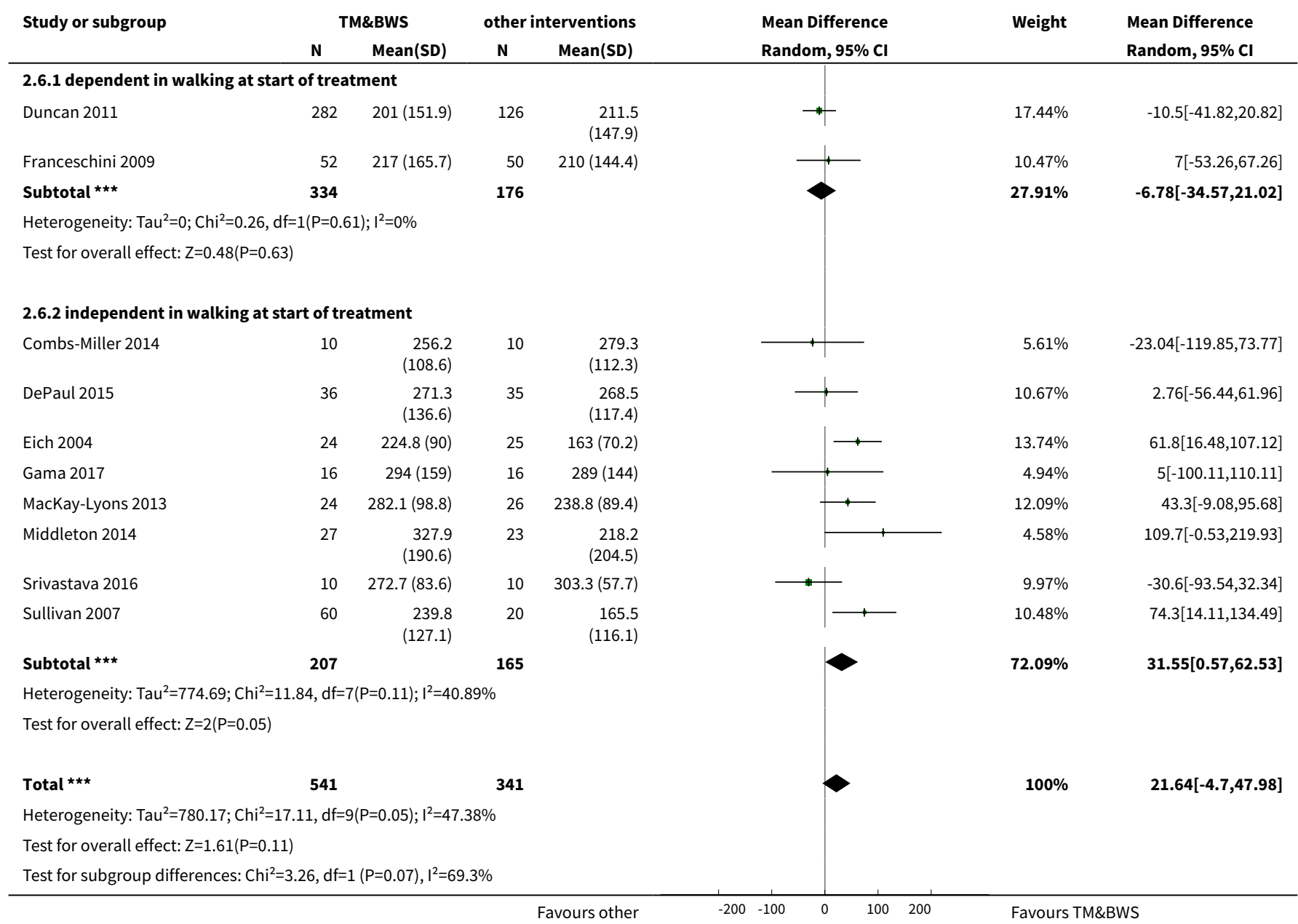

\section{Comparison 3. Treadmill training without body weight support versus other interventions}

\begin{tabular}{lllll}
\hline Outcome or subgroup title & No. of studies & $\begin{array}{l}\text { No. of partici- } \\
\text { pants }\end{array}$ & Statistical method & Effect size \\
\hline $\begin{array}{l}1 \text { Walking speed }(\mathrm{m} / \mathrm{s}) \text { at end of treat- } \\
\text { ment }\end{array}$ & 20 & & $\begin{array}{l}\text { Mean Difference (IV, Random, } \\
95 \% \mathrm{Cl})\end{array}$ & Subtotals only \\
\hline $\begin{array}{l}1.1 \text { independent in walking at start of } \\
\text { treatment }\end{array}$ & 20 & 889 & $\begin{array}{l}\text { Mean Difference (IV, Random, } \\
95 \% \mathrm{Cl})\end{array}$ & $0.05[0.01,0.09]$ \\
\hline $\begin{array}{l}2 \text { Walking endurance }(\mathrm{m}) \text { at end of } \\
\text { treatment }\end{array}$ & 13 & & $\begin{array}{l}\text { Mean Difference (IV, Random, } \\
95 \% \mathrm{Cl})\end{array}$ & Subtotals only \\
\hline $\begin{array}{l}2.1 \text { independent in walking at start of } \\
\text { treatment }\end{array}$ & 13 & 608 & $\begin{array}{l}\text { Mean Difference (IV, Random, } \\
95 \% \mathrm{Cl})\end{array}$ & $9.25[-1.99$, \\
\hline
\end{tabular}


Analysis 3.1. Comparison 3 Treadmill training without body weight support versus other interventions, Outcome 1 Walking speed $(\mathrm{m} / \mathrm{s})$ at end of treatment.

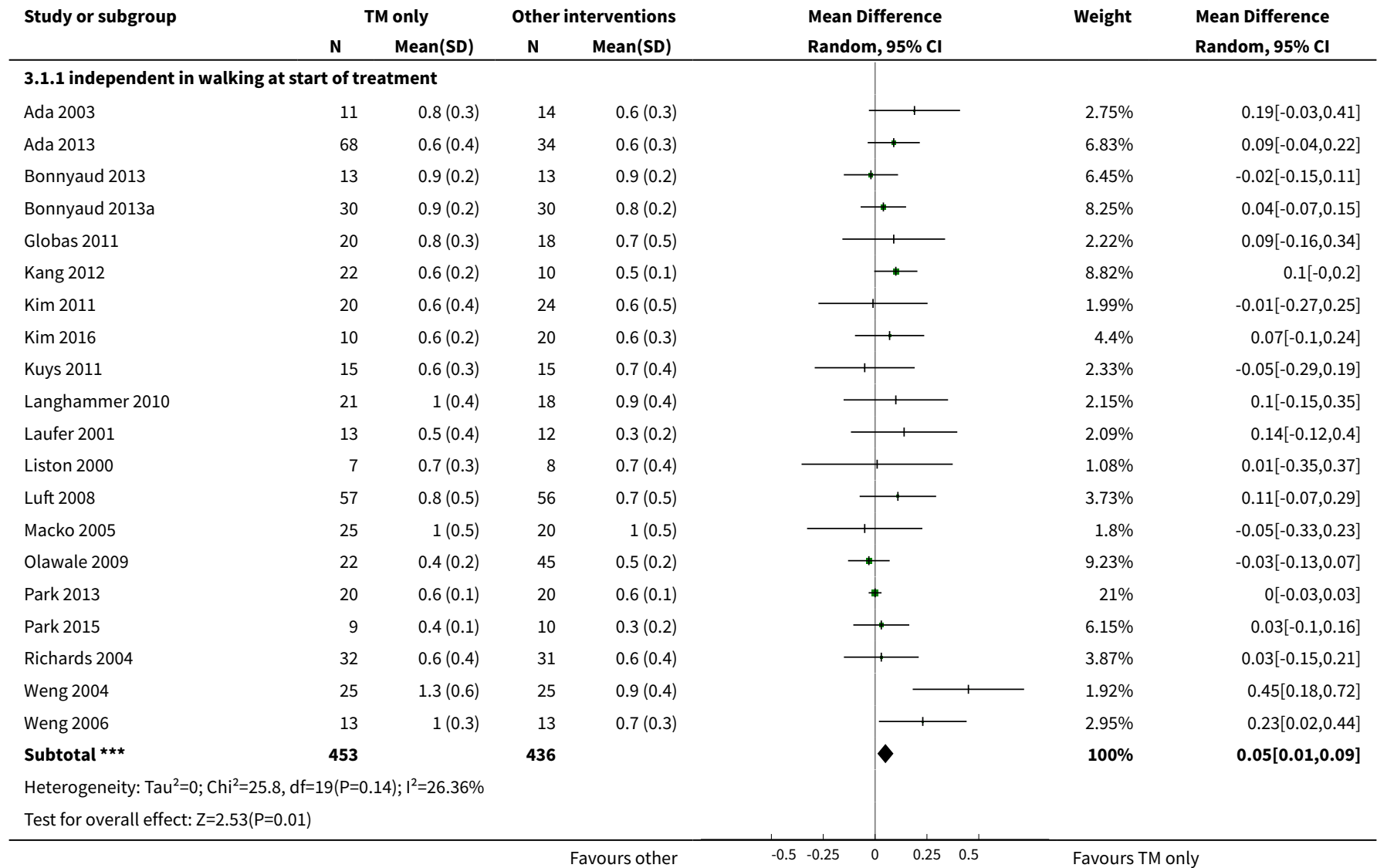

Analysis 3.2. Comparison 3 Treadmill training without body weight support versus other interventions, Outcome 2 Walking endurance $(\mathrm{m})$ at end of treatment.

\begin{tabular}{|c|c|c|c|c|c|c|c|}
\hline \multirow[t]{2}{*}{ Study or subgroup } & \multicolumn{2}{|c|}{ TM only } & \multicolumn{2}{|c|}{ Other intervention } & \multirow{2}{*}{$\begin{array}{l}\text { Mean Difference } \\
\text { Random, } 95 \% \mathrm{Cl}\end{array}$} & \multirow[t]{2}{*}{ Weight } & \multirow{2}{*}{$\begin{array}{l}\text { Mean Difference } \\
\text { Random, } 95 \% \mathrm{Cl}\end{array}$} \\
\hline & $\mathbf{N}$ & $\operatorname{Mean}(\mathrm{SD})$ & $\mathbf{N}$ & Mean(SD) & & & \\
\hline \multicolumn{8}{|c|}{ 3.2.1 independent in walking at start of treatment } \\
\hline Ada 2003 & 11 & $379(122)$ & 14 & $269(123)$ & & $1.35 \%$ & $110[13.31,206.69]$ \\
\hline Ada 2013 & 68 & $271(134.3)$ & 34 & $263(115)$ & & $5.03 \%$ & $8[-42.13,58.13]$ \\
\hline Globas 2011 & 20 & $332.1(138)$ & 18 & $265.9(189)$ & & $1.12 \%$ & $66.2[-40.01,172.41]$ \\
\hline Kang 2012 & 22 & $251.3(22)$ & 10 & $240.9(22.4)$ & 1 & $45.61 \%$ & $10.4[-6.25,27.05]$ \\
\hline Kuys 2011 & 15 & 284 (139) & 15 & $279(163)$ & & $1.08 \%$ & $5[-103.41,113.41]$ \\
\hline Langhammer 2010 & 21 & $\begin{array}{r}320.6 \\
(153.8)\end{array}$ & 18 & $\begin{array}{r}310.1 \\
(164.4)\end{array}$ & & $1.25 \%$ & $10.5[-89.97,110.97]$ \\
\hline Luft 2008 & 57 & $\begin{array}{r}226.8 \\
(145.6)\end{array}$ & 56 & $\begin{array}{r}205.2 \\
(158.1)\end{array}$ & & $4.02 \%$ & $21.6[-34.46,77.66]$ \\
\hline Macko 2005 & 25 & $281(120)$ & 20 & $\begin{array}{r}264.6 \\
(136.3)\end{array}$ & & $2.19 \%$ & $16.43[-59.61,92.47]$ \\
\hline Olawale 2009 & 22 & $145.3(75)$ & 45 & $146.1(64.7)$ & 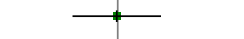 & $9.44 \%$ & $-0.8[-37.4,35.8]$ \\
\hline Park 2013 & 20 & $233.5(41.6)$ & 20 & $225.4(47.1)$ & - & $16.67 \%$ & $8.15[-19.39,35.69]$ \\
\hline Park 2015 & 9 & $125.9(49.6)$ & 10 & $123(39.1)$ & 5 & $7.72 \%$ & $2.9[-37.56,43.36]$ \\
\hline
\end{tabular}




\begin{tabular}{|c|c|c|c|c|c|c|c|}
\hline \multirow{3}{*}{$\begin{array}{l}\text { Study or subgroup } \\
\text { Toledano-Zarhi } 2011\end{array}$} & \multicolumn{2}{|c|}{ TM only } & \multicolumn{2}{|c|}{ Other intervention } & \multirow{2}{*}{$\begin{array}{l}\text { Mean Difference } \\
\text { Random, } 95 \% \mathrm{Cl}\end{array}$} & \multirow{3}{*}{$\begin{array}{r}\text { Weight } \\
0.9 \%\end{array}$} & \multirow{3}{*}{$\begin{array}{l}\begin{array}{l}\text { Mean Difference } \\
\text { Random, 95\% Cl }\end{array} \\
-15[-133.26,103.26]\end{array}$} \\
\hline & \multirow{2}{*}{$\frac{\mathbf{N}}{14}$} & \multirow{2}{*}{$\begin{array}{r}\text { Mean(SD) } \\
469.2 \\
(189.5)\end{array}$} & & \multirow{2}{*}{$\begin{array}{r}\text { Mean(SD) } \\
484.2 \\
(122.7)\end{array}$} & & & \\
\hline & & & & & 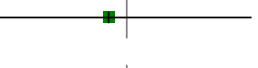 & & \\
\hline Subtotal $\star \star \star$ & 314 & & 294 & & 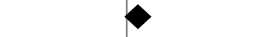 & $100 \%$ & $9.25[-1.99,20.5]$ \\
\hline \multicolumn{8}{|c|}{ Heterogeneity: $\mathrm{Tau}^{2}=0 ; \mathrm{Chi}^{2}=7.37, \mathrm{df}=12(\mathrm{P}=0.83) ; \mathrm{I}^{2}=0 \%$} \\
\hline \multicolumn{8}{|c|}{ Test for overall effect: $Z=1.61(P=0.11)$} \\
\hline
\end{tabular}

\section{Comparison 4. Treadmill and body weight support versus treadmill only}

\begin{tabular}{|c|c|c|c|c|}
\hline Outcome or subgroup title & No. of studies & $\begin{array}{l}\text { No. of partici- } \\
\text { pants }\end{array}$ & Statistical method & Effect size \\
\hline $\begin{array}{l}1 \text { Dependence on personal assistance } \\
\text { to walk at end of treatment }\end{array}$ & 2 & & $\begin{array}{l}\text { Risk Ratio (M-H, Random, } \\
95 \% \mathrm{Cl})\end{array}$ & $\begin{array}{l}\text { Totals not select- } \\
\text { ed }\end{array}$ \\
\hline $\begin{array}{l}1.1 \text { dependent in walking at start of } \\
\text { treatment }\end{array}$ & 1 & & $\begin{array}{l}\text { Risk Ratio (M-H, Random, } \\
95 \% \mathrm{Cl} \text { ) }\end{array}$ & $0.0[0.0,0.0]$ \\
\hline $\begin{array}{l}1.2 \text { independent in walking at start of } \\
\text { treatment }\end{array}$ & 1 & & $\begin{array}{l}\text { Risk Ratio (M-H, Random, } \\
95 \% \mathrm{Cl})\end{array}$ & $0.0[0.0,0.0]$ \\
\hline $\begin{array}{l}2 \text { Walking speed }(\mathrm{m} / \mathrm{s}) \text { at end of treat- } \\
\text { ment }\end{array}$ & 3 & & $\begin{array}{l}\text { Mean Difference (IV, Random, } \\
95 \% \mathrm{CI})\end{array}$ & $\begin{array}{l}\text { Totals not select- } \\
\text { ed }\end{array}$ \\
\hline $\begin{array}{l}2.1 \text { dependent in walking at start of } \\
\text { treatment }\end{array}$ & 1 & & $\begin{array}{l}\text { Mean Difference (IV, Random, } \\
95 \% \mathrm{Cl} \text { ) }\end{array}$ & $0.0[0.0,0.0]$ \\
\hline $\begin{array}{l}2.2 \text { independent in walking at start of } \\
\text { treatment }\end{array}$ & 2 & & $\begin{array}{l}\text { Mean Difference (IV, Random, } \\
95 \% \mathrm{CI})\end{array}$ & $0.0[0.0,0.0]$ \\
\hline $\begin{array}{l}3 \text { Walking endurance }(\mathrm{m}) \text { at end of } \\
\text { treatment }\end{array}$ & 3 & & $\begin{array}{l}\text { Mean Difference (IV, Random, } \\
95 \% \mathrm{Cl} \text { ) }\end{array}$ & $\begin{array}{l}\text { Totals not select- } \\
\text { ed }\end{array}$ \\
\hline $\begin{array}{l}3.1 \text { dependent in walking at start of } \\
\text { treatment }\end{array}$ & 1 & & $\begin{array}{l}\text { Mean Difference (IV, Random, } \\
95 \% \mathrm{CI} \text { ) }\end{array}$ & $0.0[0.0,0.0]$ \\
\hline $\begin{array}{l}3.2 \text { independent in walking at start of } \\
\text { treatment }\end{array}$ & 2 & & $\begin{array}{l}\text { Mean Difference (IV, Random, } \\
95 \% \mathrm{Cl} \text { ) }\end{array}$ & $0.0[0.0,0.0]$ \\
\hline $\begin{array}{l}4 \text { Dependence on personal assistance } \\
\text { to walk at end of scheduled follow-up }\end{array}$ & 2 & & $\begin{array}{l}\text { Risk Ratio (M-H, Random, } \\
95 \% \mathrm{Cl})\end{array}$ & $\begin{array}{l}\text { Totals not select- } \\
\text { ed }\end{array}$ \\
\hline $\begin{array}{l}4.1 \text { dependent in walking at start of } \\
\text { treatment }\end{array}$ & 1 & & $\begin{array}{l}\text { Risk Ratio (M-H, Random, } \\
95 \% \mathrm{Cl})\end{array}$ & $0.0[0.0,0.0]$ \\
\hline $\begin{array}{l}4.2 \text { independent in walking at start of } \\
\text { treatment }\end{array}$ & 1 & & $\begin{array}{l}\text { Risk Ratio (M-H, Random, } \\
95 \% \mathrm{Cl} \text { ) }\end{array}$ & $0.0[0.0,0.0]$ \\
\hline $\begin{array}{l}5 \text { Walking speed }(\mathrm{m} / \mathrm{s}) \text { at end of sched- } \\
\text { uled follow-up }\end{array}$ & 3 & & $\begin{array}{l}\text { Mean Difference (IV, Random, } \\
95 \% \mathrm{Cl} \text { ) }\end{array}$ & $\begin{array}{l}\text { Totals not select- } \\
\text { ed }\end{array}$ \\
\hline $\begin{array}{l}5.1 \text { dependent in walking at start of } \\
\text { treatment }\end{array}$ & 1 & & $\begin{array}{l}\text { Mean Difference (IV, Random, } \\
95 \% \mathrm{Cl})\end{array}$ & $0.0[0.0,0.0]$ \\
\hline
\end{tabular}




\begin{tabular}{lllll}
\hline Outcome or subgroup title & No. of studies & $\begin{array}{l}\text { No. of partici- } \\
\text { pants }\end{array}$ & Statistical method & Effect size \\
\hline $\begin{array}{l}5.2 \text { independent in walking at start of } \\
\text { treatment }\end{array}$ & 2 & & $\begin{array}{l}\text { Mean Difference (IV, Random, } \\
95 \% \mathrm{Cl})\end{array}$ & $0.0[0.0,0.0]$ \\
\hline $\begin{array}{l}6 \text { Walking endurance (m) at end of } \\
\text { scheduled follow-up }\end{array}$ & 3 & $\begin{array}{l}\text { Mean Difference (IV, Random, } \\
95 \% \mathrm{Cl})\end{array}$ & $\begin{array}{l}\text { Totals not select- } \\
\text { ed }\end{array}$ \\
\hline $\begin{array}{l}6.1 \text { dependent in walking at start of } \\
\text { treatment }\end{array}$ & 1 & $\begin{array}{l}\text { Mean Difference (IV, Random, } \\
95 \% \text { Cl) }\end{array}$ & $0.0[0.0,0.0]$ \\
\hline $\begin{array}{l}6.2 \text { independent in walking at start of } \\
\text { treatment }\end{array}$ & 2 & Mean Difference (IV, Random, & $0.0[0.0,0.0]$ \\
\hline
\end{tabular}

Analysis 4.1. Comparison 4 Treadmill and body weight support versus treadmill only, Outcome 1 Dependence on personal assistance to walk at end of treatment.

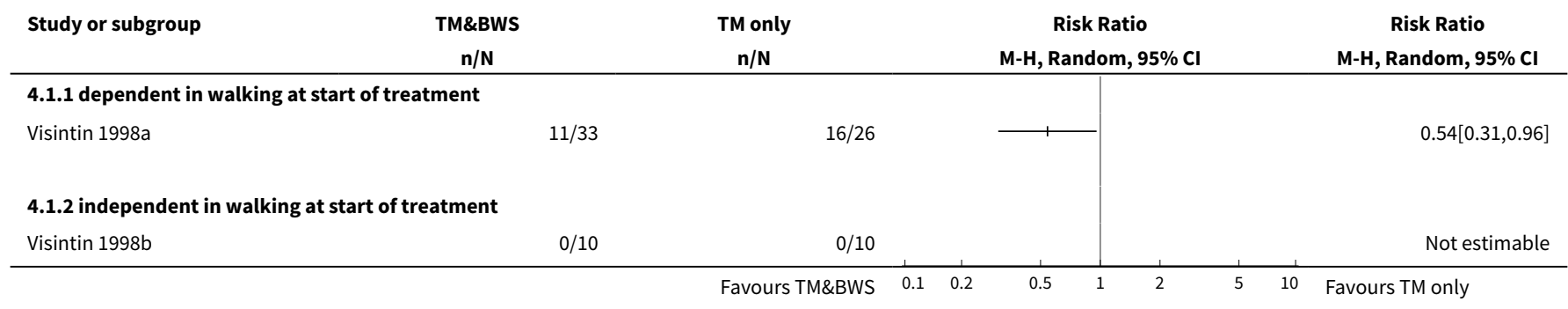

Analysis 4.2. Comparison 4 Treadmill and body weight support versus treadmill only, Outcome 2 Walking speed $(\mathrm{m} / \mathrm{s})$ at end of treatment.

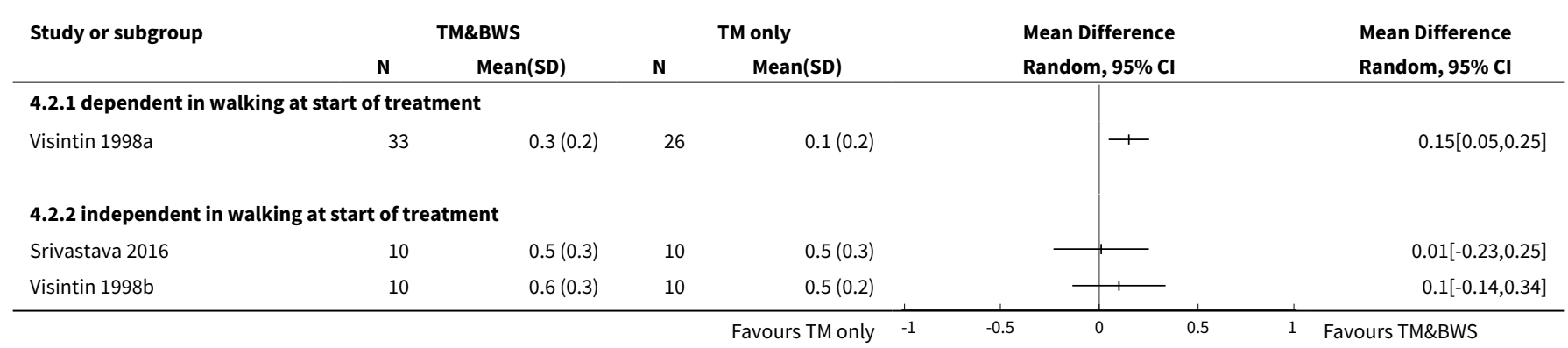

Analysis 4.3. Comparison 4 Treadmill and body weight support versus treadmill only, Outcome 3 Walking endurance $(m)$ at end of treatment.

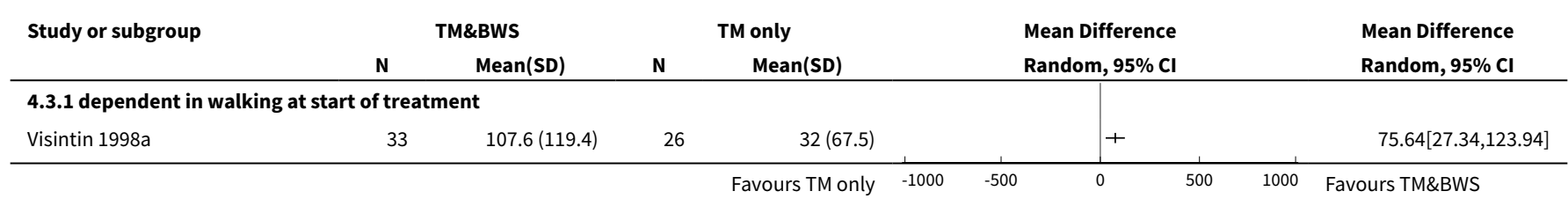




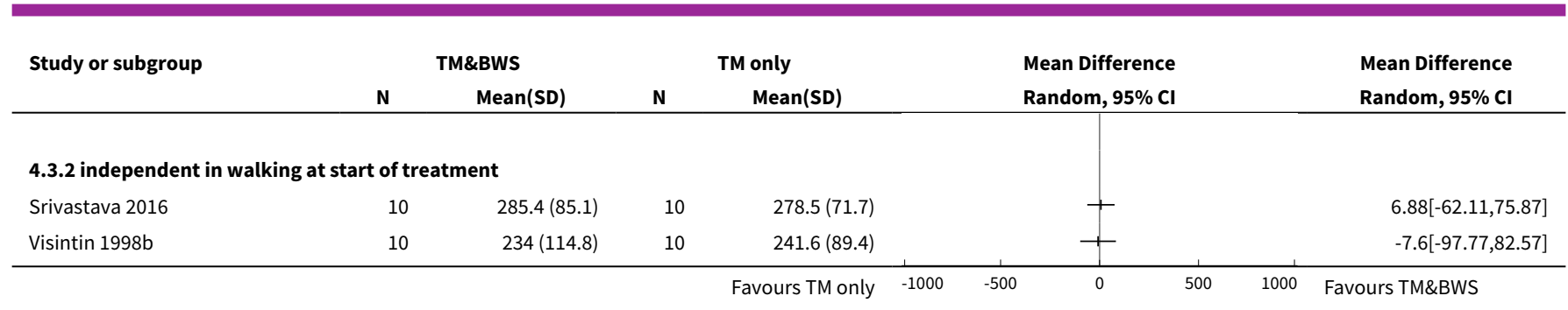

Analysis 4.4. Comparison 4 Treadmill and body weight support versus treadmill only, Outcome 4 Dependence on personal assistance to walk at end of scheduled follow-up.

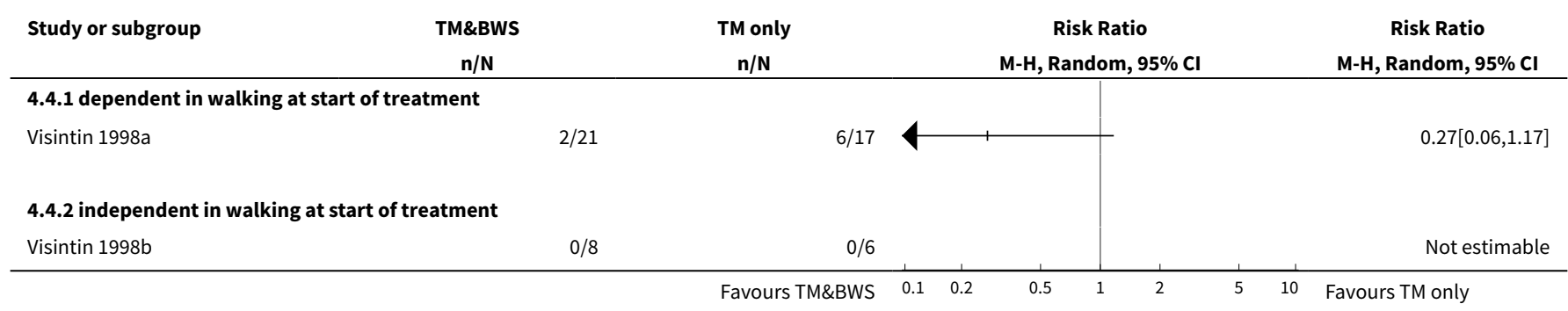

Analysis 4.5. Comparison 4 Treadmill and body weight support versus treadmill only, Outcome 5 Walking speed $(\mathrm{m} / \mathrm{s})$ at end of scheduled follow-up.

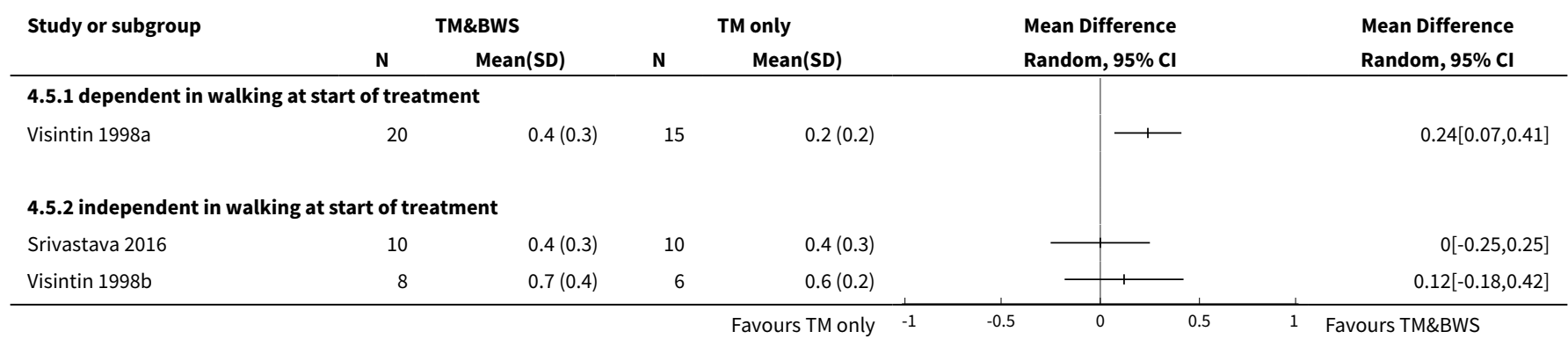

Analysis 4.6. Comparison 4 Treadmill and body weight support versus treadmill only, Outcome 6 Walking endurance $(\mathrm{m})$ ) at end of scheduled follow-up.

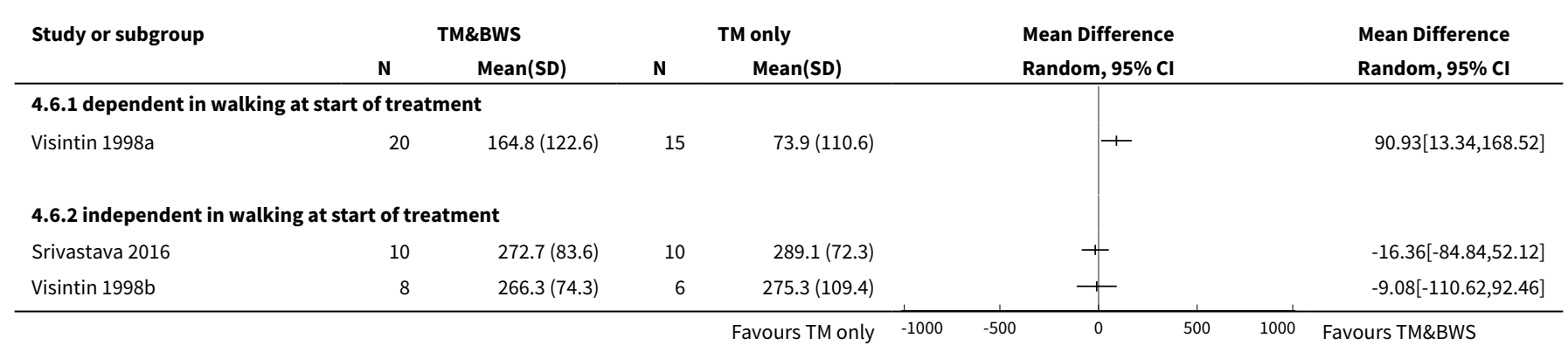


Comparison 5. Adverse events for all included trials

\begin{tabular}{lllll}
\hline Outcome or subgroup title & No. of studies & $\begin{array}{l}\text { No. of partici- } \\
\text { pants }\end{array}$ & Statistical method & Effect size \\
\hline $\begin{array}{l}1 \text { Adverse events during the treat- } \\
\text { ment }\end{array}$ & 24 & 1504 & $\begin{array}{l}\text { Risk Difference (M-H, Random, } \\
95 \% \mathrm{Cl})\end{array}$ & $0.02[-0.01,0.05]$ \\
\hline
\end{tabular}

Analysis 5.1. Comparison 5 Adverse events for all included trials, Outcome 1 Adverse events during the treatment.

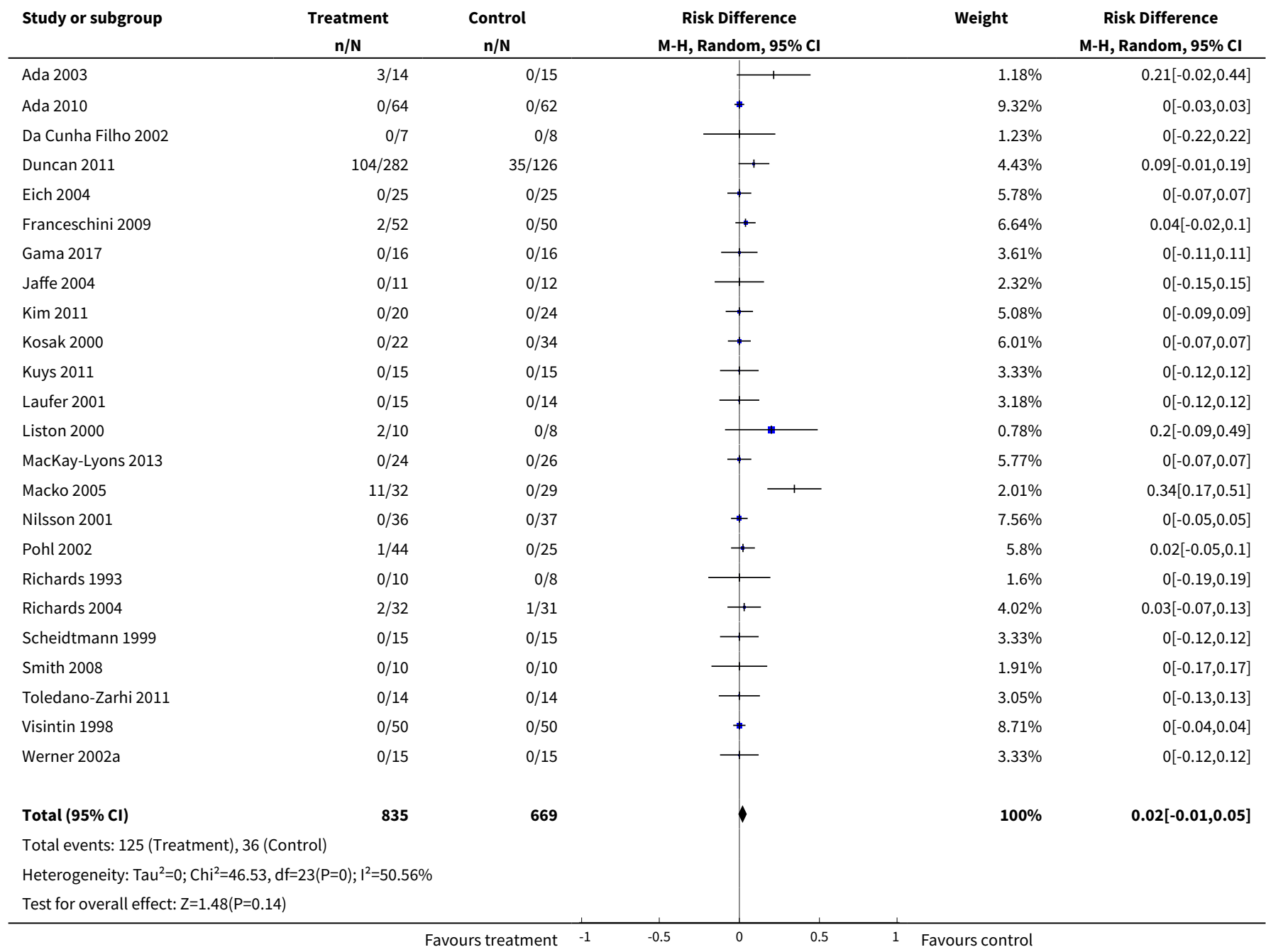

\section{Comparison 6. Dropouts for all included trials}

\begin{tabular}{lllll}
\hline Outcome or subgroup title & No. of studies & $\begin{array}{l}\text { No. of partici- } \\
\text { pants }\end{array}$ & Statistical method & Effect size \\
\hline 1 Dropouts & 56 & $\begin{array}{l}\text { Risk Difference (M-H, Random, 95\% } \\
\text { Cl) }\end{array}$ & Subtotals only \\
\hline \hline
\end{tabular}




\begin{tabular}{lllll}
\hline Outcome or subgroup title & No. of studies & $\begin{array}{l}\text { No. of partici- } \\
\text { pants }\end{array}$ & Statistical method & Effect size \\
\hline 1.1 by end of treatment phase & 56 & 3105 & $\begin{array}{l}\text { Risk Difference (M-H, Random, 95\% } \\
\text { Cl) }\end{array}$ & $0.00[-0.01,0.01]$ \\
\hline $\begin{array}{l}1.2 \text { by end of scheduled fol- } \\
\text { low-up (cumulative) }\end{array}$ & 14 & 780 & $\begin{array}{l}\text { Risk Difference (M-H, Random, 95\% } \\
\text { Cl) }\end{array}$ & $-0.02[-0.06,0.03]$ \\
\hline
\end{tabular}

Analysis 6.1. Comparison 6 Dropouts for all included trials, Outcome 1 Dropouts.

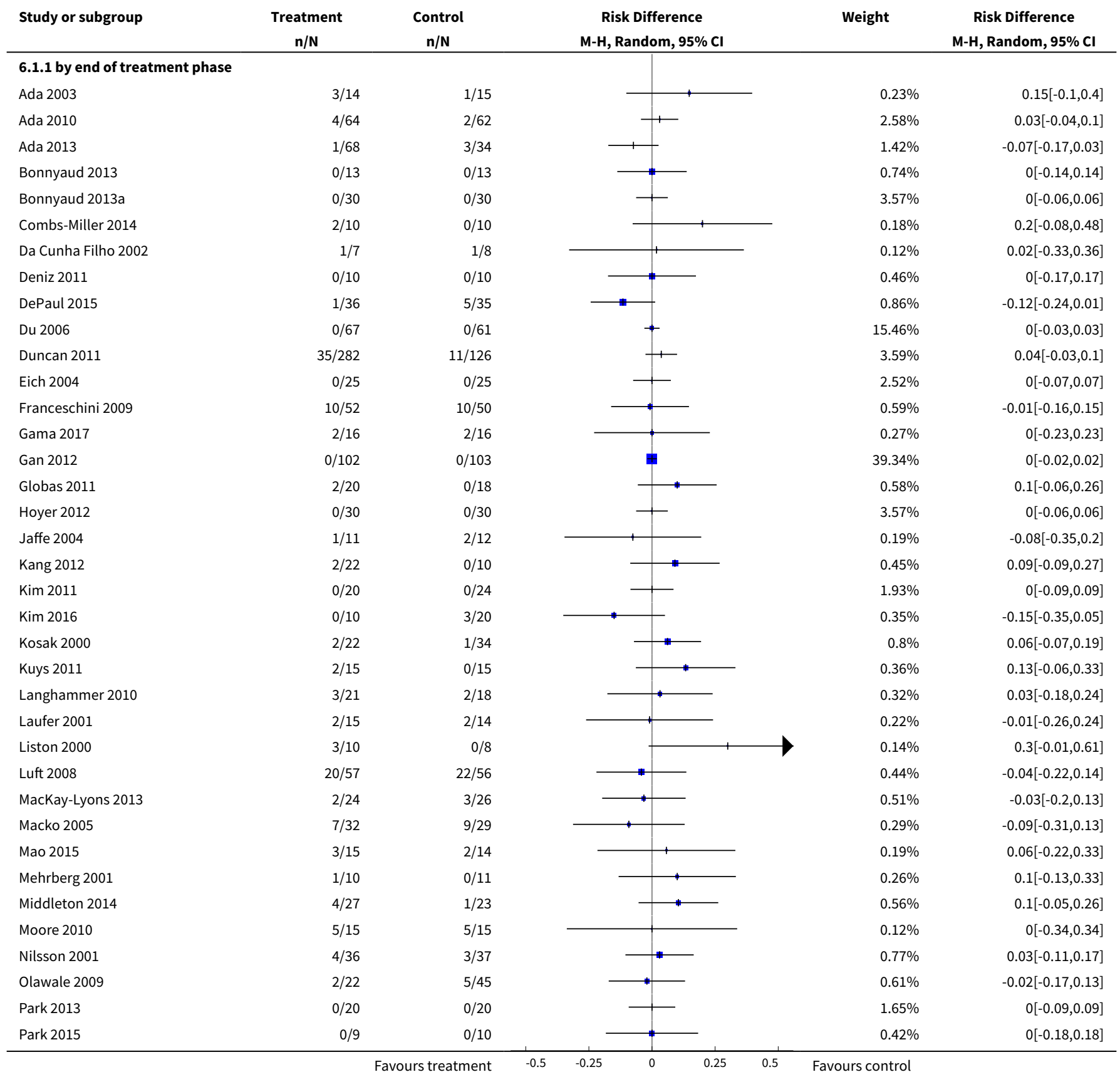




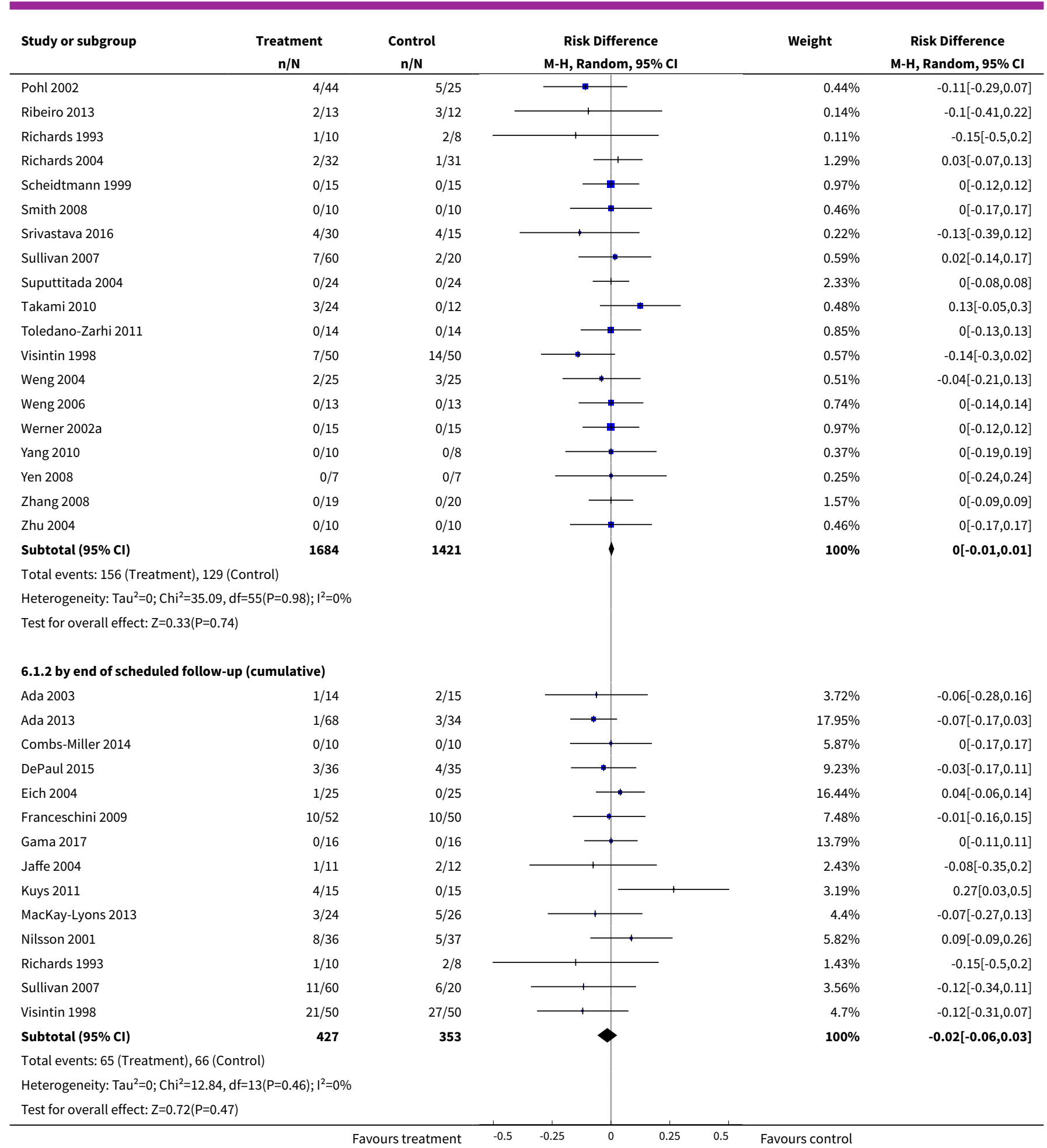


Comparison 7. Sensitivity analysis: by trial methodology (all trials involving treadmill training)

\begin{tabular}{lllll}
\hline Outcome or subgroup title & No. of studies & $\begin{array}{l}\text { No. of partici- } \\
\text { pants }\end{array}$ & Statistical method & Effect size \\
\hline 1 Walking speed & 36 & & $\begin{array}{l}\text { Mean Difference (IV, Random, } \\
95 \% \mathrm{Cl})\end{array}$ & Subtotals only \\
\hline $\begin{array}{l}1.1 \text { trials with adequate random se- } \\
\text { quence generation }\end{array}$ & 27 & 1242 & $\begin{array}{l}\text { Mean Difference (IV, Random, } \\
95 \% \mathrm{Cl})\end{array}$ & 0.03 [0.00, 0.06$]$ \\
\hline $\begin{array}{l}1.2 \text { trials with adequate concealed } \\
\text { allocation }\end{array}$ & 21 & 1266 & $\begin{array}{l}\text { Mean Difference (IV, Random, } \\
95 \% \text { Cl) }\end{array}$ & $0.06[0.01,0.10]$ \\
\hline $\begin{array}{l}1.3 \text { trials with adequate blinding of } \\
\text { assessors }\end{array}$ & 24 & 1554 & $\begin{array}{l}\text { Mean Difference (IV, Random, } \\
95 \% \mathrm{Cl})\end{array}$ & $0.06[0.02,0.11]$ \\
\hline
\end{tabular}

Analysis 7.1. Comparison 7 Sensitivity analysis: by trial methodology (all trials involving treadmill training), Outcome 1 Walking speed.

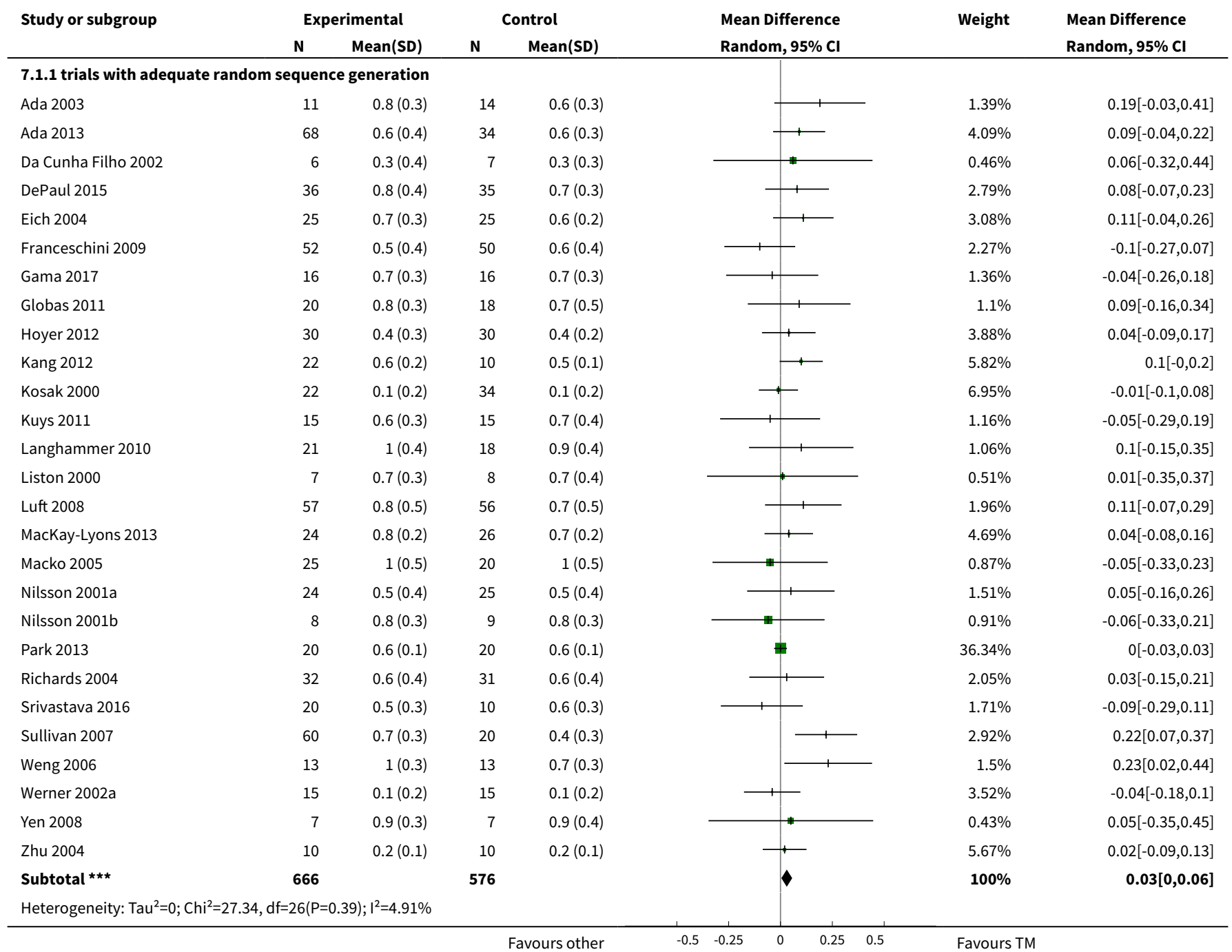




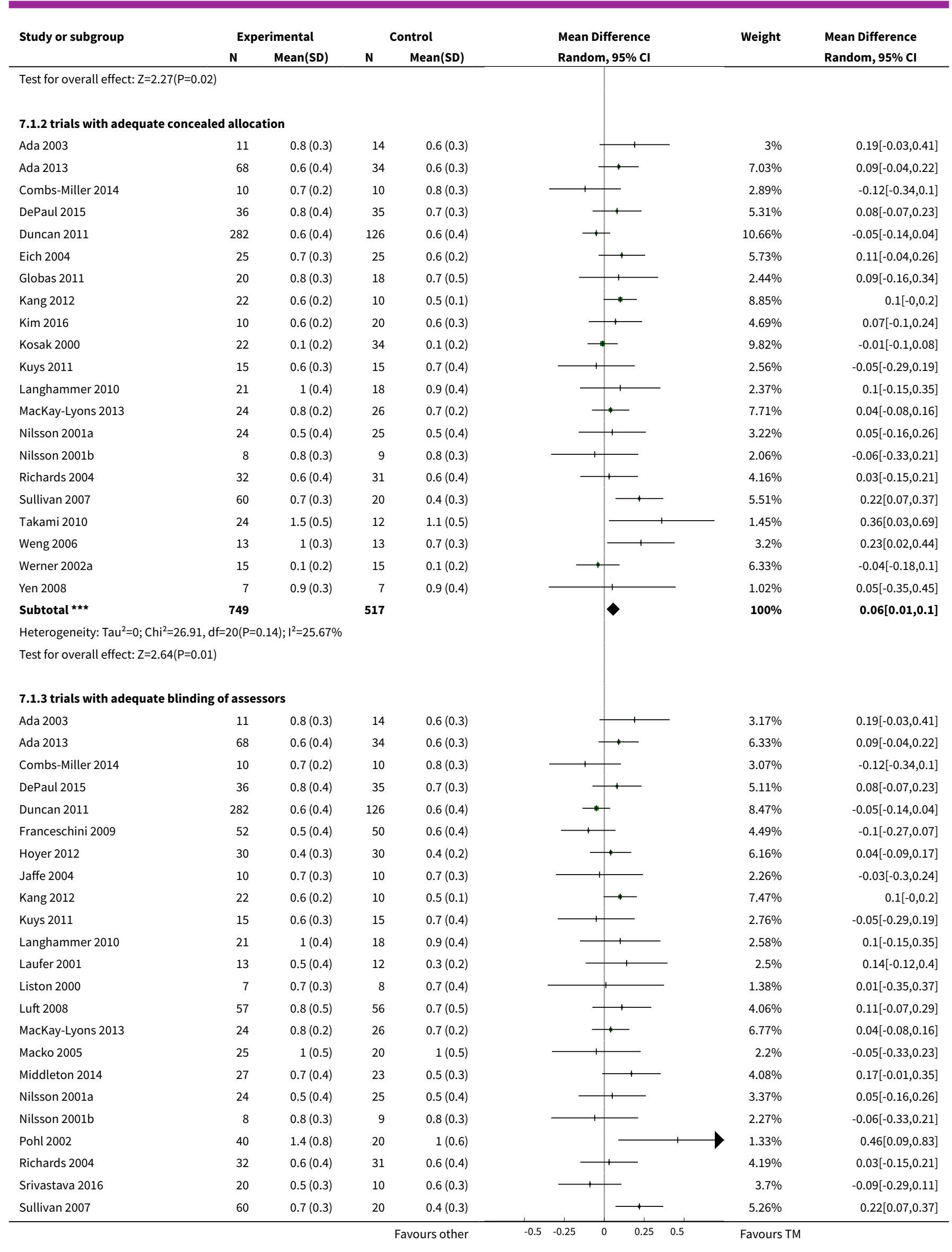




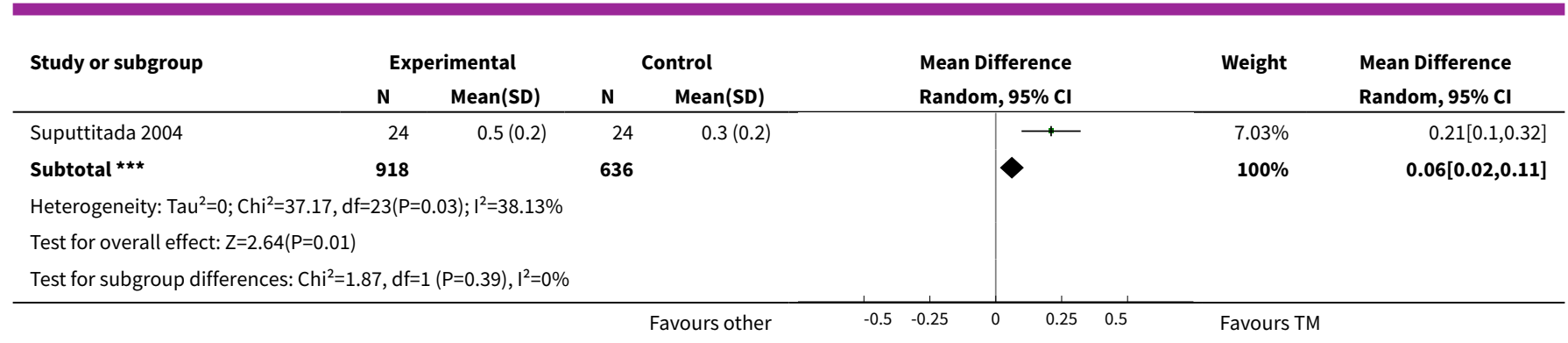

Comparison 8. Subgroup analysis: treadmill (with or without body weight support) versus other, by duration of illness (independent in walking only)

\begin{tabular}{|c|c|c|c|c|}
\hline Outcome or subgroup title & No. of studies & $\begin{array}{l}\text { No. of partici- } \\
\text { pants }\end{array}$ & Statistical method & Effect size \\
\hline 1 Walking speed $(\mathrm{m} / \mathrm{s})$ at end of treatment & 37 & & $\begin{array}{l}\text { Mean Difference (IV, Ran- } \\
\text { dom, } 95 \% \mathrm{CI} \text { ) }\end{array}$ & Subtotals only \\
\hline $\begin{array}{l}1.1 \text { Acute phase: less then or equal to } 3 \\
\text { months after stroke independent in walk- } \\
\text { ing }\end{array}$ & 11 & 347 & $\begin{array}{l}\text { Mean Difference (IV, Ran- } \\
\text { dom, } 95 \% \mathrm{CI} \text { ) }\end{array}$ & $0.15[0.07,0.23]$ \\
\hline $\begin{array}{l}1.2 \text { Chronic phase: more than } 3 \text { months af- } \\
\text { ter stroke independent in walking }\end{array}$ & 26 & 1209 & $\begin{array}{l}\text { Mean Difference (IV, Ran- } \\
\text { dom, } 95 \% \mathrm{CI} \text { ) }\end{array}$ & $0.06[0.02,0.10]$ \\
\hline $\begin{array}{l}2 \text { Walking endurance }(\mathrm{m}) \text { at end of treat- } \\
\text { ment }\end{array}$ & 23 & & $\begin{array}{l}\text { Mean Difference (IV, Ran- } \\
\text { dom, } 95 \% \mathrm{CI} \text { ) }\end{array}$ & Subtotals only \\
\hline $\begin{array}{l}\text { 2.1 Acute phase: less then or equal to } 3 \\
\text { months after stroke independent in walk- } \\
\text { ing }\end{array}$ & 5 & 178 & $\begin{array}{l}\text { Mean Difference (IV, Ran- } \\
\text { dom, } 95 \% \mathrm{CI} \text { ) }\end{array}$ & $\begin{array}{l}48.64[23.97 \\
73.32]\end{array}$ \\
\hline $\begin{array}{l}2.2 \text { Chronic phase: more than } 3 \text { months af- } \\
\text { ter stroke independent in walking }\end{array}$ & 18 & 863 & $\begin{array}{l}\text { Mean Difference (IV, Ran- } \\
\text { dom, } 95 \% \mathrm{CI} \text { ) }\end{array}$ & $\begin{array}{l}10.69[-0.28 \\
21.66]\end{array}$ \\
\hline
\end{tabular}

Analysis 8.1. Comparison 8 Subgroup analysis: treadmill (with or without body weight support) versus other, by duration of illness (independent in walking only), Outcome 1 Walking speed $(\mathrm{m} / \mathrm{s})$ at end of treatment.

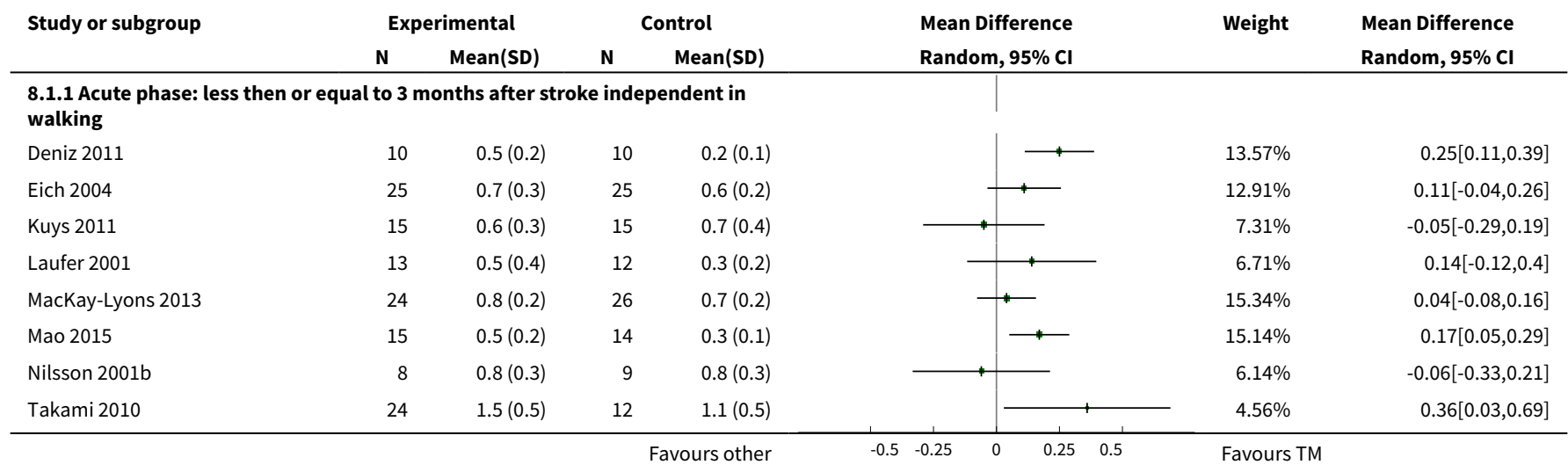




\begin{tabular}{|c|c|c|c|c|c|c|c|c|c|}
\hline \multirow{3}{*}{$\begin{array}{l}\text { Study or subgroup } \\
\text { Weng } 2004\end{array}$} & \multicolumn{2}{|c|}{ Experimental } & \multicolumn{2}{|c|}{ Control } & \multirow{2}{*}{\multicolumn{3}{|c|}{$\begin{array}{l}\text { Mean Difference } \\
\text { Random, } 95 \% \mathrm{CI}\end{array}$}} & \multirow{3}{*}{$\begin{array}{r}\text { Weight } \\
6.28 \%\end{array}$} & \multirow{3}{*}{$\begin{array}{l}\begin{array}{l}\text { Mean Difference } \\
\text { Random, 95\% Cl }\end{array} \\
0.45[0.18,0.72]\end{array}$} \\
\hline & \multirow{2}{*}{$\frac{\mathbf{N}}{25}$} & \multirow{2}{*}{$\begin{array}{r}\text { Mean(SD) } \\
1.3(0.6)\end{array}$} & \multirow{2}{*}{$\frac{\mathbf{N}}{25}$} & \multirow{2}{*}{$\frac{\operatorname{Mean}(\text { SD) }}{0.9(0.4)}$} & & & & & \\
\hline & & & & & & $\longrightarrow$ & $\rightarrow$ & & \\
\hline Weng 2006 & 13 & $1(0.3)$ & 13 & $0.7(0.3)$ & & \#- & & $8.68 \%$ & $0.23[0.02,0.44]$ \\
\hline Yen 2008 & 7 & $0.9(0.3)$ & 7 & $0.9(0.4)$ & & & & $3.37 \%$ & $0.05[-0.35,0.45]$ \\
\hline Subtotal $\star \star \star$ & 179 & & 168 & & & & & $100 \%$ & $0.15[0.07,0.23]$ \\
\hline \multicolumn{10}{|c|}{ Heterogeneity: $\mathrm{Tau}^{2}=0.01 ; \mathrm{Chi}^{2}=17.83, \mathrm{df}=10(\mathrm{P}=0.06) ; \mathrm{I}^{2}=43.92 \%$} \\
\hline \multicolumn{10}{|c|}{ Test for overall effect: $Z=3.69(P=0)$} \\
\hline \multicolumn{10}{|c|}{ 8.1.2 Chronic phase: more than 3 months after stroke independent in walking } \\
\hline Ada 2003 & 11 & $0.8(0.3)$ & 14 & $0.6(0.3)$ & & & & $2.32 \%$ & $0.19[-0.03,0.41]$ \\
\hline Ada 2013 & 68 & $0.6(0.4)$ & 34 & $0.6(0.3)$ & & $\rightarrow$ & & $5.18 \%$ & $0.09[-0.04,0.22]$ \\
\hline Bonnyaud 2013 & 13 & $0.9(0.2)$ & 13 & $0.9(0.2)$ & & - & & $4.94 \%$ & $-0.02[-0.15,0.11]$ \\
\hline Bonnyaud 2013a & 30 & $0.9(0.2)$ & 30 & $0.8(0.2)$ & & + & & $6.05 \%$ & $0.04[-0.07,0.15]$ \\
\hline Combs-Miller 2014 & 10 & $0.7(0.2)$ & 10 & $0.8(0.3)$ & & \begin{tabular}{l|l}
1 & \\
\end{tabular} & & $2.24 \%$ & $-0.12[-0.34,0.1]$ \\
\hline DePaul 2015 & 36 & $0.8(0.4)$ & 35 & $0.7(0.3)$ & & & & $4 \%$ & $0.08[-0.07,0.23]$ \\
\hline Gama 2017 & 16 & $0.7(0.3)$ & 16 & $0.7(0.3)$ & & & & $2.28 \%$ & $-0.04[-0.26,0.18]$ \\
\hline Globas 2011 & 20 & $0.8(0.3)$ & 18 & $0.7(0.5)$ & & & & $1.9 \%$ & $0.09[-0.16,0.34]$ \\
\hline Jaffe 2004 & 10 & $0.7(0.3)$ & 10 & $0.7(0.3)$ & & & & $1.61 \%$ & $-0.03[-0.3,0.24]$ \\
\hline Kang 2012 & 22 & $0.6(0.2)$ & 10 & $0.5(0.1)$ & & - & & $6.38 \%$ & $0.1[-0,0.2]$ \\
\hline Kim 2011 & 20 & $0.6(0.4)$ & 24 & $0.6(0.5)$ & & & & $1.71 \%$ & $-0.01[-0.27,0.25]$ \\
\hline Kim 2016 & 10 & $0.6(0.2)$ & 20 & $0.6(0.3)$ & & & & $3.55 \%$ & $0.07[-0.1,0.24]$ \\
\hline Langhammer 2010 & 21 & $1(0.4)$ & 18 & $0.9(0.4)$ & & & & $1.85 \%$ & $0.1[-0.15,0.35]$ \\
\hline Luft 2008 & 57 & $0.8(0.5)$ & 56 & $0.7(0.5)$ & & 1 & & $3.07 \%$ & $0.11[-0.07,0.29]$ \\
\hline Macko 2005 & 25 & $1(0.5)$ & 20 & $1(0.5)$ & & & & $1.56 \%$ & $-0.05[-0.33,0.23]$ \\
\hline Middleton 2014 & 27 & $0.7(0.4)$ & 23 & $0.5(0.3)$ & & & & $3.08 \%$ & $0.17[-0.01,0.35]$ \\
\hline Moore 2010 & 15 & $0.6(0.3)$ & 15 & $0.6(0.2)$ & & + & & $2.9 \%$ & $0.05[-0.14,0.24]$ \\
\hline Olawale 2009 & 22 & $0.4(0.2)$ & 45 & $0.5(0.2)$ & & + & & $6.61 \%$ & $-0.03[-0.13,0.07]$ \\
\hline Park 2013 & 20 & $0.6(0.1)$ & 20 & $0.6(0.1)$ & & + & & $11.81 \%$ & $0[-0.03,0.03]$ \\
\hline Park 2015 & 9 & $0.4(0.1)$ & 10 & $0.3(0.2)$ & & 1 & & $4.75 \%$ & $0.03[-0.1,0.16]$ \\
\hline Pohl 2002 & 40 & $1.4(0.8)$ & 20 & $1(0.6)$ & & & & $0.92 \%$ & $0.46[0.09,0.83]$ \\
\hline Ribeiro 2013 & 13 & $0.5(0.2)$ & 12 & $0.4(0.1)$ & & + & & $5.34 \%$ & $0.1[-0.02,0.22]$ \\
\hline Richards 2004 & 32 & $0.6(0.4)$ & 31 & $0.6(0.4)$ & & & & $3.17 \%$ & $0.03[-0.15,0.21]$ \\
\hline Srivastava 2016 & 20 & $0.5(0.3)$ & 10 & $0.6(0.3)$ & & - & & $2.75 \%$ & $-0.09[-0.29,0.11]$ \\
\hline Sullivan 2007 & 60 & $0.7(0.3)$ & 20 & $0.4(0.3)$ & & 1 & & $4.14 \%$ & $0.22[0.07,0.37]$ \\
\hline Suputtitada 2004 & 24 & $0.5(0.2)$ & 24 & $0.3(0.2)$ & & $\longrightarrow$ & & $5.9 \%$ & $0.21[0.1,0.32]$ \\
\hline 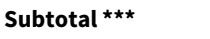 & 651 & & 558 & & & $\diamond$ & & $100 \%$ & $0.06[0.02,0.1]$ \\
\hline \multicolumn{10}{|c|}{ Heterogeneity: $\operatorname{Tau}^{2}=0 ; \mathrm{Chi}^{2}=40.81, \mathrm{df}=25(\mathrm{P}=0.02) ; \mathrm{I}^{2}=38.74 \%$} \\
\hline \multicolumn{10}{|c|}{ Test for overall effect: $Z=3.18(P=0)$} \\
\hline \multicolumn{10}{|c|}{ Test for subgroup differences: $\mathrm{Chi}^{2}=3.95, \mathrm{df}=1(\mathrm{P}=0.05), \mathrm{I}^{2}=74.66 \%$} \\
\hline
\end{tabular}

Analysis 8.2. Comparison 8 Subgroup analysis: treadmill (with or without body weight support) versus other, by duration of illness (independent in walking only), Outcome 2 Walking endurance $(m)$ at end of treatment.

\begin{tabular}{|c|c|c|c|c|c|c|c|c|c|}
\hline \multirow[t]{2}{*}{ Study or subgroup } & \multicolumn{2}{|c|}{ Experimental } & \multicolumn{2}{|c|}{ Control } & \multirow{2}{*}{\multicolumn{2}{|c|}{$\begin{array}{l}\text { Mean Difference } \\
\text { Random, } 95 \% \mathrm{Cl}\end{array}$}} & & \multirow[t]{2}{*}{ Weight } & \multirow{2}{*}{$\begin{array}{l}\text { Mean Difference } \\
\text { Random, } 95 \% \mathrm{CI}\end{array}$} \\
\hline & $\mathbf{N}$ & Mean(SD) & $\mathbf{N}$ & $\operatorname{Mean}(\mathrm{SD})$ & & & & & \\
\hline \multicolumn{10}{|c|}{$\begin{array}{l}\text { 8.2.1 Acute phase: less then or equal to } 3 \text { months after stroke independent in } \\
\text { walking }\end{array}$} \\
\hline Deniz 2011 & 10 & $148(22.2)$ & 10 & $70(60.7)$ & & $\longrightarrow$ & \pm & $33.86 \%$ & $78[37.94,118.06]$ \\
\hline Eich 2004 & 25 & $198.8(81.1)$ & 25 & $164.4(69.3)$ & & - & & $31.36 \%$ & $34.4[-7.42,76.22]$ \\
\hline
\end{tabular}




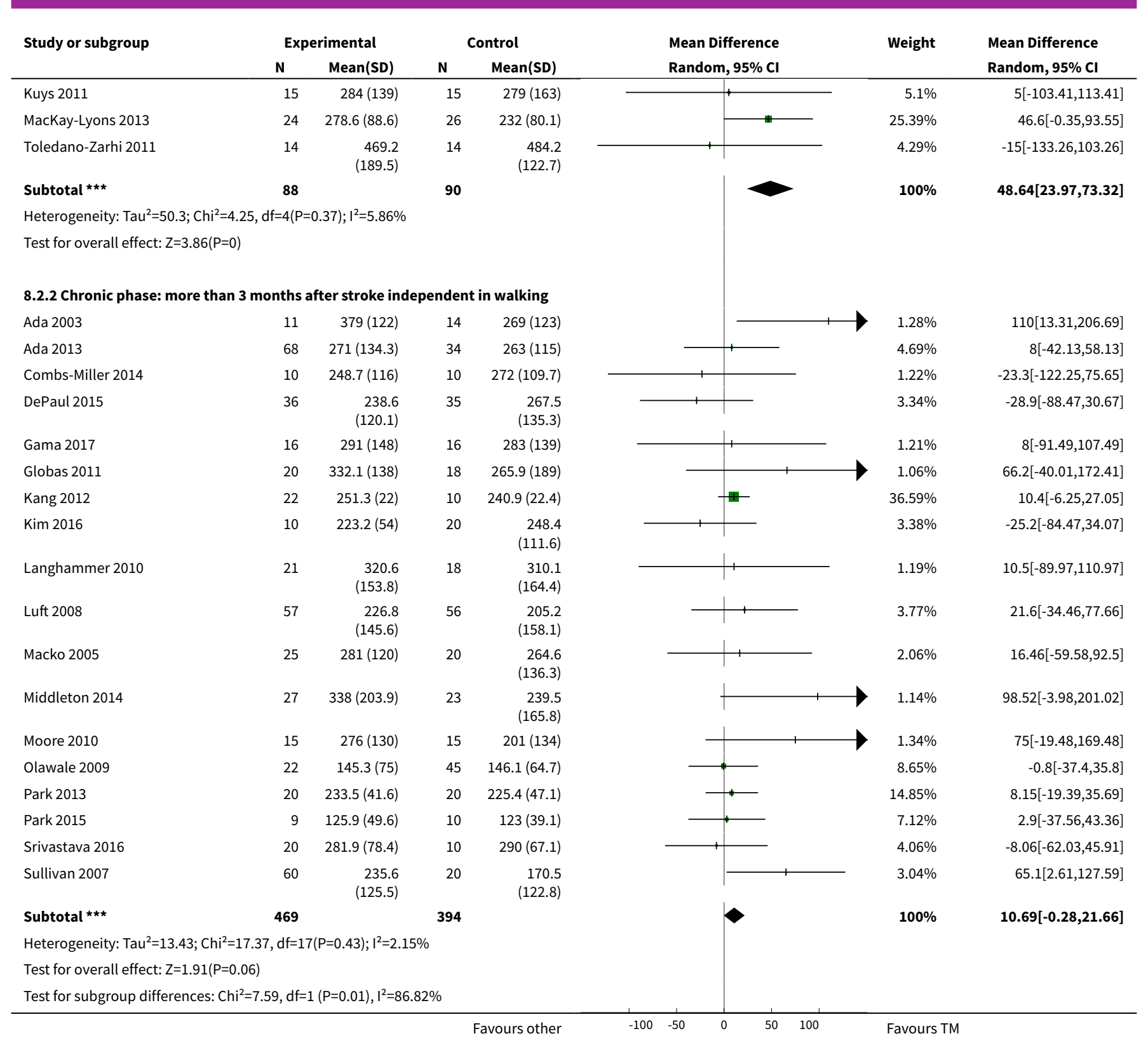

Comparison 9. Subgroup analysis: treadmill (with or without body weight support) versus other, by intensity (frequency) of training (independent in walking only)

\begin{tabular}{lllll}
\hline Outcome or subgroup title & No. of studies & $\begin{array}{l}\text { No. of partici- } \\
\text { pants }\end{array}$ & Statistical method & Effect size \\
\hline $\begin{array}{l}1 \text { Walking speed }(\mathrm{m} / \mathrm{s}) \text { at end of treat- } \\
\text { ment }\end{array}$ & 38 & & $\begin{array}{l}\text { Mean Difference (IV, Fixed, } \\
95 \% \mathrm{Cl})\end{array}$ & Subtotals only \\
\hline $\begin{array}{l}1.1 \text { treadmill training } 5 \text { times a week } \\
\text { or more }\end{array}$ & 19 & 671 & $\begin{array}{l}\text { Mean Difference (IV, Fixed, } \\
95 \% \mathrm{Cl})\end{array}$ & $0.04[0.02,0.07]$ \\
\hline $\begin{array}{l}1.2 \text { treadmill training } 3 \text { to } 4 \text { times a } \\
\text { week }\end{array}$ & 16 & 784 & $\begin{array}{l}\text { Mean Difference (IV, Fixed, } \\
95 \% \mathrm{Cl})\end{array}$ & $0.08[0.03,0.12]$ \\
\hline \hline
\end{tabular}




\begin{tabular}{|c|c|c|c|c|}
\hline Outcome or subgroup title & No. of studies & $\begin{array}{l}\text { No. of partici- } \\
\text { pants }\end{array}$ & Statistical method & Effect size \\
\hline $\begin{array}{l}1.3 \text { treadmill training less then } 3 \\
\text { times a week or unclear frequency }\end{array}$ & 3 & 116 & $\begin{array}{l}\text { Mean Difference (IV, Fixed, } \\
95 \% \mathrm{CI} \text { ) }\end{array}$ & $0.02[-0.06,0.10]$ \\
\hline $\begin{array}{l}2 \text { Walking endurance }(\mathrm{m}) \text { at end of } \\
\text { treatment }\end{array}$ & 23 & & $\begin{array}{l}\text { Mean Difference (IV, Random, } \\
95 \% \mathrm{CI} \text { ) }\end{array}$ & Subtotals only \\
\hline 2.1 treadmill training 5 times a week & 9 & 392 & $\begin{array}{l}\text { Mean Difference (IV, Random, } \\
95 \% \mathrm{Cl} \text { ) }\end{array}$ & $27.25[5.37,49.13]$ \\
\hline $\begin{array}{l}2.2 \text { treadmill training } 3 \text { to } 4 \text { times a } \\
\text { week }\end{array}$ & 13 & 621 & $\begin{array}{l}\text { Mean Difference (IV, Random, } \\
95 \% \mathrm{Cl})\end{array}$ & $12.41[-3.15,27.97]$ \\
\hline $\begin{array}{l}2.3 \text { treadmill training less then } 3 \\
\text { times a week or unclear }\end{array}$ & 1 & 28 & $\begin{array}{l}\text { Mean Difference (IV, Random, } \\
95 \% \mathrm{CI} \text { ) }\end{array}$ & $\begin{array}{l}-15.0[-133.26 \\
103.26]\end{array}$ \\
\hline
\end{tabular}

Analysis 9.1. Comparison 9 Subgroup analysis: treadmill (with or without body weight support) versus other, by intensity (frequency) of training (independent in walking only), Outcome 1 Walking speed ( $\mathrm{m} / \mathrm{s}$ ) at end of treatment.

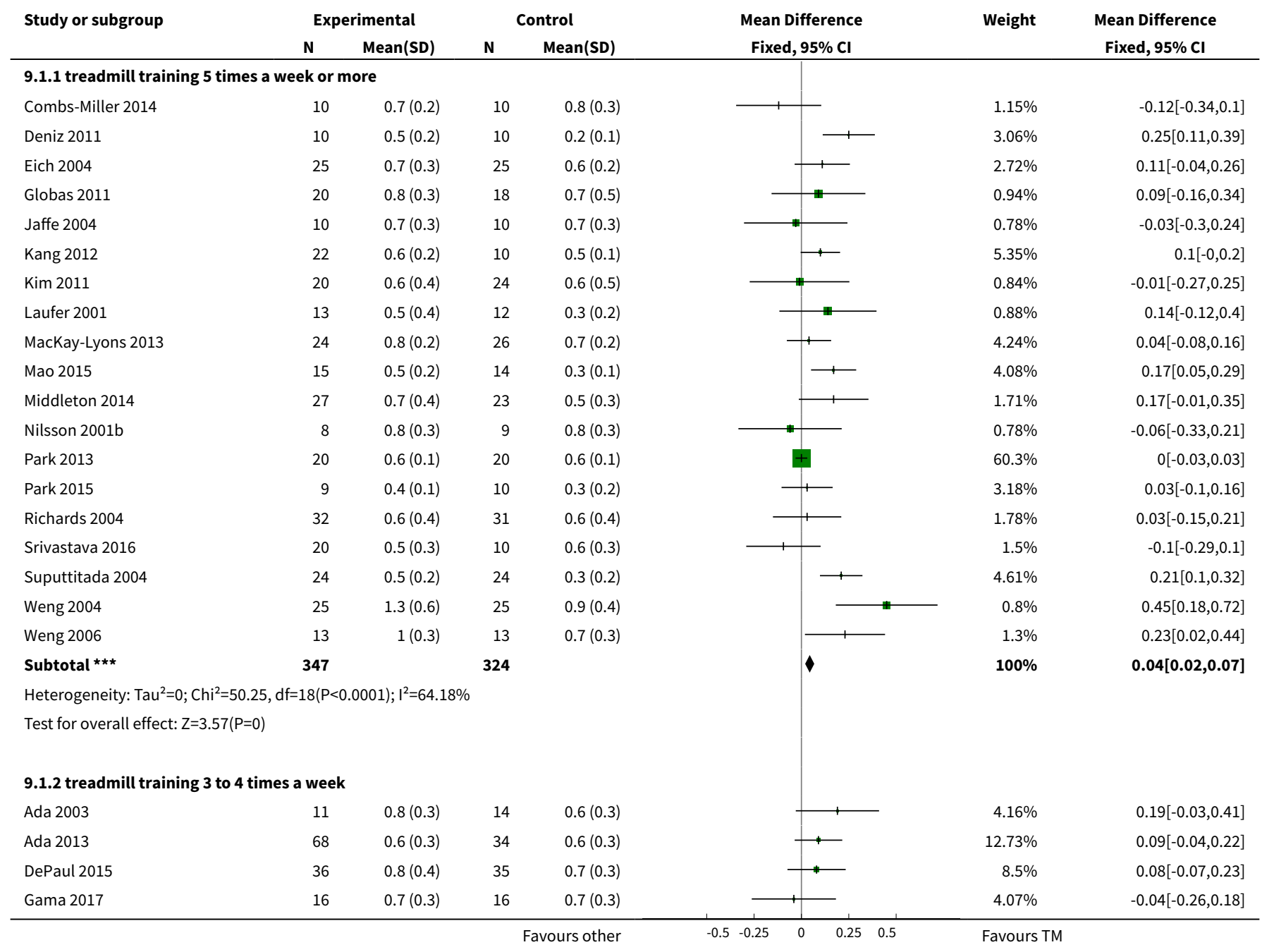




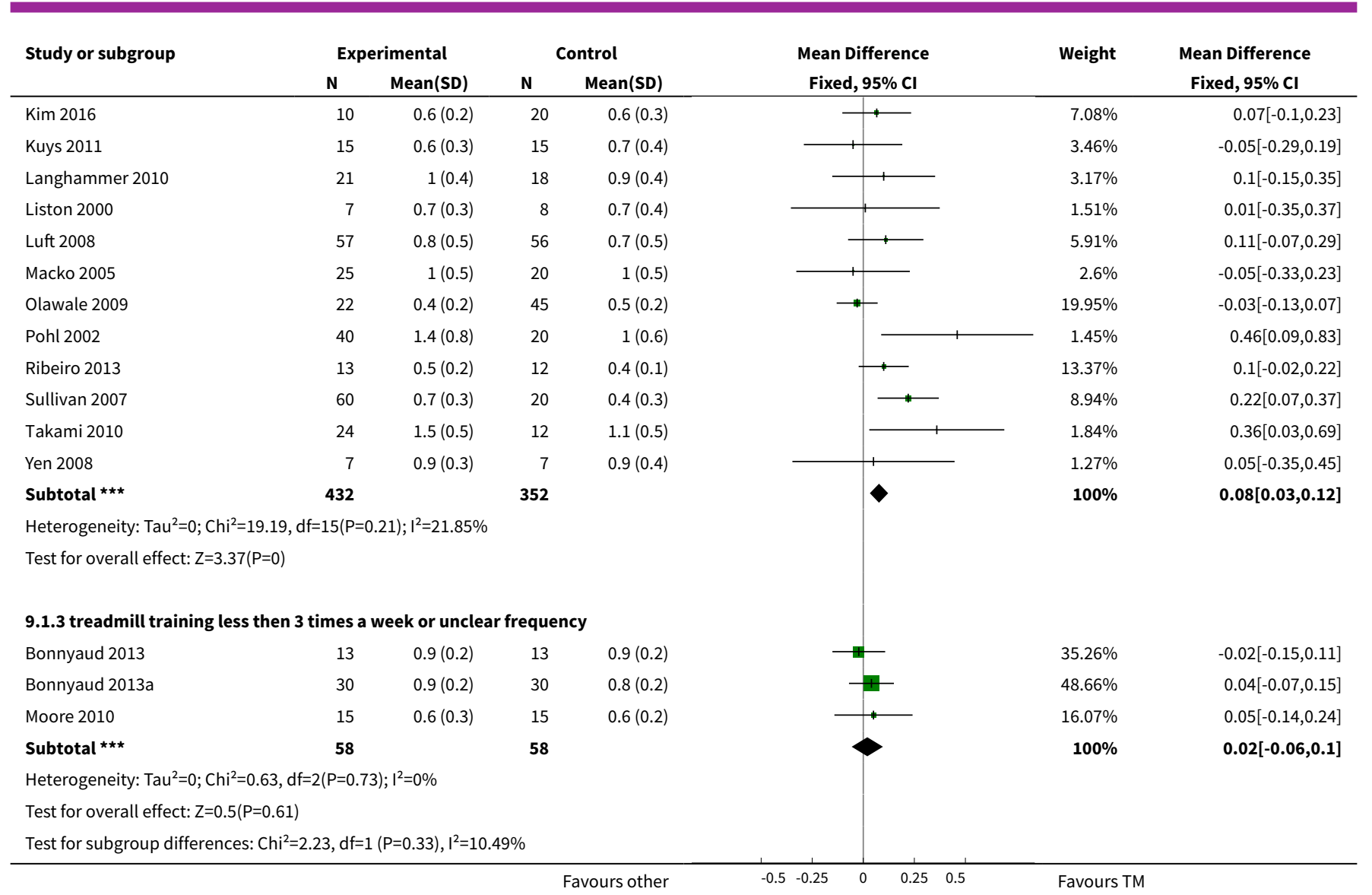

\section{Analysis 9.2. Comparison 9 Subgroup analysis: treadmill (with or without body weight support) versus other, by intensity (frequency) of training (independent in walking only), Outcome 2 Walking endurance $(m)$ at end of treatment.}

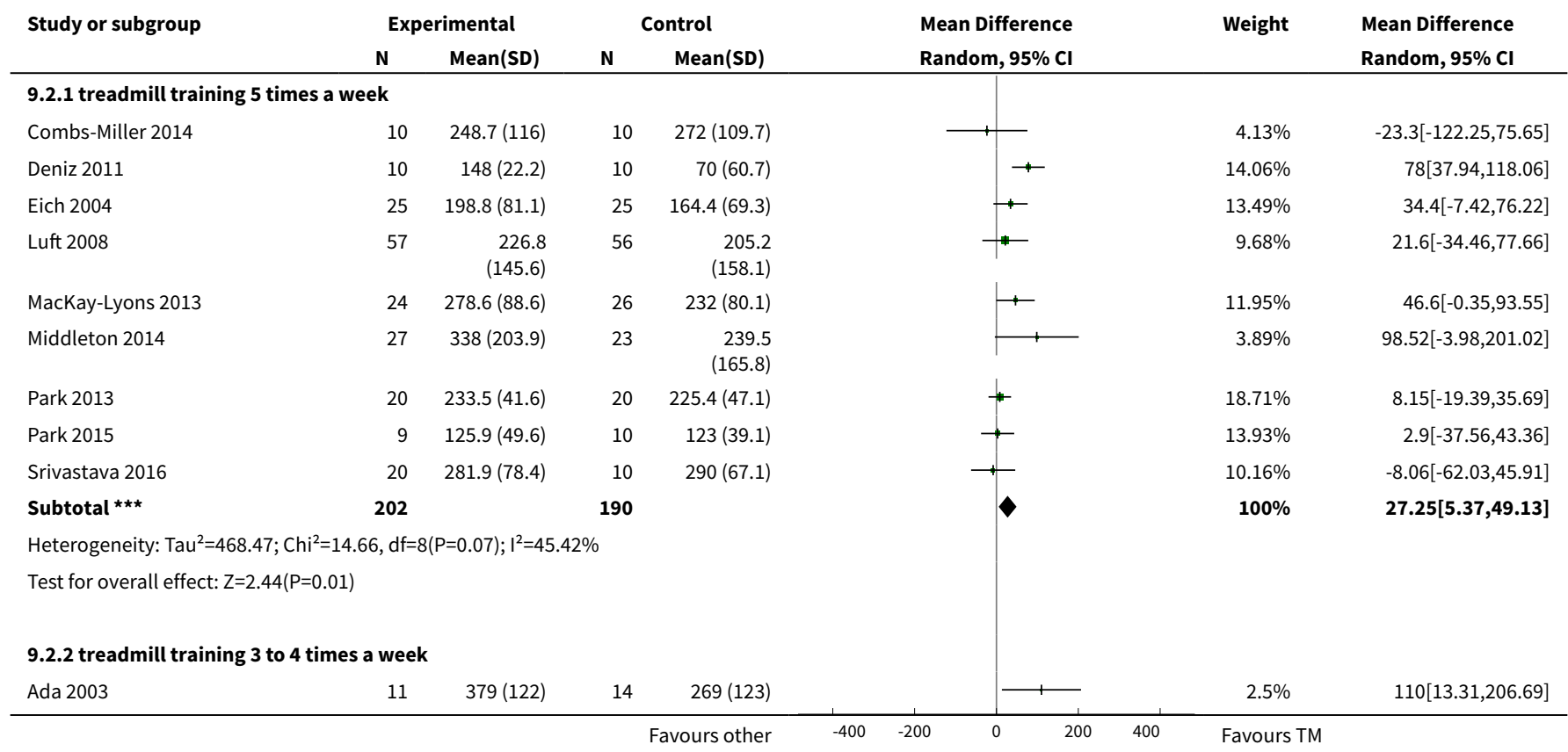




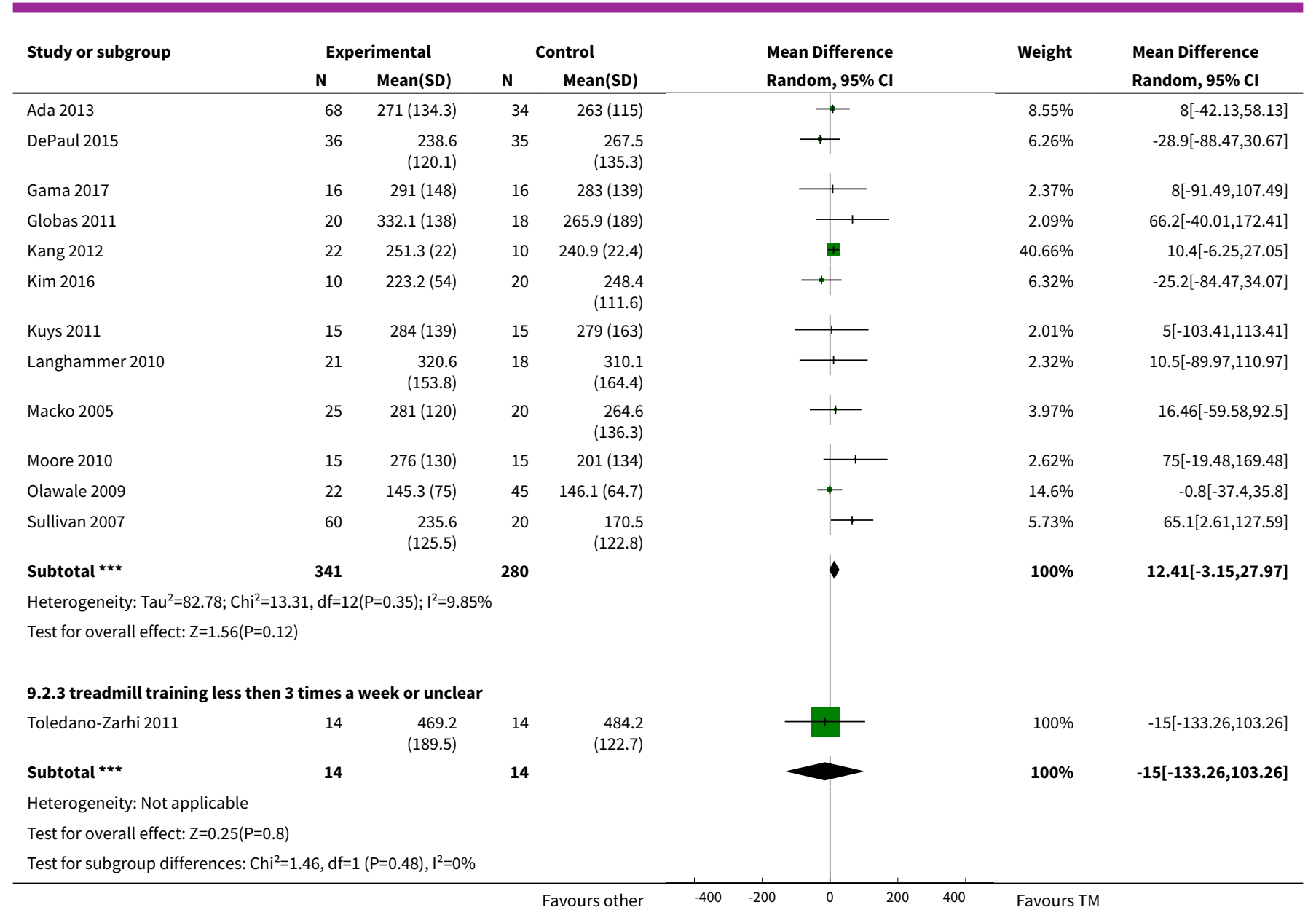

Comparison 10. Subgroup analysis: treadmill (with or without body weight support) versus other, by duration of training period (independent in walking only)

\begin{tabular}{|c|c|c|c|c|}
\hline Outcome or subgroup title & No. of studies & $\begin{array}{l}\text { No. of partici- } \\
\text { pants }\end{array}$ & Statistical method & Effect size \\
\hline $\begin{array}{l}1 \text { Walking speed }(\mathrm{m} / \mathrm{s}) \text { at end of treat- } \\
\text { ment }\end{array}$ & 38 & & $\begin{array}{l}\text { Mean Difference (IV, Random, } \\
95 \% \mathrm{CI} \text { ) }\end{array}$ & Subtotals only \\
\hline $\begin{array}{l}1.1 \text { treadmill training duration more } \\
\text { than } 4 \text { weeks }\end{array}$ & 14 & 802 & $\begin{array}{l}\text { Mean Difference (IV, Random, } \\
95 \% \mathrm{CI} \text { ) }\end{array}$ & $0.05[0.01,0.09]$ \\
\hline $\begin{array}{l}1.2 \text { treadmill training duration } 4 \\
\text { weeks }\end{array}$ & 13 & 404 & $\begin{array}{l}\text { Mean Difference (IV, Random, } \\
95 \% \mathrm{CI} \text { ) }\end{array}$ & $0.13[0.07,0.19]$ \\
\hline $\begin{array}{l}1.3 \text { treadmill training duration less } \\
\text { then } 4 \text { weeks }\end{array}$ & 11 & 365 & $\begin{array}{l}\text { Mean Difference (IV, Random, } \\
95 \% \mathrm{Cl})\end{array}$ & $0.08[0.01,0.14]$ \\
\hline $\begin{array}{l}2 \text { Walking endurance }(\mathrm{m}) \text { at end of } \\
\text { treatment }\end{array}$ & 23 & & $\begin{array}{l}\text { Mean Difference (IV, Random, } \\
95 \% \mathrm{Cl})\end{array}$ & Subtotals only \\
\hline $\begin{array}{l}2.1 \text { treadmill training duration more } \\
\text { than } 4 \text { weeks }\end{array}$ & 12 & 706 & $\begin{array}{l}\text { Mean Difference (IV, Random, } \\
95 \% \mathrm{CI})\end{array}$ & $19.09[2.29,35.88]$ \\
\hline
\end{tabular}




\begin{tabular}{lllll}
\hline Outcome or subgroup title & No. of studies & $\begin{array}{l}\text { No. of partici- } \\
\text { pants }\end{array}$ & Statistical method & Effect size \\
\hline $\begin{array}{l}2.2 \text { treadmill training duration } 4 \\
\text { weeks }\end{array}$ & 7 & 206 & $\begin{array}{l}\text { Mean Difference (IV, Random, } \\
95 \% \text { Cl) }\end{array}$ & $29.40[-4.75,63.54]$ \\
\hline $\begin{array}{l}2.3 \text { treadmill training duration less } \\
\text { then 4 weeks }\end{array}$ & 4 & 129 & $\begin{array}{l}\text { Mean Difference (IV, Random, } \\
95 \% \text { CI) }\end{array}$ & $9.82[-15.48,35.13]$ \\
\hline
\end{tabular}

Analysis 10.1. Comparison 10 Subgroup analysis: treadmill (with or without body weight support) versus other, by duration of training period (independent in walking only), Outcome 1 Walking speed $(\mathrm{m} / \mathrm{s})$ at end of treatment.

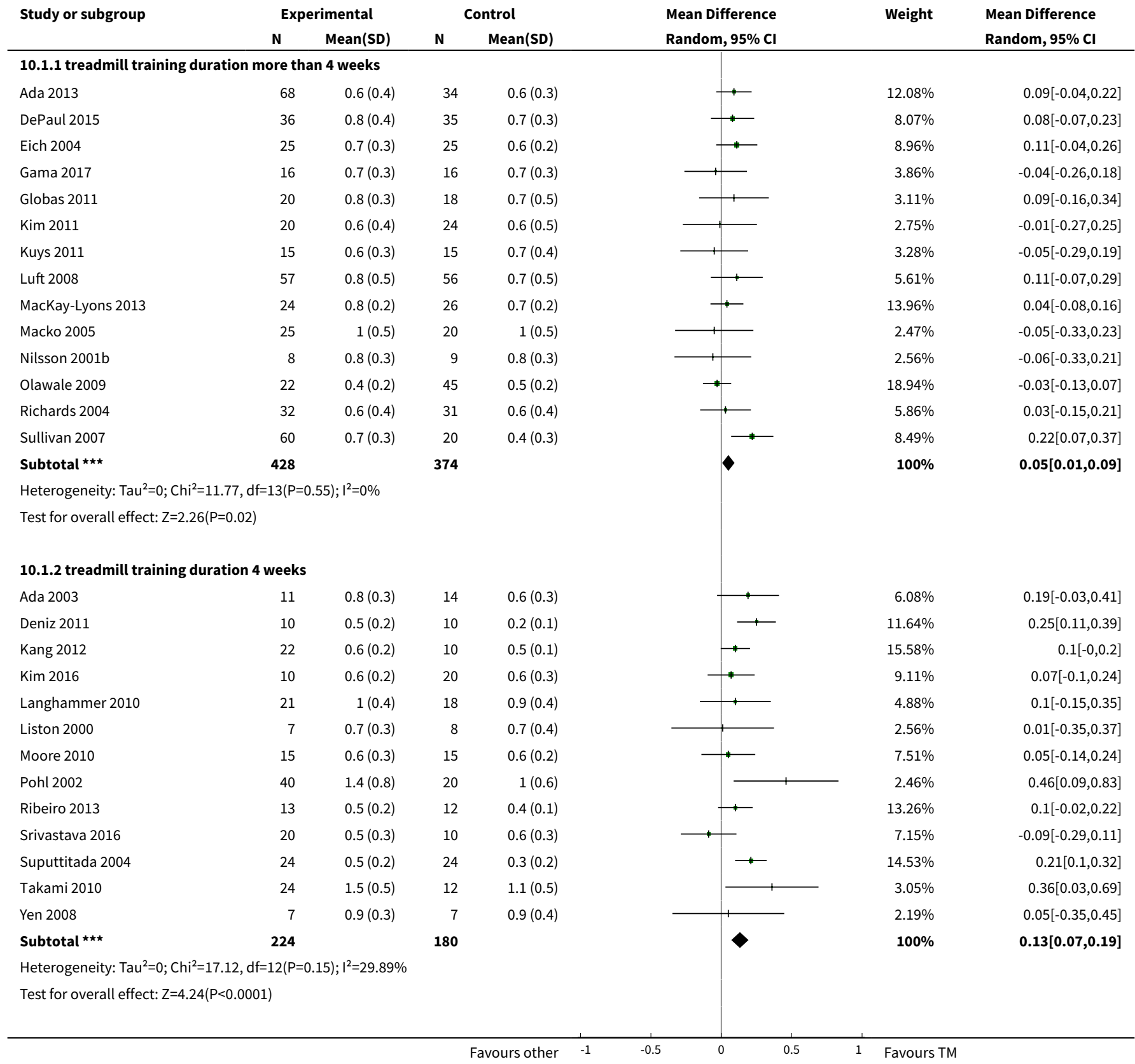




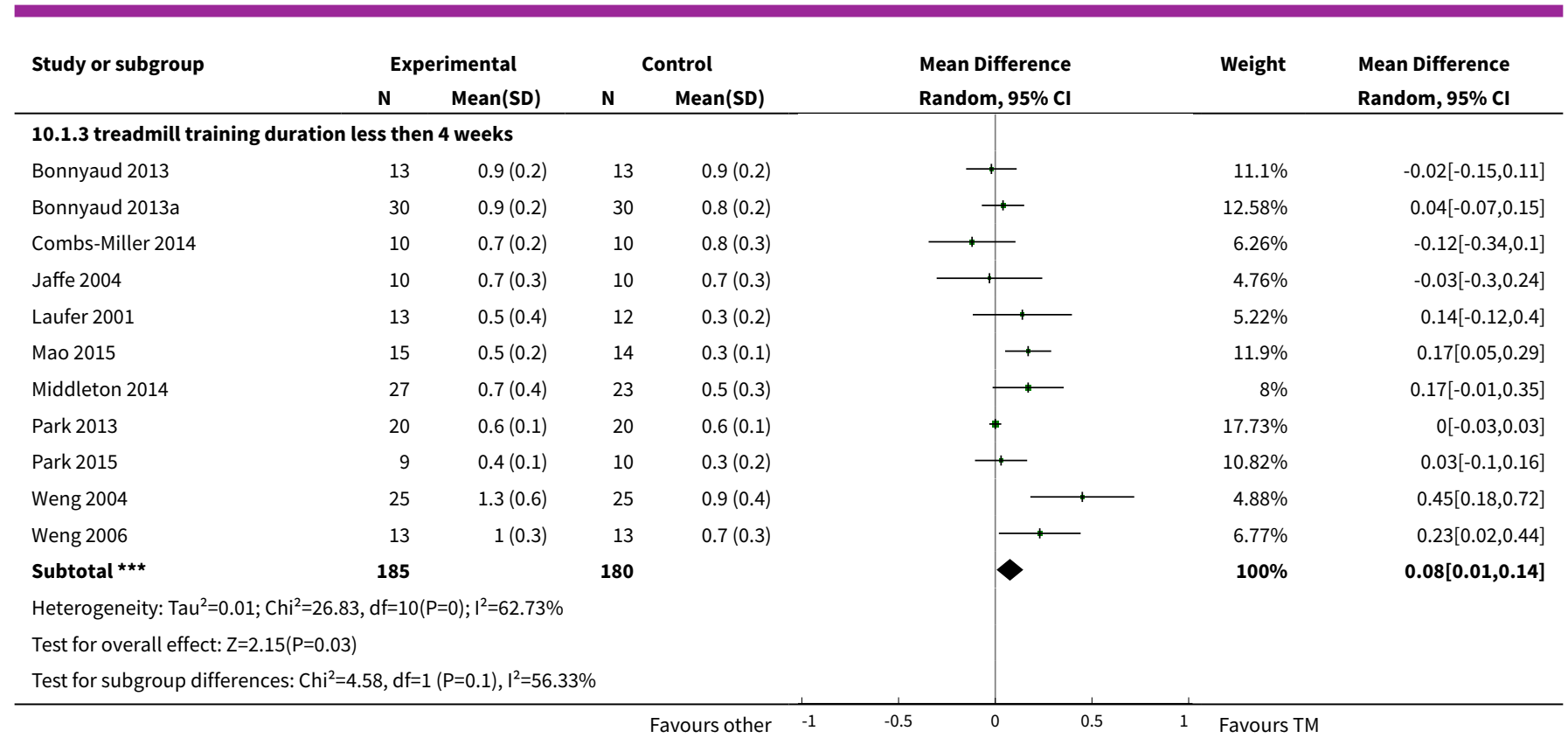

Analysis 10.2. Comparison 10 Subgroup analysis: treadmill (with or without body weight support) versus other, by duration of training period (independent in walking only), Outcome 2 Walking endurance $(\mathrm{m})$ at end of treatment.

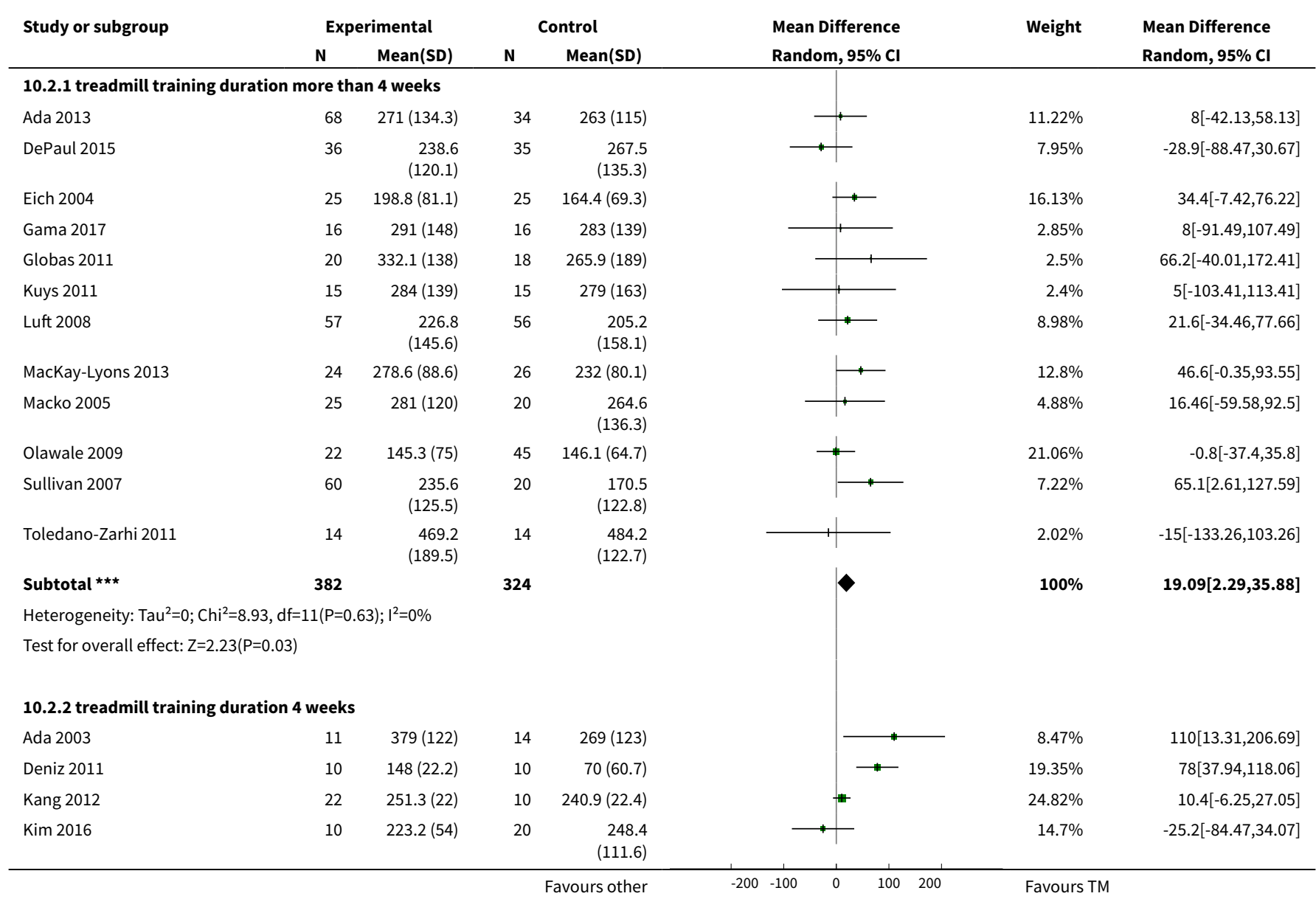




\begin{tabular}{|c|c|c|c|c|c|c|c|}
\hline \multirow[t]{2}{*}{ Study or subgroup } & \multicolumn{2}{|c|}{ Experimental } & \multicolumn{2}{|c|}{ Control } & \multirow{2}{*}{$\begin{array}{l}\text { Mean Difference } \\
\text { Random, } 95 \% \mathrm{Cl}\end{array}$} & \multirow[t]{2}{*}{ Weight } & \multirow{2}{*}{$\begin{array}{l}\text { Mean Difference } \\
\text { Random, } 95 \% \mathrm{CI}\end{array}$} \\
\hline & $\mathbf{N}$ & Mean(SD) & $\mathbf{N}$ & Mean(SD) & & & \\
\hline Langhammer 2010 & 21 & $\begin{array}{r}320.6 \\
(153.8)\end{array}$ & 18 & $\begin{array}{r}310.1 \\
(164.4)\end{array}$ & & $8.03 \%$ & $10.5[-89.97,110.97]$ \\
\hline Moore 2010 & 15 & $276(130)$ & 15 & $201(134)$ & + & $8.73 \%$ & $75[-19.48,169.48]$ \\
\hline Srivastava 2016 & 20 & $281.9(78.4)$ & 10 & $290(67.1)$ & & $15.9 \%$ & $-8.06[-62.03,45.91]$ \\
\hline Subtotal ${ }^{\star \star \star}$ & 109 & & 97 & & & $100 \%$ & $29.4[-4.75,63.54]$ \\
\hline \multicolumn{8}{|c|}{ Heterogeneity: $\mathrm{Tau}^{2}=1150.51 ; \mathrm{Chi}^{2}=17.24, \mathrm{df}=6(\mathrm{P}=0.01) ; \mathrm{I}^{2}=65.19 \%$} \\
\hline \multicolumn{8}{|c|}{ Test for overall effect: $Z=1.69(P=0.09)$} \\
\hline \multicolumn{8}{|c|}{ 10.2.3 treadmill training duration less then 4 weeks } \\
\hline Combs-Miller 2014 & 10 & $248.7(116)$ & 10 & $272(109.7)$ & $T$ & $6.29 \%$ & $-23.3[-122.25,75.65]$ \\
\hline Middleton 2014 & 27 & 338 (203.9) & 23 & $\begin{array}{r}239.5 \\
(165.8)\end{array}$ & & $5.88 \%$ & $98.52[-3.98,201.02]$ \\
\hline Park 2013 & 20 & $233.5(41.6)$ & 20 & $225.4(47.1)$ & 7 & $56.12 \%$ & $8.15[-19.39,35.69]$ \\
\hline Park 2015 & 9 & $125.9(49.6)$ & 10 & $123(39.1)$ & $\rightarrow$ & $31.7 \%$ & $2.9[-37.56,43.36]$ \\
\hline Subtotal $\star \star \star$ & 66 & & 63 & & & $100 \%$ & $9.82[-15.48,35.13]$ \\
\hline \multicolumn{8}{|c|}{ Heterogeneity: $\mathrm{Tau}^{2}=99.56 ; \mathrm{Chi}^{2}=3.43, \mathrm{df}=3(\mathrm{P}=0.33) ; \mathrm{I}^{2}=12.54 \%$} \\
\hline \multicolumn{8}{|c|}{ Test for overall effect: $Z=0.76(P=0.45)$} \\
\hline Test for subgroup dif & $35, d f=$ & $(P=0.66), I^{2}=0$ & & & & & \\
\hline
\end{tabular}

Favours other

Favours TM 


\begin{tabular}{|c|c|c|c|c|c|c|c|c|}
\hline Study ID & EXP age & CTL age & EXP gender & CTL gender & $\begin{array}{l}\text { EXP time post- } \\
\text { stroke }\end{array}$ & $\begin{array}{l}\text { CTL time post- } \\
\text { stroke }\end{array}$ & $\begin{array}{l}\text { EXP paresis } \\
\text { side }\end{array}$ & $\begin{array}{l}\text { CTL paresis } \\
\text { side }\end{array}$ \\
\hline Ada 2003 & $\begin{array}{l}\text { Mean } 66 \text { (SD 11) years } \\
\text { (excluding } 1 \text { dropout) }\end{array}$ & $\begin{array}{l}\text { Mean } 66 \text { (SD 11) } \\
\text { years (excluding } 1 \\
\text { dropout) }\end{array}$ & $\begin{array}{l}\text { Men/women } \\
9 / 4\end{array}$ & $\begin{array}{l}\text { Men/women } \\
10 / 4\end{array}$ & $\begin{array}{l}\text { Mean } 28 \text { (SD 17) } \\
\text { months }\end{array}$ & $\begin{array}{l}\text { Mean } 26 \text { (SD 20) } \\
\text { months }\end{array}$ & Left/right 5/8 & $\begin{array}{l}\text { Left/right } \\
8 / 6\end{array}$ \\
\hline Ada 2010 & Mean 70 (SD 9) years & $\begin{array}{l}\text { Mean } 71(\text { SD 9) } \\
\text { years }\end{array}$ & $\begin{array}{l}\text { Men/women } \\
38 / 26\end{array}$ & $\begin{array}{l}\text { Men/women } \\
33 / 29\end{array}$ & $\begin{array}{l}\text { Mean } 18 \text { (SD 8) } \\
\text { days }\end{array}$ & $\begin{array}{l}\text { Mean } 18(\text { SD } 7) \\
\text { days }\end{array}$ & $\begin{array}{l}\text { Left/right } \\
34 / 30\end{array}$ & $\begin{array}{l}\text { Left/right } \\
36 / 26\end{array}$ \\
\hline Ada 2013 & Mean 67 (SD 12) years & $\begin{array}{l}\text { Mean } 63(S D 13) \\
\text { years }\end{array}$ & $\begin{array}{l}\text { Men/women } \\
52 / 16\end{array}$ & $\begin{array}{l}\text { Men/women } \\
19 / 15\end{array}$ & $\begin{array}{l}\text { Mean } 21 \text { (SD 16) } \\
\text { months }\end{array}$ & $\begin{array}{l}\text { Mean } 19 \text { (SD 13) } \\
\text { months }\end{array}$ & $\begin{array}{l}\text { Left/right } \\
32 / 34\end{array}$ & $\begin{array}{l}\text { Left/right } \\
13 / 21\end{array}$ \\
\hline $\begin{array}{l}\text { Bonnyaud } \\
2013\end{array}$ & \multicolumn{2}{|c|}{ Mean 50 (SD 13) years (including both groups) } & \multicolumn{2}{|c|}{$\begin{array}{l}\text { Men/women } 45 / 15 \text { (includ- } \\
\text { ing both groups) }\end{array}$} & \multicolumn{2}{|c|}{$\begin{array}{l}\text { Mean } 6 \text { (SD 6) years (including both } \\
\text { groups) }\end{array}$} & \multicolumn{2}{|c|}{$\begin{array}{l}\text { Left/right } 30 / 30 \text { (including } \\
\text { both groups) }\end{array}$} \\
\hline $\begin{array}{l}\text { Bonnyaud } \\
2013 a\end{array}$ & \multicolumn{2}{|c|}{ Mean 50 (SD 13) years (including both groups) } & \multicolumn{2}{|c|}{$\begin{array}{l}\text { Men/women } 45 / 15 \text { (includ- } \\
\text { ing both groups) }\end{array}$} & \multicolumn{2}{|c|}{$\begin{array}{l}\text { Mean } 6 \text { (SD 6) years (including both } \\
\text { groups) }\end{array}$} & \multicolumn{2}{|c|}{$\begin{array}{l}\text { Left/right } 30 / 30 \text { (including } \\
\text { both groups) }\end{array}$} \\
\hline \multirow[t]{2}{*}{$\begin{array}{l}\text { Combs- } \\
\text { Miller } 2014\end{array}$} & Mean 45 (SD 21) years & $\begin{array}{l}\text { Mean } 48 \text { (SD 10) } \\
\text { years }\end{array}$ & $\begin{array}{l}\text { Men/women } \\
8 / 4\end{array}$ & $\begin{array}{l}\text { Men/women } \\
10 / 3\end{array}$ & Mean 6 (SD 6) years & $\begin{array}{l}\text { Mean } 5(\text { SD } 4) \\
\text { years }\end{array}$ & Left/right $8 / 4$ & $\begin{array}{l}\text { Left/right } \\
8 / 5\end{array}$ \\
\hline & Mean 56 (SD 8) years & $\begin{array}{l}\text { Mean } 64(S D 6) \\
\text { years }\end{array}$ & $\begin{array}{l}\text { Men/women } \\
4 / 6\end{array}$ & $\begin{array}{l}\text { Men/women } \\
7 / 3\end{array}$ & $\begin{array}{l}\text { Mean } 62 \text { (SD 49) } \\
\text { months }\end{array}$ & $\begin{array}{l}\text { Mean } 60 \text { (SD 52) } \\
\text { months }\end{array}$ & Left/right $6 / 4$ & $\begin{array}{l}\text { Left/right } \\
6 / 4\end{array}$ \\
\hline $\begin{array}{l}\text { Da Cunha } \\
\text { Filho } 2002\end{array}$ & $\begin{array}{l}\text { Mean } 57.8 \text { (SD 5.5) years } \\
\text { (excluding dropouts) }\end{array}$ & $\begin{array}{l}\text { Mean } 58.9 \text { (SD 12.9) } \\
\text { years (excluding } \\
\text { dropouts) }\end{array}$ & $\begin{array}{l}\text { Men/women } \\
6 / 0\end{array}$ & $\begin{array}{l}\text { Men/women } \\
7 / 0\end{array}$ & $\begin{array}{l}\text { Mean } 15.7 \text { (SD 7.7) } \\
\text { days }\end{array}$ & $\begin{array}{l}\text { Mean } 19.0(\mathrm{SD} \\
12.7) \text { days }\end{array}$ & $\begin{array}{l}\text { Left/right/bi- } \\
\text { lateral } 1 / 4 / 1\end{array}$ & $\begin{array}{l}\text { Left/right } \\
4 / 3\end{array}$ \\
\hline Deniz 2011 & Mean $61.5($ SD 4.7$)$ years & $\begin{array}{l}\text { Mean } 61.5(S D 12.5) \\
\text { years }\end{array}$ & $\begin{array}{l}\text { Men/women } \\
8 / 2\end{array}$ & $\begin{array}{l}\text { Men/women } \\
3 / 7\end{array}$ & $\begin{array}{l}\text { Mean } 71 \text { (SD 40) } \\
\text { days }\end{array}$ & $\begin{array}{l}\text { Mean } 81 \text { (SD 47) } \\
\text { months }\end{array}$ & Left/right $6 / 4$ & $\begin{array}{l}\text { Left/right } \\
3 / 7\end{array}$ \\
\hline DePaul 2015 & Mean 62 (SD 13) years & $\begin{array}{l}\text { Mean } 61.5(S D 4.7) \\
\text { years }\end{array}$ & $\begin{array}{l}\text { Men/women } \\
21 / 14\end{array}$ & $\begin{array}{l}\text { Men/women } \\
22 / 14\end{array}$ & $\begin{array}{l}\text { Median } 19 \text { (Q1 7, } \\
\text { Q2 34) weeks }\end{array}$ & $\begin{array}{l}\text { Median } 18 \text { (Q1 10, } \\
\text { Q3 30) weeks }\end{array}$ & $\begin{array}{l}\text { Left/right/ } \\
\text { bilateral } \\
20 / 12 / 3\end{array}$ & $\begin{array}{l}\text { Left/right/ } \\
\text { bilateral } \\
17 / 18 / 1\end{array}$ \\
\hline Du 2006 & $56(6)$ years & 58 (6) years & $\begin{array}{l}\text { Men/women } \\
35 / 32\end{array}$ & $\begin{array}{l}\text { Men/women } \\
30 / 31\end{array}$ & $<3$ months & $<3$ months & $\begin{array}{l}\text { Left/right } \\
31 / 36\end{array}$ & $\begin{array}{l}\text { Left/right } \\
29 / 32\end{array}$ \\
\hline $\begin{array}{l}\text { Duncan } \\
2011\end{array}$ & Mean 62 (SD 12) years & $\begin{array}{l}\text { Mean } 63 \text { (SD 13) } \\
\text { years }\end{array}$ & $\begin{array}{l}\text { Men/women } \\
159 / 123\end{array}$ & $\begin{array}{l}\text { Men/women } \\
65 / 61\end{array}$ & $\begin{array}{l}\text { Mean } 64 \text { (SD 9) } \\
\text { days }\end{array}$ & $\begin{array}{l}\text { Mean } 63 \text { (SD 8) } \\
\text { days }\end{array}$ & $\begin{array}{l}\text { Left/right } \\
121 / 161\end{array}$ & $\begin{array}{l}\text { Left/right } \\
61 / 65\end{array}$ \\
\hline
\end{tabular}




\begin{tabular}{|c|c|c|c|c|c|c|c|c|}
\hline Eich 2004 & $\begin{array}{l}\text { Mean } 62.4 \text { (SD } 4.8 \text { ) years } \\
\text { (all participants) }\end{array}$ & $\begin{array}{l}\text { Mean } 64.0 \text { (SD 6.0) } \\
\text { years (all partici- } \\
\text { pants) }\end{array}$ & $\begin{array}{l}\text { Men/women } \\
17 / 8\end{array}$ & $\begin{array}{l}\text { Men/women } \\
16 / 9\end{array}$ & $\begin{array}{l}\text { Mean } 6.1 \text { (SD 2.2) } \\
\text { weeks }\end{array}$ & $\begin{array}{l}\text { Mean } 6.3 \text { (SD 2.5) } \\
\text { weeks }\end{array}$ & $\begin{array}{l}\text { Left/right } \\
14 / 11\end{array}$ & $\begin{array}{l}\text { Left/right } \\
14 / 11\end{array}$ \\
\hline $\begin{array}{l}\text { Franceschi- } \\
\text { ni } 2009\end{array}$ & Mean 66 (SD 12) years & $\begin{array}{l}\text { Mean } 71(\text { SD 12) } \\
\text { years }\end{array}$ & $\begin{array}{l}\text { Men/women } \\
28 / 24\end{array}$ & $\begin{array}{l}\text { Men/women } \\
22 / 23 \\
\text { (only } 45 \text { de- } \\
\text { scribed) }\end{array}$ & $\begin{array}{l}\text { Mean } 17 \text { (SD 10) } \\
\text { days }\end{array}$ & $\begin{array}{l}\text { Mean } 14(\text { SD } 7) \\
\text { days }\end{array}$ & $\begin{array}{l}\text { Left/right } \\
29 / 23\end{array}$ & $\begin{array}{l}\text { Left/right } \\
15 / 30 \text { (on- } \\
\text { ly } 45 \text { de- } \\
\text { scribed) }\end{array}$ \\
\hline Gama 2017 & Mean 59 (SD 8) years & $\begin{array}{l}\text { Mean } 58 \text { (SD 10) } \\
\text { years }\end{array}$ & $\begin{array}{l}\text { Men/women } \\
7 / 7 \text { (only } 14 \\
\text { described) }\end{array}$ & $\begin{array}{l}\text { Men/women } \\
8 / 6 \\
\text { (only } 14 \text { de- } \\
\text { scribed) }\end{array}$ & $\begin{array}{l}\text { Mean } 60 \text { (SD 55) } \\
\text { months }\end{array}$ & $\begin{array}{l}\text { Mean } 54 \text { (SD 42) } \\
\text { months }\end{array}$ & $\begin{array}{l}\text { Left/right 9/5 } \\
\text { (only } 14 \text { de- } \\
\text { scribed) }\end{array}$ & $\begin{array}{l}\text { Left/right } \\
6 / 8 \text { (only } 14 \\
\text { described) }\end{array}$ \\
\hline Gan 2012 & Not described & Not described & $\begin{array}{l}\text { Not de- } \\
\text { scribed }\end{array}$ & $\begin{array}{l}\text { Not de- } \\
\text { scribed }\end{array}$ & Not described & Not described & Not described & $\begin{array}{l}\text { Not de- } \\
\text { scribed }\end{array}$ \\
\hline Globas 2011 & Mean 69 (SD 7) years & $\begin{array}{l}\text { Mean } 69(S D 6) \\
\text { years }\end{array}$ & $\begin{array}{l}\text { Men/women } \\
14 / 4 \\
\text { (only } 18 \text { de- } \\
\text { scribed) }\end{array}$ & $\begin{array}{l}\text { Men/women } \\
15 / 3 \\
\text { (only } 18 \text { de- } \\
\text { scribed) }\end{array}$ & $\begin{array}{l}\text { Mean } 60 \text { (SD 47) } \\
\text { months }\end{array}$ & $\begin{array}{l}\text { Mean } 70 \text { (SD 67) } \\
\text { months }\end{array}$ & $\begin{array}{l}\text { Left/right } 4 / 14 \\
\text { (only } 18 \text { de- } \\
\text { scribed) }\end{array}$ & $\begin{array}{l}\text { Left/right } \\
9 / 9 \\
\text { (only } 18 \text { de- } \\
\text { scribed) }\end{array}$ \\
\hline Hoyer 2012 & Mean 52 (SD 13) years & $\begin{array}{l}\text { Mean } 52(S D 6) \\
\text { years }\end{array}$ & $\begin{array}{l}\text { Men/women } \\
\text { 20/10 }\end{array}$ & $\begin{array}{l}\text { Men/women } \\
18 / 12\end{array}$ & $\begin{array}{l}\text { Mean } 99 \text { (SD 39) } \\
\text { days }\end{array}$ & $\begin{array}{l}\text { Mean } 96 \text { (SD 42) } \\
\text { days }\end{array}$ & $\begin{array}{l}\text { Left/right } \\
17 / 13\end{array}$ & $\begin{array}{l}\text { Left/right } \\
17 / 13\end{array}$ \\
\hline Jaffe 2004 & $\begin{array}{l}\text { Mean } 58.2 \text { (SD 11.2) } \\
\text { years (excluding } \\
\text { dropouts) }\end{array}$ & $\begin{array}{l}\text { Mean } 63.2 \text { (SD 8.3) } \\
\text { years (excluding } \\
\text { dropouts) }\end{array}$ & $\begin{array}{l}\text { Men/women } \\
5 / 5 \text { (ex- } \\
\text { cluding } \\
\text { dropouts) }\end{array}$ & $\begin{array}{l}\text { Men/women } \\
7 / 3 \text { (ex- } \\
\text { cluding } \\
\text { dropouts) }\end{array}$ & $\begin{array}{l}\text { Mean } 3.9 \text { (SD 2.3) } \\
\text { years (excluding } \\
\text { dropouts) }\end{array}$ & $\begin{array}{l}\text { Mean } 3.6 \text { (SD 2.6) } \\
\text { years (excluding } \\
\text { dropouts) }\end{array}$ & $\begin{array}{l}\text { Left/right 6/4 } \\
\text { (excluding } \\
\text { dropouts) }\end{array}$ & $\begin{array}{l}\text { Left/right } \\
4 / 6 \text { (ex- } \\
\text { cluding } \\
\text { dropouts) }\end{array}$ \\
\hline Kang 2012 & Mean 56 (SD 7) years & $\begin{array}{l}\text { Mean } 56(\text { SD } 8) \\
\text { years }\end{array}$ & $\begin{array}{l}\text { Men/women } \\
10 / 10 \\
\text { (excluding } \\
\text { dropouts) }\end{array}$ & $\begin{array}{l}\text { Men/women } \\
6 / 4 \\
\text { (excluding } \\
\text { dropouts) }\end{array}$ & $\begin{array}{l}\text { Mean } 14 \text { (SD 4) } \\
\text { months }\end{array}$ & $\begin{array}{l}\text { Mean } 15(\text { SD } 7) \\
\text { months }\end{array}$ & $\begin{array}{l}\text { Left/right } 8 / 12 \\
\text { (excluding } \\
\text { dropouts) }\end{array}$ & $\begin{array}{l}\text { Left/right } \\
5 / 5 \\
\text { (excluding } \\
\text { dropouts) }\end{array}$ \\
\hline Kim 2011 & Mean 51 (SD 4) years & $\begin{array}{l}\text { Mean } 50(\text { SD } 8) \\
\text { years }\end{array}$ & $\begin{array}{l}\text { Men/women } \\
11 / 9\end{array}$ & $\begin{array}{l}\text { Men/women } \\
14 / 10\end{array}$ & $\begin{array}{l}\text { Mean } 15 \text { (SD 6) } \\
\text { months }\end{array}$ & $\begin{array}{l}\text { Mean } 14 \text { (SD 3) } \\
\text { months }\end{array}$ & Left/right $8 / 12$ & $\begin{array}{l}\text { Left/right } \\
8 / 16\end{array}$ \\
\hline Kim 2016 & $\begin{array}{l}\text { Mean } 56.20 \text { (SD 7.56) } \\
\text { years }\end{array}$ & $\begin{array}{l}\text { Mean } 52.00(S D \\
7.27) \text { years }\end{array}$ & $\begin{array}{l}\text { Men/women } \\
4 / 6\end{array}$ & $\begin{array}{l}\text { Men/women } \\
5 / 5\end{array}$ & $\begin{array}{l}\text { Mean } 7.5 \text { (SD 4.4) } \\
\text { months }\end{array}$ & $\begin{array}{l}\text { Mean } 13.3 \text { (SD } \\
\text { 16.1) months }\end{array}$ & Left/right $3 / 7$ & $\begin{array}{l}\text { Left/right } \\
4 / 6\end{array}$ \\
\hline
\end{tabular}




\begin{tabular}{|c|c|c|c|c|c|c|c|c|}
\hline Kosak 2000 & $\begin{array}{l}\text { Mean } 74 \text { (SEM 2) years } \\
\text { (all participants) }\end{array}$ & $\begin{array}{l}\text { Mean } 70(\text { SEM 2) } \\
\text { years }\end{array}$ & $\begin{array}{l}\text { Men/women } \\
13 / 9\end{array}$ & $\begin{array}{l}\text { Men/women } \\
18 / 16\end{array}$ & $\begin{array}{l}\text { Mean } 39 \text { (SEM 3) } \\
\text { days }\end{array}$ & $\begin{array}{l}\text { Mean } 40 \text { (SEM 4) } \\
\text { days }\end{array}$ & $\begin{array}{l}\text { Left/right/bi- } \\
\text { lateral 8/12/2 }\end{array}$ & $\begin{array}{l}\text { Left/right/ } \\
\text { bilateral } \\
12 / 16 / 6\end{array}$ \\
\hline Kuys 2011 & Mean 63 (SD 14) years & $\begin{array}{l}\text { Mean } 72(\text { SD } 17) \\
\text { years }\end{array}$ & $\begin{array}{l}\text { Men/women } \\
8 / 7\end{array}$ & $\begin{array}{l}\text { Men/women } \\
6 / 9\end{array}$ & $\begin{array}{l}\text { Mean } 52 \text { (SD 32) } \\
\text { days } \\
\text { (excluding } \\
\text { dropouts) }\end{array}$ & $\begin{array}{l}\text { Mean } 49 \text { (SD 30) } \\
\text { days } \\
\text { (excluding } \\
\text { dropouts) }\end{array}$ & Left/right $6 / 9$ & $\begin{array}{l}\text { Left/right } \\
11 / 4\end{array}$ \\
\hline $\begin{array}{l}\text { Langham- } \\
\text { mer } 2010\end{array}$ & Mean 74 (SD 13) years & $\begin{array}{l}\text { Mean } 75(S D 10) \\
\text { years }\end{array}$ & $\begin{array}{l}\text { Men/women } \\
10 / 11\end{array}$ & $\begin{array}{l}\text { Men/women } \\
6 / 12\end{array}$ & $\begin{array}{l}\text { Mean } 419 \text { (SD 1034) } \\
\text { days }\end{array}$ & $\begin{array}{l}\text { Mean } 349(\text { SD } \\
820) \text { days }\end{array}$ & Left/right $15 / 6$ & $\begin{array}{l}\text { Left/right } \\
13 / 5\end{array}$ \\
\hline Laufer 2001 & $\begin{array}{l}\text { Mean } 66.6 \text { (SD 7.2) years } \\
\text { (excluding dropouts) }\end{array}$ & $\begin{array}{l}\text { Mean } 69.3 \text { (SD 8.1) } \\
\text { years (excluding } \\
\text { dropouts) }\end{array}$ & $\begin{array}{l}\text { Men/women } \\
7 / 6\end{array}$ & $\begin{array}{l}\text { Men/women } \\
7 / 5\end{array}$ & $\begin{array}{l}\text { Mean } 32.6 \text { (SD 21.2) } \\
\text { days }\end{array}$ & $\begin{array}{l}\text { Mean } 35.8(S D \\
17.3) \text { days }\end{array}$ & Left/right 5/8 & $\begin{array}{l}\text { Left/right } \\
5 / 7\end{array}$ \\
\hline Liston 2000 & $\begin{array}{l}\text { Mean } 79.1 \text { (SD 6.8) years ( } \\
\text { ticipants) }\end{array}$ & II EXP and CTL par- & Men/women & & Not reported & Not reported & Not reported & $\begin{array}{l}\text { Not report- } \\
\text { ed }\end{array}$ \\
\hline Luft 2008 & Mean 64 (SD 10) years & $\begin{array}{l}\text { Mean } 63 \text { (SD 9) } \\
\text { years }\end{array}$ & $\begin{array}{l}\text { Men/women } \\
14 / 20 \\
\text { (excluding } \\
\text { dropouts) }\end{array}$ & $\begin{array}{l}\text { Men/women } \\
19 / 18 \\
\text { (excluding } \\
\text { dropouts) }\end{array}$ & $\begin{array}{l}\text { Mean } 55 \text { months } \\
\text { (excluding } \\
\text { dropouts) }\end{array}$ & $\begin{array}{l}\text { Mean } 63 \text { months } \\
\text { (excluding } \\
\text { dropouts) }\end{array}$ & $\begin{array}{l}\text { Left/right } \\
21 / 12 \\
\text { (excluding } \\
\text { dropouts) }\end{array}$ & $\begin{array}{l}\text { Left/right } \\
13 / 21 \\
\text { (excluding } \\
\text { dropouts) }\end{array}$ \\
\hline $\begin{array}{l}\text { Mack- } \\
\text { ay-Lyons } \\
2013\end{array}$ & Mean 62 (SD 15) years & $\begin{array}{l}\text { Mean } 59(\text { SD 13) } \\
\text { years }\end{array}$ & $\begin{array}{l}\text { Men/women } \\
15 / 9\end{array}$ & $\begin{array}{l}\text { Men/women } \\
14 / 12\end{array}$ & $\begin{array}{l}\text { Mean } 23 \text { (SD 6) } \\
\text { days }\end{array}$ & $\begin{array}{l}\text { Mean } 23 \text { (SD 4) } \\
\text { days }\end{array}$ & Left/right $16 / 8$ & $\begin{array}{l}\text { Left/right } \\
13 / 13\end{array}$ \\
\hline Macko 2005 & Mean 63 (SD 10) years & $\begin{array}{l}\text { Mean } 64(\text { SD } 8) \\
\text { years }\end{array}$ & $\begin{array}{l}\text { Men/women } \\
22 / 10\end{array}$ & $\begin{array}{l}\text { Men/women } \\
21 / 8\end{array}$ & $\begin{array}{l}\text { Mean } 35 \text { (SD 29) } \\
\text { months }\end{array}$ & $\begin{array}{l}\text { Mean } 39 \text { (SD 59) } \\
\text { months }\end{array}$ & $\begin{array}{l}\text { Left/right } \\
18 / 14\end{array}$ & $\begin{array}{l}\text { Left/right } \\
13 / 16\end{array}$ \\
\hline Mao 2015 & Mean 59.6 (SD 9.2) years & $\begin{array}{l}\text { Mean } 60.8(S D 10.7) \\
\text { years }\end{array}$ & $\begin{array}{l}\text { Men/women } \\
10 / 5\end{array}$ & $\begin{array}{l}\text { Men/women } \\
9 / 4\end{array}$ & $\begin{array}{l}\text { Mean } 49 \text { (SD 20) } \\
\text { months }\end{array}$ & $\begin{array}{l}\text { Mean } 48 \text { (SD 17) } \\
\text { months }\end{array}$ & Left/right $6 / 9$ & $\begin{array}{l}\text { Left/right } \\
6 / 7\end{array}$ \\
\hline $\begin{array}{l}\text { Mehrberg } \\
2001\end{array}$ & Not described & Not described & $\begin{array}{l}\text { Not de- } \\
\text { scribed }\end{array}$ & $\begin{array}{l}\text { Not de- } \\
\text { scribed }\end{array}$ & Not described & Not described & Not described & $\begin{array}{l}\text { Not de- } \\
\text { scribed }\end{array}$ \\
\hline $\begin{array}{l}\text { Middleton } \\
2014\end{array}$ & $\begin{array}{l}\text { Mean } 61.4(S D 15.7) \\
\text { years }\end{array}$ & $\begin{array}{l}\text { Mean } 60.7(S D 11.4) \\
\text { years }\end{array}$ & $\begin{array}{l}\text { Men/women } \\
14 / 9\end{array}$ & $\begin{array}{l}\text { Men/women } \\
16 / 4\end{array}$ & $\begin{array}{l}\text { Mean } 50.4 \text { (SD 56.8) } \\
\text { months }\end{array}$ & $\begin{array}{l}\text { Mean } 29 \text { (SD 52) } \\
\text { months }\end{array}$ & Left/right 8/15 & $\begin{array}{l}\text { Left/right } \\
8 / 12\end{array}$ \\
\hline Moore 2010 & \multicolumn{2}{|c|}{$\begin{array}{l}\text { Mean } 50 \text { (SD 15) years (EXP and CTL partici- } \\
\text { pants) }\end{array}$} & \multicolumn{2}{|c|}{$\begin{array}{l}\text { Men/women } 14 / 6 \text { (EXP and } \\
\text { CTL) }\end{array}$} & \multicolumn{2}{|c|}{ Mean 13 (SD 8) months (EXP and CTL) } & \multicolumn{2}{|c|}{ Left/right 16/4 (EXP and CTL) } \\
\hline
\end{tabular}




\begin{tabular}{|c|c|c|c|c|c|c|c|c|}
\hline Nilsson 2001 & $\begin{array}{l}\text { Median } 54 \text { (range } 24 \text { to } \\
67 \text { ) years (all partici- } \\
\text { pants) }\end{array}$ & $\begin{array}{l}\text { Median } 56 \text { (range } \\
24 \text { to } 66 \text { ) years }\end{array}$ & $\begin{array}{l}\text { Men/women } \\
\text { 20/16 }\end{array}$ & $\begin{array}{l}\text { Men/women } \\
\text { 20/17 }\end{array}$ & $\begin{array}{l}\text { Median } 22 \text { (range } \\
10 \text { to } 56 \text { ) days }\end{array}$ & $\begin{array}{l}\text { Median } 17 \text { (range } \\
8 \text { to } 53 \text { ) days }\end{array}$ & $\begin{array}{l}\text { Left/right/ } \\
\text { bilateral } \\
21 / 11 / 4\end{array}$ & $\begin{array}{l}\text { Left/right/ } \\
\text { bilateral } \\
18 / 14 / 5\end{array}$ \\
\hline $\begin{array}{l}\text { Olawale } \\
2009\end{array}$ & Mean 56.8 (SD 6.4) years & $\begin{array}{l}\text { Mean } 57.0(\text { SD 7.1) } \\
\text { years }\end{array}$ & $\begin{array}{l}\text { Men/women } \\
12 / 8\end{array}$ & $\begin{array}{l}\text { Men/women } \\
\text { 22/18 }\end{array}$ & $\begin{array}{l}\text { Mean } 10.2 \text { (SD 6.9) } \\
\text { months }\end{array}$ & $\begin{array}{l}\text { Mean } 10.5(\mathrm{SD} \\
6.3) \text { months }\end{array}$ & Left/right $12 / 8$ & $\begin{array}{l}\text { Left/right } \\
19 / 21\end{array}$ \\
\hline Park 2013 & Mean 53 (SD 8) years & $\begin{array}{l}\text { Mean } 53(\text { SD 9) } \\
\text { years }\end{array}$ & $\begin{array}{l}\text { Men/women } \\
12 / 8\end{array}$ & $\begin{array}{l}\text { Men/women } \\
13 / 7\end{array}$ & $\begin{array}{l}\text { Mean } 21 \text { (SD 7) } \\
\text { months }\end{array}$ & $\begin{array}{l}\text { Mean } 16 \text { (SD 8) } \\
\text { months }\end{array}$ & Left/right $12 / 9$ & $\begin{array}{l}\text { Left/right } \\
10 / 10\end{array}$ \\
\hline Park 2015 & Mean 55 (SD 10) years & $\begin{array}{l}\text { Mean } 52(\text { SD 13) } \\
\text { years }\end{array}$ & $\begin{array}{l}\text { Men/women } \\
4 / 5\end{array}$ & $\begin{array}{l}\text { Men/women } \\
6 / 4\end{array}$ & $\begin{array}{l}\text { Mean } 10 \text { (SD 3) } \\
\text { months }\end{array}$ & $\begin{array}{l}\text { Mean } 13 \text { (SD 4) } \\
\text { months }\end{array}$ & Left/right $3 / 6$ & $\begin{array}{l}\text { Left/right } \\
6 / 4\end{array}$ \\
\hline Pohl 2002 & $\begin{array}{l}\text { Mean } 58.2 \text { (SD 10.5) } \\
\text { years for EXP } 1 \text { (exclud- } \\
\text { ing dropouts) } \\
\text { Mean } 57.1 \text { (SD 13.9) } \\
\text { years for EXP } 2 \text { (exclud- } \\
\text { ing dropouts) }\end{array}$ & $\begin{array}{l}\text { Mean } 61.6 \text { (SD 10.6) } \\
\text { years (excluding } \\
\text { dropouts) }\end{array}$ & $\begin{array}{l}\text { Men/women } \\
16 / 4 \text { for EXP } \\
1 \\
\text { Men/ } \\
\text { women } 14 / 6 \\
\text { for EXP } 2\end{array}$ & $\begin{array}{l}\text { Men/women } \\
13 / 7\end{array}$ & $\begin{array}{l}\text { Mean } 16.2 \text { (SD 16.4) } \\
\text { weeks for EXP } 1 \\
\text { Mean 16.8 (SD } \\
20.5) \text { weeks for EXP } \\
2\end{array}$ & $\begin{array}{l}\text { Mean } 16.1(\text { SD } \\
\text { 18.5) weeks }\end{array}$ & $\begin{array}{l}\text { Left/right } 15 / 5 \\
\text { for EXP } 1 \\
\text { Left/right } \\
16 / 4 \text { for EXP } 2\end{array}$ & $\begin{array}{l}\text { Left/right } \\
16 / 4\end{array}$ \\
\hline Ribeiro 2013 & $\begin{array}{l}\text { Mean } 56 \text { (SD 8) years } \\
\text { (without dropouts) }\end{array}$ & $\begin{array}{l}\text { Mean } 58 \text { (SD 9) } \\
\text { years (without } \\
\text { dropouts) }\end{array}$ & $\begin{array}{l}\text { Not de- } \\
\text { scribed }\end{array}$ & $\begin{array}{l}\text { Not de- } \\
\text { scribed }\end{array}$ & $\begin{array}{l}\text { Mean } 33 \text { (SD 25) } \\
\text { months }\end{array}$ & $\begin{array}{l}\text { Mean } 20 \text { (SD 10) } \\
\text { months }\end{array}$ & Not described & $\begin{array}{l}\text { Not de- } \\
\text { scribed }\end{array}$ \\
\hline $\begin{array}{l}\text { Richards } \\
1993\end{array}$ & $\begin{array}{l}\text { Mean } 69.6 \text { (SD 7.4) years } \\
\text { (all participants) }\end{array}$ & $\begin{array}{l}\text { Mean } 67.3(\text { SD 11.2) } \\
\text { years (CTL 1) }\end{array}$ & $\begin{array}{l}\text { Men/women } \\
5 / 5\end{array}$ & $\begin{array}{l}\text { Men/women } \\
2 / 6\end{array}$ & $\begin{array}{l}\text { Mean } 8.3(\text { SD 1.4) } \\
\text { days }\end{array}$ & $\begin{array}{l}\text { Mean } 8.8 \text { (SD 1.5) } \\
\text { days }\end{array}$ & Left/right $8 / 2$ & $\begin{array}{l}\text { Left/right } \\
2 / 6\end{array}$ \\
\hline $\begin{array}{l}\text { Richards } \\
2004\end{array}$ & Mean 62.9 (SD 12) years & $\begin{array}{l}\text { Mean } 60.7(S D 12) \\
\text { years }\end{array}$ & $\begin{array}{l}\text { Men/women } \\
22 / 10\end{array}$ & $\begin{array}{l}\text { Men/women } \\
21 / 10\end{array}$ & $\begin{array}{l}\text { Mean } 52.0 \text { (SD 22) } \\
\text { months }\end{array}$ & $\begin{array}{l}\text { Mean } 52.6 \text { (SD 18) } \\
\text { months }\end{array}$ & $\begin{array}{l}\text { Left/right } \\
15 / 17\end{array}$ & $\begin{array}{l}\text { Left/right } \\
20 / 11\end{array}$ \\
\hline $\begin{array}{l}\text { Scheidt- } \\
\text { mann } 1999\end{array}$ & $\begin{array}{l}\text { Mean } 57.7 \text { (SD 11.0) } \\
\text { years (all participants) }\end{array}$ & & $\begin{array}{l}\text { Men/women } \\
16 / 14\end{array}$ & & $\begin{array}{l}\text { Mean } 52.2 \text { (SD 29.6) } \\
\text { days }\end{array}$ & & $\begin{array}{l}\text { Left/right } \\
17 / 13\end{array}$ & \\
\hline Smith 2008 & Mean 57.8 (SD 7.0) years & $\begin{array}{l}\text { Mean } 56.0(\text { SD 8.3) } \\
\text { years }\end{array}$ & $\begin{array}{l}\text { Men/women } \\
8 / 2\end{array}$ & $\begin{array}{l}\text { Men/women } \\
4 / 6\end{array}$ & $\begin{array}{l}<1 \text { year: } 8 \\
1>2 \text { years: } 2\end{array}$ & $\begin{array}{l}<1 \text { year: } 8 \\
1>2 \text { years: } 2\end{array}$ & Left/right 4/16 & \\
\hline $\begin{array}{l}\text { Srivastava } \\
2016\end{array}$ & $\begin{array}{l}\text { Mean group II } 47.93 \text { (SD } \\
9.95 \text { ) years; group III } \\
44.20 \text { (SD 11.70) years }\end{array}$ & $\begin{array}{l}\text { Mean } 44.40(\mathrm{SD} \\
12.31) \text { years }\end{array}$ & $\begin{array}{l}\text { Men/women } \\
\text { group II } \\
\text { 12/3; group } \\
\text { III } 12 / 3\end{array}$ & $\begin{array}{l}\text { Men/women } \\
12 / 3\end{array}$ & $\begin{array}{l}\text { Mean group II } \\
442.07 \text { (SD 295.13) } \\
\text { days; group III } \\
391.80 \text { (SD 431.10) } \\
\text { days }\end{array}$ & $\begin{array}{l}\text { mean } 652.20(S D \\
579.04) \text { days }\end{array}$ & $\begin{array}{l}\text { left/right } \\
\text { group II 6/9; } \\
\text { group III 8/7 }\end{array}$ & $\begin{array}{l}\text { Left/right } \\
7 / 8\end{array}$ \\
\hline
\end{tabular}




\begin{tabular}{|c|c|c|c|c|c|c|c|c|}
\hline $\begin{array}{l}\text { Sullivan } \\
2007\end{array}$ & $\begin{array}{l}\text { Mean } 60.0(\text { SD 13.3) } \\
\text { years }\end{array}$ & $\begin{array}{l}\text { Mean } 63.4(\text { SD 8.4) } \\
\text { years }\end{array}$ & $\begin{array}{l}\text { Men/women } \\
34 / 26\end{array}$ & $\begin{array}{l}\text { Men/women } \\
11 / 9\end{array}$ & $\begin{array}{l}\text { Mean } 23.8 \text { (SD 15.2) } \\
\text { months }\end{array}$ & $\begin{array}{l}\text { Mean } 28.4(\mathrm{SD} \\
\text { 19.0) months }\end{array}$ & $\begin{array}{l}\text { Left/right } \\
28 / 32\end{array}$ & $\begin{array}{l}\text { Left/right } \\
10 / 10\end{array}$ \\
\hline $\begin{array}{l}\text { Suputtitada } \\
2004\end{array}$ & $\begin{array}{l}\text { Mean } 61.1(S D 10.2) \\
\text { years }\end{array}$ & $\begin{array}{l}\text { Mean } 64.9(S D \text { 10.7) } \\
\text { years }\end{array}$ & $\begin{array}{l}\text { Men/women } \\
20 / 4\end{array}$ & $\begin{array}{l}\text { Men/women } \\
15 / 9\end{array}$ & $\begin{array}{l}\text { Mean } 27.3 \text { (SD 26.6) } \\
\text { months }\end{array}$ & $\begin{array}{l}\text { Mean } 21.6(\mathrm{SD} \\
\text { 27.7) months }\end{array}$ & Left/right 9/15 & $\begin{array}{l}\text { Left/right } \\
8 / 16\end{array}$ \\
\hline $\begin{array}{l}\text { Takami } \\
2010\end{array}$ & Mean 68.6 (SD 8.9) years & $\begin{array}{l}\text { Mean } 66.9(S D \text { 10.6) } \\
\text { years }\end{array}$ & $\begin{array}{l}\text { Men/women } \\
15 / 9\end{array}$ & $\begin{array}{l}\text { Men/women } \\
7 / 7\end{array}$ & $\begin{array}{l}\text { Mean } 14.0(\text { SD 8.1) } \\
\text { days }\end{array}$ & $\begin{array}{l}\text { Mean } 13.7 \text { (SD } \\
\text { 8.9) days }\end{array}$ & $\begin{array}{l}\text { Left/right } \\
12 / 12\end{array}$ & $\begin{array}{l}\text { Left/right } \\
4 / 10\end{array}$ \\
\hline $\begin{array}{l}\text { Toledano- } \\
\text { Zarhi } 2011\end{array}$ & Mean 65 (SD 10) years & $\begin{array}{l}\text { Mean } 65(\text { SD 12) } \\
\text { years }\end{array}$ & $\begin{array}{l}\text { Men/women } \\
11 / 3\end{array}$ & $\begin{array}{l}\text { Men/women } \\
10 / 4\end{array}$ & $\begin{array}{l}\text { Mean } 11 \text { (SD 5) } \\
\text { days }\end{array}$ & $\begin{array}{l}\text { Mean } 11 \text { (SD 4) } \\
\text { days }\end{array}$ & Not described & $\begin{array}{l}\text { Not de- } \\
\text { scribed }\end{array}$ \\
\hline $\begin{array}{l}\text { Visintin } \\
1998\end{array}$ & $\begin{array}{l}\text { Mean } 66.5 \text { (SD 12.8) } \\
\text { years (all participants) }\end{array}$ & $\begin{array}{l}\text { Mean } 66.7(\text { SD 10.1) } \\
\text { years }\end{array}$ & $\begin{array}{l}\text { Men/women } \\
31 / 19\end{array}$ & $\begin{array}{l}\text { Men/women } \\
28 / 22\end{array}$ & $\begin{array}{l}\text { Mean } 68.1 \text { (SD 26.5) } \\
\text { days }\end{array}$ & $\begin{array}{l}\text { Mean } 78.4 \text { (SD } \\
\text { 30.0) days }\end{array}$ & $\begin{array}{l}\text { Left/right } \\
30 / 20\end{array}$ & $\begin{array}{l}\text { Left/right } \\
21 / 29\end{array}$ \\
\hline Weng 2004 & $55.2(15.4)$ years & $54.6(15.2)$ years & $\begin{array}{l}\text { Men/women } \\
17 / 6\end{array}$ & $\begin{array}{l}\text { Men/women } \\
17 / 5\end{array}$ & $\begin{array}{l}\text { Mean } 36.1 \text { (SD 11.3) } \\
\text { days }\end{array}$ & $\begin{array}{l}\text { Mean } 35.6 \text { (SD } \\
\text { 14.5) days }\end{array}$ & $\begin{array}{l}\text { Left/right } \\
10 / 13\end{array}$ & $\begin{array}{l}\text { Left/right } \\
8 / 14\end{array}$ \\
\hline Weng 2006 & 51 (12) years & 50 (14) years & $\begin{array}{l}\text { Men/women } \\
8 / 5\end{array}$ & $\begin{array}{l}\text { Men/women } \\
9 / 4\end{array}$ & $\begin{array}{l}\text { Mean } 62 \text { (SD 24) } \\
\text { days }\end{array}$ & $\begin{array}{l}\text { Mean } 63 \text { (SD 34) } \\
\text { days }\end{array}$ & $\begin{array}{l}\text { Left/right } \\
6 / 7\end{array}$ & $\begin{array}{l}\text { Left/right } \\
7 / 6\end{array}$ \\
\hline $\begin{array}{l}\text { Werner } \\
2002 a\end{array}$ & $\begin{array}{l}\text { Mean } 59.7 \text { (SD 10.2) } \\
\text { years (all participants) }\end{array}$ & $\begin{array}{l}\text { Mean } 60.3 \text { (SD 8.6) } \\
\text { years (all partici- } \\
\text { pants) }\end{array}$ & $\begin{array}{l}\text { Men/women } \\
8 / 7\end{array}$ & $\begin{array}{l}\text { Men/women } \\
5 / 10\end{array}$ & $\begin{array}{l}\text { Mean } 7.4 \text { (SD 2.0) } \\
\text { weeks }\end{array}$ & $\begin{array}{l}\text { Mean } 6.9 \text { (SD 2.1) } \\
\text { weeks }\end{array}$ & Left/right $7 / 8$ & $\begin{array}{l}\text { Left/right } \\
7 / 8\end{array}$ \\
\hline Yang 2010 & Mean 57.2 (SD 9.3) years & $\begin{array}{l}\text { Mean } 55.0(\text { SD 10.1) } \\
\text { years }\end{array}$ & $\begin{array}{l}\text { Men/women } \\
5 / 5\end{array}$ & $\begin{array}{l}\text { Men/women } \\
5 / 3\end{array}$ & $\begin{array}{l}\text { Mean } 1.2(\text { SD 1.1) } \\
\text { years }\end{array}$ & $\begin{array}{l}\text { Mean 1.6 (SD 1.5) } \\
\text { years }\end{array}$ & Left/right 5/5 & $\begin{array}{l}\text { Left/right } \\
4 / 4\end{array}$ \\
\hline Yen 2008 & $\begin{array}{l}\text { Mean } 57.3(\text { SD 16.4) } \\
\text { years }\end{array}$ & $\begin{array}{l}\text { Mean } 56.1(\text { SD 12.7) } \\
\text { years }\end{array}$ & $\begin{array}{l}\text { Men/women } \\
3 / 4\end{array}$ & $\begin{array}{l}\text { Men/women } \\
6 / 1\end{array}$ & $\begin{array}{l}\text { Mean } 2.0 \text { (SD 0.6) } \\
\text { months }\end{array}$ & $\begin{array}{l}\text { Mean } 2.0 \text { (SD 2.4) } \\
\text { months }\end{array}$ & Left/right 5/2 & $\begin{array}{l}\text { Left/right } \\
3 / 4\end{array}$ \\
\hline Zhang 2008 & $63.3(13.4)$ years & $62.8(15.4)$ years & $\begin{array}{l}\text { Men/women } \\
12 / 7\end{array}$ & $\begin{array}{l}\text { Men/women } \\
13 / 7\end{array}$ & 68.7 (25.6) days & 66.3 (23.3) days & $\begin{array}{l}\text { Left/right } \\
7 / 12\end{array}$ & $\begin{array}{l}\text { Left/right } \\
8 / 12\end{array}$ \\
\hline Zhu 2004 & $56.9(12.9)$ years & $57.8(12.16)$ years & $\begin{array}{l}\text { Men/women } \\
6 / 4\end{array}$ & $\begin{array}{l}\text { Men/women } \\
7 / 3\end{array}$ & $\begin{array}{l}\text { Mean } 4.1 \text { (SD 4.8) } \\
\text { months }\end{array}$ & $\begin{array}{l}\text { Mean } 3.1 \text { (SD 4.2) } \\
\text { months }\end{array}$ & $\begin{array}{l}\text { Not stated by } \\
\text { the authors }\end{array}$ & $\begin{array}{l}\text { Not stated } \\
\text { by the au- } \\
\text { thors }\end{array}$ \\
\hline
\end{tabular}

CTL: control

EXP: experimental

Q1: first quartile (descriptive statistics)

Q2: second quartile

Q Q3: third quartile 


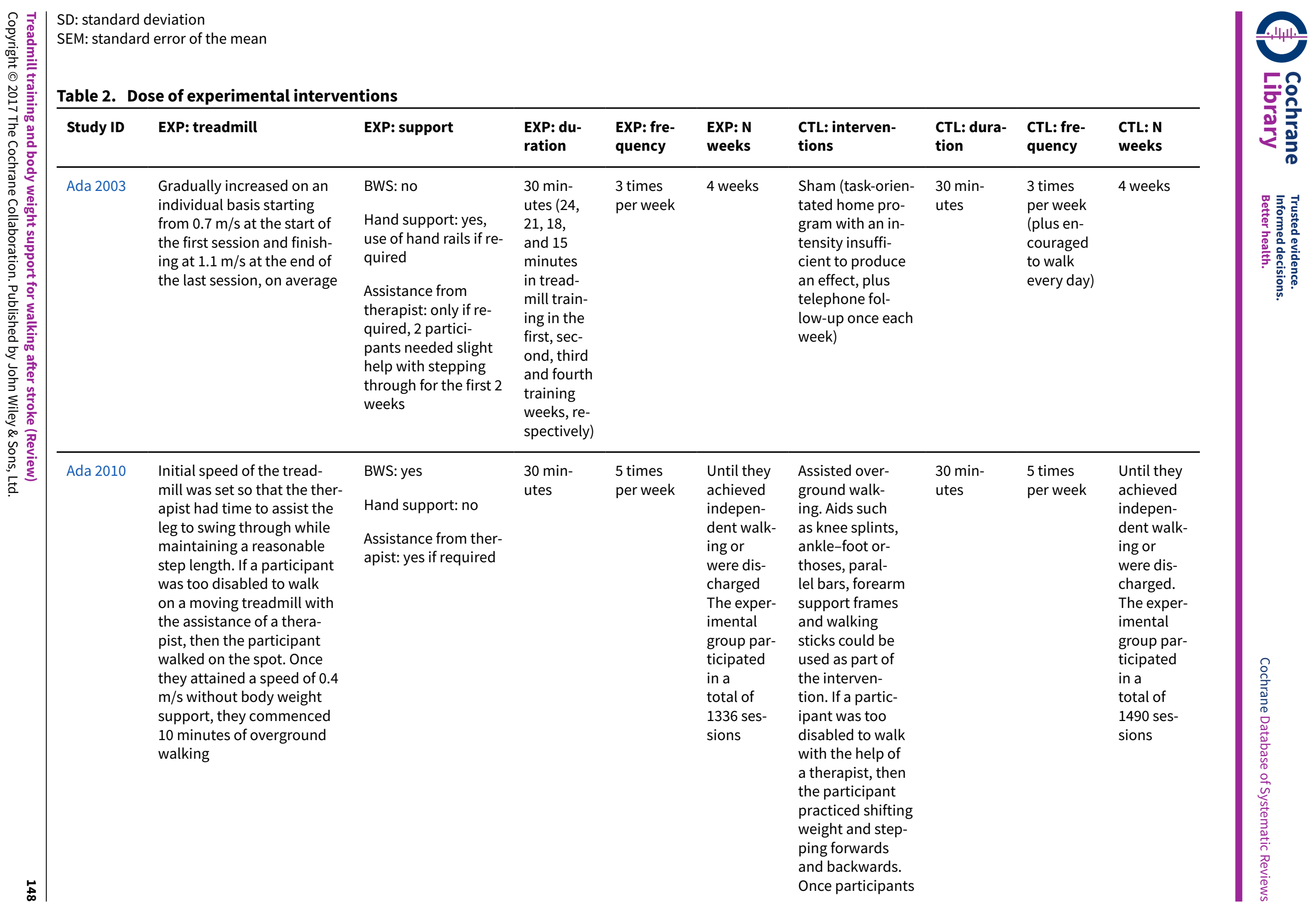




\begin{tabular}{|c|c|c|c|c|c|c|c|c|c|}
\hline $\begin{array}{l}\text { Bonnyaud } \\
2013\end{array}$ & Comfortable walking speed & No BWS & $\begin{array}{l}20 \mathrm{~min}- \\
\text { utes }\end{array}$ & $\begin{array}{l}\text { Single ses- } \\
\text { sion }\end{array}$ & - & $\begin{array}{l}\text { Overground gait- } \\
\text { training with con- } \\
\text { stant walking } \\
\text { speed }\end{array}$ & $\begin{array}{l}20 \mathrm{~min}- \\
\text { utes }\end{array}$ & $\begin{array}{l}\text { Single ses- } \\
\text { sion }\end{array}$ & - \\
\hline $\begin{array}{l}\text { Bonnyaud } \\
2013 a\end{array}$ & $\begin{array}{l}1 \text { EXP subgroup walking on } \\
\text { treadmill without a mass, } \\
\text { other EXP subgroup walking } \\
\text { on treadmill with a mass. } \\
\text { Participants were instructed } \\
\text { to walk without stopping, } \\
\text { at their own comfortable } \\
\text { speed. The mass fixed to } \\
\text { the ankle of the non-paret- } \\
\text { ic lower limb was } 2 \mathrm{~kg} \text { for } \\
\text { women and } 4 \mathrm{~kg} \text { for men }\end{array}$ & No BWS & $\begin{array}{l}20 \text { min- } \\
\text { utes }\end{array}$ & $\begin{array}{l}\text { Single ses- } \\
\text { sion }\end{array}$ & - & $\begin{array}{l}1 \text { CTL subgroup } \\
\text { walking over- } \\
\text { ground without } \\
\text { a mass other CTL } \\
\text { subgroup walk- } \\
\text { ing overground } \\
\text { with a mass. } \\
\text { Participants were } \\
\text { instructed to } \\
\text { walk without } \\
\text { stopping, at their } \\
\text { own comfortable } \\
\text { speed. The mass } \\
\text { fixed to the ankle } \\
\text { of the non-paret- } \\
\text { ic lower limb was } \\
2 \mathrm{~kg} \text { for women } \\
\text { and } 4 \text { kg for men }\end{array}$ & $\begin{array}{l}20 \mathrm{~min}- \\
\text { utes }\end{array}$ & $\begin{array}{l}\text { Single ses- } \\
\text { sion }\end{array}$ & - \\
\hline $\begin{array}{l}\text { Combs- } \\
\text { Miller } 2014\end{array}$ & $\begin{array}{l}\text { Body weight-supported } \\
\text { treadmill training. } \\
\text { Rest breaks were allowed } \\
\text { as needed, however, breaks } \\
\text { were not included in the } \\
\text { overall walking time. } \\
\text { Walking speed was in- } \\
\text { creased or decreased based } \\
\text { on the Borg rating of } 11 \text { to } \\
14 . \\
\text { Participants were instructed } \\
\text { to achieve their fastest pos- } \\
\text { sible walking pace on the } \\
\text { treadmill at every training } \\
\text { session, without exceeding } \\
\text { the moderate intensity level } \\
\text { on the Borg scale. }\end{array}$ & $\begin{array}{l}\text { BWS: began with } \\
30 \% \text { of total body } \\
\text { weight unloaded. } \\
\text { BWS was reduced to } \\
15 \% \text {, and then } 0 \% \\
\text { after participants } \\
\text { achieved a tread- } \\
\text { mill speed of at least } \\
2.0 \text { mph, required } \\
\text { no more than two } \\
\text { breaks during the } \\
30-\text { minute training } \\
\text { session, and main- } \\
\text { tained optimal qual- } \\
\text { ity of gait for } 5 \text { min- } \\
\text { utes without assis- } \\
\text { tance. }\end{array}$ & $\begin{array}{l}30 \mathrm{~min}- \\
\text { utes }\end{array}$ & $\begin{array}{l}5 \text { days per } \\
\text { week }\end{array}$ & 2 weeks & $\begin{array}{l}\text { Overground } \\
\text { walking training. } \\
\text { Rest breaks were } \\
\text { allowed as need- } \\
\text { ed, however, } \\
\text { breaks were not } \\
\text { included in the } \\
\text { overall walking } \\
\text { time. }\end{array}$ & $\begin{array}{l}30 \mathrm{~min}- \\
\text { utes }\end{array}$ & $\begin{array}{l}5 \text { days per } \\
\text { week }\end{array}$ & 2 weeks \\
\hline
\end{tabular}




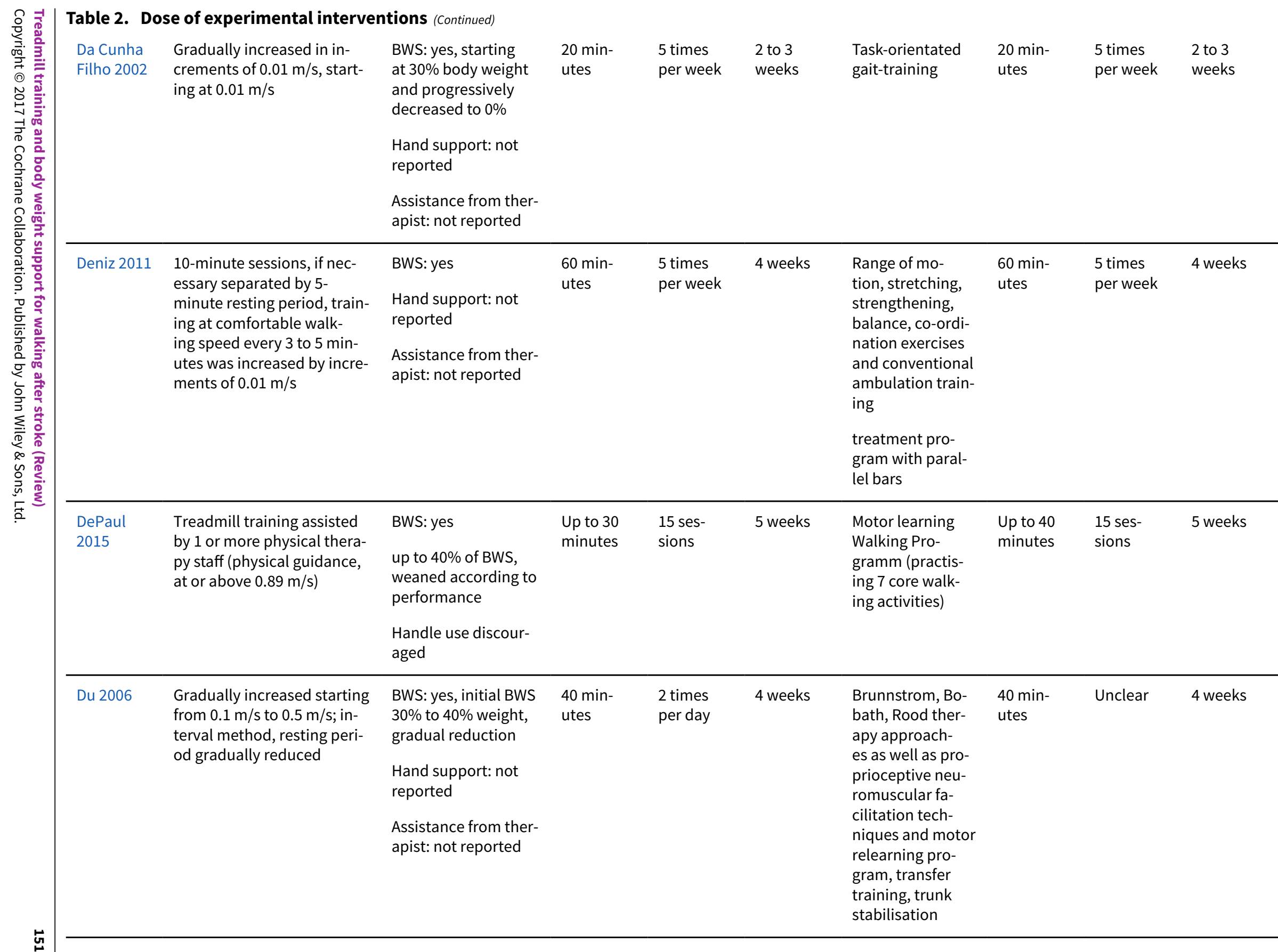


Table 2. Dose of experimental interventions (Continued)

Duncan At $0.89 \mathrm{~m} / \mathrm{s}$, followed by a progressive program of walking overground for

15 minutes. The treadmill

speeds ranged from 0 to 1.6

$\mathrm{km}$ per hour, increasing by

increments of $0.16 \mathrm{~km}$ per

hour.
BWS: yes

Hand support: not reported

Assistance from ther-

apist: yes

$\begin{array}{ll}90 \text { minute } & 3 \text { times } \\ \text { sessions } & \text { per week }\end{array}$

weeks $(30$

and 36 ex-

ercise ses

sions

within

this peri-

od) per week

a a high-

pecific walking

program. Pro-

the program was

managed by a

physical thera-

pist in the home,

with the goals of

enhancing flex-

ibility, range of

motion in joints,

strength of arms

and legs, co-ordi-

nation, and static

and dynamic

balance. Partici-

pants in this pro-

gram were en-

couraged

to walk daily.

\begin{tabular}{|c|c|c|c|c|c|c|c|c|c|}
\hline Eich 2004 & $\begin{array}{l}\text { Speed and inclination in- } \\
\text { creased on an individual } \\
\text { basis to achieve a training } \\
\text { heart rate. } \\
\text { Mean speed increased from } \\
0.35 \mathrm{~m} / \mathrm{s} \text { (SD } 0.11 \text { ) in week } \\
1 \text { to } 0.64 \mathrm{~m} / \mathrm{s} \text { (SD } 0.15 \text { ) in } \\
\text { week } 6 \text {. In week } 1 \text {, only } 1 / 25 \\
\text { participants had an incli- } \\
\text { nation of } 4 \text { degrees; this } \\
\text { increased to } 25 / 25 \text { partic- } \\
\text { ipants in week } 6 \text {, with a } \\
\text { mean inclination of } 6.2 \text { de- } \\
\text { grees. }\end{array}$ & $\begin{array}{l}\text { BWS: yes, the har- } \\
\text { ness was always } \\
\text { secured and body } \\
\text { weight was minimal- } \\
\text { ly supported ( } 0 \text { to } \\
15 \% \text { ) according to } \\
\text { participant needs. } \\
\text { Hand support: not } \\
\text { reported } \\
\text { Assistance from ther- } \\
\text { apist: yes, to set the } \\
\text { paretic leg, weight } \\
\text { shift and hip exten- } \\
\text { sion, if required }\end{array}$ & $\begin{array}{l}30 \text { min- } \\
\text { utes }\end{array}$ & $\begin{array}{l}5 \text { times } \\
\text { per week }\end{array}$ & 6 weeks & $\begin{array}{l}\text { Not task-orientat- } \\
\text { ed (neurophysio- } \\
\text { logical) }\end{array}$ & $\begin{array}{l}30 \mathrm{~min}- \\
\text { utes }\end{array}$ & $\begin{array}{l}5 \text { times } \\
\text { per week }\end{array}$ & 6 weeks \\
\hline $\begin{array}{l}\text { Frances- } \\
\text { chini } 2009\end{array}$ & $\begin{array}{l}\text { Speed starting from } 0.1 \mathrm{~m} / \\
\mathrm{s} \text { and aiming at } 1.2 \mathrm{~m} / \mathrm{s} \text { ac- } \\
\text { cording to the participant's }\end{array}$ & $\begin{array}{l}\text { BWS: yes, limited to } \\
40 \% \text { of body weight, } \\
\text { gradually reduced }\end{array}$ & $\begin{array}{l}20 \text { min- } \\
\text { utes }+40 \\
\text { minutes }\end{array}$ & $\begin{array}{l}2 \text { times } \\
\text { per day }\end{array}$ & $\begin{array}{l}20 \text { ses- } \\
\text { sions with- } \\
\text { in } 5 \text { weeks }\end{array}$ & $\begin{array}{l}20 \text { sessions of } \\
\text { overground gait- }\end{array}$ & $\begin{array}{l}60 \text { min- } \\
\text { utes }\end{array}$ & $\begin{array}{l}5 \text { times } \\
\text { per week }\end{array}$ & $\begin{array}{l}20 \text { ses- } \\
\text { sions wit } \\
\text { in } 5 \text { week }\end{array}$ \\
\hline
\end{tabular}

12 to 16 weeks (30 ercise ses-

sions

within

od) 
Table 2. Dose of experimental interventions (Continued)

compliance and progress. Hand support: not

training of 60

Conventional treatment

reported

minutes each

was performed for 40 min-

utes, not immediately

Assistance from ther-

after treadmill training.

apist: 2 trained

physical therapists

for each participant

to control the paretic

lower extremity and

pelvis, when pelvic

and paretic lower

extremity control

was considered ade-

quate,

training was admin-

istered by 1 physical

therapist only.

Gama Body weight support tread-

2017 mill training and comfort-

able treadmill speed was set

BWS: yes, from $30 \%$

$45 \mathrm{~min}$ -

3 times

6 weeks

Walking over-

45 min-

3 times

ground at com-

utes

per week

6 weeks

Hand support: al-

fortable walking

speed

Assistance from ther-

apist: allowed

Gan 2012 Body weight support tread-

mill training; treadmill

speed was initially started

BWS: yes, up to $40 \%$

of their body weight

Not de-

Not de-

Body weight sup- Not de-

Not de-

port overground scribed scribed

at $0.5 \mathrm{mph}$

supported at the be-

ambulation

ginning of the

training

reduced

Hand support: un-

clear

Assistance from ther-

apist: unclear

\begin{tabular}{|c|c|c|c|c|c|c|c|c|c|}
\hline $\begin{array}{l}\text { Globas } \\
2011\end{array}$ & $\begin{array}{l}\text { Beginning with } 10 \text { to } 20 \\
\text { minutes) at } 60 \% \text { to } 80 \% \text { of } \\
\text { the maximum heart rate re- } \\
\text { serve (starting with } 40 \% \text { to } \\
50 \% \text { HRR). Duration was in- }\end{array}$ & $\begin{array}{l}\text { BWS: no } \\
\text { Hand support: al- } \\
\text { lowed } \\
\text { Assistance from ther- } \\
\text { apist: unclear }\end{array}$ & $\begin{array}{l}30 \text { to } 50 \\
\text { minutes }\end{array}$ & $\begin{array}{l}3 \text { times } \\
\text { per week }\end{array}$ & $\begin{array}{l}3 \text { months } \\
\text { (39 ses- } \\
\text { sions) }\end{array}$ & $\begin{array}{l}\text { Passive, muscle } \\
\text { tone-regulating } \\
\text { exercises for the } \\
\text { upper and low- } \\
\text { er extremities } \\
\text { with elements of }\end{array}$ & $\begin{array}{l}60 \mathrm{~min}- \\
\text { utes }\end{array}$ & $\begin{array}{l}3 \text { times } \\
\text { per week }\end{array}$ & $\begin{array}{l}3 \text { months } \\
\text { (13 weeks) }\end{array}$ \\
\hline
\end{tabular}


Table 2. Dose of experimental interventions (Continued)

creased as tolerated by 1 to Treadmill inclination

balance training

conducted on an

5 minutes per week

at $0^{\circ}$

tpatient basis

readmill speed was pro-

gressed by 0.1 to $0.3 \mathrm{~km}$ /

hour every 1 to 2 weeks

in physiotherapy

practices or re-

habilitation cen-

tres. No aerobic

Training was a group in-

fitness training

tervention ( 3 participants

was performed.

trained in parallel)

Hoyer Treadmill therapy with BWS

and on days without TTB-

WS, conventional gait-train-

BWS: yes

30 min-

Daily for

30 ses-

Intensive gait-

30 min-

Daily

For a mini-

training (30 min-

utes

mum of 10

first 4 a period utes) and func-

weeks (20 of a mini- tional training (30

reported

Assistance from ther-

sessions)

mum of 10 minutes) daily for

apist: not reported

and then 1

weeks

minimum of 10

a week (10

weeks

sessions)

for the re-

maining 6

weeks

\begin{tabular}{|c|c|c|c|c|c|c|c|c|c|}
\hline Jaffe 2004 & $\begin{array}{l}\text { Comfortable walking speed } \\
\text { (speed not reported), speed } \\
\text { was not progressed }\end{array}$ & $\begin{array}{l}\text { BWS: no, harness } \\
\text { used to prevent falls } \\
\text { only } \\
\text { Hand support: yes, } \\
\text { use of hand rails, if } \\
\text { required } \\
\text { Assistance from ther- } \\
\text { apist: no }\end{array}$ & $\begin{array}{l}60 \text { min- } \\
\text { utes }\end{array}$ & $\begin{array}{l}3 \text { times } \\
\text { per week }\end{array}$ & 2 weeks & $\begin{array}{l}\text { Task-orientated } \\
\text { (overground ob- } \\
\text { stacle training) }\end{array}$ & $\begin{array}{l}60 \text { min- } \\
\text { utes }\end{array}$ & $\begin{array}{l}3 \text { times } \\
\text { per week }\end{array}$ & 2 weeks \\
\hline Kang 2012 & $\begin{array}{l}\text { Group 1: treadmill training } \\
\text { with optic flow } \\
\text { (optic flow was applied } \\
\text { and treadmill speed was } \\
\text { increased by } 0.1 \mathrm{~km} / \text { hour } \\
\text { each time once the partici- } \\
\text { pant could walk stably for } \\
\text { more than } 20 \text { seconds) } \\
\text { Group 2: treadmill training } \\
\text { without optic flow }\end{array}$ & $\begin{array}{l}\text { BWS: no } \\
\text { Hand support: al- } \\
\text { lowed but discour- } \\
\text { aged } \\
\text { Assistance from ther- } \\
\text { apist: no }\end{array}$ & $\begin{array}{l}30 \text { min- } \\
\text { utes ( } 2 \\
\text { times for } \\
15 \text { min- } \\
\text { utes with } \\
\text { a rest be- } \\
\text { tween) }\end{array}$ & $\begin{array}{l}3 \text { times } \\
\text { per week }\end{array}$ & 4 weeks & $\begin{array}{l}\text { General stretch- } \\
\text { ing with added } \\
\text { range of motion } \\
\text { exercises in the } \\
\text { less and more af- } \\
\text { fected sides of } \\
\text { the trunk, arms } \\
\text { and legs for the } \\
\text { same time. Exer- } \\
\text { cise therapy was } \\
\text { performed using }\end{array}$ & $\begin{array}{l}30 \mathrm{~min}- \\
\text { utes }\end{array}$ & $\begin{array}{l}3 \text { times } \\
\text { per week }\end{array}$ & 4 weeks \\
\hline
\end{tabular}




\begin{tabular}{|c|c|c|c|c|c|c|c|c|c|}
\hline & $\begin{array}{l}\text { (treadmill speed was in- } \\
\text { creased by } \\
0.1 \mathrm{~km} / \text { hour each time once } \\
\text { the participants could walk } \\
\text { stably for more than } 20 \mathrm{sec}- \\
\text { onds) }\end{array}$ & & & & & $\begin{array}{l}\text { the traditional } \\
\text { motor develop- } \\
\text { ment theory and } \\
\text { neurodevelop- } \\
\text { mental treatment } \\
\text { based on motor }\end{array}$ & & & \\
\hline Kim 2011 & $\begin{array}{l}\text { Gradually increased starting } \\
\text { from } 0.3 \mathrm{~m} / \mathrm{s} \text { to } 0.7 \mathrm{~m} / \mathrm{s}\end{array}$ & $\begin{array}{l}\text { BWS: no } \\
\text { Hand support: no } \\
\text { Assistance from ther- } \\
\text { apist: no }\end{array}$ & $\begin{array}{l}30 \mathrm{~min}- \\
\text { utes }\end{array}$ & $\begin{array}{l}5 \text { times } \\
\text { per week }\end{array}$ & 6 weeks & $\begin{array}{l}\text { Control group re- } \\
\text { ceived muscle } \\
\text { strengthening } \\
\text { (seated leg press, } \\
\text { knee extension, } \\
\text { leg abductor) }\end{array}$ & $\begin{array}{l}30 \mathrm{~min}- \\
\text { utes }\end{array}$ & $\begin{array}{l}5 \text { times } \\
\text { per week }\end{array}$ & 6 weeks \\
\hline Kim 2016 & $\begin{array}{l}\text { Treadmill training with vir- } \\
\text { tual reality in addition to } \\
\text { general physical therapy } \\
\text { If the participant main- } \\
\text { tained the speed and felt } \\
\text { safe for } 20 \text { s, the treadmill } \\
\text { speed was then increased } \\
\text { by } 5 \% \text { during next training } \\
\text { session }\end{array}$ & $\begin{array}{l}\text { BWS: no } \\
\text { Hand support: un- } \\
\text { clear } \\
\text { Assistance from ther- } \\
\text { apist: unclear }\end{array}$ & $\begin{array}{l}30 \text { min- } \\
\text { utes }\end{array}$ & $\begin{array}{l}3 \text { times } \\
\text { per week }\end{array}$ & 4 weeks & $\begin{array}{l}2 \text { control groups: } \\
1 \text { control group } \\
\text { received com- } \\
\text { munity ambula- } \\
\text { tion in addition to } \\
\text { general physical } \\
\text { therapy, the oth- } \\
\text { er control group } \\
\text { no additional } \\
\text { walking training } \\
\text { to general physi- } \\
\text { cal therapy }\end{array}$ & $\begin{array}{l}30 \mathrm{~min}- \\
\text { utes }\end{array}$ & $\begin{array}{l}3 \text { times } \\
\text { per week }\end{array}$ & 4 weeks \\
\hline $\begin{array}{l}\text { Kosak } \\
2000\end{array}$ & $\begin{array}{l}\text { Gradually increased from } \\
0.22 \text { to } 0.89 \mathrm{~m} / \mathrm{s} \text {, as tolerat- } \\
\text { ed }\end{array}$ & $\begin{array}{l}\text { BWS: yes, starting } \\
\text { at } 30 \% \text { body weight } \\
\text { and progressively } \\
\text { decreased to } 0 \% \text { or } \\
\text { eliminated } \\
\text { Hand support: yes, } \\
\text { use of hand rails, if } \\
\text { required } \\
\text { Assistance from ther- } \\
\text { apist: yes, assisted } \\
\text { with swing phase, } \\
\text { foot placement and } \\
\text { weight shift, if re- } \\
\text { quired }\end{array}$ & $\begin{array}{l}45 \mathrm{~min}- \\
\text { utes }\end{array}$ & $\begin{array}{l}5 \text { times } \\
\text { per week }\end{array}$ & $\begin{array}{l}2 \text { to } 3 \\
\text { weeks }\end{array}$ & $\begin{array}{l}\text { Not task-orientat- } \\
\text { ed (orthopaedic) }\end{array}$ & $\begin{array}{l}45 \mathrm{~min}- \\
\text { utes }\end{array}$ & $\begin{array}{l}5 \text { times } \\
\text { per week }\end{array}$ & $\begin{array}{l}2 \text { to } 3 \\
\text { weeks }\end{array}$ \\
\hline
\end{tabular}

(treadmill speed was in-

$0.1 \mathrm{~km} /$ hour each time once

the participants could walk

tably for more than $20 \mathrm{sec}$

Gradually increased startin

rom $0.3 \mathrm{~m} / \mathrm{s}$ to $0.7 \mathrm{~m} / \mathrm{s}$

the traditiona

ment theory anc

eurodevelop-

mental treatment

based on moto

knee extension,

1 control group

control grou

t $30 \%$ body weigh

decreased to $0 \%$

iminated 
Table 2. Dose of experimental interventions (Continued)

Kuys 2011 Walked on the treadmill at an intensity of $40 \%$ to $60 \%$ heart rate reserve or a Borg Rating of Perceived ExerBWS: no

Hand support: yes, were encouraged to

tion of 11 to 14 . Participants hold the handrail commenced at an intensi-

ty level of $40 \%$ heart rate reserve for 30 minutes, pro-

gressing each week aiming

for a $5 \%$ to $10 \%$ increase un

til $60 \%$ heart rate reserve

was reached. For partici-

pants unable to reach $40 \%$

heart rate reserve on com-

mencement of treadmill

walking, treadmill speeds

were set as fast as tolerated

and progressed as quickly

as possible.

Also received task-orient-

ed physiotherapy, approximately 1 hour per day

\begin{tabular}{ll}
\hline Langham- & Walking speed was start- \\
mer 2010 & ed on the lowest level and \\
& was increased within the \\
& first minutes to the working \\
& level. The working load was \\
& increased in co-operation \\
& with the participants to a \\
& level they felt comfortable \\
& with and they felt no insecu- \\
& rity in balance or discomfort \\
& otherwise.
\end{tabular}

\begin{tabular}{ll}
\hline Laufer & $\begin{array}{l}\text { Comfortable walking speed, } \\
\text { speed used and progression } \\
\text { not reported }\end{array}$
\end{tabular}

not reported

Assistance from ther-

apist: yes, a physio-

therapist provided

assistance as

required to ensure

foot clearance during

swing phase

BWS: no

Hand support: yes,

use of hand rails, if

\section{$30 \mathrm{~min}$}

$\begin{array}{llll}30 \text { min- } & 3 \text { times } & 6 \text { weeks } & \begin{array}{l}\text { Received usual } \\ \text { physiotherapy in- } \\ \text { tervention only }\end{array}\end{array}$

Unclear

(probably

the same

as the EXP

group)
Unclear

probably

as the EXP

group)

\begin{tabular}{|c|c|c|c|c|c|c|c|}
\hline $\begin{array}{l}\text { BWS: no } \\
\text { Hand support: yes } \\
\text { Assistance from ther- } \\
\text { apist: no, and no in- } \\
\text { clination }\end{array}$ & $\begin{array}{l}30 \mathrm{~min}- \\
\text { utes }\end{array}$ & $\begin{array}{l}\text { (Up to) } 5 \\
\text { times per } \\
\text { week }\end{array}$ & $\begin{array}{l}\text { Mean of } \\
16 \text { days of } \\
\text { inpatient } \\
\text { stay } \\
\text { (mean } 10 \\
\text { walking } \\
\text { sessions) }\end{array}$ & $\begin{array}{l}\text { Outdoor walking } \\
\text { at a comfortable } \\
\text { speed and with } \\
\text { the use of ordi- } \\
\text { nary assistive de- } \\
\text { vices, when nec- } \\
\text { essary }\end{array}$ & $\begin{array}{l}30 \mathrm{~min}- \\
\text { utes }\end{array}$ & $\begin{array}{l}\text { (Up to) } 5 \\
\text { times per } \\
\text { week }\end{array}$ & $\begin{array}{l}\text { Mean of } \\
17 \text { days of } \\
\text { inpatient } \\
\text { stay (mean } \\
11 \text { walking } \\
\text { sessions) }\end{array}$ \\
\hline
\end{tabular}

3 weeks

8 to 20

5 times

3 weeks

required

Assistance from ther-

apist: yes, assisted 


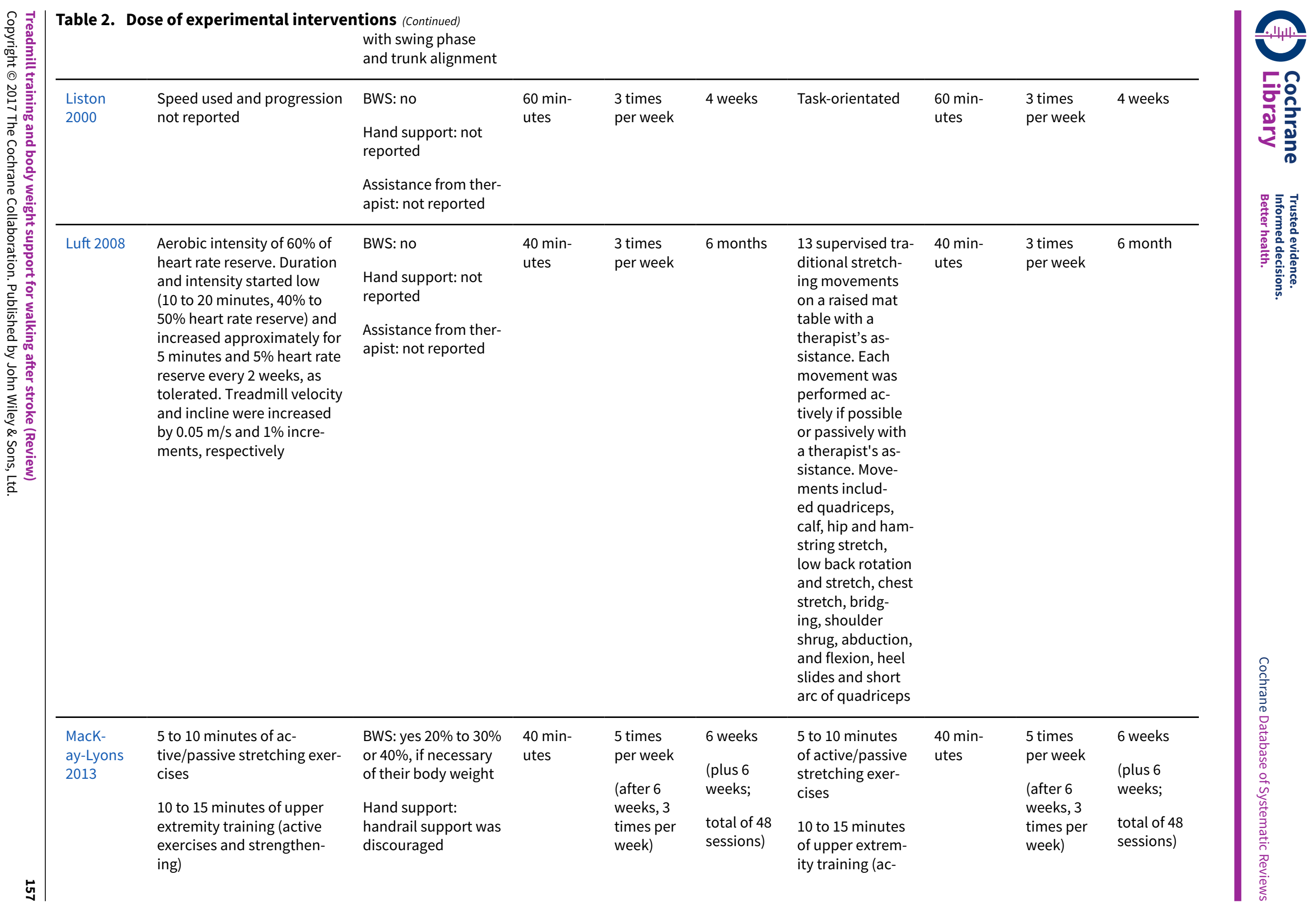


Table 2. Dose of experimental interventions (Continued)

10 to 15 minutes of lower Assistance from ther-

extremity training (active

exercises and strengthen-

ing)

25 to 30 minutes of BWSTT

including warm-up and

cool-down

BWSTT initiated in 5 to 10 minute bouts at the heart rate achieved at $40 \%$ to $50 \%$ of baseline $\mathrm{VO}_{2}$ peak. The

goal was to achieve a target exercise duration (at least 20 minutes, exclusive of warm-up and cool-down) and intensity (heart rates corresponding to $60 \%$ to $75 \%$ of baseline $\mathrm{VO}_{2}$ peak 27) by the fourth or fifth week.

Initially, ambulatory-independent participants walked at a treadmill speed of $80 \%$ to $90 \%$ of their selfpaced overground speed

Ambulatory-dependent participants walked at a treadmill speed of $70 \%$ to $80 \%$ of their overground speed

Treadmill speed and grade were gradually increased and percentage of manual and body weight support decreased, as tolerated

Macko Increased from a mean of 0.48 (SE 0.30) $\mathrm{m} / \mathrm{s}$ at base line to $0.75(\mathrm{SE} 0.30) \mathrm{m} / \mathrm{s}$ at treatment end on an ind - apist: therapist em -

hasised trunk and

limb alignment,

oading of the stance

limb, hip extension

terminal stance,

and advancement of

the swing limb tive exercises and

strengthening)

10 to 15 minutes

of lower extrem-

ity training (ac-

tive exercises and

strengthening

25 to 30 minutes

of overground

gait-training

\begin{tabular}{|c|c|c|c|c|c|c|c|}
\hline $\begin{array}{l}\text { BWS: no } \\
\text { Hand support: yes, } \\
\text { use of handrails, if } \\
\text { required }\end{array}$ & $\begin{array}{l}40 \text { min- } \\
\text { utes (in- } \\
\text { cluding } 5 \\
\text { minutes } \\
\text { warm-up } \\
\text { and } 5 \text { min- }\end{array}$ & $\begin{array}{l}3 \text { times } \\
\text { per week }\end{array}$ & 6 months & Task-orientated & $\begin{array}{l}40 \text { min- } \\
\text { utes }\end{array}$ & $\begin{array}{l}3 \text { times } \\
\text { per week }\end{array}$ & 6 months \\
\hline
\end{tabular}




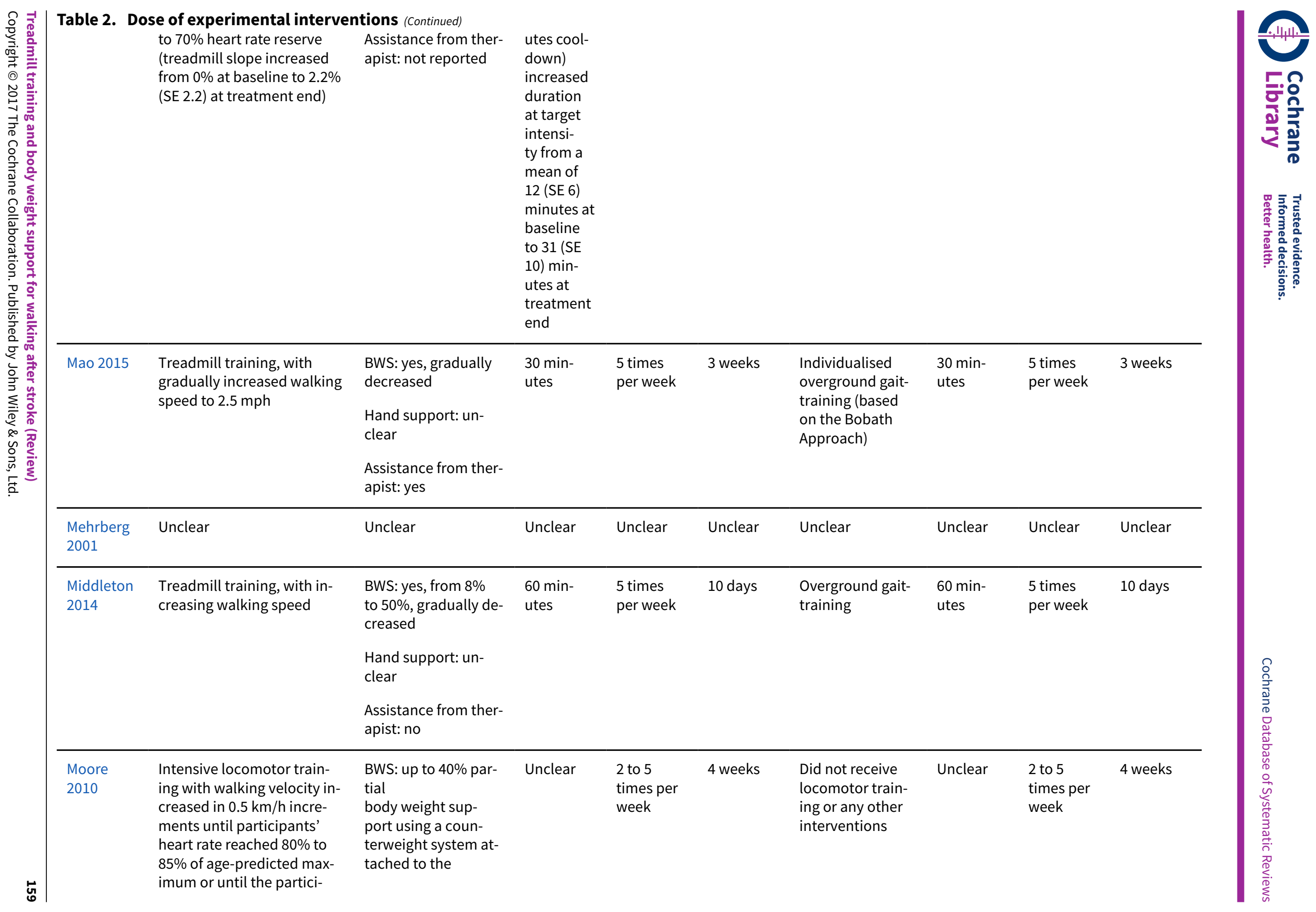




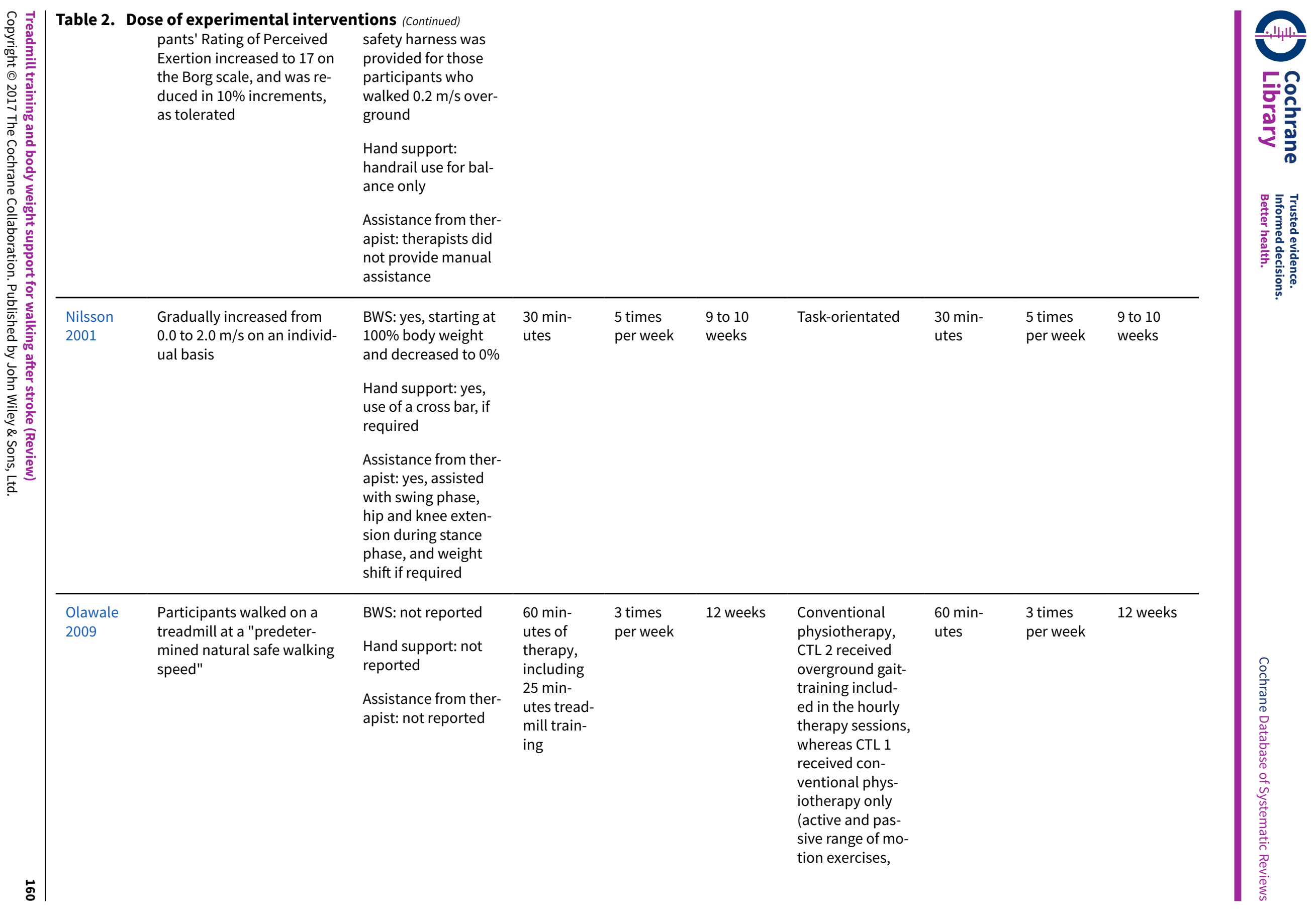




\begin{tabular}{|c|c|c|c|c|c|c|c|c|c|}
\hline & & & & & & $\begin{array}{l}\text { strength, and bal- } \\
\text { ance training) }\end{array}$ & & & \\
\hline Park 2013 & $\begin{array}{l}\text { Treadmill gait-training at } \\
\text { comfortable walking speed }\end{array}$ & $\begin{array}{l}\text { BWS: not reported } \\
\text { Hand support: not } \\
\text { reported } \\
\text { Assistance from ther- } \\
\text { apist: not reported }\end{array}$ & $\begin{array}{l}30 \text { min- } \\
\text { utes twice } \\
\text { a day }\end{array}$ & $\begin{array}{l}5 \text { times } \\
\text { per week }\end{array}$ & 1 week & $\begin{array}{l}\text { Overground gait- } \\
\text { training }\end{array}$ & $\begin{array}{l}30 \text { min- } \\
\text { utes twice } \\
\text { a day }\end{array}$ & $\begin{array}{l}5 \text { times } \\
\text { per week }\end{array}$ & 1 week \\
\hline Park 2015 & $\begin{array}{l}\text { Treadmill training with } \\
\text { rhythmic auditory stimula- } \\
\text { tion at convenient walking } \\
\text { speed }\end{array}$ & $\begin{array}{l}\text { BWS: not reported } \\
\text { Hand support: not } \\
\text { reported } \\
\text { Assistance from ther- } \\
\text { apist: not reported }\end{array}$ & $\begin{array}{l}30 \text { min- } \\
\text { utes }\end{array}$ & $\begin{array}{l}5 \text { times } \\
\text { per week }\end{array}$ & 3 weeks & $\begin{array}{l}\text { Ground walking } \\
\text { with rhythmic au- } \\
\text { ditory stimula- } \\
\text { tion }\end{array}$ & $\begin{array}{l}30 \text { min- } \\
\text { utes }\end{array}$ & $\begin{array}{l}5 \text { times } \\
\text { per week }\end{array}$ & 3 weeks \\
\hline Pohl 2002 & $\begin{array}{l}\text { Speed-dependent treadmill } \\
\text { training (EXP 1) - aggressive } \\
\text { increase in speed starting } \\
\text { from the highest speed the } \\
\text { participant could walk at } \\
\text { without stumbling and in- } \\
\text { creasing at } 10 \% \text { increments } \\
\text { of this speed several times } \\
\text { within a session. The av- } \\
\text { erage treadmill speed in- } \\
\text { creased from } 0.68 \mathrm{~m} / \mathrm{s} \text { (SD } \\
0.34 \text { ) at the start of training } \\
\text { to } 2.05 \mathrm{~m} / \mathrm{s} \text { (SD } 0.71 \text { ) at the } \\
\text { end of training; } \\
\text { limited progressive tread- } \\
\text { mill training (EXP } 2 \text { ) - gradu- } \\
\text { ally increased in increments } \\
\text { of } 5 \% \text { of the initial maxi- } \\
\text { mum walking speed each } \\
\text { week. The average treadmill } \\
\text { speed increased from } 0.66 \\
\mathrm{~m} / \mathrm{s} \text { (SD } 0.39 \text { ) at the start } \\
\text { of training to } 0.79 \mathrm{~m} / \mathrm{s} \text { (SD } \\
0.47 \text { ) at the end of training. }\end{array}$ & $\begin{array}{l}\text { Speed-dependent } \\
\text { treadmill training } \\
\text { BWS: yes, no more } \\
\text { than } 10 \% \text { body } \\
\text { weight for the first } \\
3 \text { training sessions } \\
\text { only (participants } \\
\text { always wore an un- } \\
\text { weighted harness) } \\
\text { Hand support: not } \\
\text { reported } \\
\text { Assistance from ther- } \\
\text { apist: no } \\
\text { Limited progressive } \\
\text { treadmill training } \\
\text { BWs: yes, no more } \\
\text { than } 10 \% \text { body } \\
\text { weight for the first } 3 \\
\text { training sessions on- } \\
\text { ly }\end{array}$ & $\begin{array}{l}30 \mathrm{~min}- \\
\text { utes }\end{array}$ & $\begin{array}{l}3 \text { times } \\
\text { per week }\end{array}$ & 4 weeks & $\begin{array}{l}\text { Not task-orientat- } \\
\text { ed (neurophysio- } \\
\text { logical) }\end{array}$ & $\begin{array}{l}45 \mathrm{~min}- \\
\text { utes }\end{array}$ & $\begin{array}{l}3 \text { times } \\
\text { per week }\end{array}$ & 4 weeks \\
\hline & & $\begin{array}{l}\text { Hand support: not } \\
\text { reported }\end{array}$ & & & & & & & \\
\hline
\end{tabular}




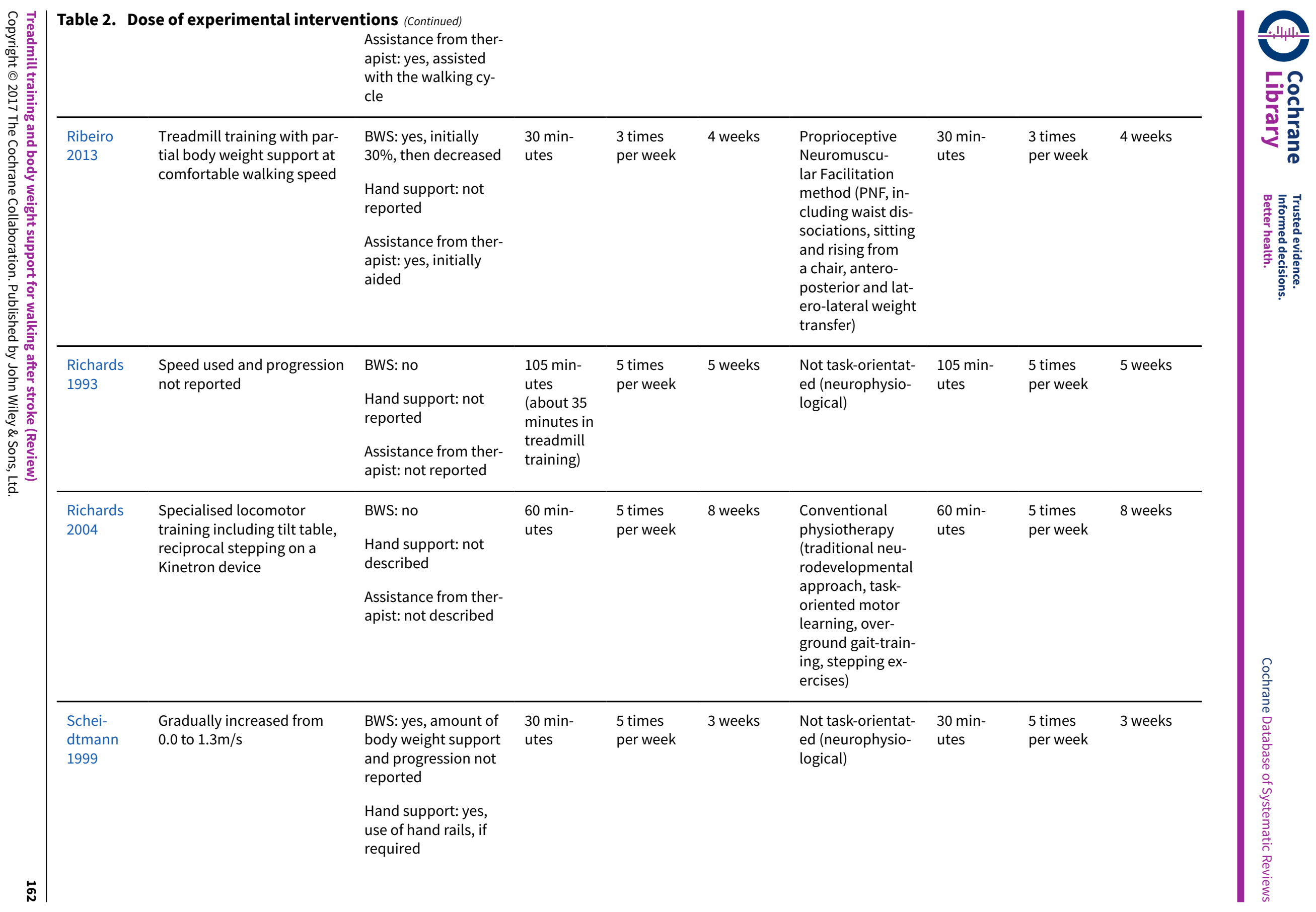




\begin{tabular}{|c|c|c|c|c|c|c|c|c|c|}
\hline & & $\begin{array}{l}\text { Assistance from ther- } \\
\text { apist: yes, assisted } \\
\text { with swing phase, } \\
\text { foot placement, hip } \\
\text { and knee extension } \\
\text { during stance phase, } \\
\text { and weight shift, if } \\
\text { required }\end{array}$ & & & & & & & \\
\hline $\begin{array}{l}\text { Smith } \\
2008\end{array}$ & $\begin{array}{l}\text { Participants walked for } 5 \\
\text { minutes with a "slightly } \\
\text { hard" rate of perceived ex- } \\
\text { ertion (RPE), then the speed } \\
\text { was increased by incre- } \\
\text { ments of } 0.2 \text { m/hour every } \\
10 \text { minutes of walking with } \\
\text { a "slightly hard" RPE }\end{array}$ & $\begin{array}{l}\text { BWS: not clearly stat- } \\
\text { ed } \\
\text { Hand support: not } \\
\text { reported } \\
\text { Assistance from } \\
\text { therapist: only if re- } \\
\text { quired, } 2 \text { partici- } \\
\text { pants needed slight } \\
\text { help with stepping } \\
\text { through for the first } 2 \\
\text { weeks }\end{array}$ & $\begin{array}{l}20 \text { min- } \\
\text { utes }\end{array}$ & $\begin{array}{l}12 \text { times } \\
\text { per month }\end{array}$ & 4 weeks & $\begin{array}{l}\text { Sham (week- } \\
\text { ly phone calls, } \\
\text { recording of a } \\
\text { daily life log) }\end{array}$ & $\begin{array}{l}\text { Not re- } \\
\text { ported }\end{array}$ & $\begin{array}{l}1 \text { tele- } \\
\text { phone call } \\
\text { per week }\end{array}$ & 4 weeks \\
\hline $\begin{array}{l}\text { Srivastava } \\
2016\end{array}$ & $\begin{array}{l}2 \text { treadmill groups: group } 1 \\
\text { with BWS and group } 2 \text { with- } \\
\text { out BWS at gradually in- } \\
\text { creased walking speed }\end{array}$ & $\begin{array}{l}\text { BWS: group } 1 \text { yes } \\
(40 \%), \text { group } 2 \text { no } \\
\text { Hand support: yes } \\
\text { Assistance from ther- } \\
\text { apist: not described }\end{array}$ & $\begin{array}{l}30 \text { min- } \\
\text { utes }\end{array}$ & $\begin{array}{l}5 \text { times } \\
\text { per week }\end{array}$ & 4 weeks & $\begin{array}{l}\text { Overground task- } \\
\text { oriented training }\end{array}$ & $\begin{array}{l}30 \mathrm{~min}- \\
\text { utes }\end{array}$ & $\begin{array}{l}5 \text { times } \\
\text { per week }\end{array}$ & 4 weeks \\
\hline $\begin{array}{l}\text { Sullivan } \\
2007\end{array}$ & $\begin{array}{l}\text { Initially } 4 \times 5 \text {-minute train- } \\
\text { ing bouts at individualised } \\
\text { speeds, initially within the } \\
\text { range of } 0.7 \text { to } 1.1 \mathrm{~m} / \mathrm{s} \text {, fol- } \\
\text { lowed by } 15 \text { m overground } \\
\text { walking and either (1) sham } \\
\text { or (2) progressive resistive } \\
\text { leg cycling, or (3) individu- } \\
\text { alised progressive resistive } \\
\text { strength training }\end{array}$ & $\begin{array}{l}\text { BWS: yes, initially be- } \\
\text { tween } 30 \% \text { and } 40 \% \\
\text { of the participant's } \\
\text { weight and being de- } \\
\text { creased as partici- } \\
\text { pants improved } \\
\text { Hand support: not } \\
\text { described } \\
\text { Assistance from ther- } \\
\text { apist: up to } 3 \text { ther- } \\
\text { apists assisting in } \\
\text { placing of both feet }\end{array}$ & $\begin{array}{l}60 \text { min- } \\
\text { utes }\end{array}$ & $\begin{array}{l}4 \text { times } \\
\text { per week }\end{array}$ & 6 weeks & $\begin{array}{l}\text { Sham (upper ex- } \\
\text { tremity cycle er- } \\
\text { gometry with } \\
\text { minimal physical } \\
\text { exertion) }\end{array}$ & $\begin{array}{l}60 \mathrm{~min}- \\
\text { utes }\end{array}$ & $\begin{array}{l}4 \text { times } \\
\text { per week }\end{array}$ & 6 weeks \\
\hline
\end{tabular}




\begin{tabular}{|c|c|c|c|c|c|c|c|c|c|}
\hline & & $\begin{array}{l}\text { and the pelvis, if nec- } \\
\text { essary }\end{array}$ & & & & & & & \\
\hline $\begin{array}{l}\text { Suputtita- } \\
\text { da } 2004\end{array}$ & $\begin{array}{l}\text { Speed was initiated from } \\
0.044 \mathrm{~m} / \mathrm{s} \text { for } 10 \text { minutes, } \\
\text { followed by a rest for } 5 \mathrm{~min} \text { - } \\
\text { utes and then increased by } \\
\text { increments of } 0.044 \mathrm{~m} / \mathrm{s} \text { for } \\
10 \text { minutes }\end{array}$ & $\begin{array}{l}\text { BWS: yes, } 30 \% \text { dur- } \\
\text { ing the first week, } \\
20 \% \text { during the sec- } \\
\text { ond week, } 10 \% \text { dur- } \\
\text { ing the third week, } \\
\text { and no BWS during } \\
\text { the fourth week } \\
\text { Hand support: un- } \\
\text { clear } \\
\text { Assistance from ther- } \\
\text { apist: initially } 2 \text { ther- } \\
\text { apists assisted in } \\
\text { placing the foot and } \\
\text { the pelvis }\end{array}$ & $\begin{array}{l}25 \text { min- } \\
\text { utes }\end{array}$ & $\begin{array}{l}7 \text { times } \\
\text { per week }\end{array}$ & 4 weeks & $\begin{array}{l}\text { Walking at a self- } \\
\text { adopted speed } \\
\text { on a } 15 \mathrm{~m} \text { walk- } \\
\text { way for } 10 \text { min- } \\
\text { utes, rested } 5 \\
\text { minutes, and } \\
\text { walked again } 10 \\
\text { minutes }\end{array}$ & $\begin{array}{l}25 \text { min- } \\
\text { utes }\end{array}$ & $\begin{array}{l}7 \text { times } \\
\text { per week }\end{array}$ & 4 weeks \\
\hline $\begin{array}{l}\text { Takami } \\
2010\end{array}$ & $\begin{array}{l}\text { For } 3 \text { minutes twice (with } \\
4 \text { minute rest); week } 1: 0.8 \\
\mathrm{~km} / \text { hour, week } 2: 1.0 \mathrm{~km} / \\
\text { hour, week } 3: 1.3 \mathrm{~km} / \text { hour }\end{array}$ & $\begin{array}{l}\text { BWS: yes 30\% } \\
\text { Hand support: yes, } \\
\text { use of hand rails, if } \\
\text { required } \\
\text { Assistance from ther- } \\
\text { apist: not described }\end{array}$ & $\begin{array}{l}30 \text { min- } \\
\text { utes con- } \\
\text { trol inter- } \\
\text { vention } \\
\text { followed } \\
\text { by } 10 \text { min- } \\
\text { utes tread- } \\
\text { mill train- } \\
\text { ing either } \\
\text { in forward } \\
\text { or back- } \\
\text { ward di- } \\
\text { rection }\end{array}$ & $\begin{array}{l}3 \text { times } \\
\text { per week }\end{array}$ & 4 weeks & $\begin{array}{l}\text { Conventional } \\
\text { training (stretch- } \\
\text { ing, strengthen- } \\
\text { ing), including } \\
\text { overground walk- } \\
\text { ing }<200 \text { m and } \\
\text { ADL training }\end{array}$ & $\begin{array}{l}80 \text { min- } \\
\text { utes }\end{array}$ & $\begin{array}{l}5.5 \text { times } \\
\text { per week }\end{array}$ & 4 weeks \\
\hline $\begin{array}{l}\text { Toledano- } \\
\text { Zarhi } 2011\end{array}$ & $\begin{array}{l}\text { Intervention consisted of } \\
\text { treadmill training, training } \\
\text { on a hand bike machine, } \\
\text { and a stationary bicycle }\end{array}$ & $\begin{array}{l}\text { BWS: not stated } \\
\text { Hand support: not } \\
\text { stated } \\
\text { Assistance from ther- } \\
\text { apist: not stated }\end{array}$ & $\begin{array}{l}90 \text { min- } \\
\text { utes exer- } \\
\text { cise train- } \\
\text { ing, in- } \\
\text { cluding } 35 \\
\text { to } 55 \text { min- } \\
\text { utes tread- } \\
\text { mill train- } \\
\text { ing }\end{array}$ & $\begin{array}{l}2 \text { times } \\
\text { per week }\end{array}$ & 6 weeks & $\begin{array}{l}\text { Home exercise } \\
\text { booklet with in- } \\
\text { cluded instruc- } \\
\text { tions for flexibil- } \\
\text { ity and muscle } \\
\text { strength exercis- } \\
\text { es, participants } \\
\text { were encouraged } \\
\text { to stick to their } \\
\text { normal commu- } \\
\text { nity routine }\end{array}$ & NA & NA & 6 weeks \\
\hline
\end{tabular}




\begin{tabular}{|c|c|c|c|c|c|c|c|c|c|}
\hline $\begin{array}{l}\text { Visintin } \\
1998\end{array}$ & $\begin{array}{l}\text { Gradually increased in in- } \\
\text { crements of } 0.04 \mathrm{~m} / \mathrm{s} \text {, from } \\
0.23 \text { to } 0.42 \mathrm{~m} / \mathrm{s} \text {, on aver- } \\
\text { age, on an individual basis }\end{array}$ & $\begin{array}{l}\text { BWS: yes, starting } \\
\text { at } 40 \% \text { body weight } \\
\text { and progressively } \\
\text { decreased to } 0 \% \\
\text { Hand support: yes, } \\
\text { use of hand rails, if } \\
\text { required } \\
\text { Assistance from ther- } \\
\text { apist: yes, assisted } \\
\text { with stepping and } \\
\text { limb control during } \\
\text { stance and swing } \\
\text { phases, and weight } \\
\text { shift, if required }\end{array}$ & $\begin{array}{l}20 \mathrm{~min}- \\
\text { utes }\end{array}$ & $\begin{array}{l}4 \text { times } \\
\text { per week }\end{array}$ & 6 weeks & $\begin{array}{l}\text { Task-orientated } \\
\text { (treadmill only) } \\
\text { - gradually in- } \\
\text { creased speed } \\
\text { from } 0.19 \text { to } 0.34 \\
\mathrm{~m} / \mathrm{s} \text {, on average, } \\
\text { on an individual } \\
\text { basis }\end{array}$ & $\begin{array}{l}20 \mathrm{~min}- \\
\text { utes }\end{array}$ & $\begin{array}{l}4 \text { times } \\
\text { per week }\end{array}$ & 6 weeks \\
\hline Weng 2004 & $\begin{array}{l}\text { Initial speed was half of the } \\
\text { measured maximal walk- } \\
\text { ing speed prior to training } \\
\text { session for } 5 \text { minutes as a } \\
\text { warm-up, then intervals of } \\
\text { higher speed for } 10 \text { s were } \\
\text { delivered, returning back to } \\
\text { warm-up speed for } 2 \text { min- } \\
\text { utes; in the next phase the } \\
\text { speed would be increased } \\
\text { or decreased by } 10 \% \text {, re- } \\
\text { spectively }\end{array}$ & $\begin{array}{l}\text { BWS: no } \\
\text { Hand support: un- } \\
\text { clear } \\
\text { Assistance from ther- } \\
\text { apist: yes, assisted } \\
\text { with foot placing and } \\
\text { pelvis rotation }\end{array}$ & $\begin{array}{l}20 \mathrm{~min}- \\
\text { utes }\end{array}$ & $\begin{array}{l}5 \text { times } \\
\text { per week }\end{array}$ & 4 weeks & $\begin{array}{l}\text { Neuromuscular } \\
\text { facilitation tech- } \\
\text { niques }\end{array}$ & $\begin{array}{l}20 \mathrm{~min}- \\
\text { utes }\end{array}$ & $\begin{array}{l}5 \text { times } \\
\text { per week }\end{array}$ & 4 weeks \\
\hline Weng 2006 & $\begin{array}{l}\text { Participants walked back- } \\
\text { wards on a treadmill with } \\
\text { increasing speed }\end{array}$ & $\begin{array}{l}\text { BWS: no } \\
\text { Hand support: un- } \\
\text { clear } \\
\text { Assistance from ther- } \\
\text { apist: yes; assisted } \\
\text { with foot placing and } \\
\text { pelvis rotation }\end{array}$ & $\begin{array}{l}30 \text { min- } \\
\text { utes of } \\
\text { control in- } \\
\text { tervention } \\
\text { and } 30 \\
\text { minutes of } \\
\text { treadmill } \\
\text { training }\end{array}$ & $\begin{array}{l}5 \text { times } \\
\text { per week }\end{array}$ & 3 weeks & $\begin{array}{l}\text { Neuromuscular } \\
\text { facilitation tech- } \\
\text { niques including } \\
\text { lower limb move- } \\
\text { ments and over- } \\
\text { ground gait exer- } \\
\text { cises }\end{array}$ & $\begin{array}{l}60 \mathrm{~min}- \\
\text { utes }\end{array}$ & $\begin{array}{l}5 \text { times } \\
\text { per week }\end{array}$ & 3 weeks \\
\hline $\begin{array}{l}\text { Werner } \\
2002 a\end{array}$ & $\begin{array}{l}\text { Increased from a mean of } \\
0.32(S D 0.05) \mathrm{m} / \mathrm{s} \text { at base- } \\
\text { line on an individual basis }\end{array}$ & $\begin{array}{l}\text { BWS: yes, starting at } \\
\text { a mean of } 8.93 \% \text { (SD } \\
1.84 \text { ) body weight } \\
\text { and progressively } \\
\text { decreased }\end{array}$ & $\begin{array}{l}15 \text { to } 20 \\
\text { minutes }\end{array}$ & $\begin{array}{l}5 \text { times } \\
\text { per week }\end{array}$ & 2 weeks & Task-orientated & $\begin{array}{l}15 \text { to } 20 \\
\text { minutes }\end{array}$ & $\begin{array}{l}5 \text { times } \\
\text { per week }\end{array}$ & 2 weeks \\
\hline
\end{tabular}




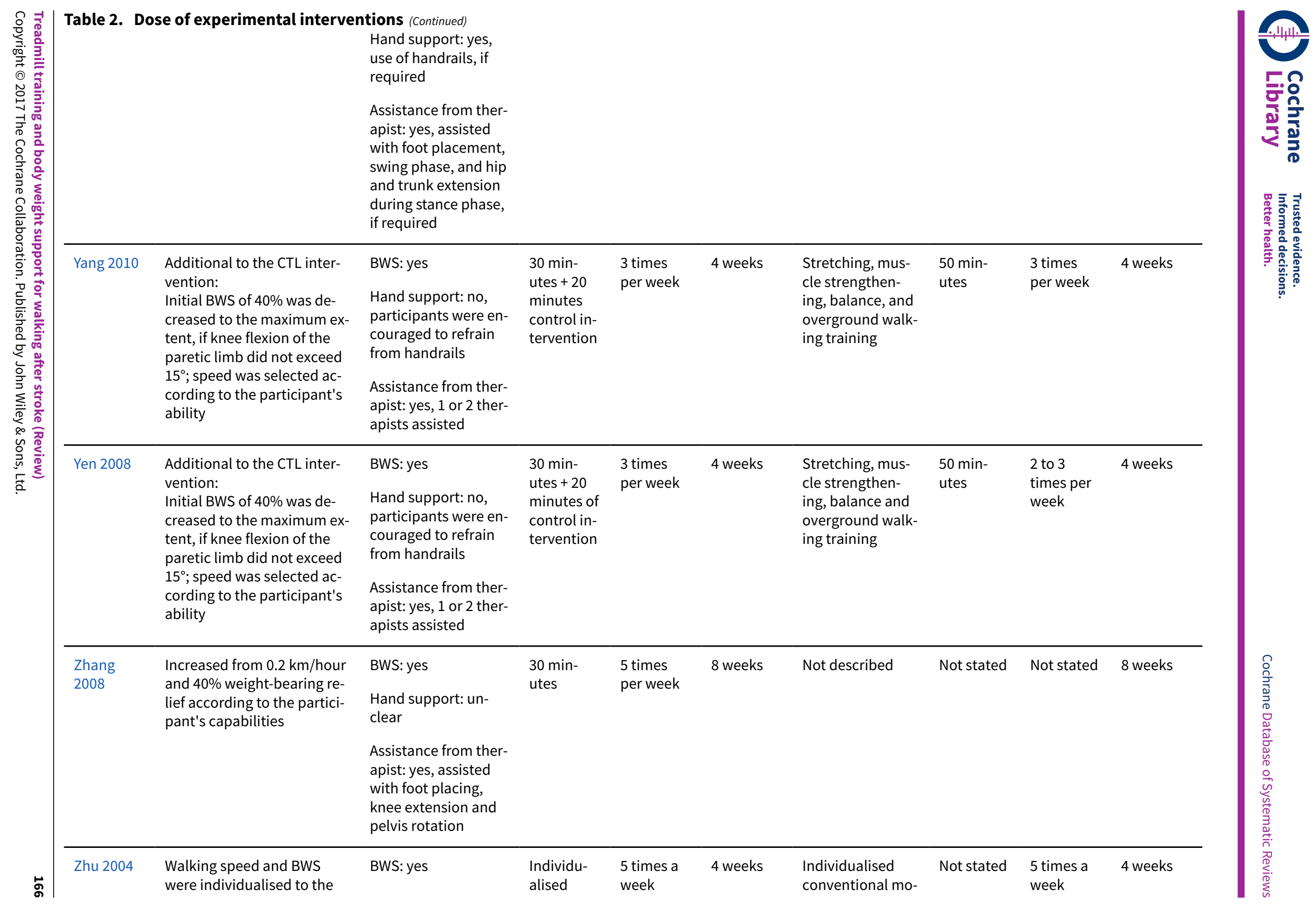


Table 2. Dose of experimental interventions (Continued)

participants' capabilities Hand support: un-

tor rehabilitation

aiming at improv-

(with a mean walking speed

clear

ing strength and

$0.17 \mathrm{~m} / \mathrm{s}$ at the end of the

Assistance from ther-

endurance

intervention phase)

apist: unclear

ADL: activities of daily living

BWS: body weight support

BWSTT: body weight support treadmill training

CTL: control

EXP: experimental

GT: gait trainer

HRR: heart rate reserve

NA: not applicable

PNF: Proprioceptive Neuromuscular Facilitation

RPE: rate of perceived exertion

SE: standard error

SD: standard deviation

TTBWS: treadmill training with body weight support

VO2: volume of oxygen consumption 
Table 3. Adverse events during the treatment

\begin{tabular}{|c|c|c|c|c|}
\hline Study ID & Injurious falls & Other injuries & Cardiovascular event & Other adverse event \\
\hline Ada 2003 & $\begin{array}{l}\text { EXP }=1 \text { (hip fracture } \\
\text { caused by a fall at } \\
\text { home after the first } \\
\text { week of training) } \\
\text { CTL = } 0\end{array}$ & $\begin{array}{l}\text { EXP = } 1 \text { (missed post- } \\
\text { treatment measure- } \\
\text { ment session due to } \\
\text { low back pain) } \\
C T L=0\end{array}$ & $\begin{array}{l}\mathrm{EXP}=0 \\
\mathrm{CTL}=0\end{array}$ & $\begin{array}{l}\text { EXP }=1 \text { (fall during overground com- } \\
\text { ponent of training but no injuries } \\
\text { sustained) } \\
C T L=0\end{array}$ \\
\hline Ada 2010 & $\begin{array}{l}\mathrm{EXP}=0 \\
C T L=0\end{array}$ & $\begin{array}{l}\mathrm{EXP}=0 \\
C T L=0\end{array}$ & $\begin{array}{l}\mathrm{EXP}=0 \\
C T L=0\end{array}$ & $\begin{array}{l}\text { EXP }=47 \text { reports } \\
C T L=27 \text { reports }\end{array}$ \\
\hline
\end{tabular}

All reports included musculoskeletal problems (back, hip, knee, calf, foot pain, and gout), headaches, dizziness, or chest pain. There were 6 reports of falling, 1 of which resulted in a fracture and none of which occurred during the delivery of the intervention.

2 participants in the experimental group experienced anxiety attributable to being on a treadmill that was severe enough for them to withdraw from the study.

\begin{tabular}{|c|c|c|c|c|}
\hline Ada 2013 & $\begin{array}{l}\mathrm{EXP}=\text { not reported } \\
\mathrm{CTL}=\text { not reported }\end{array}$ & $\begin{array}{l}\mathrm{EXP}=\text { not reported } \\
\mathrm{CTL}=\text { not reported }\end{array}$ & $\begin{array}{l}\mathrm{EXP}=\text { not reported } \\
\mathrm{CTL}=\text { not reported }\end{array}$ & $\begin{array}{l}\mathrm{EXP}=\text { not reported } \\
\mathrm{CTL}=\text { not reported }\end{array}$ \\
\hline Bonnyaud 2013 & $\begin{array}{l}\mathrm{EXP}=0 \\
\mathrm{CTL}=0\end{array}$ & $\begin{array}{l}\mathrm{EXP}=0 \\
\mathrm{CTL}=0\end{array}$ & $\begin{array}{l}\mathrm{EXP}=0 \\
\mathrm{CTL}=0\end{array}$ & $\begin{array}{l}\mathrm{EXP}=0 \\
\mathrm{CTL}=0\end{array}$ \\
\hline Bonnyaud 2013a & $\begin{array}{l}\mathrm{EXP}=0 \\
\mathrm{CTL}=0\end{array}$ & $\begin{array}{l}\mathrm{EXP}=0 \\
\mathrm{CTL}=0\end{array}$ & $\begin{array}{l}\mathrm{EXP}=0 \\
\mathrm{CTL}=0\end{array}$ & $\begin{array}{l}\mathrm{EXP}=0 \\
\mathrm{CTL}=0\end{array}$ \\
\hline $\begin{array}{l}\text { Combs-Miller } \\
2014\end{array}$ & $\begin{array}{l}\text { EXP }=0 \\
C T L=0\end{array}$ & $\begin{array}{l}\text { EXP }=0 \\
C T L=0\end{array}$ & $\begin{array}{l}\text { EXP }=0 \\
C T L=0\end{array}$ & $\begin{array}{l}\text { EXP }=0 \\
C T L=0\end{array}$ \\
\hline $\begin{array}{l}\text { Da Cunha Filho } \\
2002\end{array}$ & $\begin{array}{l}\text { EXP }=0 \\
C T L=0\end{array}$ & $\begin{array}{l}\mathrm{EXP}=0 \\
\mathrm{CTL}=0\end{array}$ & $\begin{array}{l}\text { EXP }=0 \\
C T L=0\end{array}$ & $\begin{array}{l}\text { EXP }=0 \\
C T L=0\end{array}$ \\
\hline Deniz 2011 & $\begin{array}{l}\mathrm{EXP}=\text { not reported } \\
\mathrm{CTL}=\text { not reported }\end{array}$ & $\begin{array}{l}\mathrm{EXP}=\text { not reported } \\
\mathrm{CTL}=\text { not reported }\end{array}$ & $\begin{array}{l}\mathrm{EXP}=\text { not reported } \\
\mathrm{CTL}=\text { not reported }\end{array}$ & $\begin{array}{l}\mathrm{EXP}=\text { not reported } \\
\mathrm{CTL}=\text { not reported }\end{array}$ \\
\hline DePaul 2015 & $\begin{array}{l}\mathrm{EXP}=\text { not reported } \\
\mathrm{CTL}=\text { not reported }\end{array}$ & $\begin{array}{l}\mathrm{EXP}=\text { not reported } \\
\mathrm{CTL}=\text { not reported }\end{array}$ & $\begin{array}{l}\mathrm{EXP}=\text { not reported } \\
\mathrm{CTL}=\text { not reported }\end{array}$ & $\begin{array}{l}\mathrm{EXP}=\text { not reported } \\
\mathrm{CTL}=\text { not reported }\end{array}$ \\
\hline Du 2006 & $\begin{array}{l}\mathrm{EXP}=\text { not reported } \\
\mathrm{CTL}=\text { not reported }\end{array}$ & $\begin{array}{l}\mathrm{EXP}=\text { not reported } \\
\mathrm{CTL}=\text { not reported }\end{array}$ & $\begin{array}{l}\mathrm{EXP}=\text { not reported } \\
\mathrm{CTL}=\text { not reported }\end{array}$ & $\begin{array}{l}\mathrm{EXP}=\text { not reported } \\
\mathrm{CTL}=\text { not reported }\end{array}$ \\
\hline Duncan 2011 & $\begin{array}{l}\mathrm{EXP}=0 \\
\mathrm{CTL}=0\end{array}$ & $\begin{array}{l}\mathrm{EXP}=16 \text { (fracture) } \\
\mathrm{CTL}=\text { not reported }\end{array}$ & $\begin{array}{l}\text { EXP }=1 \text { (myocardial } \\
\text { infarction) } \\
C T L=1 \text { (myocardial } \\
\text { infarction) }\end{array}$ & $\begin{array}{l}\mathrm{EXP}=139+143 \text { (all reported events) } \\
\mathrm{CTL}=126 \text { (all reported events) }\end{array}$ \\
\hline Eich 2004 & $\begin{array}{l}\mathrm{EXP}=0 \\
\mathrm{CTL}=0\end{array}$ & $\begin{array}{l}\text { EXP }=0 \\
C T L=0\end{array}$ & $\begin{array}{l}\text { EXP }=0 \\
C T L=0\end{array}$ & $\begin{array}{l}\mathrm{EXP}=0 \\
\mathrm{CTL}=0\end{array}$ \\
\hline
\end{tabular}


Table 3. Adverse events during the treatment (Continued)

\begin{tabular}{|c|c|c|c|c|}
\hline $\begin{array}{l}\text { Franceschini } \\
2009\end{array}$ & $\begin{array}{l}\mathrm{EXP}=\text { not reported } \\
\mathrm{CTL}=\text { not reported }\end{array}$ & $\begin{array}{l}\mathrm{EXP}=\text { not reported } \\
\mathrm{CTL}=\text { not reported }\end{array}$ & $\begin{array}{l}\mathrm{EXP}=\text { not reported } \\
\mathrm{CTL}=\text { not reported }\end{array}$ & $\begin{array}{l}\mathrm{EXP}=\text { not reported } \\
\mathrm{CTL}=\text { not reported }\end{array}$ \\
\hline Gama 2017 & $\begin{array}{l}\mathrm{EXP}=0 \\
\mathrm{CTL}=0\end{array}$ & $\begin{array}{l}\mathrm{EXP}=0 \\
\mathrm{CTL}=0\end{array}$ & $\begin{array}{l}\mathrm{EXP}=0 \\
\mathrm{CTL}=0\end{array}$ & $\begin{array}{l}\mathrm{EXP}=0 \\
\mathrm{CTL}=0\end{array}$ \\
\hline Gan 2012 & $\begin{array}{l}\mathrm{EXP}=\text { not reported } \\
\mathrm{CTL}=\text { not reported }\end{array}$ & $\begin{array}{l}\mathrm{EXP}=\text { not reported } \\
\mathrm{CTL}=\text { not reported }\end{array}$ & $\begin{array}{l}\mathrm{EXP}=\text { not reported } \\
\mathrm{CTL}=\text { not reported }\end{array}$ & $\begin{array}{l}\mathrm{EXP}=\text { not reported } \\
\mathrm{CTL}=\text { not reported }\end{array}$ \\
\hline Globas 2011 & $\begin{array}{l}\mathrm{EXP}=0 \\
\mathrm{CTL}=0\end{array}$ & $\begin{array}{l}\mathrm{EXP}=0 \\
\mathrm{CTL}=0\end{array}$ & $\begin{array}{l}\mathrm{EXP}=0 \\
\mathrm{CTL}=0\end{array}$ & $\begin{array}{l}\text { EXP }=1 \text { recurrent stroke, } 1 \text { trans- } \\
\text { portation problem } \\
C T L=0\end{array}$ \\
\hline Hoyer 2012 & $\begin{array}{l}\mathrm{EXP}=\text { not reported } \\
\mathrm{CTL}=\text { not reported }\end{array}$ & $\begin{array}{l}\mathrm{EXP}=\text { not reported } \\
\mathrm{CTL}=\text { not reported }\end{array}$ & $\begin{array}{l}\mathrm{EXP}=\text { not reported } \\
\mathrm{CTL}=\text { not reported }\end{array}$ & $\begin{array}{l}\mathrm{EXP}=\text { not reported } \\
\mathrm{CTL}=\text { not reported }\end{array}$ \\
\hline Jaffe 2004 & $\begin{array}{l}\mathrm{EXP}=0 \\
\mathrm{CTL}=0\end{array}$ & $\begin{array}{l}\mathrm{EXP}=0 \\
\mathrm{CTL}=0\end{array}$ & $\begin{array}{l}\mathrm{EXP}=0 \\
\mathrm{CTL}=0\end{array}$ & $\begin{array}{l}\mathrm{EXP}=0 \\
\mathrm{CTL}=0\end{array}$ \\
\hline Kang 2012 & $\begin{array}{l}\text { EXP }=\text { not reported } \\
C T L=\text { not reported }\end{array}$ & $\begin{array}{l}\mathrm{EXP}=\text { not reported } \\
\mathrm{CTL}=\text { not reported }\end{array}$ & $\begin{array}{l}\mathrm{EXP}=\text { not reported } \\
\mathrm{CTL}=\text { not reported }\end{array}$ & $\begin{array}{l}\mathrm{EXP}=\text { not reported } \\
\mathrm{CTL}=\text { not reported }\end{array}$ \\
\hline Kim 2011 & $\begin{array}{l}\mathrm{EXP}=\text { not reported } \\
\mathrm{CTL}=\text { not reported }\end{array}$ & $\begin{array}{l}\mathrm{EXP}=\text { not reported } \\
\mathrm{CTL}=\text { not reported }\end{array}$ & $\begin{array}{l}\mathrm{EXP}=\text { not reported } \\
\mathrm{CTL}=\text { not reported }\end{array}$ & $\begin{array}{l}\mathrm{EXP}=\text { not reported } \\
\mathrm{CTL}=\text { not reported }\end{array}$ \\
\hline Kim 2016 & $\begin{array}{l}\mathrm{EXP}=\text { not reported } \\
\mathrm{CTL}=\text { not reported }\end{array}$ & $\begin{array}{l}\mathrm{EXP}=\text { not reported } \\
\mathrm{CTL}=\text { not reported }\end{array}$ & $\begin{array}{l}\mathrm{EXP}=\text { not reported } \\
\mathrm{CTL}=\text { not reported }\end{array}$ & $\begin{array}{l}\mathrm{EXP}=\text { not reported } \\
\mathrm{CTL}=\text { not reported }\end{array}$ \\
\hline Kosak 2000 & $\begin{array}{l}\text { EXP }=0 \\
C T L=0\end{array}$ & $\begin{array}{l}\mathrm{EXP}=0 \\
C T L=0\end{array}$ & $\begin{array}{l}\text { EXP }=1 \text { (acute myocar- } \\
\text { dial infarction } 2 \text { days } \\
\text { after last treatment } \\
\text { session) } \\
\text { CTL = } 1 \text { (stroke pro- } \\
\text { gression) }\end{array}$ & $\begin{array}{l}\text { EXP }=0 \\
C T L=0\end{array}$ \\
\hline Kuys 2011 & $\begin{array}{l}\mathrm{EXP}=0 \\
\mathrm{CTL}=0\end{array}$ & $\begin{array}{l}\mathrm{EXP}=0 \\
\mathrm{CTL}=0\end{array}$ & $\begin{array}{l}\mathrm{EXP}=0 \\
\mathrm{CTL}=0\end{array}$ & $\begin{array}{l}\mathrm{EXP}=0 \\
\mathrm{CTL}=0\end{array}$ \\
\hline $\begin{array}{l}\text { Langhammer } \\
2010\end{array}$ & $\begin{array}{l}\mathrm{EXP}=\text { not reported } \\
\mathrm{CTL}=\text { not reported }\end{array}$ & $\begin{array}{l}\mathrm{EXP}=\text { not reported } \\
\mathrm{CTL}=\text { not reported }\end{array}$ & $\begin{array}{l}\mathrm{EXP}=\text { not reported } \\
\mathrm{CTL}=\text { not reported }\end{array}$ & $\begin{array}{l}\mathrm{EXP}=\text { not reported } \\
\mathrm{CTL}=\text { not reported }\end{array}$ \\
\hline Laufer 2001 & $\begin{array}{l}\mathrm{EXP}=0 \\
\mathrm{CTL}=0\end{array}$ & $\begin{array}{l}\mathrm{EXP}=0 \\
\mathrm{CTL}=0\end{array}$ & $\begin{array}{l}\mathrm{EXP}=0 \\
\mathrm{CTL}=0\end{array}$ & $\begin{array}{l}\mathrm{EXP}=0 \\
\mathrm{CTL}=0\end{array}$ \\
\hline Liston 2000 & $\begin{array}{l}\mathrm{EXP}=0 \\
\mathrm{CTL}=\text { not reported }\end{array}$ & $\begin{array}{l}\text { EXP }=1 \text { (knee pain af- } \\
\text { ter first } 4 \text { treadmill } \\
\text { sessions) } \\
C T L=\text { not reported }\end{array}$ & $\begin{array}{l}\mathrm{EXP}=0 \\
\mathrm{CTL}=\text { not reported }\end{array}$ & $\begin{array}{l}\text { EXP = } 1 \text { (hospitalised after first train- } \\
\text { ing session and subsequently died, } \\
\text { reason for hospitalisation not re- } \\
\text { ported) } \\
C T L=\text { not reported }\end{array}$ \\
\hline Luft 2008 & $\begin{array}{l}\text { EXP }=\text { not reported } \\
C T L=\text { not reported }\end{array}$ & $\begin{array}{l}\mathrm{EXP}=\text { not reported } \\
\mathrm{CTL}=\text { not reported }\end{array}$ & $\begin{array}{l}\mathrm{EXP}=\text { not reported } \\
\mathrm{CTL}=\text { not reported }\end{array}$ & $\begin{array}{l}\mathrm{EXP}=\text { not reported } \\
\mathrm{CTL}=\text { not reported }\end{array}$ \\
\hline $\begin{array}{l}\text { MacKay-Lyons } \\
2013\end{array}$ & $\begin{array}{l}\mathrm{EXP}=0 \\
\mathrm{CTL}=0\end{array}$ & $\begin{array}{l}\mathrm{EXP}=0 \\
\mathrm{CTL}=0\end{array}$ & $\begin{array}{l}\mathrm{EXP}=0 \\
\mathrm{CTL}=0\end{array}$ & $\begin{array}{l}\mathrm{EXP}=0 \\
\mathrm{CTL}=0\end{array}$ \\
\hline
\end{tabular}


Table 3. Adverse events during the treatment (Continued)
Macko 2005
$\mathrm{EXP}=0$
EXP $=0$
$\operatorname{EXP}=0$
$\mathrm{CTL}=0$
$\mathrm{CTL}=0$
$\mathrm{CTL}=0$

EXP $=11$ (5 falls during treadmill

training but no injuries sustained; 6

minor medical complications)

$\mathrm{CTL}=0$

\begin{tabular}{|c|c|c|c|c|}
\hline Mao 2015 & $\begin{array}{l}\mathrm{EXP}=\text { not reported } \\
\mathrm{CTL}=\text { not reported }\end{array}$ & $\begin{array}{l}\mathrm{EXP}=\text { not reported } \\
\mathrm{CTL}=\text { not reported }\end{array}$ & $\begin{array}{l}\mathrm{EXP}=\text { not reported } \\
\mathrm{CTL}=\text { not reported }\end{array}$ & $\begin{array}{l}\mathrm{EXP}=\text { not reported } \\
\mathrm{CTL}=\text { not reported }\end{array}$ \\
\hline Mehrberg 2001 & $\begin{array}{l}\text { EXP }=\text { not reported } \\
C T L=\text { not reported }\end{array}$ & $\begin{array}{l}\mathrm{EXP}=\text { not reported } \\
\mathrm{CTL}=\text { not reported }\end{array}$ & $\begin{array}{l}\mathrm{EXP}=\text { not reported } \\
\mathrm{CTL}=\text { not reported }\end{array}$ & $\begin{array}{l}\mathrm{EXP}=\text { not reported } \\
\mathrm{CTL}=\text { not reported }\end{array}$ \\
\hline Middleton 2014 & $\begin{array}{l}\mathrm{EXP}=\text { not reported } \\
\mathrm{CTL}=\text { not reported }\end{array}$ & $\begin{array}{l}\mathrm{EXP}=\text { not reported } \\
\mathrm{CTL}=\text { not reported }\end{array}$ & $\begin{array}{l}\mathrm{EXP}=\text { not reported } \\
\mathrm{CTL}=\text { not reported }\end{array}$ & $\begin{array}{l}\mathrm{EXP}=\text { not reported } \\
\mathrm{CTL}=\text { not reported }\end{array}$ \\
\hline Moore 2010 & $\begin{array}{l}\mathrm{EXP}=0 \\
\mathrm{CTL}=0\end{array}$ & $\begin{array}{l}\mathrm{EXP}=0 \\
\mathrm{CTL}=0\end{array}$ & $\begin{array}{l}\mathrm{EXP}=0 \\
\mathrm{CTL}=0\end{array}$ & $\begin{array}{l}\mathrm{EXP}=0 \\
\mathrm{CTL}=0\end{array}$ \\
\hline Nilsson 2001 & $\begin{array}{l}\mathrm{EXP}=0 \\
\mathrm{CTL}=0\end{array}$ & $\begin{array}{l}\mathrm{EXP}=0 \\
\mathrm{CTL}=0\end{array}$ & $\begin{array}{l}\mathrm{EXP}=0 \\
\mathrm{CTL}=0\end{array}$ & $\begin{array}{l}\mathrm{EXP}=0 \\
\mathrm{CTL}=0\end{array}$ \\
\hline Olawale 2009 & $\begin{array}{l}\mathrm{EXP}=\text { not reported } \\
\mathrm{CTL}=\text { not reported }\end{array}$ & $\begin{array}{l}\mathrm{EXP}=\text { not reported } \\
\mathrm{CTL}=\text { not reported }\end{array}$ & $\begin{array}{l}\mathrm{EXP}=\text { not reported } \\
\mathrm{CTL}=\text { not reported }\end{array}$ & $\begin{array}{l}\mathrm{EXP}=\text { not reported } \\
\mathrm{CTL}=\text { not reported }\end{array}$ \\
\hline Park 2013 & $\begin{array}{l}\mathrm{EXP}=\text { not reported } \\
\mathrm{CTL}=\text { not reported }\end{array}$ & $\begin{array}{l}\mathrm{EXP}=\text { not reported } \\
\mathrm{CTL}=\text { not reported }\end{array}$ & $\begin{array}{l}\mathrm{EXP}=\text { not reported } \\
\mathrm{CTL}=\text { not reported }\end{array}$ & $\begin{array}{l}\mathrm{EXP}=\text { not reported } \\
\mathrm{CTL}=\text { not reported }\end{array}$ \\
\hline Park 2015 & $\begin{array}{l}\mathrm{EXP}=\text { not reported } \\
\mathrm{CTL}=\text { not reported }\end{array}$ & $\begin{array}{l}\mathrm{EXP}=\text { not reported } \\
\mathrm{CTL}=\text { not reported }\end{array}$ & $\begin{array}{l}\mathrm{EXP}=\text { not reported } \\
\mathrm{CTL}=\text { not reported }\end{array}$ & $\begin{array}{l}\mathrm{EXP}=\text { not reported } \\
\mathrm{CTL}=\text { not reported }\end{array}$ \\
\hline Pohl 2002 & $\begin{array}{l}\operatorname{EXP} 1=0 \\
\operatorname{EXP} 2=0 \\
C T L=0\end{array}$ & $\begin{array}{l}\operatorname{EXP} 1=0 \\
\operatorname{EXP} 2=0 \\
C T L=0\end{array}$ & $\begin{array}{l}\operatorname{EXP} 1=0 \\
\operatorname{EXP} 2=0 \\
C T L=0\end{array}$ & $\begin{array}{l}\text { EXP } 1=0 \\
\text { EXP } 2=1 \text { (vertigo, but did not have } \\
\text { to terminate training) } \\
\mathrm{CTL}=0\end{array}$ \\
\hline Ribeiro 2013 & $\begin{array}{l}\mathrm{EXP}=\text { not reported } \\
\mathrm{CTL}=\text { not reported }\end{array}$ & $\begin{array}{l}\mathrm{EXP}=\text { not reported } \\
\mathrm{CTL}=\text { not reported }\end{array}$ & $\begin{array}{l}\mathrm{EXP}=\text { not reported } \\
\mathrm{CTL}=\text { not reported }\end{array}$ & $\begin{array}{l}\mathrm{EXP}=\text { not reported } \\
\mathrm{CTL}=\text { not reported }\end{array}$ \\
\hline Richards 1993 & $\begin{array}{l}\mathrm{EXP}=\text { not reported } \\
\mathrm{CTL}=\text { not reported }\end{array}$ & $\begin{array}{l}\mathrm{EXP}=\text { not reported } \\
\mathrm{CTL}=\text { not reported }\end{array}$ & $\begin{array}{l}\mathrm{EXP}=\text { not reported } \\
\mathrm{CTL}=\text { not reported }\end{array}$ & $\begin{array}{l}\mathrm{EXP}=\text { not reported } \\
\mathrm{CTL}=\text { not reported }\end{array}$ \\
\hline Richards 2004 & $\begin{array}{l}E X P=\text { not reported } \\
C T L=\text { not reported }\end{array}$ & $\begin{array}{l}\mathrm{EXP}=1 \text { (hip fracture) } \\
C T L=\text { not reported }\end{array}$ & $\begin{array}{l}\text { EXP }=1 \text { (cardiac prob- } \\
\text { lems) } \\
C T L=\text { not reported }\end{array}$ & $\begin{array}{l}\mathrm{EXP}=\text { not reported } \\
\mathrm{CTL}=\text { not reported }\end{array}$ \\
\hline $\begin{array}{l}\text { Scheidtmann } \\
1999\end{array}$ & $\begin{array}{l}\mathrm{EXP}=0 \\
\mathrm{CTL}=0\end{array}$ & $\begin{array}{l}\mathrm{EXP}=0 \\
\mathrm{CTL}=0\end{array}$ & $\begin{array}{l}\mathrm{EXP}=0 \\
\mathrm{CTL}=0\end{array}$ & $\begin{array}{l}\mathrm{EXP}=0 \\
\mathrm{CTL}=0\end{array}$ \\
\hline Smith 2008 & $\begin{array}{l}E X P=\text { not reported } \\
C T L=\text { not reported }\end{array}$ & $\begin{array}{l}\mathrm{EXP}=\text { not reported } \\
\mathrm{CTL}=\text { not reported }\end{array}$ & $\begin{array}{l}\mathrm{EXP}=\text { not reported } \\
\mathrm{CTL}=\text { not reported }\end{array}$ & $\begin{array}{l}\mathrm{EXP}=\text { not reported } \\
\mathrm{CTL}=\text { not reported }\end{array}$ \\
\hline Srivastava 2016 & $\begin{array}{l}E X P=\text { not reported } \\
C T L=\text { not reported }\end{array}$ & $\begin{array}{l}\mathrm{EXP}=\text { not reported } \\
\mathrm{CTL}=\text { not reported }\end{array}$ & $\begin{array}{l}\mathrm{EXP}=\text { not reported } \\
\mathrm{CTL}=\text { not reported }\end{array}$ & $\begin{array}{l}\mathrm{EXP}=\text { not reported } \\
\mathrm{CTL}=\text { not reported }\end{array}$ \\
\hline Sullivan 2007 & $\begin{array}{l}\mathrm{EXP}=7 \\
\mathrm{CTL}=2\end{array}$ & & & \\
\hline Suputtitada 2004 & EXP $=$ not reported & EXP $=$ not reported & EXP $=$ not reported & EXP $=$ not reported \\
\hline
\end{tabular}


Table 3. Adverse events during the treatment (Continued)

\begin{tabular}{|c|c|c|c|c|}
\hline & $\mathrm{CTL}=$ not reported & $\mathrm{CTL}=$ not reported & $\mathrm{CTL}=$ not reported & $\mathrm{CTL}=$ not reported \\
\hline Takami 2010 & $\begin{array}{l}\mathrm{EXP}=\text { not reported } \\
\mathrm{CTL}=\text { not reported }\end{array}$ & $\begin{array}{l}\mathrm{EXP}=\text { not reported } \\
\mathrm{CTL}=\text { not reported }\end{array}$ & $\begin{array}{l}\mathrm{EXP}=\text { not reported } \\
\mathrm{CTL}=\text { not reported }\end{array}$ & $\begin{array}{l}\mathrm{EXP}=\text { not reported } \\
\mathrm{CTL}=\text { not reported }\end{array}$ \\
\hline $\begin{array}{l}\text { Toledano-Zarhi } \\
2011\end{array}$ & $\begin{array}{l}\mathrm{EXP}=0 \\
\mathrm{CTL}=0\end{array}$ & $\begin{array}{l}\mathrm{EXP}=0 \\
\mathrm{CTL}=0\end{array}$ & $\begin{array}{l}\mathrm{EXP}=0 \\
\mathrm{CTL}=0\end{array}$ & $\begin{array}{l}\mathrm{EXP}=0 \\
\mathrm{CTL}=0\end{array}$ \\
\hline Visintin 1998 & $\begin{array}{l}\mathrm{EXP}=\text { not reported } \\
\mathrm{CTL}=\text { not reported }\end{array}$ & $\begin{array}{l}\mathrm{EXP}=\text { not reported } \\
\mathrm{CTL}=\text { not reported }\end{array}$ & $\begin{array}{l}\mathrm{EXP}=\text { not reported } \\
\mathrm{CTL}=\text { not reported }\end{array}$ & $\begin{array}{l}\mathrm{EXP}=\text { not reported } \\
\mathrm{CTL}=\text { not reported }\end{array}$ \\
\hline Weng 2004 & $\begin{array}{l}\mathrm{EXP}=0 \\
\mathrm{CTL}=0\end{array}$ & $\begin{array}{l}\mathrm{EXP}=0 \\
\mathrm{CTL}=0\end{array}$ & $\begin{array}{l}\mathrm{EXP}=0 \\
\mathrm{CTL}=0\end{array}$ & $\begin{array}{l}\mathrm{EXP}=0 \\
\mathrm{CTL}=0\end{array}$ \\
\hline Weng 2006 & $\begin{array}{l}\mathrm{EXP}=\text { not reported } \\
\mathrm{CTL}=\text { not reported }\end{array}$ & $\begin{array}{l}\mathrm{EXP}=\text { not reported } \\
\mathrm{CTL}=\text { not reported }\end{array}$ & $\begin{array}{l}\mathrm{EXP}=\text { not reported } \\
\mathrm{CTL}=\text { not reported }\end{array}$ & $\begin{array}{l}\mathrm{EXP}=\text { not reported } \\
\mathrm{CTL}=\text { not reported }\end{array}$ \\
\hline Werner 2002a & $\begin{array}{l}\mathrm{EXP}=0 \\
\mathrm{CTL}=0\end{array}$ & $\begin{array}{l}\mathrm{EXP}=0 \\
\mathrm{CTL}=0\end{array}$ & $\begin{array}{l}\mathrm{EXP}=0 \\
\mathrm{CTL}=0\end{array}$ & $\begin{array}{l}\mathrm{EXP}=0 \\
\mathrm{CTL}=0\end{array}$ \\
\hline Yang 2010 & $\begin{array}{l}\mathrm{EXP}=\text { not reported } \\
\mathrm{CTL}=\text { not reported }\end{array}$ & $\begin{array}{l}E X P=\text { not reported } \\
C T L=\text { not reported }\end{array}$ & $\begin{array}{l}\text { EXP }=\text { not reported } \\
C T L=\text { not reported }\end{array}$ & $\begin{array}{l}\text { EXP }=\text { not reported } \\
C T L=\text { not reported }\end{array}$ \\
\hline Yen 2008 & $\begin{array}{l}\mathrm{EXP}=\text { not reported } \\
\mathrm{CTL}=\text { not reported }\end{array}$ & $\begin{array}{l}E X P=\text { not reported } \\
C T L=\text { not reported }\end{array}$ & $\begin{array}{l}\text { EXP }=\text { not reported } \\
C T L=\text { not reported }\end{array}$ & $\begin{array}{l}\text { EXP }=\text { not reported } \\
C T L=\text { not reported }\end{array}$ \\
\hline Zhang 2008 & $\begin{array}{l}\mathrm{EXP}=\text { not reported } \\
\mathrm{CTL}=\text { not reported }\end{array}$ & $\begin{array}{l}\mathrm{EXP}=\text { not reported } \\
\mathrm{CTL}=\text { not reported }\end{array}$ & $\begin{array}{l}\mathrm{EXP}=\text { not reported } \\
\mathrm{CTL}=\text { not reported }\end{array}$ & $\begin{array}{l}\mathrm{EXP}=\text { not reported } \\
\mathrm{CTL}=\text { not reported }\end{array}$ \\
\hline Zhu 2004 & $\begin{array}{l}\mathrm{EXP}=\text { not reported } \\
\mathrm{CTL}=\text { not reported }\end{array}$ & $\begin{array}{l}\mathrm{EXP}=\text { not reported } \\
\mathrm{CTL}=\text { not reported }\end{array}$ & $\begin{array}{l}\mathrm{EXP}=\text { not reported } \\
\mathrm{CTL}=\text { not reported }\end{array}$ & $\begin{array}{l}\mathrm{EXP}=\text { not reported } \\
\mathrm{CTL}=\text { not reported }\end{array}$ \\
\hline
\end{tabular}

CTL: control

EXP: experimental

Table 4. Dropouts

\begin{tabular}{|c|c|c|c|c|}
\hline Study ID & EXP - treatment phase & EXP - follow-up & CTL - treatment & CTL - follow-up \\
\hline Ada 2003 & $\begin{array}{l}1 \text { - hip fracture caused by a fall at home } \\
\text { after the first week of training } \\
2 \text { - not measured at post-test for med- } \\
\text { ical reasons, } 1 \text { due to low back pain } \\
\text { (these participants completed the fol- } \\
\text { low-up assessment) }\end{array}$ & No dropouts & 1 - moved out of area & $\begin{array}{l}1 \text { - moved out of } \\
\text { area }\end{array}$ \\
\hline Ada 2010 & $\begin{array}{l}2 \text { - died } \\
2 \text { - withdrew }\end{array}$ & $\begin{array}{l}\text { No follow-up pe- } \\
\text { riod }\end{array}$ & 2 - died & $\begin{array}{l}\text { No follow-up pe- } \\
\text { riod }\end{array}$ \\
\hline Ada 2013 & 1 - withdrew & No dropouts & 3 - withdrew & No dropouts \\
\hline Bonnyaud 2013 & No dropouts & No dropouts & No dropouts & No dropouts \\
\hline Bonnyaud 2013a & No dropouts & No dropouts & No dropouts & No dropouts \\
\hline
\end{tabular}


Table 4. Dropouts (Continued)

\begin{tabular}{|c|c|c|c|c|}
\hline $\begin{array}{l}\text { Combs-Miller } \\
2014\end{array}$ & 2 dropouts & No dropouts & No dropouts & No dropouts \\
\hline $\begin{array}{l}\text { Da Cunha Filho } \\
2002\end{array}$ & $\begin{array}{l}1 \text { - completed fewer than } 9 \text { treadmill } \\
\text { and body weight support sessions }\end{array}$ & $\begin{array}{l}\text { No follow-up pe- } \\
\text { riod }\end{array}$ & $\begin{array}{l}1 \text { - pulmonary complications } \\
\text { (not related to the protocol) }\end{array}$ & $\begin{array}{l}\text { No follow-up pe- } \\
\text { riod }\end{array}$ \\
\hline Deniz 2011 & Dropouts not stated & $\begin{array}{l}\text { Dropouts not } \\
\text { stated }\end{array}$ & Dropouts not stated & $\begin{array}{l}\text { Dropouts not } \\
\text { stated }\end{array}$ \\
\hline DePaul 2015 & 1 dropout & 3 dropouts & 5 dropouts & 4 dropouts \\
\hline Du 2006 & No dropouts & $\begin{array}{l}\text { No follow-up pe- } \\
\text { riod }\end{array}$ & No dropouts & $\begin{array}{l}\text { No follow-up pe- } \\
\text { riod }\end{array}$ \\
\hline Duncan 2011 & $\begin{array}{l}35 \text { ( } 12 \text { withdrew, } 7 \text { died, } 13 \text { moved, } 3 \\
\text { other) }\end{array}$ & Unclear & $\begin{array}{l}11 \text { ( } 2 \text { withdrew, } 6 \text { died, } 3 \\
\text { moved) }\end{array}$ & \\
\hline Eich 2004 & No dropouts & 1 - refusal & No dropouts & No dropouts \\
\hline $\begin{array}{l}\text { Franceschini } \\
2009\end{array}$ & 10 - dropouts & $\begin{array}{l}\text { No follow-up pe- } \\
\text { riod }\end{array}$ & 10 - dropouts & $\begin{array}{l}\text { No follow-up pe- } \\
\text { riod }\end{array}$ \\
\hline Gama 2017 & 2 - dropouts & No dropouts & 2 -dropouts & No dropouts \\
\hline Gan 2012 & No dropouts & $\begin{array}{l}\text { No follow-up pe- } \\
\text { riod }\end{array}$ & No dropouts & $\begin{array}{l}\text { No follow-up pe- } \\
\text { riod }\end{array}$ \\
\hline Globas 2011 & $\begin{array}{l}1 \text { - recurrent stroke } \\
1 \text { - transportation problem }\end{array}$ & $\begin{array}{l}2 \text { dropouts (but } \\
\text { unclear which } \\
\text { group) }\end{array}$ & No dropouts & $\begin{array}{l}2 \text { dropouts (but } \\
\text { unclear which } \\
\text { group) }\end{array}$ \\
\hline Hoyer 2012 & No dropouts & $\begin{array}{l}\text { No follow-up pe- } \\
\text { riod }\end{array}$ & No dropouts & $\begin{array}{l}\text { No follow-up pe- } \\
\text { riod }\end{array}$ \\
\hline Jaffe 2004 & $\begin{array}{l}1 \text { - endurance level too low to continue } \\
\text { treatment }\end{array}$ & No dropouts & $\begin{array}{l}2 \text { - medical conditions unre- } \\
\text { lated to the study ( } 1 \text { partici- } \\
\text { pant with arthritis and } 1 \text { par- } \\
\text { ticipant with a heart condi- } \\
\text { tion) }\end{array}$ & No dropouts \\
\hline Kang 2012 & $\begin{array}{l}1 \text { - dropout - another treatment } \\
1 \text { - lack of participation }\end{array}$ & No dropouts & No dropouts & No dropouts \\
\hline Kim 2011 & Dropouts not stated & $\begin{array}{l}\text { Dropouts not } \\
\text { stated }\end{array}$ & Dropouts not stated & $\begin{array}{l}\text { Dropouts not } \\
\text { stated }\end{array}$ \\
\hline Kim 2016 & No dropouts & $\begin{array}{l}\text { No follow-up pe- } \\
\text { riod }\end{array}$ & $\begin{array}{l}3 \text { dropouts in the control } \\
\text { group without additional } \\
\text { training }\end{array}$ & $\begin{array}{l}\text { No follow-up pe- } \\
\text { riod }\end{array}$ \\
\hline Kosak 2000 & $\begin{array}{l}1 \text { - chose to discontinue treatment (did } \\
\text { not want to walk on the treadmill) } \\
1 \text { - acute myocardial infarction requir- } \\
\text { ing readmission to acute care }\end{array}$ & $\begin{array}{l}\text { No follow-up pe- } \\
\text { riod }\end{array}$ & $\begin{array}{l}1 \text { - Stroke progression requir- } \\
\text { ing readmission to acute care }\end{array}$ & $\begin{array}{l}\text { No follow-up pe- } \\
\text { riod }\end{array}$ \\
\hline Kuys 2011 & 1 - withdrew & 1 - moved & No dropouts & No dropouts \\
\hline
\end{tabular}


Table 4. Dropouts (Continued)
1 - fall
1 - medical con-
dition

\begin{tabular}{lllll}
\hline $\begin{array}{l}\text { Langhammer } \\
2010\end{array}$ & 3 - dropouts (unclear reasons) & $\begin{array}{l}\text { No follow-up pe- } \\
\text { riod }\end{array}$ & $\begin{array}{l}2 \text {-dropouts (unclear rea- } \\
\text { sons) }\end{array}$ & $\begin{array}{l}\text { No follow-up pe- } \\
\text { riod }\end{array}$ \\
\hline Laufer 2001 & $\begin{array}{l}\text { 2- discharged prior to completion of } \\
\text { data collection }\end{array}$ & $\begin{array}{l}\text { No follow-up pe- } \\
\text { riod }\end{array}$ & $\begin{array}{l}1 \text { - discharged prior to com- } \\
\text { pletion of data collection } \\
1 \text { - readmitted to an acute } \\
\text { hospital (not related to the } \\
\text { protocol) }\end{array}$ & $\begin{array}{l}\text { No follow-up pe- } \\
\text { riod }\end{array}$ \\
& & &
\end{tabular}

\begin{tabular}{|c|c|c|c|c|}
\hline Liston 2000 & $\begin{array}{l}1 \text { - hospitalised after first treatment } \\
\text { and subsequently died (reason for hos- } \\
\text { pitalisation not reported) } \\
1 \text { - chose to discontinue treatment due } \\
\text { to knee pain } \\
1 \text { - chose to discontinue treatment } \\
\text { (felt unsafe and frightened on the } \\
\text { treadmill) }\end{array}$ & $\begin{array}{l}\text { No follow-up pe- } \\
\text { riod }\end{array}$ & No dropouts & $\begin{array}{l}\text { No follow-up pe- } \\
\text { riod }\end{array}$ \\
\hline Luft 2008 & $\begin{array}{l}12 \text { - unrelated medical condition } \\
2 \text { - recurrent stroke } \\
6 \text { - noncompliance }\end{array}$ & $\begin{array}{l}\text { No follow-up pe- } \\
\text { riod }\end{array}$ & $\begin{array}{l}11 \text { - unrelated medical condi- } \\
\text { tion } \\
11 \text { - noncompliance }\end{array}$ & $\begin{array}{l}\text { No follow-up pe- } \\
\text { riod }\end{array}$ \\
\hline $\begin{array}{l}\text { MacKay-Lyons } \\
2013\end{array}$ & $\begin{array}{l}1 \text { - seizure activity } \\
1 \text { - moved }\end{array}$ & $1-$ refused & $\begin{array}{l}2 \text { - medical reasons } \\
1 \text { - disinterest }\end{array}$ & $\begin{array}{l}1 \text { - refused } \\
1 \text { - lost to fol- } \\
\text { low-up }\end{array}$ \\
\hline Macko 2005 & $\begin{array}{l}3 \text { - medical conditions ( } 1 \text { participant } \\
\text { had sinus surgery, } 1 \text { participant had } \\
\text { pre-existing shoulder pain, } 1 \text { partici- } \\
\text { pant had a gastrointestinal bleed and } \\
\text { recurrent stroke) } \\
1 \text { - fall at home } \\
3 \text { - chose to discontinue treatment ( } 1 \\
\text { participant had transportation prob- } \\
\text { lems, } 1 \text { participant had poor adher- } \\
\text { ence, and } 1 \text { participant decided to } \\
\text { train at home) }\end{array}$ & $\begin{array}{l}\text { No follow-up pe- } \\
\text { riod }\end{array}$ & $\begin{array}{l}4 \text { - medical conditions ( } 1 \text { par- } \\
\text { ticipant had a hernia repair, } 1 \\
\text { participant had elective car- } \\
\text { diac surgery, } 1 \text { participant } \\
\text { had a radiculopathy, and } 1 \\
\text { participant had a foot infec- } \\
\text { tion and poor control of hy- } \\
\text { pertension) } \\
2 \text { - fracture caused by a fall at } \\
\text { home } \\
3 \text { - chose to discontinue } \\
\text { treatment (1 participant } \\
\text { moved out of area, } 1 \text { partici- } \\
\text { pant returned to work, and } 1 \\
\text { participant was disinterested } \\
\text { in stretching) }\end{array}$ & $\begin{array}{l}\text { No follow-up pe- } \\
\text { riod }\end{array}$ \\
\hline Mao 2015 & $\begin{array}{l}1 \text { - discontinued treatment, cardiovas- } \\
\text { cular instability } \\
2 \text { - discontinued treatment, early dis- } \\
\text { charged }\end{array}$ & $\begin{array}{l}\text { No follow-up pe- } \\
\text { riod }\end{array}$ & $\begin{array}{l}\text { 2- discontinued treatment, } \\
\text { early discharge }\end{array}$ & $\begin{array}{l}\text { No follow-up pe- } \\
\text { riod }\end{array}$ \\
\hline Mehrberg 2001 & Missing information & $\begin{array}{l}\text { Missing informa- } \\
\text { tion }\end{array}$ & Missing information & $\begin{array}{l}\text { Missing informa- } \\
\text { tion }\end{array}$ \\
\hline
\end{tabular}


Table 4. Dropouts (Continued)
Middleton 2014
4 - discontinued treatment, lost to fol-
low-up, unable to contact
No follow-up pe-
1- discontinued treatment, riod lost to follow-up, unable to contact

\begin{tabular}{|c|c|c|c|c|}
\hline Moore 2010 & $\begin{array}{l}\text { Authors stated: } 10 \text { did not complete the } \\
\text { wearing accelerometer, } n=5) \text {, early disc } \\
(n=1) \text {, or previous diagnosis of seconda }\end{array}$ & $\begin{array}{l}\text { rotocol because of } \\
\text { large from clinical } \\
\text { y neurological injur }\end{array}$ & $\begin{array}{l}\text { oncompliance with study requi } \\
(n=2) \text {, orthopaedic injury whic } \\
(n=2) \text {. }\end{array}$ & $\begin{array}{l}\text { ements (i.e. not } \\
\text { limited walking }\end{array}$ \\
\hline Nilsson 2001 & $\begin{array}{l}2 \text { - chose to discontinue treatment (did } \\
\text { not want to walk on the treadmill) } \\
2 \text { - medical reasons }\end{array}$ & $\begin{array}{l}2 \text { - medical rea- } \\
\text { sons } \\
1 \text { - death } \\
1 \text { - moved out of } \\
\text { area }\end{array}$ & $\begin{array}{l}1 \text { - chose to discontinue } \\
\text { treatment (wanted to walk } \\
\text { on the treadmill) } \\
1 \text { - medical reasons } \\
1 \text { - death }\end{array}$ & $\begin{array}{l}1 \text { - moved out of } \\
\text { area } \\
1 \text { - did not want } \\
\text { to attend the fol- } \\
\text { low-up tests }\end{array}$ \\
\hline Olawale 2009 & 2 - did not attend all training sessions & $\begin{array}{l}\text { No follow-up pe- } \\
\text { riod }\end{array}$ & $\begin{array}{l}5 \text { - Did not attend all training } \\
\text { sessions }\end{array}$ & $\begin{array}{l}\text { No follow-up pe- } \\
\text { riod }\end{array}$ \\
\hline Park 2013 & none & $\begin{array}{l}\text { No follow-up pe- } \\
\text { riod }\end{array}$ & None & $\begin{array}{l}\text { No follow-up pe- } \\
\text { riod }\end{array}$ \\
\hline Park 2015 & none & $\begin{array}{l}\text { No follow-up pe- } \\
\text { riod }\end{array}$ & None & $\begin{array}{l}\text { No follow-up pe- } \\
\text { riod }\end{array}$ \\
\hline Pohl 2002 & $\begin{array}{l}2 \text { - medical conditions ( } 1 \text { participant } \\
\text { with bladder infection and fever, and } \\
1 \text { participant with viral infection and } \\
\text { fever) from EXP } 1 \\
2 \text { - medical conditions ( } 1 \text { participant } \\
\text { with bladder infection and fever, and } 1 \\
\text { participant with pneumonia) from EXP } \\
2\end{array}$ & $\begin{array}{l}\text { No follow-up pe- } \\
\text { riod }\end{array}$ & $\begin{array}{l}5 \text { - medical conditions ( } 3 \text { par- } \\
\text { ticipants with pneumonia } \\
\text { and } 2 \text { with viral infection and } \\
\text { fever) }\end{array}$ & $\begin{array}{l}\text { No follow-up pe- } \\
\text { riod }\end{array}$ \\
\hline Ribeiro 2013 & 2 - dropouts & $\begin{array}{l}\text { No follow-up pe- } \\
\text { riod }\end{array}$ & 3 - dropouts & $\begin{array}{l}\text { No follow-up pe- } \\
\text { riod }\end{array}$ \\
\hline Richards 1993 & 1 - reason not reported & $\begin{array}{l}\text { No follow-up da- } \\
\text { ta reported }\end{array}$ & 2 - reason not reported & $\begin{array}{l}\text { No follow-up da- } \\
\text { ta reported }\end{array}$ \\
\hline Richards 2004 & $\begin{array}{l}1 \text { - medical conditions (hip fracture) } \\
1 \text { - medical conditions (cardiac prob- } \\
\text { lems) }\end{array}$ & $\begin{array}{l}5 \text { - being unavail- } \\
\text { able }\end{array}$ & 1 - reason not stated & $\begin{array}{l}7 \text { - being unavail- } \\
\text { able }\end{array}$ \\
\hline $\begin{array}{l}\text { Scheidtmann } \\
1999\end{array}$ & No dropouts & $\begin{array}{l}\text { No follow-up pe- } \\
\text { riod }\end{array}$ & No dropouts & $\begin{array}{l}\text { No follow-up pe- } \\
\text { riod }\end{array}$ \\
\hline Smith 2008 & Dropouts not stated & $\begin{array}{l}\text { Dropouts not } \\
\text { stated }\end{array}$ & Dropouts not stated & $\begin{array}{l}\text { Dropouts not } \\
\text { stated }\end{array}$ \\
\hline Srivastava 2016 & 4 - dropouts & $\begin{array}{l}\text { No follow-up pe- } \\
\text { riod }\end{array}$ & 4 - dropouts & $\begin{array}{l}\text { No follow-up pe- } \\
\text { riod }\end{array}$ \\
\hline Sullivan 2007 & $\begin{array}{l}6 \text { - withdrawn by administration } \\
1 \text { - refused to participate }\end{array}$ & $\begin{array}{l}4 \text { - refused to } \\
\text { participate }\end{array}$ & $\begin{array}{l}2 \text { - withdrawn by administra- } \\
\text { tion }\end{array}$ & $\begin{array}{l}1 \text { - withdrawn by } \\
\text { administration } \\
3 \text { - refused to } \\
\text { participate }\end{array}$ \\
\hline
\end{tabular}


Table 4. Dropouts (Continued)

\begin{tabular}{|c|c|c|c|c|}
\hline Suputtitada 2004 & Dropouts not stated & $\begin{array}{l}\text { No follow-up pe- } \\
\text { riod }\end{array}$ & Dropouts not stated & $\begin{array}{l}\text { No follow-up pe- } \\
\text { riod }\end{array}$ \\
\hline Takami 2010 & 3 - for family reasons & $\begin{array}{l}\text { No follow-up pe- } \\
\text { riod }\end{array}$ & Dropouts not stated & $\begin{array}{l}\text { No follow-up pe- } \\
\text { riod }\end{array}$ \\
\hline $\begin{array}{l}\text { Toledano-Zarhi } \\
2011\end{array}$ & 1 - chose to discontinue treatment & $\begin{array}{l}\text { No follow-up pe- } \\
\text { riod }\end{array}$ & No dropouts & $\begin{array}{l}\text { No follow-up pe- } \\
\text { riod }\end{array}$ \\
\hline Visintin 1998 & $\begin{array}{l}2 \text { - chose to discontinue treatment } \\
2 \text { - medical reasons } \\
2 \text { - discharged to chronic care prior } \\
\text { to completion of data collection (no } \\
\text { longer eligible) } \\
1 \text { - discharged home prior to comple- } \\
\text { tion of data collection and was unwill- } \\
\text { ing or unable to complete the training }\end{array}$ & $\begin{array}{l}14 \text { - medical } \\
\text { event, repeat- } \\
\text { ed stroke, lack } \\
\text { of willingness } \\
\text { to participate } \\
\text { or moved away } \\
\text { from area }\end{array}$ & $\begin{array}{l}4 \text { - chose to discontinue } \\
\text { treatment } \\
5 \text { - medical reasons } \\
3 \text { - discharged to chronic } \\
\text { care prior to completion of } \\
\text { data collection (no longer eli- } \\
\text { gible) } \\
2 \text { - discharged home prior to } \\
\text { completion of data collection } \\
\text { and were unwilling or unable } \\
\text { to complete the training }\end{array}$ & $\begin{array}{l}13 \text { - medical } \\
\text { event, repeat- } \\
\text { ed stroke, lack } \\
\text { of willingness } \\
\text { to participate } \\
\text { or moved away } \\
\text { from area }\end{array}$ \\
\hline
\end{tabular}

\begin{tabular}{|c|c|c|c|c|}
\hline Weng 2004 & $\begin{array}{l}2 \text { - reasons unknown due to issues of } \\
\text { translation }\end{array}$ & $\begin{array}{l}\text { No follow-up pe- } \\
\text { riod }\end{array}$ & $\begin{array}{l}3 \text { - reasons unknown due to } \\
\text { issues of translation }\end{array}$ & $\begin{array}{l}\text { No follow-up pe- } \\
\text { riod }\end{array}$ \\
\hline Weng 2006 & Dropouts not stated & $\begin{array}{l}\text { No follow-up pe- } \\
\text { riod }\end{array}$ & Dropouts not stated & $\begin{array}{l}\text { No follow-up pe- } \\
\text { riod }\end{array}$ \\
\hline Werner 2002a & No dropouts & $\begin{array}{l}\text { No follow-up pe- } \\
\text { riod }\end{array}$ & No dropouts & $\begin{array}{l}\text { No follow-up pe- } \\
\text { riod }\end{array}$ \\
\hline Yang 2010 & No dropouts & $\begin{array}{l}\text { No follow-up pe- } \\
\text { riod }\end{array}$ & No dropouts & $\begin{array}{l}\text { No follow-up pe- } \\
\text { riod }\end{array}$ \\
\hline Yen 2008 & No dropouts & $\begin{array}{l}\text { No follow-up pe- } \\
\text { riod }\end{array}$ & No dropouts & $\begin{array}{l}\text { No follow-up pe- } \\
\text { riod }\end{array}$ \\
\hline Zhang 2008 & Dropouts not stated & $\begin{array}{l}\text { No follow-up pe- } \\
\text { riod }\end{array}$ & Dropouts not stated & $\begin{array}{l}\text { No follow-up pe- } \\
\text { riod }\end{array}$ \\
\hline Zhu 2004 & No dropouts & $\begin{array}{l}\text { No follow-up pe- } \\
\text { riod }\end{array}$ & No dropouts & $\begin{array}{l}\text { No follow-up pe- } \\
\text { riod }\end{array}$ \\
\hline
\end{tabular}

CTL: control

EXP: experimental

PT: physiotherapy

\section{AP PE N D I C E S}

\section{Appendix 1. Cochrane Central Register of Controlled Trials (CENTRAL)}

\#1. [mh $\wedge^{\prime \prime c e r e b r o v a s c u l a r ~ d i s o r d e r s "] ~ o r ~[m h ~ " b a s a l ~ g a n g l i a ~ c e r e b r o v a s c u l a r ~ d i s e a s e "] ~ o r ~[m h ~ " b r a i n ~ i s c h e m i a "] ~ o r ~[m h ~ " c a r o t i d ~ a r t e r y ~}$ diseases"] or [mh "intracranial arterial diseases"] or [mh "intracranial embolism and thrombosis"] or [mh "intracranial hemorrhages"] or [mh^stroke] or [mh "brain infarction"] or [ $\mathrm{mh}^{\wedge}$ "stroke, lacunar"] or [mh^"vasospasm, intracranial"] or [mh ^"vertebral artery dissection"] \#2. stroke or poststroke or "post-stroke" or cerebrovasc* or brain next vasc* or cerebral next vasc* or cva* or apoplex* or SAH \#3. (brain* or cerebr ${ }^{\star}$ or cerebell ${ }^{\star}$ or intracran* or intracerebral) near/5 (isch*emi* or infarct* or thrombo* or emboli* or occlus ${ }^{\star}$ ) \#4. (brain* or cerebr ${ }^{\star}$ or cerebell ${ }^{\star}$ or intracerebral or intracranial or subarachnoid) near/5 (haemorrhage* or hemorrhage* or haematoma* or hematoma* or bleed*) 
\#5. [mh^hemiplegia] or [mh paresis]

\#6. hemipleg* or hemipar $^{\star}$ or paresis or paretic

$\# 7$. [mh ${ }^{\wedge}$ "gait disorders, neurologic"]

\#8. \#1 or \#2 or \#3 or \#4 or \#5 or \#6 or \#7

\#9. [mh ${ }^{\wedge}$ exercise] or [mh^"exercise test"] or [mh^"exercise therapy"] or [mh^"motion therapy, continuous passive"]

$\# 10$. [mh^"body weight"] or [mh ^ weight-bearing]

$\# 11$. treadmill* or tread next mill* or running next wheel ${ }^{*}$ or running next machine ${ }^{*}$

\#12. (walking or walk or exercise) near/5 (machine* or device*)

\#13. (walking or gait or locomotor or ambulation) near $/ 5$ (train ${ }^{\star}$ or re-train ${ }^{\star}$ or retrain ${ }^{\star}$ )

\#14. [mh ${ }^{\wedge}$ walking]

$\# 15$. machine ${ }^{\star}$ or device ${ }^{\star}$ or train ${ }^{\star}$ or re-train* or retrain $^{\star}$

\#16. \#14 and \#15

\#17. (weight or "body-weight" or bodyweight) near/5 (support* or suspen* or relief)

$\# 18$. (walk or walking or ambulat* or locomot* or gait or overhead) near/5 support*

$\# 19$. harness ${ }^{\star}$

\#20. \#9 or \#10 or \#11 or \#12 or \#13 or \#16 or \#17 or \#18 or \#19

$\# 21$. [mh^^walking] or [mh ^gait] or [mh^"mobility limitation"] or [mh^locomotion]

\#22. walk* or gait* or ambulat* or mobil ${ }^{\star}$ or locomot ${ }^{\star}$ or stride

\#23. \#21 or \#22

\#24. \#8 and \#20 and \#23

\section{Appendix 2. MEDLINE ovid search strategy}

1. cerebrovascular disorders/ or exp basal ganglia cerebrovascular disease/ or exp brain ischemia/ or exp carotid artery diseases/ or exp intracranial arterial diseases/ or exp "intracranial embolism and thrombosis"/ or exp intracranial hemorrhages/or stroke/ or exp brain infarction/ or stroke, lacunar/ or vasospasm, intracranial/ or vertebral artery dissection/

2. (stroke or poststroke or post-stroke or cerebrovasc\$ or brain vasc\$ or cerebral vasc\$ or cva $\$$ or apoplex\$ or SAH).tw.

3. ((brain $\$$ or cerebr $\$$ or cerebell\$ or intracran $\$$ or intracerebral) adj5 (isch?emi or infarct $\$$ or thrombo $\$$ or emboli\$ or occlus\$)).tw.

4. ((brain $\$$ or cerebr\$ or cerebell\$ or intracerebral or intracranial or subarachnoid) adj5 (haemorrhage\$ or hemorrhage\$ or haematoma

\$ or hematoma\$ or bleed\$)).tw.

5. hemiplegia/ or exp paresis/

6. (hemipleg\$ or hemipar\$ or paresis or paretic).tw.

7. exp gait disorders, neurologic/

8. 1 or 2 or 3 or 4 or 5 or 6 or 7

9. exercise/ or exercise test/ or exercise therapy/ or motion therapy, continuous passive/

10. body weight/ or weight-bearing/

11. (treadmill\$ or tread mill\$ or running wheel\$ or running machine\$).tw.

12. ((walking or walk or exercise) adj5 (machine\$ or device\$)).tw.

13. ((walking or gait or locomotor or ambulation) adj5 (train $\$$ or re-train $\$$ or retrain $\$)$ ).tw.

14. exp walking/ and (machine\$ or device or train\$ or re-train\$ or retrain\$).tw.

15. ((weight or body-weight or bodyweight) adj5 (support\$ or suspen $\$$ or relief)).tw.

16. ((walk or walking or ambulat $\$$ or locomot\$ or gait or overhead) adj5 support\$).tw.

17. harness\$.tw.

18.9 or 10 or 11 or 12 or 13 or 14 or 15 or 16 or 17

19. exp walking/ or gait/ or mobility limitation/ or locomotion/

20. (walk\$ or gait $\$$ or ambulat\$ or mobil\$ or locomot\$ or stride).tw.

21. 19 or 20

22. Randomized Controlled Trials as Topic/

23. random allocation/

24. Controlled Clinical Trials as Topic/

25. control groups/

26. clinical trials as topic/

27. double-blind method/

28. single-blind method/

29. Placebos/

30. placebo effect/

31. cross-over studies/

32. Therapies, Investigational/

33. Research Design/

34. randomized controlled trial.pt.

35. controlled clinical trial.pt.

36. clinical trial.pt. 
37. (random\$ or RCT or RCTs).tw.

38. (controlled adj5 (trial\$ or stud\$)).tw.

39. (clinical\$ adj5 trial\$).tw.

40. ((control or treatment or experiment\$ or intervention) adj5 (group\$ or subject\$ or patient\$)).tw.

41. (quasi-random $\$$ or quasi random\$ or pseudo-random\$ or pseudo random\$).tw.

42. ((control or experiment $\$$ or conservative) adj5 (treatment or therapy or procedure or manage $\$)$ ).tw.

43. ((singl\$ or doubl\$ or tripl\$ or trebl\$) adj5 (blind\$ or mask\$)).tw.

44. (cross-over or cross over or crossover).tw.

45. (placebo $\$$ or sham).tw.

46. trial.ti.

47. (assign\$ or allocat).tw.

48. or $/ 22-47$

49. 8 and 18 and 21 and 48

50. exp animals/ not humans.sh.

51.49 not 50

\section{Appendix 3. Embase ovid search strategy}

1. cerebrovascular disease/ or exp basal ganglion hemorrhage/ or exp brain hematoma/or exp brain hemorrhage/or exp brain infarction/or exp brain ischemia/ or exp carotid artery disease/ or cerebral artery disease/ or exp cerebrovascular accident/ or exp intracranial aneurysm/ or exp occlusive cerebrovascular disease/ or vertebrobasilar insufficiency/

2. stroke patient/ or stroke unit/

3. exp neurologic gait disorder/ or hemiparesis/ or hemiplegia/ or paresis/

4. (stroke or poststroke or post-stroke or cerebrovasc\$ or brain vasc\$ or cerebral vasc\$ or cva\$ or apoplex\$ or SAH).tw.

5. ((brain $\$$ or cerebr $\$$ or cerebell\$ or intracran $\$$ or intracerebral) adj5 (isch?emi or infarct\$ or thrombo $\$$ or emboli\$ or occlus\$)).tw.

6 . ((brain $\$$ or cerebr $\$$ or cerebell\$ or intracerebral or intracranial or subarachnoid) adj5 (haemorrhage $\$$ or hemorrhage $\$$ or haematoma

\$ or hematoma or bleed\$)).tw.

7. (hemipleg\$ or hemipar\$ or paresis or paretic).tw.

8.1 or 2 or 3 or 4 or 5 or 6 or 7

9. treadmill/ or treadmill exercise/ or treadmill ergometry/

10. walking harness/ or walking machine/

11. exp exercise/ or exp kinesiotherapy/ or exercise test/

12. body weight/ or weight bearing/

13. (treadmill\$ or tread mill\$ or running wheel\$ or running machine\$).tw.

14. ((walking or walk or exercise) adj5 (machine\$ or device\$)).tw.

15. ((walking or gait or locomotor or ambulation) adj5 (train\$ or re-train\$ or retrain\$)).tw.

16. exp walking/ and (machine\$ or device or train $\$$ or re-train $\$$ or retrain\$).tw.

17. ((weight or body-weight or bodyweight) adj5 (support\$ or suspen\$ or relief)).tw.

18. ((walk or walking or ambulat $\$$ or locomot\$ or gait or overhead) adj5 support\$).tw.

19. harness\$.tw.

20.9 or 10 or 11 or 12 or 13 or 14 or 15 or 16 or 17 or 18 or 19

21. walking/ or walking speed/ or gait/ or locomotion/ or walking difficulty/

22. (walk\$ or gait $\$$ or ambulat\$ or mobil\$ or locomot\$ or stride).tw.

23. 21 or 22

24. Randomized Controlled Trial/

25. Randomization/

26. Controlled Study/

27. control group/

28. clinical trial/

29. Crossover Procedure/

30. Double Blind Procedure/

31. Single Blind Procedure/ or triple blind procedure/

32. placebo/

33. "types of study"/

34. random\$.tw.

35. (controlled adj5 (trial\$ or stud\$)).tw.

36. (clinical\$ adj5 trial\$).tw.

37. ((control or treatment or experiment $\$$ or intervention) adj5 (group\$ or subject\$ or patient\$)).tw.

38. (quasi-random $\$$ or quasi random $\$$ or pseudo-random $\$$ or pseudo random $\$$ ).tw.

39. ((control or experiment\$ or conservative) adj5 (treatment or therapy or procedure or manage $\$)$ ).tw.

40. ((singl\$ or doubl\$ or tripl\$ or trebl\$) adj5 (blind\$ or mask\$)).tw.

41. (cross-over or cross over or crossover).tw. 
42. placebo\$.tw.

43. sham.tw.

44. (assign\$ or allocat\$).tw.

45. trial.ti. or (RCT or RCT).tw.

46. or/24-45

47.8 and 20 and 23 and 46

48. exp animals/ or exp invertebrate/ or animal experiment/ or animal model/ or animal tissue/ or animal cell/ or nonhuman/

49. human/ or normal human/ or human cell/

50.48 not 49

51.47 not 50

\section{Appendix 4. CINAHL EBSCO search strategy}

S48. S13 AND S24 AND S28 AND S47

S47. S29 OR S30 OR S31 OR S32 OR S33 OR S34 OR S35 OR S36 OR S37 OR S40 OR S41 OR S44 OR S45 OR S46

S46. TI trial OR ( TI (RCT or RCTs) OR AB (RCT or RCTs) )

S45. TI ( counterbalance* or multiple baseline ${ }^{\star}$ or $A B A B$ design ) or AB ( counterbalance* or multiple baseline ${ }^{\star}$ or $A B A B$ design )

S44. S42 and S43

S43. TI trial* or AB trial*

S42. $\mathrm{TI}$ ( clin $^{\star}$ or intervention ${ }^{\star}$ or compar ${ }^{\star}$ or experiment ${ }^{\star}$ or preventive or therapeutic ) or AB ( clin* or intervention* or compar ${ }^{\star}$ or experiment ${ }^{\star}$ or preventive or therapeutic)

S41. TI (crossover or cross-over or placebo* or control* or factorial or sham ) or AB ( crossover or cross-over or placebo* or control ${ }^{\star}$ or factorial or sham )

S40. S38 and S39

S39. TI ( blind ${ }^{\star}$ or mask ${ }^{\star}$ ) or AB ( blind ${ }^{\star}$ or mask* ${ }^{*}$

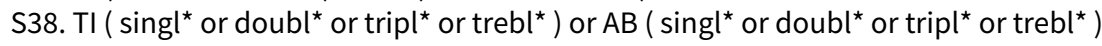

S37. TI random* or AB random*

S36. (MH "Community Trials") or (MH "Experimental Studies") or (MH "One-Shot Case Study") or (MH "Pretest-Posttest Design+") or (MH "Solomon Four-Group Design") or (MH "Static Group Comparison") or (MH "Study Design")

S35. (MH "Clinical Research") or (MH "Clinical Nursing Research")

S34. (MH "Placebo Effect") or (MH "Placebos") or (MH "Meta Analysis")

S33. (MH "Factorial Design") or (MH "Quasi-Experimental Studies") or (MH "Nonrandomized Trials")

S32. (MH "Control (Research)") or (MH "Control Group")

S31. (MH "Crossover Design") or (MH "Clinical Trials+") or (MH "Comparative Studies")

S30. (MH "Random Assignment") or (MH "Random Sample+")

S29. PT randomized controlled trial or clinical trial

S28. S25 OR S26 OR S27

S27. TI (walk* or gait* or ambulat* or mobil* or locomot* or stride) OR AB (walk* or gait* or ambulat* or mobil* or locomot* or stride)

S26. (MH "Gait Analysis") OR (MH "Gait Training")

S25. (MH "Locomotion") OR (MH "Walking") OR (MH "Gait") OR (MH "Step")

S24. S14 OR S15 OR S16 OR S17 OR S18 OR S19 OR S20 OR S21 OR S22 OR S23

S23. TI harness* OR AB harness*

S22. ( TI (walk or walking or ambulat* or locomot* or gait or overhead) OR AB (walk or walking or ambulat* or locomot $^{\star}$ or gait or overhead) ) AND ( TI support ${ }^{\star}$ OR AB support ${ }^{\star}$ )

S21. ( TI (weight or body-weight or bodyweight) OR AB (weight or body-weight or bodyweight) ) AND ( TI (support* or suspen* or relief) OR AB (support* or suspen* or relief))

S20. ( (MH "Walking") OR (MH "Gait training") ) AND ( TI (machine* or device* or train* or re-train* or retrain*) OR AB (machine* or device* or train* or re-train* or retrain $\left.\left.{ }^{\star}\right)\right)$

S19. ( TI (walking or gait or locomotor or ambulation) OR AB (walking or gait or locomotor or ambulation) ) AND ( TI (train* or re-train* or retrain*) OR AB (train* or re-train* or retrain $\left.{ }^{\star}\right)$ )

S18. ( TI (walking or walk or exercise) OR AB (walking or walk or exercise) ) AND ( TI (machine* or device*) OR AB (machine* or device*))

S17. TI ( treadmill* or tread mill* or running wheel ${ }^{\star}$ or running machine ${ }^{\star}$ ) OR AB ( treadmill* or tread mill ${ }^{\star}$ or running wheel ${ }^{\star}$ or running machine* ${ }^{*}$

S16. (MH "Weight-Bearing") or (MH "Body Weight")

S15. (MH "Exercise+") or (MH "Therapeutic Exercise+") or (MH "Exercise Test")

S14. (MH "Treadmills")

S13. S1 OR S2 OR S3 OR S6 OR S9 OR S10 OR S11 OR S12

S12. (MH "Gait Disorders, Neurologic+")

S11. TI ( hemipleg* or hemipar* or paresis or paretic ) or AB ( hemipleg* or hemipar* or paresis or paretic)

S10. (MH "Hemiplegia")

S9. S7 and S8 
S8. TI ( haemorrhage* or hemorrhage* or haematoma* or hematoma* or bleed ${ }^{\star}$ ) or AB ( haemorrhage* or hemorrhage* or haematoma* or hematoma* or bleed*)

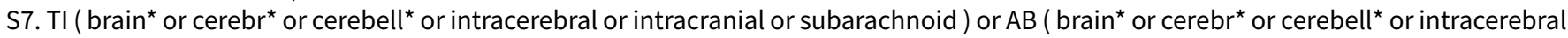
or intracranial or subarachnoid )

S6. S4 and S5

S5. TI ( ischemi ${ }^{\star}$ or ischaemi ${ }^{\star}$ or infarct ${ }^{\star}$ or thrombo* or emboli* or occlus ${ }^{\star}$ ) or AB ( ischemi ${ }^{\star}$ or ischaemi ${ }^{\star}$ or infarct ${ }^{\star}$ or thrombo* $^{\star}$ or $^{*}$ emboli* or occlus* $\left.{ }^{\star}\right)$

S4. TI ( brain ${ }^{\star}$ or cerebr ${ }^{\star}$ or cerebell ${ }^{\star}$ or intracran ${ }^{\star}$ or intracerebral ) or AB ( brain* or cerebr $^{\star}$ or cerebell ${ }^{\star}$ or intracran ${ }^{\star}$ or intracerebral )

S3. TI ( stroke or poststroke or post-stroke or cerebrovasc* or brain vasc* or cerebral vasc or cva or apoplex or SAH ) or AB ( $\mathrm{stroke}$ or poststroke or post-stroke or cerebrovasc ${ }^{\star}$ or brain vasc* or cerebral vasc or cva or apoplex or SAH )

S2. (MH "Stroke Patients") OR (MH "Stroke Units")

S1. (MH "Cerebrovascular Disorders") OR (MH "Basal Ganglia Cerebrovascular Disease+") OR (MH "Carotid Artery Diseases+") OR (MH "Cerebral Ischemia+") OR (MH "Cerebral Vasospasm") OR (MH "Intracranial Arterial Diseases+") OR (MH "Intracranial Embolism and Thrombosis") OR (MH "Intracranial Hemorrhage+") OR (MH "Stroke") OR (MH "Vertebral Artery Dissections")

\section{Appendix 5. AMED Ovid (Allied and Complementary Medicine) search strategy}

1. cerebrovascular disorders/ or cerebral hemorrhage/ or cerebral infarction/ or cerebral ischemia/ or cerebrovascular accident/ or stroke/

2. (stroke or poststroke or post-stroke or cerebrovasc\$ or brain vasc\$ or cerebral vasc\$ or cva\$ or apoplex\$ or SAH).tw.

3. ((brain $\$$ or cerebr $\$$ or cerebell\$ or intracran\$ or intracerebral) adj5 (isch?emi\$ or infarct\$ or thrombo $\$$ or emboli\$ or occlus\$)).tw.

4. ((brain $\$$ or cerebr $\$$ or cerebell\$ or intracerebral or intracranial or subarachnoid) adj5 (haemorrhage $\$$ or hemorrhage $\$$ or haematoma

\$ or hematoma\$ or bleed\$)).tw.

5. hemiplegia/ or gait disorders/

6. (hemipleg\$ or hemipar\$ or paresis or paretic).tw.

7. 1 or 2 or 3 or 4 or 5 or 6

8. exercise/ or exercise testing/ or exercise therapy/ or continuous passive motion/

9. body weight/ or weight bearing/

10. (treadmill\$ or tread mill\$ or running wheel\$ or running machine\$).tw.

11. ((walking or walk or exercise) adj5 (machine\$ or device\$)).tw.

12. ((walking or gait or locomotor or ambulation) adj5 (train\$ or re-train\$ or retrain\$)).tw.

13. exp walking/ and (machine\$ or device\$ or train\$ or re-train\$ or retrain\$).tw.

14. ((weight or body-weight or bodyweight) adj5 (support\$ or suspen $\$$ or relief)).tw.

15. ((walk or walking or ambulat $\$$ or locomot\$ or gait or overhead) adj5 support\$).tw.

16. harness\$.tw.

17.8 or 9 or 10 or 11 or 12 or 13 or 14 or 15 or 16

18. exp walking/ or gait/ or locomotion/ or mobility limitation/ or gait analysis/

19. (walk\$ or gait\$ or ambulat\$ or mobil\$ or locomot\$ or stride).tw.

20. 18 or 19

21. 7 and 17 and 20

22. (clinical trial or clinical trial phase iii or clinical trialb or clinical trials or controlled clinical trial or controlled trial or randomised controlled trial or randomized controlled trial).pt.

23. clinical trials/ or randomized controlled trials/ or double blind method/ or random allocation/

24. (random\$ or RCT or RCTs).tw.

25. (controlled adj5 (trial\$ or stud\$)).tw.

26. (clinical\$ adj5 trial\$).tw.

27. ((control or treatment or experiment $\$$ or intervention) adj5 (group\$ or subject\$ or patient\$)).tw.

28. (quasi-random $\$$ or quasi random\$ or pseudo-random $\$$ or pseudo random\$).tw.

29. ((control or experiment\$ or conservative) adj5 (treatment or therapy or procedure or manage\$)).tw.

30. ((singl\$ or doubl\$ or tripl\$ or trebl\$) adj5 (blind\$ or mask\$)).tw.

31. (cross-over or cross over or crossover).tw.

32. (placebo $\$$ or sham).tw.

33. trial.ti.

34. (assign $\$$ or allocat).tw.

35. or/22-34

36. 21 and 35

\section{Appendix 6. SPORTDiscus EBSCO search strategy}

S30. S28 AND S29

S29. TI ( random* or RCT or trial* or placebo* or sham or double-blind* or single-blind or control or controls or assign* or allocat* ) OR AB ( random* or RCT or trial* or placebo* or sham or double-blind* or single-blind or control or controls or assign* or allocat* )

S28. S13 AND S24 AND S27

S27. S25 OR S26 
S26. TI (walk* or gait* or ambulat* or mobil* or locomot* or stride) OR AB (walk* or gait* or ambulat* or mobil* or locomot* or stride)

S25. (DE "WALKING" OR DE "GAIT in humans") AND (DE "LOCOMOTION" OR DE "HUMAN locomotion")

S24. S14 OR S15 OR S16 OR S17 OR S18 OR S19 OR S20 OR S21 OR S22 OR S23

S23. TI harness* OR AB harness*

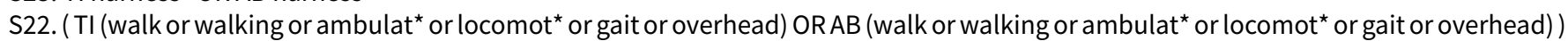
AND ( TI support* OR AB support ${ }^{\star}$ )

S21. ( TI (weight or body-weight or bodyweight) OR AB (weight or body-weight or bodyweight) ) AND ( TI (support $^{\star}$ or suspen $^{\star}$ or relief) OR AB (support* or suspen* or relief))

S20. (DE "WALKING" OR DE "FITNESS walking" OR DE "GAIT in humans") AND (TI (machine* or device* or train* or re-train* or retrain*) OR $A B$ (machine* or device* or train* or re-train* or retrain $\left.{ }^{\star}\right)$ )

S19. ( TI (walking or gait or locomotor or ambulation) OR AB (walking or gait or locomotor or ambulation) ) AND ( TI (train* or re-train* or retrain*) OR AB (train* or re-train* or retrain*))

S18. ( TI (walking or walk or exercise) OR AB (walking or walk or exercise) ) AND ( TI (machine* or device*) OR AB (machine* or device*))

S17. $\mathrm{TI}$ ( treadmill ${ }^{\star}$ or tread mill ${ }^{\star}$ or running wheel ${ }^{\star}$ or running machine ${ }^{\star}$ ) OR AB ( treadmill* or tread mill* or running wheel ${ }^{\star}$ or running machine $\left.{ }^{*}\right)$

S16. (DE "BODY weight") OR (DE "WEIGHT-bearing (Orthopedics)")

S15. DE "EXERCISE" OR DE "AEROBIC exercises" OR DE "EXERCISE for people with disabilities" OR DE "EXERCISE therapy" OR DE "KNEE exercises" OR DE "LEG exercises" OR DE "STRENGTH training" OR DE "EXERCISE therapy" OR DE "EXERCISE tests" OR DE "EXERCISE -Equipment \& supplies"

S14. DE "TREADMILL exercise tests" OR DE "TREADMILL exercise" OR DE "TREADMILLS (Exercise equipment)"

S13. S1 or S2 or S3 or S4 or S7 or S10 or S11 or S12

S12. DE "GAIT disorders"

S11. TI ( hemipleg* or hemipar* or paresis or paretic ) or AB ( hemipleg* or hemipar* or paresis or paretic )

S10. S8 and S9

S9. TI ( haemorrhage* or hemorrhage* or haematoma* or hematoma* or bleed ${ }^{\star}$ ) or AB ( haemorrhage* or hemorrhage* or haematoma* or hematoma* or bleed*)

S8. TI ( brain* or cerebr ${ }^{\star}$ or cerebell ${ }^{\star}$ or intracerebral or intracranial or subarachnoid ) or AB ( brain* or cerebr ${ }^{\star}$ or cerebell $^{\star}$ or intracerebral or intracranial or subarachnoid)

S7. S5 and S6

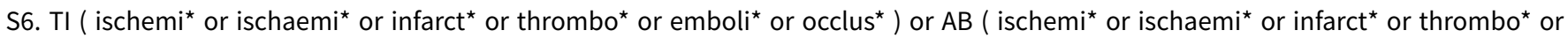
emboli* or occlus $\left.{ }^{\star}\right)$

S5. TI ( brain* or cerebr ${ }^{\star}$ or cerebell ${ }^{\star}$ or intracran* or intracerebral ) or AB ( brain* or cerebr ${ }^{\star}$ or cerebell ${ }^{\star}$ or intracran* or intracerebral )

S4. TI ( stroke or poststroke or post-stroke or cerebrovasc* or brain vasc* or cerebral vasc or cva or apoplex or SAH ) or AB ( poststroke or post-stroke or cerebrovasc ${ }^{\star}$ or brain vasc* or cerebral vasc or cva or apoplex or SAH )

S3. DE "HEMIPLEGIA" OR DE "HEMIPLEGICS"

S2. DE "CEREBROVASCULAR disease -- Patients"

S1. DE "CEREBROVASCULAR disease" OR DE "BRAIN -- Hemorrhage" OR DE "CEREBRAL embolism \& thrombosis"

\section{Appendix 7. US National Institutes of Health Ongoing Trials Register (ClinicalTrials.gov) search strategy}

(stroke OR CVA OR CVI OR (cerebrovasc ${ }^{\star}$ (accid* OR incid))) AND (walk* OR ambul ${ }^{\star}$ OR treadmill) | Interventional Studies | Adult, Senior Number of hits: 107

\section{Appendix 8. World Health Organization International Clinical Trials Registry Platform search strategy}

$\# 1$ stroke OR CVA OR CVI

\#2 ambul* OR walk* OR treadmill

\# 3 \#1 AND \#2

Number of hits: 3

WHAT'S NEW

\begin{tabular}{lll}
\hline Date & Event & Description \\
\hline 21 March 2017 & $\begin{array}{l}\text { New citation required and conclusions } \\
\text { have changed }\end{array}$ & $\begin{array}{l}\text { The conclusions of the review have changed. The previous ver- } \\
\text { sion of this review concluded that, overall, no statistically sig- } \\
\text { nificant effect of treadmill training with or without body weight } \\
\text { support could be detected. This updated version concludes that }\end{array}$ \\
\end{tabular}




\begin{tabular}{lll}
\hline Date Event Description & Den
\end{tabular}

overall walking ability was not improved but a statistically significant effect of treadmill training with or without body weight support was detected for improving walking speed and walking endurance. This review did not find, however, that improvements in walking speed and endurance may have persisting beneficial effects.

The authorship of the review has changed for the update of this review.

21 March $2017 \quad$ New search has been performed

We have updated the searches to March 2017 and revised the text as appropriate. We have included 56 trials, with 3105 participants, in this update compared with 44 trials, with 2658 participants, in the last updated version of this review from 2014.

\section{H I S T O R Y}

Protocol first published: Issue 4, 2000

Review first published: Issue 3, 2003

\begin{tabular}{lll}
\hline Date & Event & Description \\
\hline 30 August 2013 & New search has been performed & $\begin{array}{l}\text { We have updated the searches to June 2013 and revised the text } \\
\text { as appropriate. We have included 44 trials with 2658 participants } \\
\text { in this update compared with 15 trials with 622 participants in } \\
\text { the last version of this review from 2005. }\end{array}$ \\
\hline
\end{tabular}

15 August $2013 \quad$ New citation required and conclusions have changed

The conclusions of the review have changed. The previous version of this review concluded that, overall, no statistically significant effect of treadmill training with or without body weight support could be detected. This updated version concludes that overall walking ability was not improved but a statistically significant effect of treadmill training with or without body weight support was detected for improving walking speed and walking endurance. The authorship of the review has changed.

\begin{tabular}{lll}
\hline 18 August 2008 & Amended & Converted to new review format. \\
\hline 14 April 2005 & New search has been performed & $\begin{array}{l}\text { The search for trials was extended from March 2003 to March } \\
\text { 2005. Four trials (Eich 2004; Jaffe 2004; Macko 2005; Werner }\end{array}$ \\
& 2002a) and one outcome measure (walking endurance) have \\
& been added to our original review. We have been able to obtain \\
& individual patient data for another trial (Visintin 1998). \\
\hline
\end{tabular}

\section{CONTRIBUTIONS OF AUTHORS}

On 28 March 2013, we were contacted by the Cochrane Stroke Group and our author team took over this review and updated it from 2005. We contacted the former review team from 2005 and received all requested data. We used the data collection provided by the former review team and, based on this information, we updated the review by including all eligible studies published from 2005 onwards.

For this 2017 update, BE and JM conducted the literature selection, data extraction, and analyses, and were responsible for the major content of the review. BE, JM, and ST interpreted the data from the individual trials and the statistically-pooled results, and contributed to the manuscript. All authors edited the manuscript. 


\section{DECLARATIONS OF INTEREST}

Bernhard Elsner: none known.

Simone Thomas: none known.

Jan Mehrholz: author of one included trial (Pohl 2002). He did not participate in quality assessment and data extraction for this study.

\section{SOURCES OF SUPPORT}

\section{Internal sources}

- Rehabilitation Studies Unit, Northern Clinical School, Faculty of Medicine, The University of Sydney, Australia.

- School of Physiotherapy, The University of Sydney, Australia.

- Department of Public Health, Medizinische Fakultät 'Carl Gustav Carus', TU Dresden, Germany.

- Wissenschaftliches Institut, Private Europäische Medizinische Akademie der Klinik Bavaria in Kreischa GmbH, An der Wolfsschlucht 1-201731 Kreischa, Germany.

\section{External sources}

- No sources of support supplied

\section{DIFFERENCES BETWEEN PROTOCOL AND REVIEW}

In the protocol, it was stated that we would use the PEDro Scale to assess the methodological quality of the included trials. However, in Chapter 8 of the latest edition of the Cochrane Handbook for Systematic Reviews of Interventions (Higgins 2011), it is suggested that scales that yield a summary score should be avoided. In accordance with this suggestion, we no longer used the PEDro Scale to assess the methodological quality of the included trials. Instead, we used the Cochrane 'Risk of bias' tool to analyse trial methodology as suggested by the Cochrane Handbook for Systematic Reviews of Interventions (Higgins 2011).

In the protocol, it was planned to test the homogeneity between trial results using the $\mathrm{Chi}^{2}$ test and, if there was statistically significant heterogeneity $(P<0.10)$, to calculate the overall effects using a random-effects model and perform a series of sensitivity analyses to investigate. In this update, we estimated all effects using a random-effects model, regardless of the level of heterogeneity.

In the protocol, it was planned to calculate relative risks and 95\% confidence intervals for dichotomous variables. In this update, we used risk differences for dichotomous variables because many studies reported no events and it was therefore not possible to calculate relative risks.

In the protocol, it was planned to include participant quality of life, ability to perform activities of daily living, and the combined outcomes of 'death or dependency' and 'death or institutional care'. However, we did not find enough studies to perform such analyses.

\section{INDEX TERMS}

\section{Medical Subject Headings (MeSH)}

*Walking Speed; Body Weight; Exercise Therapy [instrumentation] [*methods]; Orthotic Devices; Patient Dropouts [statistics \& numerical data]; Randomized Controlled Trials as Topic; Stroke Rehabilitation [ ${ }^{\star}$ methods]; Walking; Weight-Bearing

\section{MeSH check words}

Humans; Middle Aged 